\title{
Electro-catalytically Active, High Surface Area Cathodes for Low Temperature SOFCs
}

\author{
FINAL REPORT \\ Reporting Period Start Date: October 1, 2003 \\ Reporting Period End Date: September 30, 2006
}

Eric D. Wachsman

January, 2007

CONTRACT NUMBER: DE-FC26-03NT41959

Department of Materials Science and Engineering, University of Florida

Gainesville, FL, 32611-6400

Phone: (352) 846-2991; Fax: (352) 846-0326; E-mail: ewach@mse.ufl.edu

DOE Project Manager: Lane Wilson

Phone: (304) 285-1370; E-mail: Lane.Wilson@netl.doe.gov 


\section{DISCLAIMER}

“This report was prepared as an account of work sponsored by an agency of the United States Government. Neither the United States Government nor any agency thereof, nor any of their employees, makes any warranty, express or implied, or assumes any legal liability or responsibility for the accuracy, completeness, or usefulness of any information, apparatus, product, or process disclosed, or represents that its use would not infringe privately owned rights. Reference herein to any specific commercial product, process, or service by trade name, trademark, manufacturer, or otherwise does not necessarily constitute or imply its endorsement, recommendation, or favoring by the United States Government or any agency thereof. The views and opinions of authors expressed herein do not necessarily state or reflect those of the United States Government or any agency thereof." 


\section{ABSTRACT}

This research focused on developing low polarization (area specific resistance, ASR) cathodes for intermediate temperature solid oxide fuel cells (IT-SOFCs). In order to accomplish this we focused on two aspects of cathode development: (1) development of novel materials; and (2) developing the relationships between microstructure and electrochemical performance.

The materials investigated ranged from Ag-bismuth oxide composites (which had the lowest reported ASR at the beginning of this contract) to a series of pyrochlore structured ruthenates $\left(\mathrm{Bi}_{2-\mathrm{x}} \mathrm{M}_{\mathrm{x}} \mathrm{Ru}_{2} \mathrm{O}_{7}\right.$, where $\mathrm{M}=\mathrm{Sr}, \mathrm{Ca}, \mathrm{Ag} ; \mathrm{Pb}_{2} \mathrm{Ru}_{2} \mathrm{O}_{6.5}$; and $\left.\mathrm{Y}_{2-2 \mathrm{x}} \mathrm{Pr}_{2 \mathrm{x}} \mathrm{Ru}_{2} \mathrm{O}_{7}\right)$, to composites of the pyrochchlore ruthenates with bismuth oxide.

To understand the role of microstructure on electrochemical performance, we optimized the Ag-bismuth oxide and the ruthenate-bismuth oxide composites in terms of both two-phase composition and particle size/microstructure. We further investigated the role of thickness and current collector on ASR.

Finally, we investigated issues of stability and found the materials investigated did not form deleterious phases at the cathode/electrolyte interface. Further, we established the ability through particle size modification to limit microstructural decay, thus, enhancing stability.

The resulting $\mathrm{Ag}-\mathrm{Bi}_{0.8} \mathrm{Er}_{0.2} \mathrm{O}_{1.5}$ and $\mathrm{Bi}_{2} \mathrm{Ru}_{2} \mathrm{O}_{7}-\mathrm{Bi}_{0.8} \mathrm{Er}_{0.2} \mathrm{O}_{1.5}$ composite cathodes had ASRs of $1.0 \Omega \mathrm{cm}^{2}$ and $0.73 \Omega \mathrm{cm}^{2}$ at $500{ }^{\circ} \mathrm{C}$ and $0.048 \Omega \mathrm{cm}^{2}$ and $0.053 \Omega \mathrm{cm}^{2}$ at $650{ }^{\circ} \mathrm{C}$, respectively. These ASRs are truly impressive and makes them among the lowest IT-SOFC ASRs reported to date. 


\section{TABLE OF CONTENTS}

ABSTRACT

TABLE OF CONTENTS ........................................................................................................................IV

LIST OF GRAPHICAL MATERIALS ............................................................................................................VI

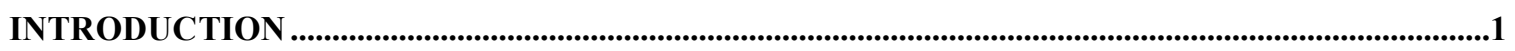

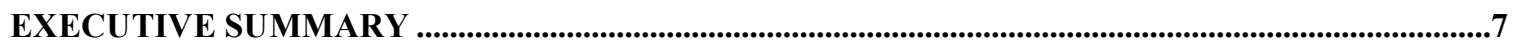

EXPERIMENTAL _............................................................................................................................................

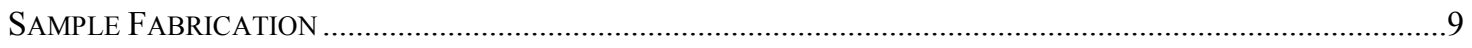

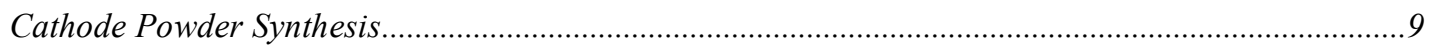

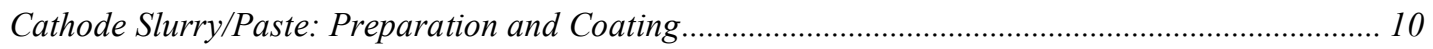

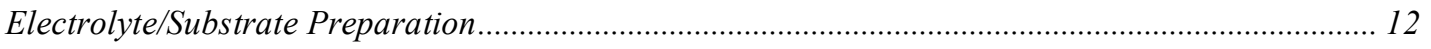

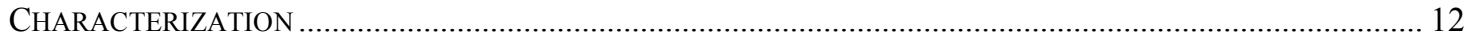

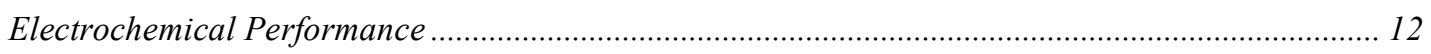

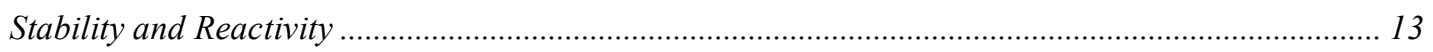

RESULTS AND DISCUSSION..................................................................................................................... 15

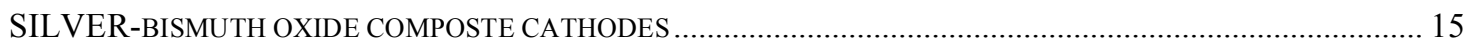

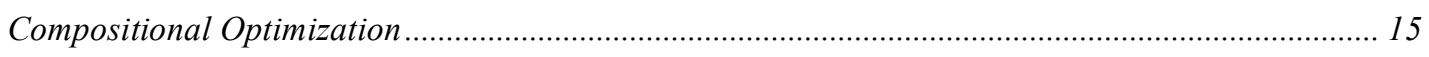

Stability: Thermal Performance Decay due to Microstructural Evolution ......................................... 17

Stability: Performance Decay Under Applied D.C. Bias ......................................................... 26

Improving Stability and Area Specific Resistance through Microstructural Control............................ 32

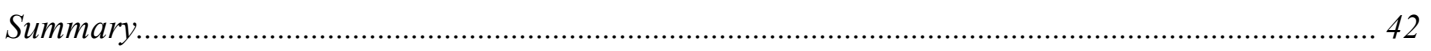

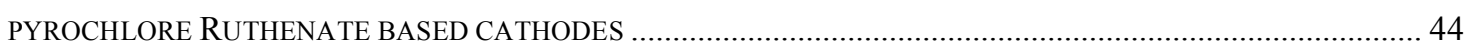

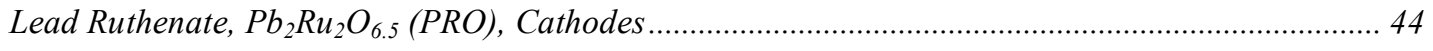

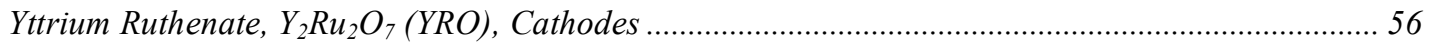

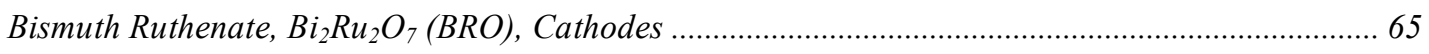

Doping Strategies to Increase Ionic Conductivity in Bismuth Ruthenates ........................................ 70

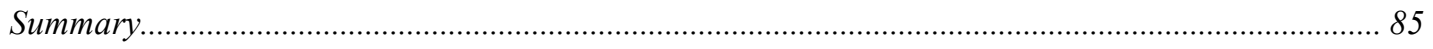

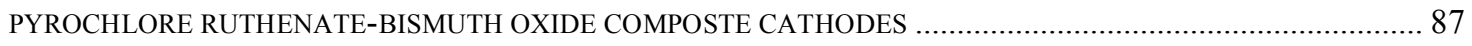

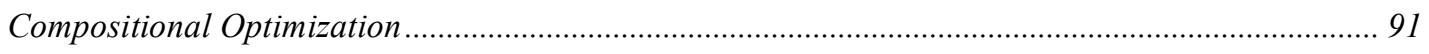

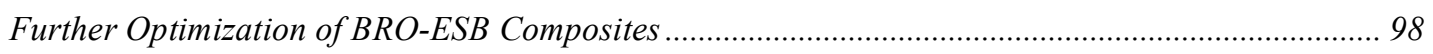




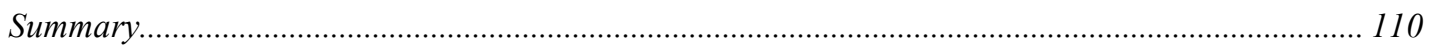

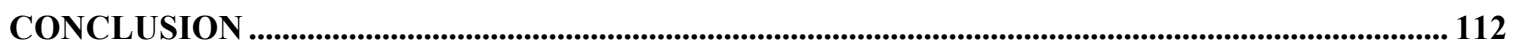




\section{LIST OF GRAPHICAL MATERIALS}

Figure 1. ARRHENIUS PLOT OF AREA SPECIFIC RESistanCE (ASR) OF SELECTED CATHODES, ADAPTED From Xia ET $A L .$.

FigURE 2. SCHEMATIC REPRESENTATION OF (A) THE TPB LINES FORMED BETWEEN METALLIC PARTICLES AND AN ELECTROLYTE SUBSTRATE, AND (B) THE REACTION ZONE OF A SINGLE-PHASE METALLIC ELECTRODE.

FigURE 3. SCHEMATIC REPRESENTATION OF (A) THE TPB LINES FORMED BETWEEN A METALLIC PARTICLE, AN IONCONDUCTING PARTICLE, AND AN ELECTROLYTE SUBSTRATE, AND (B) THE REACTION ZONE OF A DUAL-PHASE METALLIC-ION-CONDUCTING ELECTRODE.

Figure 4. (A) IMPEDANCE SPECTRA AND (B) ELECTRODE ASR VS SILVER CONTENT OF AG-ESB SHOWING COMPOSITIONAL OPTIMIZATION AT $600^{\circ} \mathrm{C}$.

Figure 5. ARrhENIUS PLOt, ADAPTED From Xia ET. AL., COMPARING THE ASR OF AG-ESB (THIS WORK) WITH THE BEST CATHODES REPORTED IN THE LITERATURE AT THE START OF THIS STUDY.

Figure 6. IMPEDANCE SPECTRA OBTAINED FROM A SYMMETRICAL Ag-ESB/ESB/Ag-ESB (A), Ag-YSB/YSB/AgYSB (B), AND Ag/ESB/Ag (C) CELls TESTED AT $650^{\circ} \mathrm{C}$ OVER A PERIOD of $100 \mathrm{H}$. The DATA ARE $\mathrm{R}_{\mathrm{S}}$ CORRECTED. ARROWS INDICATE DIRECTION OF INCREASING TIME.

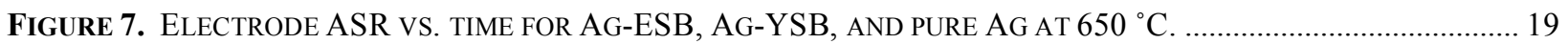

Figure 8. Change IN ELECTROLYTE RELATIVE CONDUCTIVITY VS. TIME FOR ESB AND YSB AT $650{ }^{\circ} \mathrm{C}$.................. 20

FigURE 9. EPMA LINE-SCAN OF A SAMPLE WITH PURE AG ELECTRODES, ANNEALED AT $750{ }^{\circ} \mathrm{C}$ FOR 48 H. ............... 21

FigURE 10. XRD SPECTRA OF AG-ESB POWDER MIXTURES BEFORE AND AFTER CO-FIRING AT $750{ }^{\circ} \mathrm{C}$ FOR $48 \mathrm{H}$. SQUARE MARKERS IDENTIFY CUBIC FLUORITE PEAKS OF THE ESB PHASE, CIRCLE MARKERS IDENTIFY SILVER PEAKS

FigurE 11. SEM MiCROGRAPHS COMPARING THE MORPHOLOGY OF AG-ESB ELECTRODES BEFORE (A) AND AFTER (B) FIRING AT $750{ }^{\circ} \mathrm{C}$ FOR $1 \mathrm{H}$ AND (C) AFTER TESTING AT $650{ }^{\circ} \mathrm{C}$ FOR $100 \mathrm{H}$.

FigURE 12. SEM MICROGRAPHS COMPARING THE MORPHOLOGY OF AG-YSB ELECTRODES BEFORE (A) AND AFTER (B) FIRING AT $750{ }^{\circ} \mathrm{C}$ FOR $1 \mathrm{H}$ AND (C) AFTER TESTING AT $650^{\circ} \mathrm{C}$ FOR $100 \mathrm{H}$.

FigurE 13. SEM MiCROGRAPHS COMPARING THE MORPHOLOGY OF PURE AG ELECTRODES BEFORE (A) AND AFTER (B) FIRING AT $750^{\circ} \mathrm{C}$ FOR $1 \mathrm{H}$ AND (C) AFTER TESTING AT $650^{\circ} \mathrm{C}$ FOR $100 \mathrm{H}$. DelAMINATION CAUSED By FRACTURING FOR SEM ANALYSIS.

FiguRE 14. IMPEDANCE PLOTS OF AG-ESB ELECTRODE AT $500{ }^{\circ} \mathrm{C}$ UNDER DIFFERENT BIAS CURRENTS (A) AND (B) IMAGINARY VS. REAL IMPEDANCE (C) AND (D) IMAGINARY IMPEDANCE VS. FREQUENCY .................................. 26

FIGURE 15. AG-ESB ELECTRODE RESISTANCE VS. BIAS CURRENT AT 500 AND $625^{\circ} \mathrm{C}$................................................. 27

Figure 16. IMPEDANCE PLOTS OF AG-ESB ELECTRODE AT $625^{\circ} \mathrm{C}$ UNDER DIFFERENT BIAS CURRENTS (A) IMAGINARY VS. REAL IMPEDANCE (B) IMAGINARY IMPEDANCE VS. FREQUENCY. 28 
Figure 16. IMPEDANCE PLOTS OF AG-ESB ELECTRODE UNDER 250MA BIAS AT $625^{\circ} \mathrm{C}$ (A) IMAGINARY VS. REAL IMPEDANCE (B) IMAGINARY IMPEDANCE VS. FREQUENCY.

Figure 18. CROSS-SECTION OF THE ELECTROLYTE/ELECTRODE INTERFACE AFTER ANNEALING EXPERIMENTS AT 625 ${ }^{\circ} \mathrm{C}$ UNDER 250 MA BIAS FOR 26H (A) ANODE (B) ELECTROLYTE INTERFACE AFTER CATHODE PEELED OFF...... 30

Figure 19. Proposed electrode reaction mechanism For AG-ESB Electrodes Under (A) NO BIAS AND (B) BIAS

Figure 20. NyQUIST PLOTS FOR SILVER-ESB COMPOSITE ELECTRODES CONTAINING 0 VOL \% (A), 5 VOL \% (B), 10 VOL\% (C), AND 15VOL\% (D) 8YSZ NANOPARTICLES. SAMPLES WERE TESTED AT $650{ }^{\circ} \mathrm{C}$ IN AIR FOR $100 \mathrm{H}$ UNDER NO APPLIED BIAS. NOTE THAT THE ELECTROLYTE RESISTANCE HAS BEEN SUBTRACTED FROM ALL NYQUIST PLOTS.

FIGURE 21. EFFECT OF TIME ON ASR OF SILVER-ESB COMPOSITE ELECTRODES CONTAINING VARIOUS VOLUMETRIC AMOUNTS OF $8 \mathrm{MOL} \%$ YSZ NANO-PARTICLES. MEASUREMENTS TAKEN AT $650{ }^{\circ} \mathrm{C}$ IN AIR UNDER NO APPLIED BIAS. .

Figure 22. BACKSCATTERED ELECTRON SEM IMAGES OF TESTED ( $650^{\circ} \mathrm{C}, 100 \mathrm{H}$ IN AIR UNDER NO APPLIED BIAS) AG-ESB ELECTRODES CONTAINING 0 VOL\% (A), 5 VOL\% (B), 10 VOL\% (C), AND 15 VOL\% (D) YSZ NANOPARTICLES.

Figure 23. SEM IMAGES OF AN UNTESTED (A) AND TESTED (600 ${ }^{\circ} \mathrm{C}, 48 \mathrm{H}$ IN AIR UNDER NO APPLIED BIAS) (B) SILVER-ESB ELECTRODES CONTAINING 15 VOL\% 8YSZ NANO-PARTICLES.

FigurE 24. ELECTRON MICROGRAPHS OF TYPICAL ESB POWDER AFTER SIEVING, WITH (A) AND WITHOUT (B) VIBRATORY MILLING, AND PARTICLE SIZE ANALYSIS (PSA) RESULTS (C). PSA RESULTS FOR THE SIEVED ESB POWDERS MAY BE SKEWED TO LOWER PARTICLE SIZES SINCE LARGER PARTICLES SETTLE OUT OF SUSPENSION QUICKLY, AND CONSEQUENTLY MAY BE OMITTED FROM THE MEASUREMENT COUNT.

Figure 24. COMPARISON OF ASR VS. RECIPROCAL TEMPERATURE FOR AG-YSB (XIA ET. AL.) AND AG-ESB (THIS WORK) WITH MICRON-SIZED AND NANO-SIZED ESB PARTICLES. .....

FigurE 26. NYQUiST PLOTS (A) AND IMAGINARY PART OF IMPEDANCE VS. LOG-SCALE FREQUENCY (B) FOR 50-50 VOL\% SILVER-ESB COMPOSITE ELECTRODES, WHERE THE ESB PHASE WAS PREPARED FROM SIEVED (ESB ${ }_{S}$, LARGER CURVES) AND VIBRATORY MILLED (ESB ${ }_{V M}$, SMALLER CURVES) POWDERS. SAMPLES WERE TESTED AT $650{ }^{\circ} \mathrm{C}$ IN AIR FOR $100 \mathrm{H}$ UNDER NO APPLIED BIAS. NOTE THAT THE ELECTROLYTE RESISTANCE HAS BEEN SUBTRACTED FROM ALL NYQUIST PLOTS

FIGURE 27. ElECTRODE ASR VS. TIME FOR 50-50 VOL\% SILVER-ESB COMPOSITE ELECTRODES, WHERE THE ESB PHASE WAS PREPARED FROM SIEVED (ESB , TRIANGLES) AND VIBRATORY MILLED (ESB ${ }_{\mathrm{VM}}$, SQUARES) POWDERS. SAMPLES WERE TESTED AT $650^{\circ} \mathrm{C}$ IN AIR FOR $100 \mathrm{H}$ UNDER NO APPLIED BIAS. 38

FigurE 28. NYQUiST PLOTS (A) AND IMAGINARY PART OF IMPEDANCE PLOTTED VS. LOG-SCALE FREQUENCY (B) FOR 50-50 VOL\% SILVER-ESB COMPOSITE ELECTRODES, WHERE THE ESB PHASE WAS PREPARED FROM SIEVED $\left(E_{S}\right.$, LARGER CURVES) AND VIBRATORY MILLED (ESB ${ }_{V M}$, SMALLER CURVES) POWDERS. SAMPLES WERE TESTED AT $650{ }^{\circ} \mathrm{C}$ IN AIR FOR 40 H UNDER A $250 \mathrm{MV}$ BIAS. NOTE THAT THE ELECTROLYTE RESISTANCE HAS BEEN SUBTRACTED FROM ALL NYQUIST PLOTS. 
Figure 29. ELECTRODE ASR VS. TIME FOR 50-50 VOL\% SILVER-ESB COMPOSITE ELECTRODES, WHERE THE ESB PHASE WAS PREPARED FROM SIEVED (ESB, , TRIANGLES) AND VIBRATORY MILLED (ESB ${ }_{\mathrm{VM}}$, CIRCLES) POWDERS. SAMPLES WERE TESTED AT $650^{\circ} \mathrm{C}$ IN AIR FOR $40 \mathrm{H}$ UNDER A $250 \mathrm{MV}$ BIAS. 40

Figure 30. Microstructural IMAGES OF SILVER-ESB COMPOSITE ELECTRODES, WHERE THE ESB PHASE WAS PREPARED FROM SIEVED POWDERS — SURFACE BEFORE TESTING (A) AND CROSS-SECTION OF THE COUNTER ELECTRODE (B), WORKING ELECTRODE SURFACE (C), AND COUNTER ELECTRODE SURFACE (D) OF A CELL AFTER $48 \mathrm{H}$ OF TESTING AT $650^{\circ} \mathrm{C}$ UNDER A $250 \mathrm{MV}$ APPLIED BIAS. .....

FigurE 31. CROSS-SECTIONAL MICROSTRUCTURAL IMAGES OF SILVER-ESB COMPOSITE ELECTRODES, WHERE THE ESB PHASE WAS PREPARED FROM VIBRATORY MILLED POWDERS, AFTER 48 H OF TESTING AT $650{ }^{\circ} \mathrm{C}$ UNDER A $250 \mathrm{MV}$ APPLIED BIAS - WORKING ELECTRODE (A) WITH CLOSE-UP VIEW OF THE WORKING ELECTRODE/ELECTROLYTE INTERFACE (B) AND COUNTER ELECTRODE (C) WITH CLOSE-UP VIEW OF THE COUNTER ELECTRODE/ELECTROLYTE INTERFACE (D).

FIgURE 32. XRD PATtERnS OF $\mathrm{PB}_{2} \mathrm{RU}_{2} \mathrm{O}_{6.5}(\mathrm{PRO})$ GEL PRECURSOR DRIED $80^{\circ} \mathrm{C}$, AND CALCINED AT 400, 600, 700, 800, AND $900^{\circ} \mathrm{C}$ FOR 6 HOURS. 44

Figure 33. FE-SEM MiCROGRAPH OF $\mathrm{PB}_{2} \mathrm{RU}_{2} \mathrm{O}_{6.5}(\mathrm{PRO})$ POWDER PREPARED AT $700{ }^{\circ} \mathrm{C}$ FOR 6 HOURS. 45

Figure 34. FE-SEM Micrograph OF THE SURFACE OF $\mathrm{PB}_{2} \mathrm{RU}_{2} \mathrm{O}_{6.5}$ ELECTRODES SinTERED AT $700{ }^{\circ} \mathrm{C}$ FOR 3 HOURS. 46

Figure 35. FE-SEM MICROGRAPH OF THE FRACTURED CROSS-SECTION OF $\mathrm{PB}_{2} \mathrm{RU}_{2} \mathrm{O}_{6.5}$ (PRO) ELECTRODES SINTERED AT $875^{\circ} \mathrm{C}$ FOR 3 HOURS. 46

FIgURE 36. FE-SEM MICROGRAPH OF PRO-ESB COMPOSITE ELECTRODES SINTERED AT $800{ }^{\circ} \mathrm{C}$ FOR 3 HOURS. ...... 47

Figure 37. COMPLEX IMPEDANCE PLOT OF PRO700 SAMPLE, MEASURED AT $300{ }^{\circ} \mathrm{C}$ IN AIR (A); DETAIL AT LOW FREQUENCIES (B).

Figure 38. COMPLEX IMPEDANCE PLOT OF PRO875 SAMPLE, MEASURED AT $350{ }^{\circ} \mathrm{C}$ IN AIR (A); DETAIL AT LOW FREQUENCIES (B). 50

Figure 39. COMPLEX IMPEDANCE PlOTS OF PRO875 SAMPLE, MEASURED AT 550, 600 AND $650{ }^{\circ} \mathrm{C}$ IN AIR........... 50

FigurE 40. COMPLEX IMPEDANCE PLOTS OF PRO875 SAMPLE, MEASURED AT 700, 750 AND $780{ }^{\circ} \mathrm{C}$ IN AIR........... 51

FIGURE 41. COMPLEX IMPEDANCE PLOT OF PRO700, PRO800 AND PRO875 SAMPLES, AT $650{ }^{\circ} \mathrm{C}$ IN AIR.............. 52

Figure 42. COMPLEX IMPEDANCE PLOT OF PRO-ESB800 SAMPLE, MEASURED AT 700 AND $750{ }^{\circ} \mathrm{C}$ IN AIR.............. 52

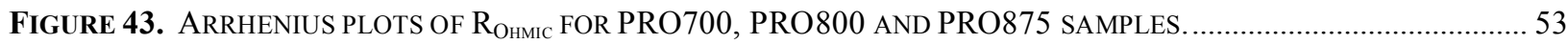

Figure 44. ASR ARrheniUs PLOTS OF $\mathrm{R}_{\text {Снем }}$ FOR PRO800, PRO875, PRO-ESB700 AND PRO-ESB800 SAMPLES. 54

FIGURE 45. XRD PATTERNS OF $\mathrm{PB}_{2} \mathrm{RU}_{2} \mathrm{O}_{6.5}$-ESB (MOLAR RATIO 1:1) SINTERED AT $850{ }^{\circ} \mathrm{C}$ FOR 12 HOURS.............. 55

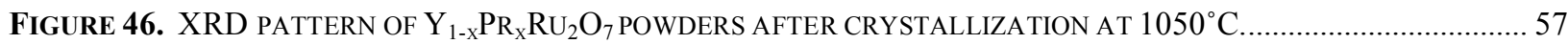

Figure 47. FE-SEM IMAGE OF (A) $\mathrm{Y}_{2} \mathrm{RU}_{2} \mathrm{O}_{7}$ AFTER CRYSTALlization AT $1050^{\circ} \mathrm{C}$ AND (B) $\mathrm{Y}_{1.8} \mathrm{PR}_{0.2} \mathrm{RU}_{2} \mathrm{O}_{7} \mathrm{AFTER}$

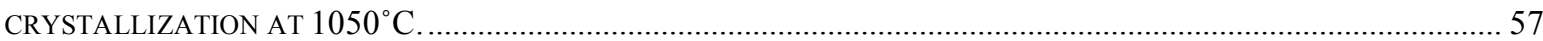

Figure 48. SEM-EDS IMAGE OF THE PR-DOPED PYROCHLORE POWDER AFTER CRYSTALLIZATION AT $1050^{\circ} \mathrm{C} . . . . . . .57$

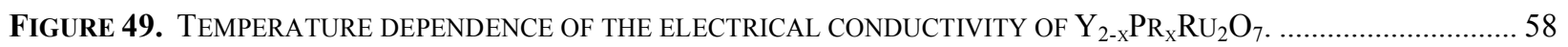

FigurE 50. TyPiCAL COMPLEX IMPEDANCE PLOT OF $\mathrm{Y}_{2} \mathrm{RU}_{2} \mathrm{O}_{7} / \mathrm{ESB} / \mathrm{Y}_{2} \mathrm{RU}_{2} \mathrm{O}_{7} \mathrm{CELL}$, IN AIR AT $300^{\circ} \mathrm{C}$ AND $700^{\circ} \mathrm{C} . . .59$ 
FigURE 51. TYPICAL COMPLEX IMPEDANCE PLOTS FOR $\mathrm{Y}_{1.8} \mathrm{PR}_{0.2} \mathrm{RU}_{2} \mathrm{O}_{7} / \mathrm{ESB} / \mathrm{Y}_{1.8} \mathrm{PR}_{0.2} \mathrm{RU}_{2} \mathrm{O}_{7} \mathrm{AND}_{\mathrm{Y}} \mathrm{Y}_{1.5} \mathrm{PR}_{0.5} \mathrm{RU}_{2} \mathrm{O}_{7}$ $/ \mathrm{ESB} / \mathrm{Y}_{1.5} \mathrm{PR}_{0.5} \mathrm{RU}_{2} \mathrm{O}_{7}$ CELLS, MEASURED IN AIR AT $700{ }^{\circ} \mathrm{C}$

Figure 52. ARRHENIUS PLOT OF THE ELECTRODE ASR $\left(\Omega \mathrm{CM}^{2}\right)$. 61

FigURE 53. $X$-RAY SPECTRA OF $Y_{2-x} P_{x} R_{U_{2}} \mathrm{O}_{7} /$ ESB MIXTURE AND $Y_{2-\mathrm{x}} \mathrm{PR}_{\mathrm{X}} \mathrm{RU}_{2} \mathrm{O}_{7} /$ GDC MIXTURE THAT WERE PRESSED AND TREATED AT $800^{\circ} \mathrm{C}$ FOR $24 \mathrm{H}$.

Figure 54. TyPiCAL COMPLEX IMPEDANCE PLOTS FOR I. Y1.5PR0.5RU2O7/GDC/Y1.5PR0.5RU2O7, AND II. Y1.5PR0.5RU2O7/ESB/Y1.5PR0.5RU2O7 CELLS, MEASURED IN AIR AT 700OC.

Figure 55. ASR VALUES OF $Y_{2-\mathrm{x}} \mathrm{PR}_{\mathrm{X}} \mathrm{RU}_{2} \mathrm{O}_{7}$ ON ESB AND ON GDC PELLETS AS FUNCTION OF PR CONTENT. 63

Figure 56. ASR VALUES OF $Y_{1.5} \mathrm{PR}_{0.5} \mathrm{RU}_{2} \mathrm{O}_{7}$ ON GDC ELECTROLYTE AS FUNCTION OF OXYGEN PARTIAL PRESSURE.

Figure 57. XRD PATTERNS OF $\mathrm{Bi}_{2} \mathrm{RU}_{2} \mathrm{O}_{7}$ AFTER CALCINATION AT $900^{\circ} \mathrm{C}$ FOR $10 \mathrm{H}$ BEFORE (TOP) AND AFTER (BOTTOM) LEACHING.

FIGURE 58. XRD PATTERN FOR $\mathrm{BI}_{2} \mathrm{RU}_{2} \mathrm{O}_{7}$ AND GDC POWDER MIXTURE AFTER HEAT TREATMENT AT $850^{\circ} \mathrm{C}$ FOR 10 H. .

Figure 59. (A) SURFACE AND (B) CROSS-SECTIONAL MICROGRAPHS OF $\mathrm{BI}_{2} \mathrm{RU}_{2} \mathrm{O}_{7}$ ELECTRODE ON GDC ELECTROLYTE.

FiguRE 60. IMPEDANCE PLOTS OF $\mathrm{BI}_{2} \mathrm{RU}_{2} \mathrm{O}_{7}$ ELECTROde ON GDC AT 500 (A), AND $700^{\circ} \mathrm{C}$ (B) ............................. 68

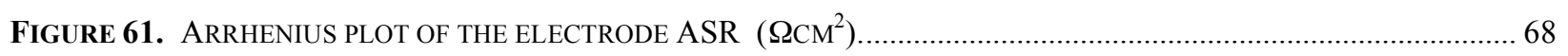

FigURE 62. LN ASR $V S$. LN PO2 AT DIFFERENT TEMPERATURES WITH $M$ IN PARENTHESIS $T M$ 69

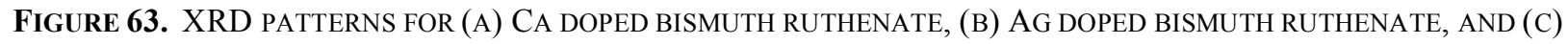
SR DOPED BISMUTH RUTHENATE POWDERS.

FiguRE 64. LATTICE CONSTANTS AS A FUNCTION OF DOPANT CONCENTRATION FOR CA, AG, AND SR DOPED BISMUTH RUTHENATE POWDERS (* - FROM REFERENCE 14 AND 15). 73

Figure 65. Cross-SECTION Micrographs OF (A) $\mathrm{BI}_{2} \mathrm{RU}_{2} \mathrm{O}_{7}$, (B) $\left(\mathrm{BI}_{0.95} \mathrm{CA}_{0.05}\right)_{2} \mathrm{RU}_{2} \mathrm{O}_{7}$, AND (C) $\left(\mathrm{BI}_{0.95} \mathrm{AG}_{0.05}\right)_{2} \mathrm{RU}_{2} \mathrm{O}_{7}$ ELECTRODES ON GDC ELECTROLYTE SINTERED AT $850^{\circ} \mathrm{C}$.

FiguRE 66. IMPEDANCE PLOTS OF CA DOPED $\mathrm{BI}_{2} \mathrm{RU}_{2} \mathrm{O}_{7}$ ELECTRODES ON GDC AT $700{ }^{\circ} \mathrm{C}$ (A) AND (B) IMAGINARY VS. REAL IMPEDANCE, (C) AND (D) IMAGINARY IMPEDANCE VS. FREQUENCY …………….................................. 75

FigURE 67. ARRHENIUS PLOT OF CA DOPED $\mathrm{BI}_{2} \mathrm{RU}_{2} \mathrm{O}_{7}$ ELECTRODE ASR $\left(\Omega \mathrm{CM}^{2}\right)$ IN AIR. ........................................... 76

Figure 68. IMPEDANCE PLOTS OF AG DOPED $\mathrm{BI}_{2} \mathrm{RU}_{2} \mathrm{O}_{7}$ ELECTRODES ON GDC AT $700{ }^{\circ} \mathrm{C}$ (A) IMAGINARY VS. REAL IMPEDANCE, (B) IMAGINARY IMPEDANCE VS. FREQUENCY. .77

Figure 69. ARrhenius PLOT OF AG DOPED $\mathrm{Bi}_{2} \mathrm{RU}_{2} \mathrm{O}_{7}$ ELECTROdE ASR $\left(\Omega \mathrm{CM}^{2}\right)$ IN AIR. 77

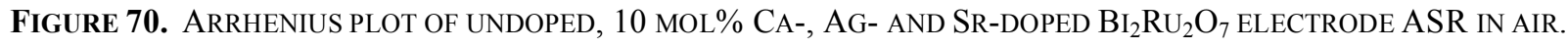

Figure 71. IMPEDANCE PLOTS OF $5 \mathrm{MOL} \%$ CA-DOPED $\mathrm{BI}_{2} \mathrm{RU}_{2} \mathrm{O}_{7}$ ELECTRODES ON GDC AT $700{ }^{\circ} \mathrm{C}$ (A) AND (B) IMAGINARY VS. REAL IMPEDANCE, (C) AND (D) IMAGINARY IMPEDANCE VS. FREQUENCY 79

FigurE 72. IMPEDANCE PLOTS OF $5 \mathrm{MOL} \%$ AG-DOPED $\mathrm{BI}_{2} \mathrm{RU}_{2} \mathrm{O}_{7}$ ELECTRODES ON GDC AT $700{ }^{\circ} \mathrm{C}$ (A) IMAGINARY VS. REAL IMPEDANCE, (B) AND (C) IMAGINARY IMPEDANCE VS. FREQUENCY. 
Figure 73. $\mathrm{LN}(\mathrm{ASR}) \mathrm{VS}$. LN $\left(\mathrm{P}_{\mathrm{O}_{2}}\right)$ OF $5 \mathrm{MOL} \% \mathrm{CA}$ DOPED $\mathrm{B}_{2} \mathrm{RU}_{2} \mathrm{O}_{7}$ ELECTRODE AT DIFFERENT TEMPERATURES WiTH M IN PARENTHESIS, I.E., T(M)

Figure 74. LN(ASR) VS. LN $\left(\mathrm{P}_{\mathrm{O}_{2}}\right)$ OF 5 MOL\% AG-DOPED $\mathrm{BI}_{2} \mathrm{RU}_{2} \mathrm{O}_{7}$ ELECTRODE AT DiFFERENT TEMPERATURES With

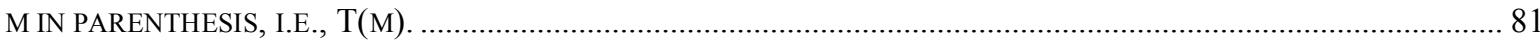

Figure 75. CAPACITANCE $\left(\mu \mathrm{F} / \mathrm{CM}^{2}\right)$ IN AIR OF $\mathrm{Bi}_{2} \mathrm{RU}_{2} \mathrm{O}_{7}, 5 \mathrm{MOL} \% \mathrm{CA}$ - AND AG-DOPED $\mathrm{Bi}_{2} \mathrm{RU}_{2} \mathrm{O}_{7}$ ELECTROdeS. .... 82

Figure 76. Electrode CAPACITANCE $\left(\mu \mathrm{F} / \mathrm{CM}^{2}\right) \mathrm{VS} \mathrm{LN}\left(\mathrm{P}_{\mathrm{O}_{2}}\right) \mathrm{OF} \mathrm{BI}_{2} \mathrm{RU}_{2} \mathrm{O}_{7}, 5 \mathrm{MOL} \% \mathrm{CA}$ AND AG DOPED $\mathrm{Bi}_{2} \mathrm{RU}_{2} \mathrm{O}_{7}$ ELECTRODES AT 500 AND $700^{\circ} \mathrm{C}$

FiguRE 77. DTA PLOTS OF $\mathrm{BI}_{2} \mathrm{O}_{3}, \mathrm{BI}_{2} \mathrm{RU}_{2} \mathrm{O}_{7.3}-\mathrm{BI}_{2} \mathrm{O}_{3}\left(50 \mathrm{wT} \% \mathrm{BI}_{2} \mathrm{O}_{3}\right)$, AND $\mathrm{Bi}_{2} \mathrm{RU}_{2} \mathrm{O}_{7}-\mathrm{BI}_{2} \mathrm{O}_{3}\left(50 \mathrm{wT} \% \mathrm{BI}_{2} \mathrm{O}_{3}\right.$ ) POWDERS IN HEATING CYCLE.

FiguRE 78. XRD PATtERnS FOR POWDER MIXTURE (A) $\mathrm{BI}_{2} \mathrm{RU}_{2} \mathrm{O}_{7.3}$-GDC AND (B) $\mathrm{BI}_{2} \mathrm{RU}_{2} \mathrm{O}_{7}$-GDC FIRED AT 850 ${ }^{\circ} \mathrm{C} / 10$ HOURS

Figure 79. XRD PATTERNS FOR POWDER MIXTURE OF $\mathrm{BI}_{2} \mathrm{RU}_{2} \mathrm{O}_{7.3}$-ESB FIRED AT (A) $750{ }^{\circ} \mathrm{C} / 10$ HOURS, (B) 800 ${ }^{\circ} \mathrm{C} / 10$ HOURS, AND (C) $850^{\circ} \mathrm{C} / 10$ HOURS.

FigURE 80. XRD PATTERNS FOR POWDER MIXTURE OF $\mathrm{BI}_{2} \mathrm{RU}_{2} \mathrm{O}_{7}$-ESB FIRED AT (A) $800{ }^{\circ} \mathrm{C} / 10$ HOURS AND (B) 850 ${ }^{\circ} \mathrm{C} / 10$ HOURS 90

Figure 81. SuRface MicrographS OF (A) $\mathrm{BI}_{2} \mathrm{RU}_{2} \mathrm{O}_{7}$, (B) $\mathrm{BI}_{2} \mathrm{RU}_{2} \mathrm{O}_{7}$-ESB (50 WT\% ESB) ELECTROdes ON GDC ELECTROLYTE SINTERED AT $800^{\circ} \mathrm{C}$

Figure 82. CRoss-SeCtion micrographs of (A) $\mathrm{BI}_{2} \mathrm{RU}_{2} \mathrm{O}_{7}$, (B) $\mathrm{BI}_{2} \mathrm{RU}_{2} \mathrm{O}_{7}-\mathrm{Bi}_{2} \mathrm{O}_{3}$ (25 WT\% ESB), AND (C) $\mathrm{BI}_{2} \mathrm{RU}_{2} \mathrm{O}_{7}-\mathrm{BI}_{2} \mathrm{O}_{3}\left(37.5 \mathrm{WT} \%\right.$ ESB) ELECTRODES ON GDC ELECTROLYTE SINTERED AT $800{ }^{\circ} \mathrm{C}$.

Figure 83. IMPEDANCE PLOTS OF $\mathrm{BI}_{2} \mathrm{RU}_{2} \mathrm{O}_{7}$-ESB ELECTROdES ON GDC AT $500^{\circ} \mathrm{C}$ (A) AND (B) IMAGINARY VS. REAL IMPEDANCE, (C) AND (D) IMAGINARY IMPEDANCE VS. FREQUENCY

Figure 84. IMPEDANCE PLOTS OF $\mathrm{BI}_{2} \mathrm{RU}_{2} \mathrm{O}_{7}$-ESB ELECTRODES ON GDC AT $700^{\circ} \mathrm{C}$ (A) AND (B) IMAGinARY VS. REAL IMPEDANCE, (C) AND (D) IMAGINARY IMPEDANCE VS. FREQUENCY 94

Figure 85. ASR $\left(\Omega \mathrm{CM}^{2}\right)$ OF $\mathrm{BI}_{2} \mathrm{RU}_{2} \mathrm{O}_{7}$-ESB COMPOSITE ELECTRODES AS A FUNCTION OF WT\% ESB........................ 95

Figure 86. ARRHENIUS PLOT OF $\mathrm{Bi}_{2} \mathrm{RU}_{2} \mathrm{O}_{7}$-ESB COMPOSITE ELECTROdE ASR $\left(\wedge \mathrm{CM}^{2}\right)$. .95

FigURE 87. ASR $\left(\Omega \mathrm{CM}^{2}\right)$ OF $\mathrm{BI}_{2} \mathrm{RU}_{2} \mathrm{O}_{7.3}$-ESB $(25,37.5,50 \mathrm{WT} \% \mathrm{ESB})$ COMPOSITE ELECTRODES IN COMPARISON TO $\mathrm{BI}_{2} \mathrm{RU}_{2} \mathrm{O}_{7}$ ELECTRODE. AS-CALCINED BISMUTH RUTHENATE POWDERS USED FOR FABRICATION....................... 96

Figure 88. EleCtrode CAPACITANCE $\left(\mu \mathrm{F} / \mathrm{CM}^{2}\right)$ OF $\mathrm{BI}_{2} \mathrm{RU}_{2} \mathrm{O}_{7}$-ESB COMPOSITE ELECTRODES. 97

Figure 89. Electrode CAPACitANCE $\left(\mu \mathrm{F} / \mathrm{CM}^{2}\right)$ OF $\mathrm{BI}_{2} \mathrm{RU}_{2} \mathrm{O}_{7}, 5 \mathrm{MOL} \% \mathrm{CA}$ DOPED $\mathrm{BI}_{2} \mathrm{RU}_{2} \mathrm{O}_{7}$ (BCR5), 5 MOL \% AG DOPED $\mathrm{BI}_{2} \mathrm{RU}_{2} \mathrm{O}_{7}$ (BAR5), AND $\mathrm{BI}_{2} \mathrm{RU}_{2} \mathrm{O}_{7.3}$-ESB COMPOSITE ELECTRODES. As-CALCINED BISMUTH RUTHENATE POWDERS USED FOR FABRICATION.

FiguRE 90. NYQUIST (A) AND BODE (B) PLOTS AT $625^{\circ} \mathrm{C}$ FOR DIFFERENT COMPOSITIONS OF BRO $\mathrm{VM}_{\mathrm{V}, \mathrm{AP}}$-ESB $\mathrm{B}_{\mathrm{S}, \mathrm{AP}}$ ELECTRODES TESTED IN AIR. 99

FigURE 91. EFFECT OF ELECTRODE COMPOSITION FOR THE ESB $\mathrm{S}_{\mathrm{A}, \mathrm{AP}}-\mathrm{BRO}_{\mathrm{VM}, \mathrm{AP}}$ SYSTEM. 100

FigURE 92. SEM MICROGRAPH OF AS-PREPARED ESB AND BRO POWDERS BEFORE (LEFT) AND AFTER (RIGHT) VIBRATORY-MILLING. 
FIGURE 93. TEM MICROGRAPH OF AS-PREPARED BRO VM POWDERS BEFORE (LEFT) AND AFTER (RIGHT) SONICATION AND SEDIMENTATION.

FIGURE 94. SEM IMAGE OF FOUR FULLY-FIRED BRO-ESB CATHODE SYSTEMS USED IN THIS STUDY-BROS,AP$\mathrm{ESB}_{\mathrm{S}, \mathrm{AP}}(\mathrm{A}), \mathrm{BRO}_{\mathrm{VM}, \mathrm{AP}}-\mathrm{ESB}_{\mathrm{S}, \mathrm{AP}}(\mathrm{B}), \mathrm{BRO}_{\mathrm{S}, \mathrm{AP}}-\mathrm{ESB}_{\mathrm{VM}, \mathrm{AP}}(\mathrm{C}), \mathrm{BRO}_{\mathrm{VM}, \mathrm{AP}}-\mathrm{ESB}_{\mathrm{VM}, \mathrm{AP}}(\mathrm{D})$. 103

Figure 95. NyQUiST (A) AND BODE (B) PLOTS AT $625^{\circ} \mathrm{C}$ FOR DIFFERENT 50-50 WT\% BRO-ESB ELECTRODE MICROSTRUCTURES TESTED IN AIR

FIGURE 96. ARRHENIUS PLOT OF ASR VS RECIPROCAL TEMPERATURE FOR THE FOUR DIFFERENT MICROSTRUCTURES STUDIED.

Figure 97. NyQUist (A) AND BODE (B) PLOTS AT $625^{\circ} \mathrm{C}$ FOR DIFFERENT 50-50 WT\% BRO-ESB ELECTRODE MICROSTRUCTURES TESTED IN AIR BEFORE (OPEN SYMBOLS) AND AFTER (CLOSED SYMBOLS) SONICATION AND SEDIMENTATION OF ELECTRODE POWDERS.

FIGURE 98. ARRHENIUS PLOT OF ASR—COMPARISON BETWEEN ELECTRODES PREPARED FROM AS-PREPARED POWDERS (OPEN SYMBOLS) AND POWDERS WHICH UNDERWENT ULTRASONICATION AND SEDIMENTATION (CLOSED SYMBOLS).

Figure 99. EFFECT OF ELECTRODE THICKNESS ON ASR AT $625^{\circ} \mathrm{C}$ FOR THE FOUR DIFFERENT ELECTRODE MICROSTRUCTURES PREPARED AFTER ULTRASONICATION AND SEDIMENTATION OF THE AS-PREPARED POWDERS.

Figure 100. NyQuist (A,C) AND BODE (B,D) PLOTS AT $625^{\circ} \mathrm{C}$ FOR 50-50 WT\% BRO-ESB AT DIFFERENT THICKNESSES WITHOUT (OPEN SYMBOLS) AND WITH (CLOSED SYMBOLS) PURE BRO CURRENT COLLECTORS.

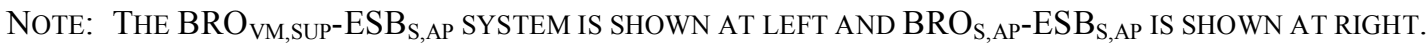

FIGURE 101. ARRHENIUS PLOT OF ASR—A COMPARISON BETWEEN ELECTRODES WITHOUT (OPEN SYMBOLS) AND WITH (CLOSED SYMBOLS) CURRENT COLLECTORS FOR THE BRO $\mathrm{VM}_{\mathrm{S}, \mathrm{SUP}}-\mathrm{ESB}_{\mathrm{S}, \mathrm{AP}}(\mathrm{A}) \mathrm{AND}_{\mathrm{BRO}} \mathrm{BR}_{\mathrm{S}, \mathrm{AP}} \mathrm{ESB}_{\mathrm{S}, \mathrm{AP}}(\mathrm{B})$ SYSTEMS.

Figure 102. COMPARISON OF ASR vS. RECIPROCAL TEMPERATURE FOR AG-YSB (XiA ET. AL.), $\mathrm{BA}_{0.5} \mathrm{SR}_{0.5} \mathrm{CO}_{0.8} \mathrm{FE}_{0.8} \mathrm{O}_{3-\delta}$ (ZHANG AND HAILE) AND OPTIMIZED AG-ESB (THIS WORK) AND OPTIMIZED BRO-ESB (THIS WORK). 


\section{INTRODUCTION}

The ability of solid oxide fuel cells (SOFCs) to directly convert the chemical energy of readily available fuels into useful power and heat without combustion or complete external reforming, makes it one of the highest efficiency devices for power generation to date- - higher than steam turbines, internal combustion engines, diesel engines, and even polymer electrolyte fuel cells ${ }^{1}$. For this reason, among others, SOFCs are the focus of much recent research.

Solid oxide fuel cells are electrochemical devices that offer clean, cheap and efficient conversion of the chemical energy of a fuel to electrical energy. State of the art SOFCs employ yttria stabilized zirconia (YSZ) as the electrolyte material operating at $700-1000{ }^{\circ} \mathrm{C}$. High operation temperatures are required to overcome the resistive loss across the YSZ electrolyte. There is considerable driving force to reduce the operating temperatures of SOFCs to 500-700 ${ }^{\circ} \mathrm{C}$. Advantages include use of cheap ferritic stainless steel as the interconnect material, lower operating cost, faster starting times for mobile applications and greater stability ${ }^{2,3,4,5}$.

The cathode plays a critical role in establishing cell operating temperatures. Activation polarization is typically more of an issue in cathodes than in anodes due primarily to the kinetics of the oxygen reduction reaction (attributable to the high bond strength present in oxygen molecules), which is several orders of magnitude slower than the reactions involving fuel oxidation $^{6,7,8,9,10,11,12}$. At the cathode, the dissociative adsorption of oxygen is a thermally activated process $^{12}$ - as the operating temperature is lowered, the rates of chemical reactions drop dramatically, and activation polarization at the cathode becomes an even larger issue. Thus, cathode development is crucial for SOFC operating temperature reduction.

Cathode performance is strongly dependent on interfacial polarization that occurs at the cathode/electrolyte interface, and is directly related to the resistance associated with each component $^{13}$. The charge transfer rate is correlated with microstructural characteristics of the electro-catalyst such as particle size and surface area. Hence, it is important to understand the behavior of electrodes in terms of microstructural and electrochemical parameters to optimize the material performance ${ }^{14}$, as well as limit formation of resistive phase(s) at the electrode/electrolyte interface that increase electrode polarization ${ }^{15}$. 


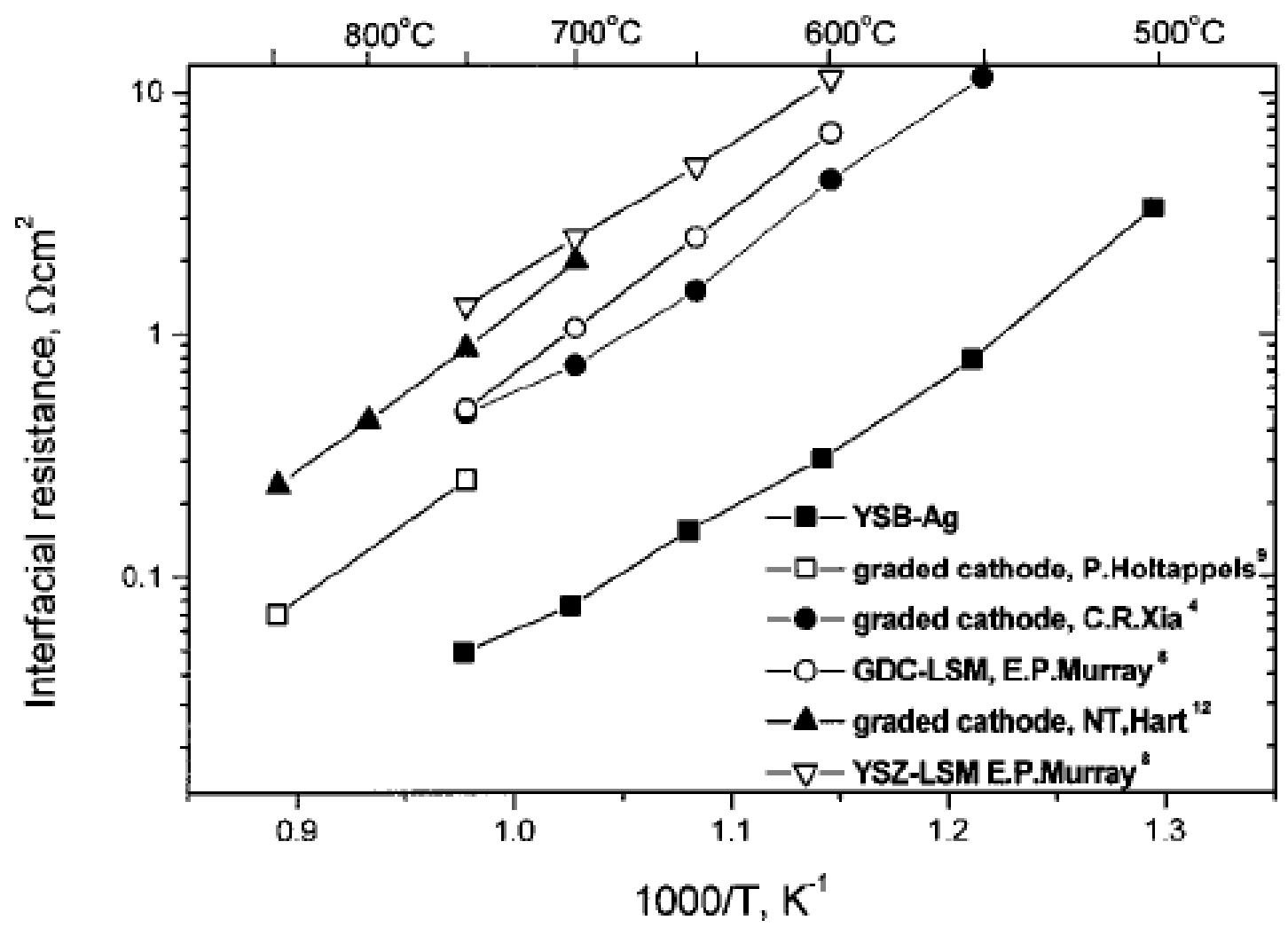

Figure 1. Arrhenius plot of area specific resistance (ASR) of selected cathodes, adapted from Xia et al. ${ }^{16}$.

At the start of this project, the best performing-i.e., lowest area specific resistance (ASR) — cathodes were the $\mathrm{Ag}-\mathrm{Bi}_{1.5} \mathrm{Y}_{0.5} \mathrm{O}_{3}$ (Ag-YSB) composite cathodes developed by Xia et $a l{ }^{16}$, Fig. 1. It was our intent to surpass this benchmark, both in performance as well as stability. To achieve these goals two complimentary strategies were employed, (a) the development of novel cathode materials and (b) the optimization of (composite) cathode microstructures.

Novel Cathode Materials. Perovskites based on lanthanum manganese-cobalt-iron oxide system have been the material of choice $^{6}$ for cathodes. Numerous groups were already investigating this system, therefore we decided to investigate pyrochlores based on bismuth ruthenate, lead ruthenate, and yttrium ruthenate. ${ }^{7-10}$ Ruthenium oxide is known to be catalytic active towards oxygen reduction and has been studied as a cathode material. ${ }^{11}$ It is expected that solid solutions containing ruthenium oxide will also be catalytically active for $\mathrm{O}_{2}$ reduction.

Catalytic activity of $\mathrm{RuO}_{2}$ and other transition metal oxides toward oxygen in red-ox reactions is well known ${ }^{17}$ and $\mathrm{Ru}$ is largely employed in low temperature polymer electrolyte 
membrane fuel cells ${ }^{18}$. Ruthenium based pyrochlores have been investigated because of their high metallic or semiconducting electrical conductivity ${ }^{19,20}$ that allows the use of these oxides in catalysis $^{21}$ and for electrochemical sensors ${ }^{22} \cdot A_{2} \mathrm{Ru}_{2} \mathrm{O}_{7-\delta}(A=\mathrm{Pb}, \mathrm{Bi}, \mathrm{Y})$ possess electric and catalytic properties similar to those of $\mathrm{RuO}_{2}{ }^{20,23,24,25,26} . \quad A_{2} \mathrm{Ru}_{2} \mathrm{O}_{6.5}$ is a metallic conductor because of the interaction between $\mathrm{Ru}_{2} \mathrm{O}_{6}$ and $\mathrm{A}_{2} \mathrm{O}^{\prime}$ through the $\mathrm{Ru}-\mathrm{O}-A$ bonds (7), described with a Mott-Hubbard mechanism for metallic conductivity ${ }^{27}$.

Yttrium ruthenium oxide, $\mathrm{Y}_{2} \mathrm{Ru}_{2} \mathrm{O}_{7}$ (YRO), has demonstrated promise as an SOFC cathode. Nevertheless, YRO, which is a semiconductor, has relatively low electronic conductivity in the temperature range of $300-700^{\circ} \mathrm{C}$. Hence, to improve its conductivity we investigated the effects of doping YRO with praseodymium (to obtain $\mathrm{Y}_{2-\mathrm{x}} \mathrm{Pr}_{\mathrm{x}} \mathrm{Ru}_{2} \mathrm{O}_{7}$ ) to take advantage of the Mott-Hubbard mechanism, since $\mathrm{Pr}^{3+} / \mathrm{Pr}^{4+}$ is a larger cation than $\mathrm{Y}^{3+}$.

Another promising pyrochlore ruthenate is lead ruthenate and its electrochemical properties were evaluated in this study. Moreover, since the preparation of lead ruthenate by solid-state reactions ${ }^{28,29}$ has the disadvantage of needing excess lead, due to lead evaporation, and a synthesis temperature close to the lead ruthenate decomposition temperature $(\mathrm{T}=1130 \mathrm{~K})^{30}$ a new chemical route, called direct condensation method (DCM), was used to synthesize lead ruthenate nanocrystalline powders.

Bismuth ruthenate has also shown promise as a cathode and indeed has even higher electrical conductivity than lead ruthenate. Thus, we investigated the effect on the performance of bismuth ruthenate electrodes from (a) doping on Bi-site with aliovalent cations, and (b) using bismuth ruthenate-bismuth oxide composites.

Finally, since the presence of resistive phase(s) at the cathode-electrolyte interface significantly increase the ASR, reactivity tests were performed to check the occurrence of chemical reactions between cathode and electrolyte materials.

Composite Cathode Microstructure. The oxygen reduction reaction is given by:

$$
\frac{1}{2} \mathrm{O}_{2}+\underbrace{\mathrm{V}_{\mathrm{O}}^{* \bullet}}_{\text {electrolyte }}+\underbrace{2 e^{\prime}}_{\text {cathode }} \rightarrow \underbrace{\mathrm{O}_{\mathrm{O}}^{\times}}_{\text {electrolyte }}
$$


where $\mathrm{V}_{\mathrm{O}}^{*}$ and $\mathrm{O}_{\mathrm{O}}^{\times}$represent vacant and regular oxygen sites in the electrolyte lattice, respectively. For electronic conducting cathodes, it is evident from Eq. (1) that the oxygen reduction reaction must occur where the gas phase, the cathode, and the electrolyte are in intimate contact. These boundaries form one-dimensional lines called three phase boundary (TPB) lines. As shown in Fig. 2, the reaction zone is restricted to a narrow region at the electrolyte/cathode interface. The reaction zone can be extended to a three-dimensional volume above this interface by introducing a second, ion-conducting phase, Fig. 3. The performance of these dual phase cathodes is significantly improved due to the increase in available sites for oxygen reduction.

A well-behaved cathode must be a good catalyst for oxygen reduction, highly conductive, and chemically and thermally compatible with the electrolyte. Due to the high concentration of oxygen defects present in its crystal structure, stabilized bismuth oxide exhibits excellent ionic conductivity, ranking among the highest of all fast-ion conductors at $600{ }^{\circ} \mathrm{C}^{31}$. Below this temperature, stabilized bismuth oxide undergoes defect ordering, where the conductivity rapidly decreases with time ${ }^{32}$. The exact transition temperature has not yet been fully resolved. Silver is known to be an excellent catalyst for the oxygen reduction reaction, has high electronic conductivity, and is relatively inexpensive. As shown above, Fig. 2, composites of silver and YSB were our benchmark since they exhibit some of the lowest area-specific resistance (ASR)
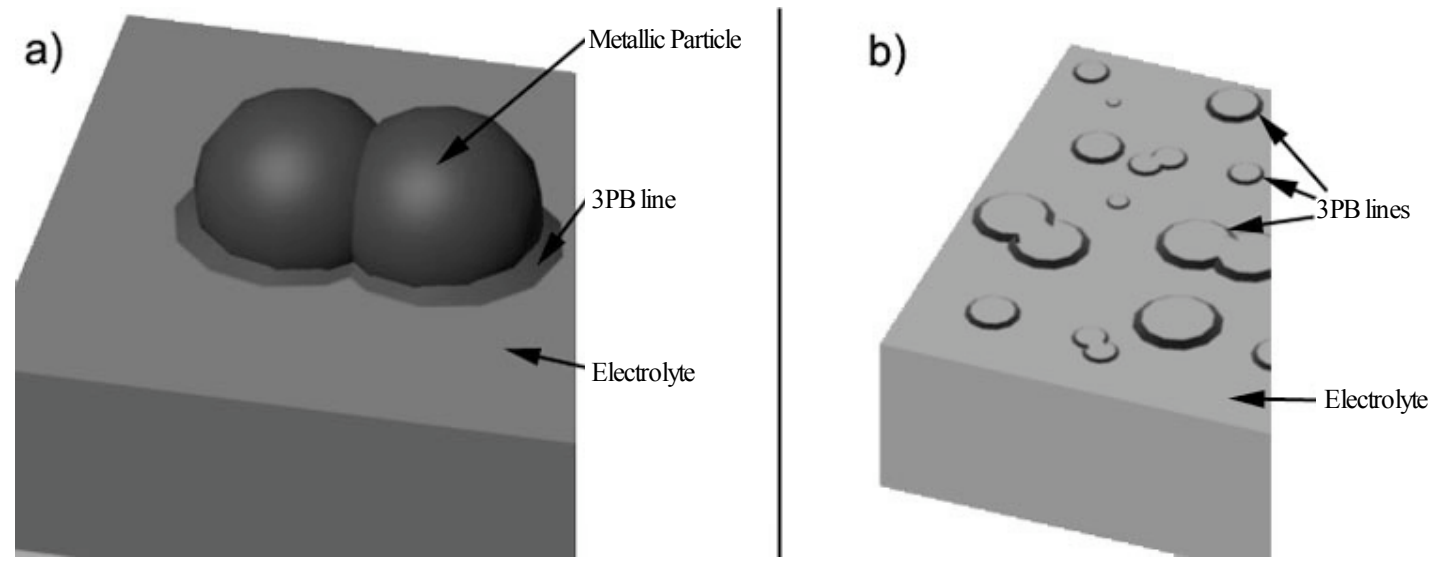

Figure 2. Schematic representation of (a) the TPB lines formed between metallic particles and an electrolyte substrate, and (b) the reaction zone of a single-phase metallic electrode. 

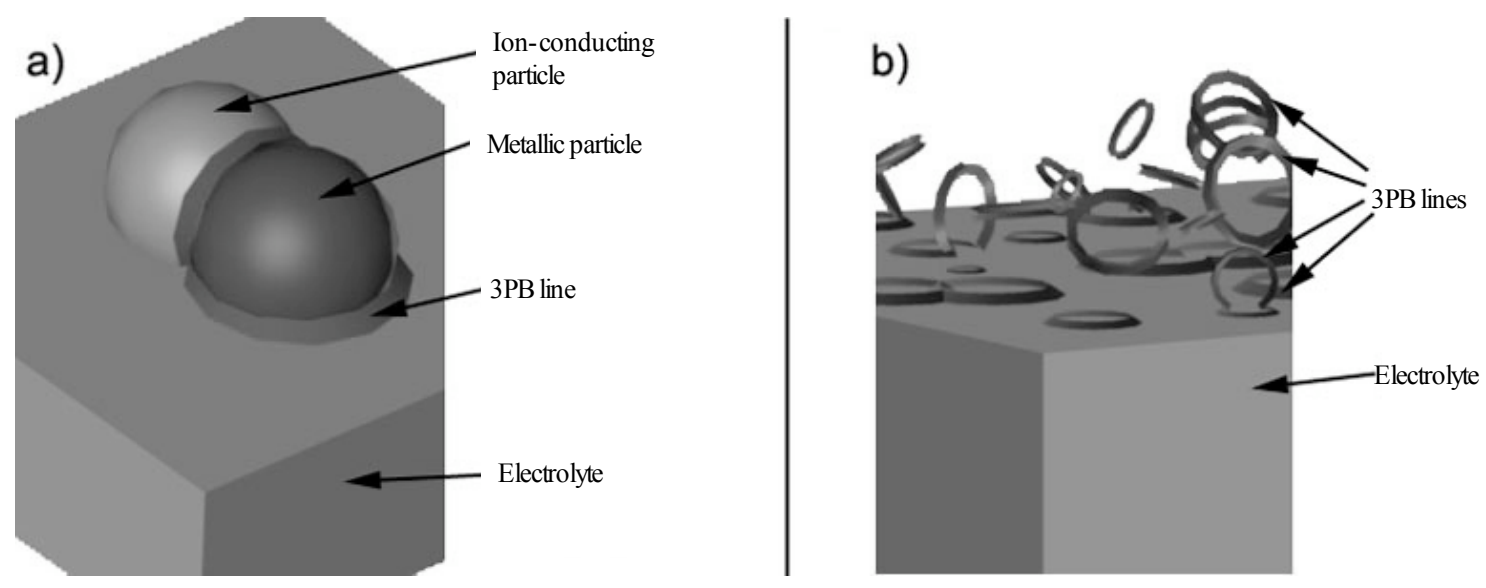

Figure 3. Schematic representation of (a) the TPB lines formed between a metallic particle, an ionconducting particle, and an electrolyte substrate, and (b) the reaction zone of a dual-phase metallic-ionconducting electrode.

values known to date for YSZ electrolyte substrates, over the temperature range of interest ${ }^{1}$. However, the long-term stability of these materials remains unchecked.

The performance and long-term stability of $\mathrm{Ag}-\mathrm{YSB}, \mathrm{Ag}-\mathrm{Bi}_{1.6} \mathrm{Er}_{0.4} \mathrm{O}_{3}$ (Ag-ESB) and bismuth ruthenate-ESB (BRO-ESB) composite cathodes were examined. Ag-YSB composites were chosen for direct comparison to our benchmark system, developed by Xia et al. ${ }^{16}$. Ag-ESB composites were studied for verification purposes and to improve performance (due to the higher ionic conductivity of ESB compared to $\mathrm{YSB}^{33}$ ). Knowledge gained on the effects of microstructure was then applied to BRO-ESB, the most promising of the cathodes developed in this study.

YSB (for Ag-YSB composites) and ESB (for Ag-ESB and BRO-ESB composites) were chosen as the electrolyte substrates, since these should be chemically and thermally compatible with their respective composite cathodes, and to help identify possible ordering phenomena or phase transformation of the stabilized bismuth oxide phase. The composition was varied to minimize ASR then the microstructure optimized by control of the relative particle sizes of the constituent phases of composites. The isothermal annealing temperature was chosen to be 650 ${ }^{\circ} \mathrm{C}$ to avoid defect ordering in the bismuth oxide phase. It should be noted that at this temperature, YSB undergoes a massive cubic to rhombohedral phase transformation ${ }^{34,35}$, but its onset is somewhat sluggish and can be monitored by impedance measurements. Finally, since 
stable SOFC components should deliver relatively constant, non-changing performance for thousands of hours of operation, the effect of an applied DC bias on the electro-migration of the silver phase, is explored. 


\section{EXECUTIVE SUMMARY}

This research focused on developing low polarization (area specific resistance, ASR) cathodes for intermediate temperature solid oxide fuel cells (IT-SOFCs). In order to accomplish this we focused on two aspects of cathode development: (1) development of novel materials, based on Ag-bismuth oxide composites, a series of pyrochlore structured ruthenates $\left(\mathrm{Bi}_{2}\right.$ ${ }_{x} \mathrm{M}_{\mathrm{x}} \mathrm{Ru}_{2} \mathrm{O}_{7}$, where $\mathrm{M}=\mathrm{Sr}, \mathrm{Ca}, \mathrm{Ag} ; \mathrm{Pb}_{2} \mathrm{Ru}_{2} \mathrm{O}_{6.5}$; and $\mathrm{Y}_{2-2 \mathrm{x}} \mathrm{Pr}_{2 \mathrm{x}} \mathrm{Ru}_{2} \mathrm{O}_{7}$ ), and composites of the pyrochlore ruthenates with bismuth oxide; and (2) developing the relationships between microstructure and electrochemical performance by optimizing the Ag-bismuth oxide and the ruthenate-bismuth oxide composites in terms of both two-phase composition and particle size/microstructure. We further investigated the role of thickness and current collector on ASR, as well as investigated issues of stability.

Ag-ESB cermet electrodes showed excellent electrochemical performance. Our Ag-ESB composite cathode has an ASR of $0.18 \Omega \mathrm{cm}^{2}$ at $600{ }^{\circ} \mathrm{C}$, making it one of the lowest-resistance electrode systems reported to date and a significant improvement over our benchmark by Xia et. al who obtained an ASR of $0.3 \Omega \mathrm{cm}^{2}$ at $600{ }^{\circ} \mathrm{C}$ for their Ag-YSB composite. However, impedance studies under current bias showed that the electrode microstructure was unstable at high bias currents at $625^{\circ} \mathrm{C}$, primarily due to the electro-migration of $\mathrm{Ag}$ along with the oxygen flux. The high oxygen solubility in Ag results in good performance of the electrode, but it also results in the lowering of the melting point of $\mathrm{Ag}$ and its consequent electro-migration.

Addition of 5 vol\% YSZ nano-powders significantly improved unbiased electrode stability by $97 \%$, and reduced the initial, zero time ASR value by $31 \%$. Similar results were obtained when YSZ-free electrodes were prepared from ESB powders composed of particles hundreds of nanometers in size as opposed to electrodes prepared from ESB powders composed of micron-sized particles - the zero time ASR value was reduced by $25 \%$, and ASR vs. time slope during unbiased testing of the silver-ESB system at $650{ }^{\circ} \mathrm{C}$ was reduced by $95 \%$.

ASR vs. time slopes during testing under a $250 \mathrm{mV}$ external applied bias were lowered by $50 \%$ using the smaller ESB particles due to suppression of silver phase electro-migration. The stability of composite Ag-ESB electrodes under an applied bias still needs some improvement. Improvements are likely with further reduction in ESB particle size down to several tens of nanometers. Also, as the operating temperature of SOFCs is reduced, the migration of the silver phase will be suppressed even further.

Lead ruthenate (PRO) was successfully synthesized by direct condensation method (DCM). Sintering of PRO electrodes was optimized at $800{ }^{\circ} \mathrm{C}$. Low ASR values, e.g., 0.41 $\Omega \mathrm{cm}^{2}$ at $750{ }^{\circ} \mathrm{C}$, of these PRO electrodes were obtained. Also, ESB and PRO were determined to be compatible and thus suitable constituents of composite electrodes. Above $600^{\circ} \mathrm{C}$ where reaction at the TPB is not rate limiting PRO is a better cathode than PRO-ESB. However, below $600^{\circ} \mathrm{C}$ the extended TPB of the PRO-ESB composite results in a lower ASR cathode. Further optimization of the microstructure and $\mathrm{ESB} / \mathrm{Pb}_{2} \mathrm{Ru}_{2} \mathrm{O}_{6.5}$ ratio could result in lower ASRs.

Yttrium ruthenate (YRO) is compatible with both GDC and ESB since no reaction products were found by XRD analysis after heat-treatment at $800{ }^{\circ} \mathrm{C}$ for $24 \mathrm{~h}$. We evaluated the 
effect of Pr doping and found the best performing electrode was $\mathrm{Y}_{1.5} \mathrm{Pr}_{0.5} \mathrm{Ru}_{2} \mathrm{O}_{7}$ with an ASR, at $700{ }^{\circ} \mathrm{C}$, of $0.19 \Omega \mathrm{cm}^{2}$ on an ESB electrolyte and $4.23 \Omega \mathrm{cm}^{2}$ on a GDC electrolyte. The low value of resistivity of the $\mathrm{Y}_{1.5} \mathrm{Pr}_{0.5} \mathrm{Ru}_{2} \mathrm{O}_{7} / \mathrm{ESB} / \mathrm{Y}_{1.5} \mathrm{Pr}_{0.5} \mathrm{Ru}_{2} \mathrm{O}_{7}$ symmetric cell suggests that $\mathrm{Y}_{1.5} \mathrm{Pr}_{0.5} \mathrm{Ru}_{2} \mathrm{O}_{7}$ in a composite with ESB would be a promising cathode material for IT-SOFCs.

This study further showed that the performance of bismuth ruthenate (BRO) cathodes is very promising. However, doping with lower valent cations on the Bi-site, in order to improve the ionic conductivity, was not very effective in improving the performance of bismuth ruthenate cathodes. At $700{ }^{\circ} \mathrm{C}$, the ASRs of undoped, $5 \mathrm{~mol} \% \mathrm{Ca}$, and $5 \mathrm{~mol} \% \mathrm{Sr}$ doped BRO electrode were $1.45 \Omega \mathrm{cm}^{2}, 1.24 \Omega \mathrm{cm}^{2}$, and $1.41 \Omega \mathrm{cm}^{2}$, respectively. The rate limiting step for the oxygen reduction reaction in $5 \mathrm{~mol} \% \mathrm{Ag}$ doped bismuth ruthenate electrode was found to be the surface diffusion of dissociatively adsorbed oxygen, while for $5 \mathrm{~mol} \% \mathrm{Ca}$ doped system multiple rate limiting steps were observed in the oxygen partial pressure range studied. Doping with 5 mol\% $\mathrm{Ca}$ and $\mathrm{Ag}$ changed the electrode capacitance behavior, both as function of temperature and oxygen partial pressure.

Finally, BRO-ESB composite cathodes developed in this study show performance that is comparable to the very best new IT-SOFC cathode materials. The high performance of BROESB composites is due to the high ionic conductivity of ESB and high electronic conductivity of BRO. Addition of the ESB phase reduced the ASR of single phase BRO electrode by as much as a factor of twenty. The presence of ESB particles not only increases the concentration of TPBs and ionic conductivity of the composite electrode, but possibly also reduces the surface diffusion path to the TPBs resulting in improved electrode performance. Moreover, both BRO and ESB are catalytic active towards oxygen reduction. Furthermore, BRO is compatible with stabilized zirconia, doped ceria, and stabilized bismuth oxide, and therefore, BRO-ESB composites could be suitable for IT-SOFCs based on any of the three fluorite electrolyte systems.

The resulting $\mathrm{Bi}_{2} \mathrm{Ru}_{2} \mathrm{O}_{7}-\mathrm{Bi}_{0.8} \mathrm{Er}_{0.2} \mathrm{O}_{1.5}$ composite cathode has an ASR of $0.73 \Omega \mathrm{cm}^{2}$ at 500 ${ }^{\circ} \mathrm{C}, 0.053 \Omega \mathrm{cm}^{2}$ at $650{ }^{\circ} \mathrm{C}$ and 0.03 at $700{ }^{\circ} \mathrm{C}$. These ASRs are truly impressive and makes them among the lowest IT-SOFC ASRs reported to date. At high temperatures, the optimized BROESB composite has outstanding performance and is comparable with our Ag-ESB. In addition, due to its low activation energy, it is even more competitive at lower temperatures, and has better performance than BSCF at temperatures below $500{ }^{\circ} \mathrm{C}$. Further improvements are likely to result from a compositional study of the optimized electrode. 


\section{EXPERIMENTAL}

\section{SAMPLE FABRICATION}

\section{Cathode Powder Synthesis}

Bismuth Ruthenate $\left(\mathrm{Bi}_{2-x} \mathrm{M}_{x} \mathrm{Ru}_{2} \mathrm{O}_{7}\right.$, where $\left.\mathrm{M}=\mathrm{Sr}, \mathrm{Ca}, \mathrm{Ag}\right)$. Conventional solid state synthesis was used to fabricate the bismuth ruthenate powders. $\mathrm{Bi}_{2} \mathrm{O}_{3}$ (99.9995\%, Alfa Aesar), $\mathrm{RuO}_{2} \cdot \mathrm{XH}_{2} \mathrm{O}$ (99.99\%, Alfa Aesar), $\mathrm{CaCO}_{3}$ (99\%, Fisher Scientific), $\mathrm{Sr}\left(\mathrm{NO}_{3}\right)_{2}$ (99.97\%, Alfa Aesar) and Ag (99.9\%, Alfa Aesar) were mixed in stoichiometric amounts in an agate mortar and pestle, and calcined at $900{ }^{\circ} \mathrm{C}$ for 10-12 hours to achieve undoped and doped $\mathrm{Bi}_{2} \mathrm{Ru}_{2} \mathrm{O}_{7}$ pyrochlore phase. The calcined powder was leached with dilute $\mathrm{HNO}_{3}$ to remove the sillenite type-impurity phase.

Lead Ruthenate $\left(\mathrm{Pb}_{2} \mathrm{Ru}_{2} \mathrm{O}_{6.5}\right)$. A $10^{-1} \mathrm{M}$ water solution of $\mathrm{Pb}\left(\mathrm{NO}_{3}\right)_{2}$ and $\mathrm{RuCl}_{3}$ (Alfa Aesar) was prepared under stirring. Tetramethylethylendiamine (TEMED) was added to the solution in the ratio 20:1 to the total amount of cations. The amine in water leads to a strong exothermic hydrolysis reaction and to the co-precipitation of a $\mathrm{Pb} / \mathrm{Ru}$ gel precursor. Then, the gel was aged for three days, filtered and washed several times with deionized water. The resulting aged gel was dried overnight and calcined in air at selected temperatures in the 400-900 ${ }^{\circ} \mathrm{C}$ range. The products were milled in an agate mortar.

Prasodymium-Doped Yttrium Ruthenate $\left(\mathrm{Y}_{2-2 x} \operatorname{Pr}_{2 x} \mathrm{Ru}_{2} \mathrm{O}_{7}\right)$. A co-precipitation method was used to prepare the pyrochlore powder, using $\mathrm{Y}\left(\mathrm{NO}_{3}\right)_{3} \bullet 6 \mathrm{H}_{2} \mathrm{O}$ and $\mathrm{RuCl}_{3} \bullet \mathrm{xH}_{2} \mathrm{O}$ (Alfa Aesar) as starting materials, in a stoichiometric ratio. Both reagents were dissolved in de-ionized water; then the two solutions were mixed together to obtain a $0.1 \mathrm{M}$ cationic concentration. The precipitation of the hydroxide complexes was obtained using an organic amine [10]. The precipitate was separated by filtration and washed several times in de-ionized water. The hydroxides were calcined at $1050^{\circ} \mathrm{C}$ for 10 hours to obtain $\mathrm{Y}_{2} \mathrm{Ru}_{2} \mathrm{O}_{7}$. The same chemical process was used to obtain $\mathrm{Y}_{2-\mathrm{x}} \mathrm{Pr}_{\mathrm{x}} \mathrm{Ru}_{2} \mathrm{O}_{7}$, using $\operatorname{Pr}\left(\mathrm{NO}_{3}\right)_{3} \bullet \mathrm{xH}_{2} \mathrm{O}$ (Alfa Aesar) as starting material. 
Erbia- and Yttria-Stabilized Bismuth Oxides. YSB $\left(\mathrm{Bi}_{0.75} \mathrm{Y}_{0.25} \mathrm{O}_{1.5}\right)$ and ESB $\left(\mathrm{Bi}_{0.8} \mathrm{Er}_{0.2} \mathrm{O}_{1.5}\right)$ powders were prepared by conventional solid-state synthesis. Stoichiometric amounts of bismuth oxide (Alfa Stock \#10658) and yttrium oxide (Alfa Stock \#11181) or erbium oxide (Alfa Stock \#11309) were ball-milled in ethanol for $24 \mathrm{~h}$. The solutions were then dried at $90{ }^{\circ} \mathrm{C}$ for $4 \mathrm{~h}$, calcined at $800{ }^{\circ} \mathrm{C}$ for $15 \mathrm{~h}$, crushed and sieved (325 mesh size).

For the composite electrodes, $20 \mathrm{~mol} \%$ erbia stabilized bismuth oxide (ESB) powder was prepared using an amorphous citrate route. $\mathrm{Bi}\left(\mathrm{NO}_{3}\right)_{3} .5 \mathrm{H}_{2} \mathrm{O}(99.999 \%$, Alfa Aesar) and $\mathrm{Er}\left(\mathrm{NO}_{3}\right)_{3} .5 \mathrm{H}_{2} \mathrm{O}(99.9 \%$, Alfa Aesar) in desired weight ratios were first dissolved in dilute nitric acid solution, and then citric acid was added in a metal cation:citric acid molar ratio of 1:1.5. The solution was gelled and foamed at $80-100{ }^{\circ} \mathrm{C}$. The precursor was then calcined at $500^{\circ} \mathrm{C}$.

\section{Cathode Slurry/Paste: Preparation and Coating}

Bismuth Ruthenate. BRO electrode paste was made by mixing the desired weight ratios of the powders with Heraeus V006 binder. The electrode paste was brush-painted on GDC electrolyte pellets, dried at $150^{\circ} \mathrm{C}$, and sintered with Pt lead wires at $800{ }^{\circ} \mathrm{C}$ for 2 hours to form symmetrical cells. BRO powders were mixed with polyethylene glycol and ethanol and milled for several hours. The BRO suspension was ultrasonically stirred for $2 \mathrm{~h}$ and dried overnight at $80{ }^{\circ} \mathrm{C}$, and the resultant slurry was deposited asymmetric electrodes on ESB and GDC pellet surfaces by hand-painting.

Lead Ruthenate. Electrodes were fabricated starting from lead ruthenate powder calcined at $700{ }^{\circ} \mathrm{C}$ for six hours. $\mathrm{Pb}_{2} \mathrm{Ru}_{2} \mathrm{O}_{6.5}$ and $\mathrm{Pb}_{2} \mathrm{Ru}_{2} \mathrm{O}_{6.5}$ - $\mathrm{ESB}$ (50\% vol) slurries were prepared using an organic binder in ethanol, and mixing in ball mill overnight. Screen printing was used to deposit the electrodes. $\mathrm{Pb}_{2} \mathrm{Ru}_{2} \mathrm{O}_{6.5}$ electrodes were sintered at selected temperatures between 700 ${ }^{\circ} \mathrm{C}$ and $875{ }^{\circ} \mathrm{C}$ : $700{ }^{\circ} \mathrm{C}, 800{ }^{\circ} \mathrm{C}$ for 3 hours (PRO700 and PRO800) and $875^{\circ} \mathrm{C}$ for 30 minutes (PRO875). While $\mathrm{Pb}_{2} \mathrm{Ru}_{2} \mathrm{O}_{6.5}$-ESB composite electrodes were sintered at $700{ }^{\circ} \mathrm{C}$ and $800{ }^{\circ} \mathrm{C}$ for 3 hours (PRO-ESB700 and PRO-ESB800).

Erbia- and Yttria-Stabilized Bismuth Oxide. For the composite electrode slurry, crushed and sieved ESB and YSB25 powders were either used as-prepared or a vibratory mill was used to reduce particle size. For vibratory milling, $10 \mathrm{~g}$ of powder plus $300 \mathrm{~g}$ of cylindrical zirconia

grinding media and $200 \mathrm{~mL}$ isopropyl alcohol were placed into $250 \mathrm{~mL}$ Nalgene bottles. These 
bottles were covered with duct tape and placed into a Sweco model M18-5 vibratory mill for seven days using appropriate counter weights. Inks were prepared by combining organic vehicles with mixtures of metallic (silver) and ceramic (ESB alone or ESB and Tosoh 8YSZ) powders. Once an appropriate viscosity was reached, the inks were applied to both sides of the electrolyte substrates by screen printing (AMI model HC-53 screen printer) to give symmetrically-electroded cells. The electrodes had thicknesses of $\sim 30 \mu \mathrm{m}$ and geometric surface areas of $\sim 0.79 \mathrm{~cm}^{2}$. These cells were dried at room temperature for $1 \mathrm{~h}$, followed by drying at $120{ }^{\circ} \mathrm{C}$ for $1 \mathrm{~h}$. This process was repeated for a second coat. The doubly-coated cells were then fired at $750{ }^{\circ} \mathrm{C}$ for $1 \mathrm{~h}$.

Composite Ag-bismuth oxide cathode inks were prepared by adding $\mathrm{Ag}$ to the sieved oxide powders (volume ratio of Ag:bismuth oxide $=60: 40$ ). Ethanol and organic vehicles (aterpineol as the solvent, di-n-butyl phthalate as the plasticizer, and polyvinylbutyral as the binder) were added until a viscosity appropriate for brushing was achieved. A similar recipe was followed for preparing the pure silver electrode ink. Symmetric cells were prepared by paint brushing the cathode slurry to each side of the bismuth oxide pellets, drying at $120^{\circ} \mathrm{C}$ for $1 \mathrm{~h}$, and firing at $750^{\circ} \mathrm{C}$ for $1 \mathrm{~h}$.

For the BRO-ESB composite electrode slurries, the crushed and sieved powders were either used as-prepared or a vibratory mill was used to reduce particle size as described above. In addition, sedimentation was performed to further reduce particle size and size distribution. Powders were mixed in a medium $(1 \mathrm{~g} / 50 \mathrm{~mL}$ ratio $)$ in Nalgene bottles, ultrasonicated for $30 \mathrm{~min}$ to break up soft agglomerates, and allowed to settle for $1.5 \mathrm{~h}$ for the case where smaller particles were preferred or two minutes for the case where larger particles were preferred. The supernatant was carefully collected with pipettes and dried to $80^{\circ} \mathrm{C}$. Note that isopropanol was used as the sedimentation medium in preference to de-ionized water to avoid the formation of $\mathrm{Bi}(\mathrm{OH})_{3}$ platelettes which convert $\delta-\mathrm{Bi}_{2} \mathrm{O}_{3}$ upon firing.

$\mathrm{BRO}$ and ESB powders were then weighed in appropriate ratios. Inks were prepared by combining organic vehicles with these mixtures of BRO and ESB powders or pure BRO for the current collector. Once an appropriate viscosity was reached, the inks were applied to both sides of the electrolyte substrates by paint brushing to give symmetrically-electroded cells. 
These cells were dried at room temperature for $1 \mathrm{~h}$, followed by drying at $120^{\circ} \mathrm{C}$ for $1 \mathrm{~h}$, and firing at $800{ }^{\circ} \mathrm{C}$ for $2 \mathrm{~h}$. Note that in order to vary electrode thickness, or for the addition of the current collector, successive layers were added after the drying stage, but before the firing stage. This was done to reduce densification and grain growth within the cathode, as well as minimize ruthenium loss in the BRO phase. ${ }^{25}$

\section{Electrolyte/Substrate Preparation}

Electrolyte pellets were made from gadolinia doped ceria (GDC) powders (Rhodia) uniaxially pressed and sintered at $1450{ }^{\circ} \mathrm{C}$. ESB and YSB powders were uniaxially pressed at $\sim 70 \mathrm{MPa}$ using a cylindrical half-inch die, isostatically pressed at $250 \mathrm{MPa}$, and sintered at 890 ${ }^{\circ} \mathrm{C}$ for $15 \mathrm{~h}$ to form electrolyte support pellets. All pellets measured $\sim 1.1 \mathrm{~cm}$ in diameter. ESB and YSB pellets measured $\sim 3.1 \mathrm{~mm}$ and $\sim 3.6 \mathrm{~mm}$ in thickness, respectively. The relative porosities of the ESB and YSB pellets were $\sim 92 \%$ and $\sim 84 \%$ of theoretical, respectively. Pellet surfaces were carefully polished to obtain a flat and smooth surface before the electrode deposition.

\section{CHARACTERIZATION}

\section{Electrochemical Performance}

Current collectors and ( $\mathrm{Au}$ or $\mathrm{Pt}$ ) lead wires were pressed against the samples in a quartz reactor by the use of a ceramic screw-and-bolt assembly. The quartz reactor was placed into a temperature-controlled furnace and cell temperature was maintained and monitored by a thermocouple flanking the sample. Various gas mixtures were fed through the reactor using mass flow controllers. For some experiments oxygen partial pressure was varied between $0.04 \mathrm{~atm}$ and 1 atm by using $\mathrm{O}_{2} /$ air- $\mathrm{N}_{2}$ gas mixtures.

Cathode performance was determined by electrical impedance spectroscopy (EIS) using a Solartron 1260 frequency response analyzer with a perturbation voltage of $50-100 \mathrm{mV}$ in the frequency range of $0.1 \mathrm{~Hz}$ to $32 \mathrm{MHz}$. All impedance studies were conducted on symmetrical 
cells at temperatures between $200-800{ }^{\circ} \mathrm{C}$. A Solartron 1287 interface was added for testing under an applied bias of $250 \mathrm{mV}$. EIS data were analyzed using Zview ${ }^{\circledR}$ software.

\section{Stability and Reactivity}

X-Ray Diffraction (XRD) and Differential Thermal Analysis (DTA). The samples were characterized using XRD (Philips APD - 3720; CuK $\alpha$ x-rays). Lattice parameters of the cathode materials were calculated by JADE (MDI) software using whole pattern fitting and Rietveld refinement. $\mathrm{X}$ ray diffraction in Braggs-Brentano configuration was used for phase identification. X-ray diffraction was also used to determine inter-phase reactivity between silver and ESB. The diffraction spectra of mixed raw powders were compared against mixed powders which were annealed at $600{ }^{\circ} \mathrm{C}$ for $48 \mathrm{~h}$.

Reactivity tests between ESB, lead ruthenate and $\mathrm{RuO}_{2}$ (Alfa Aesar) were performed on ESB- $\mathrm{Pb}_{2} \mathrm{Ru}_{2} \mathrm{O}_{6.5}$ (molar ratio 1:1), ESB- $\mathrm{RuO}_{2}$ (molar ratio 1:3) and $\mathrm{ESB}-\mathrm{Pb}_{2} \mathrm{Ru}_{2} \mathrm{O}_{6.5}-\mathrm{RuO}_{2}$ (molar ratio 4:1:8) composite pellets uniaxially pressed and sintered at $850{ }^{\circ} \mathrm{C}$ for $12 \mathrm{~h}$. XRD and EDS analysis were used to identify crystalline phases and chemical compositions.

Differential thermal analysis (TA-1290) was used to study the eutectic between bismuth ruthenate and bismuth oxide; powder mixtures of $\sim 10 \mathrm{mg}$ mass were heated from room temperature to $900{ }^{\circ} \mathrm{C}$ at $20^{\circ} \mathrm{C} / \mathrm{min}$ in alumina cups with calcined $\mathrm{Al}_{2} \mathrm{O}_{3}$ as reference material. For the reactivity tests, powders mixtures of bismuth ruthenate with 11 mol\% GDC (Rhodia) and ESB were heat-treated at temperatures between $750{ }^{\circ} \mathrm{C}$ and $850{ }^{\circ} \mathrm{C}$ for 10 hours.

Scanning Electron Microscopy (SEM) and Energy Dispersive Spectroscopy (EDS). Scanning electron microscopy (SEM) was used to analyze electrode microstructures. Both JEOL JSM 6400 scanning electron microscope and JEOL JSM 6335F field emission scanning electron microscopes were used in this study for generating secondary and backscattered microstructural images. Energy dispersive spectroscopy (EDS, INCA) were used to analyze the elemental composition of powders and precursors.

Electron probe microanalysis (JEOL Superprobe 733) was performed on a sample with

pure silver electrodes to determine if any diffusion of silver into the electrolyte has occurred during testing. A sample was annealed at $600{ }^{\circ} \mathrm{C}$ for 7 days, encased in epoxy resin and set for 
$24 \mathrm{~h}$. The sample was then polished down to $1 \mu \mathrm{m}$, and a line-scan was performed across the electrolyte/cathode interface - the atomic percent of each element present recorded at each position in the scan.

Cathode morphology was characterized by the use of a JEOL model JSM-6335F fieldemission scanning electron microscopy (FESEM). Samples which had undergone long-term stability testing were compared against virgin samples to detect any visible microstructural changes that might have occurred during testing. 


\section{RESULTS AND DISCUSSION}

\section{SILVER-BISMUTH OXIDE COMPOSTE CATHODES}

As stated in the introduction Ag-YSB (1) was our benchmark for the lowest published ASR, therefore, we started our studies by reproducing its performance. Subsequently, we were able to surpass the benchmark by optimizing the composition (i.e., the volume ratio of the constituent phases) and the microstructure (i.e., the particle size ratio of the constituent phases). Stability issues, which are often under reported, were also addressed for this cathode system.

\section{Compositional Optimization}

Figure 4 shows the impedance and corresponding trend in cathode ASR over a range of composition for the ESB-Ag system at $600{ }^{\circ} \mathrm{C}$. A minimum value observed at 50 vol\% ESB. For a two-phase composite whose particle sizes are roughly the same, and assuming the solid phases and pores are randomly distributed and the porosity is open and sufficiently large, the TPB length should reach a maximum if the two solid phases are present in equal fractions of the overall electrode volume. As discussed previously, TPB length is important in two-phase cathode systems since the oxygen reduction reaction that is occurring can only proceed at sites where all three reactants are present - as the cathode TPB length increases, so do the number of reaction sites, and hence cathode activation polarization decreases.

Electrode area specific resistance (ASR) was calculated from

$$
\mathrm{ASR}=\mathrm{R}_{\mathrm{p}} \times \mathrm{A} / 2
$$

where $R_{p}$ is the electrode polarization discussed above, $A$ is the electrode area, and the factor ' 2 ' is used to account for the fact that each cell contains two (approximately identical) electrodes. 

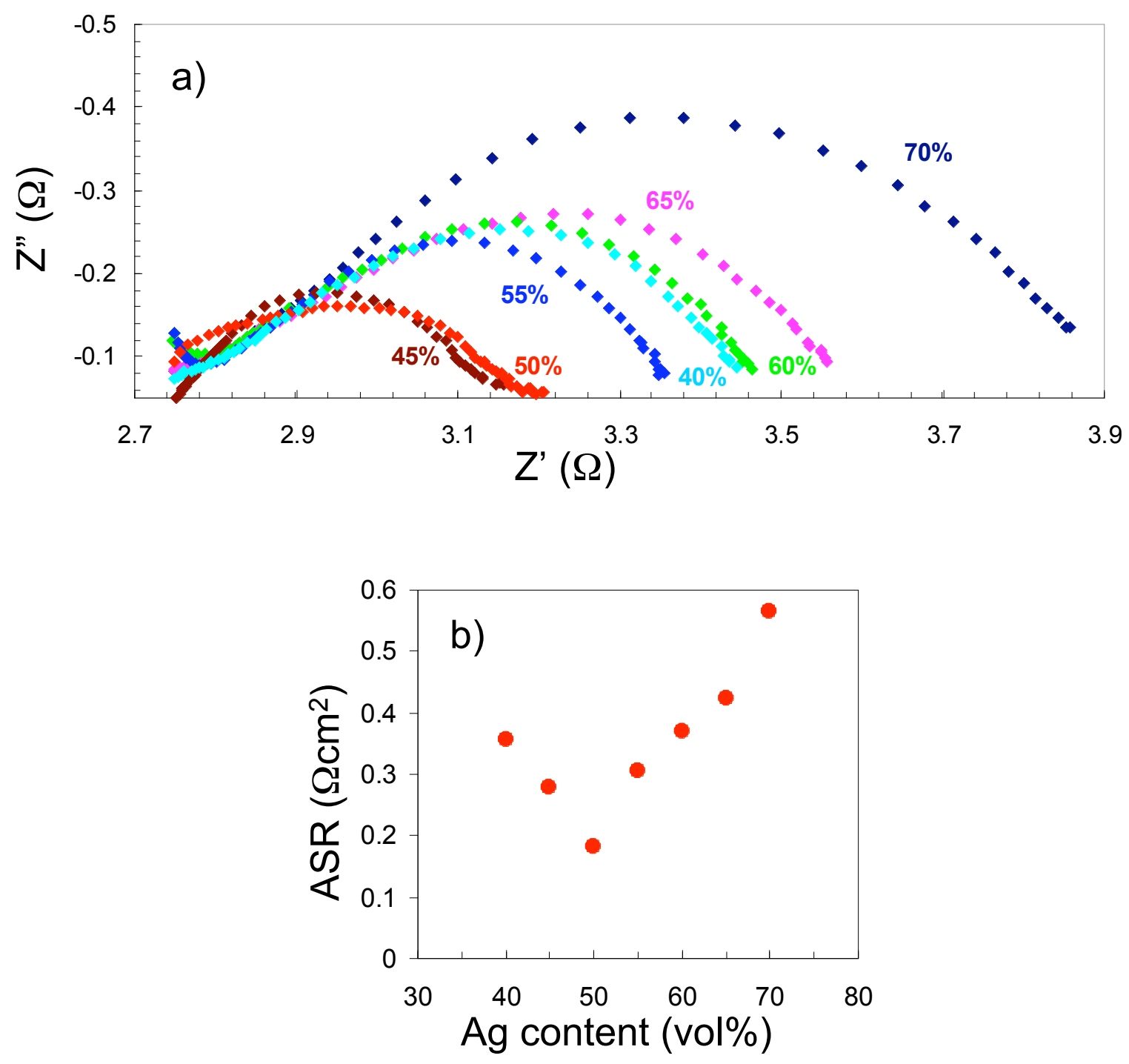

Figure 4. (a) Impedance spectra and (b) electrode ASR vs silver content of Ag-ESB showing compositional optimization at $600{ }^{\circ} \mathrm{C}$.

Figure 5 shows the comparison of the ASR obtained in this study for Ag-ESB cathodes (on an ESB electrolyte) with the results adapted from Xia et. al. ${ }^{16}$ for Ag-YSB (on YSZ honeycomb electrolytes) and other reported cathodes. The Ag-ESB composite cathode has an ASR of $0.18 \Omega \mathrm{cm}^{2}$ at $600{ }^{\circ} \mathrm{C}$, making it one of the lowest-resistance electrode systems reported to date and a significant improvement over that produced by Xia et. al ${ }^{16}$, Fig. 1, who obtained an ASR of $0.3 \Omega \mathrm{cm}^{2}$ at $600{ }^{\circ} \mathrm{C}$ for their Ag-YSB composite (our benchmark). 


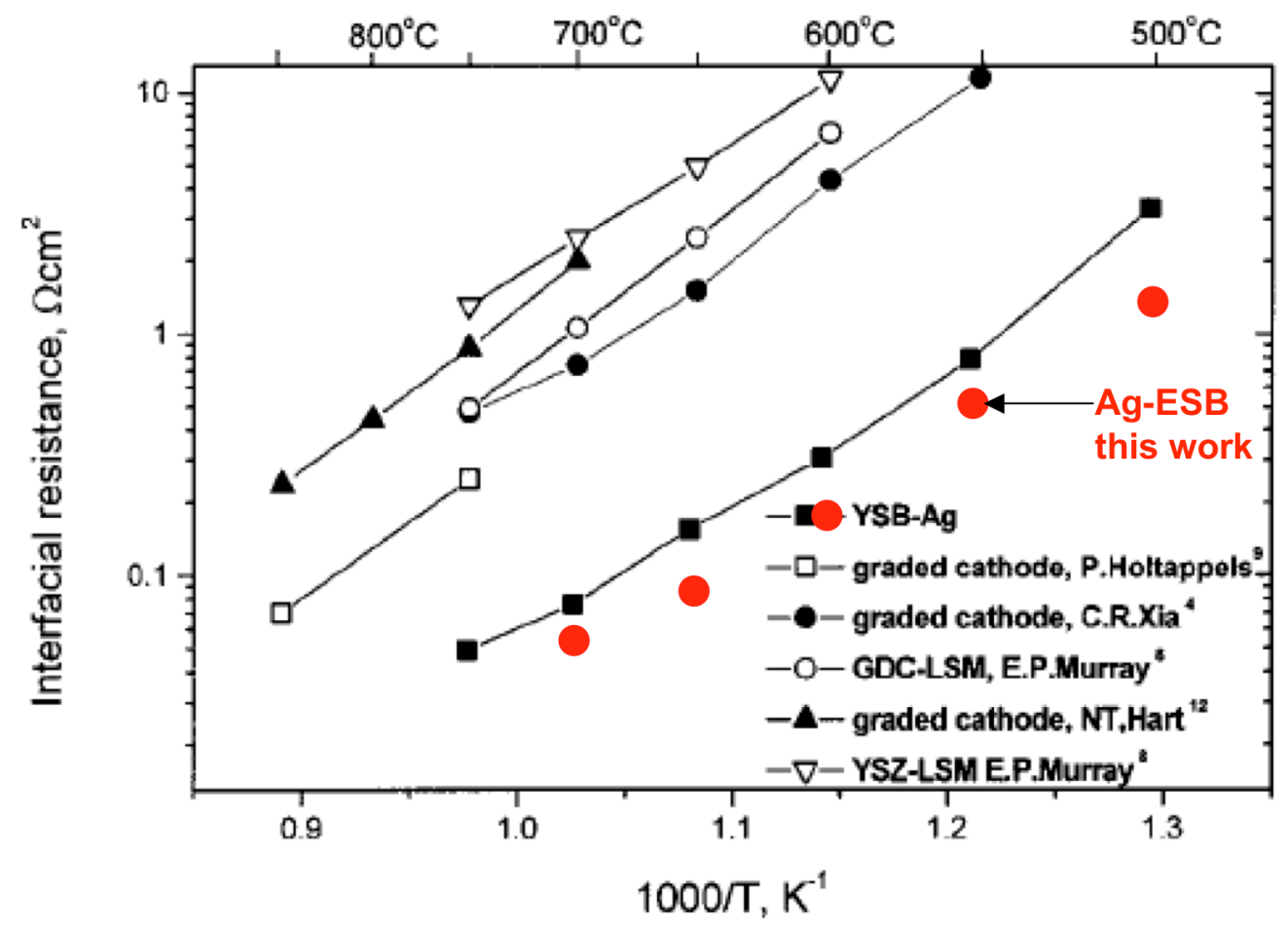

Figure 5. Arrhenius plot, adapted from Xia et. al. ${ }^{16}$, comparing the ASR of Ag-ESB (this work) with the best cathodes reported in the literature at the start of this study.

\section{Stability: Thermal Performance Decay due to Microstructural Evolution}

Once we reproduced/exceeded the performance of the Ag-YSB cathodes of Xia et al. ${ }^{16}$, we next focused on the stability of these low ASR cathodes.

Impedance spectra for the long-term testing of pure Ag, Ag-ESB and Ag-YSB systems at $650{ }^{\circ} \mathrm{C}$ are shown in Fig. 6, with the data $\mathrm{R}_{\mathrm{s}}$-corrected for ease in comparison. That is, the highfrequency real-axis intercept (bulk resistance or $R_{s}$ ) of each spectrum has been subtracted from the real component of each data point in the spectrum. Plotted this way, the low-frequency realaxis intercept corresponds to the electrode polarization resistance, $R_{p}$. It is clear from this figure that the electrode polarization for each system is increasing with time.

Electrode area specific resistance (ASR) is plotted against time for all systems at $650{ }^{\circ} \mathrm{C}$ in Fig. 7. The initial zero time value of ASR for the Ag-YSB and Ag-ESB systems were similar- $0.04 \Omega \mathrm{cm}^{2}$ and $0.06 \Omega \mathrm{cm}^{2}$, respectively. Surprisingly, the Ag-YSB electrode system exhibited lower resistance than the Ag-ESB system, despite the higher ionic conductivity of the ESB phase. Also, the resistance of these electrodes is significantly lower than that reported by 

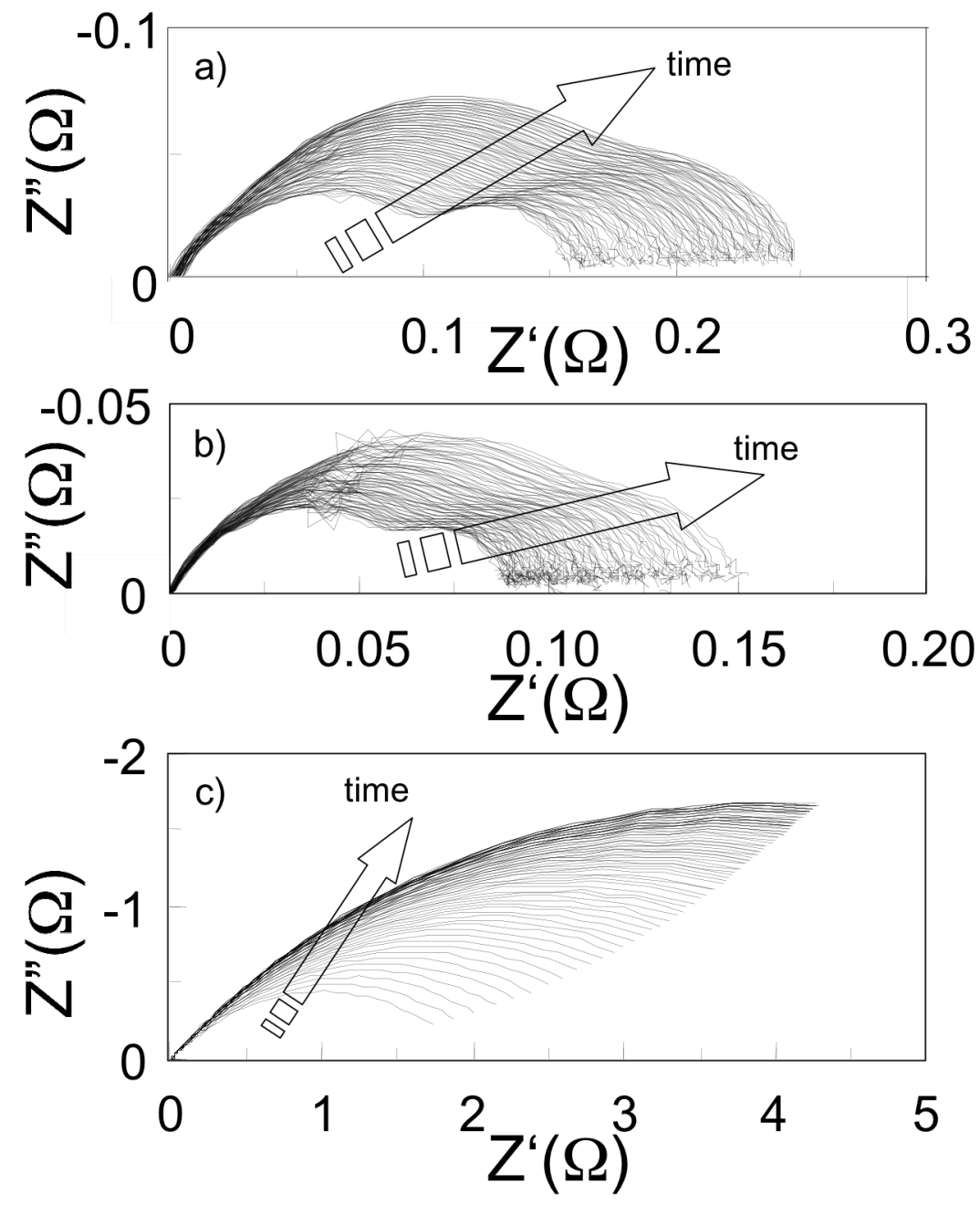

Figure 6. Impedance spectra obtained from a symmetrical Ag-ESB/ESB/Ag-ESB (a), Ag-YSB/YSB/AgYSB (b), and $\mathrm{Ag} / \mathrm{ESB} / \mathrm{Ag}$ (c) cells tested at $650{ }^{\circ} \mathrm{C}$ over a period of $100 \mathrm{~h}$. The data are $\mathrm{R}_{\mathrm{s}}$-corrected. Arrows indicate direction of increasing time.

Xia et. $a l .{ }^{16}$ for their Ag-YSB system at the same temperature (greater than $0.1 \Omega \mathrm{cm}^{2}$ ). Differences in processing routines could lead to variations in electrode porosity, thickness, relative particle sizes, and inter-particle necking, accounting for the observed differences in performance between the two studies and between the two electrodes Ag-YSB and Ag-ESB. In addition, since the present electrode study was performed on electrolytes having the same composition as the ionic conducting phase in the electrodes, the interfacial resistance may be lower than similar electrodes placed on YSZ electrolytes.

All systems experience significant increases in ASR during the $100 \mathrm{~h}$ stability experiment both the Ag-YSB and Ag-ESB electrode ASR values increased by around $70 \%$ (from $0.04 \Omega \mathrm{cm}^{2}$ 


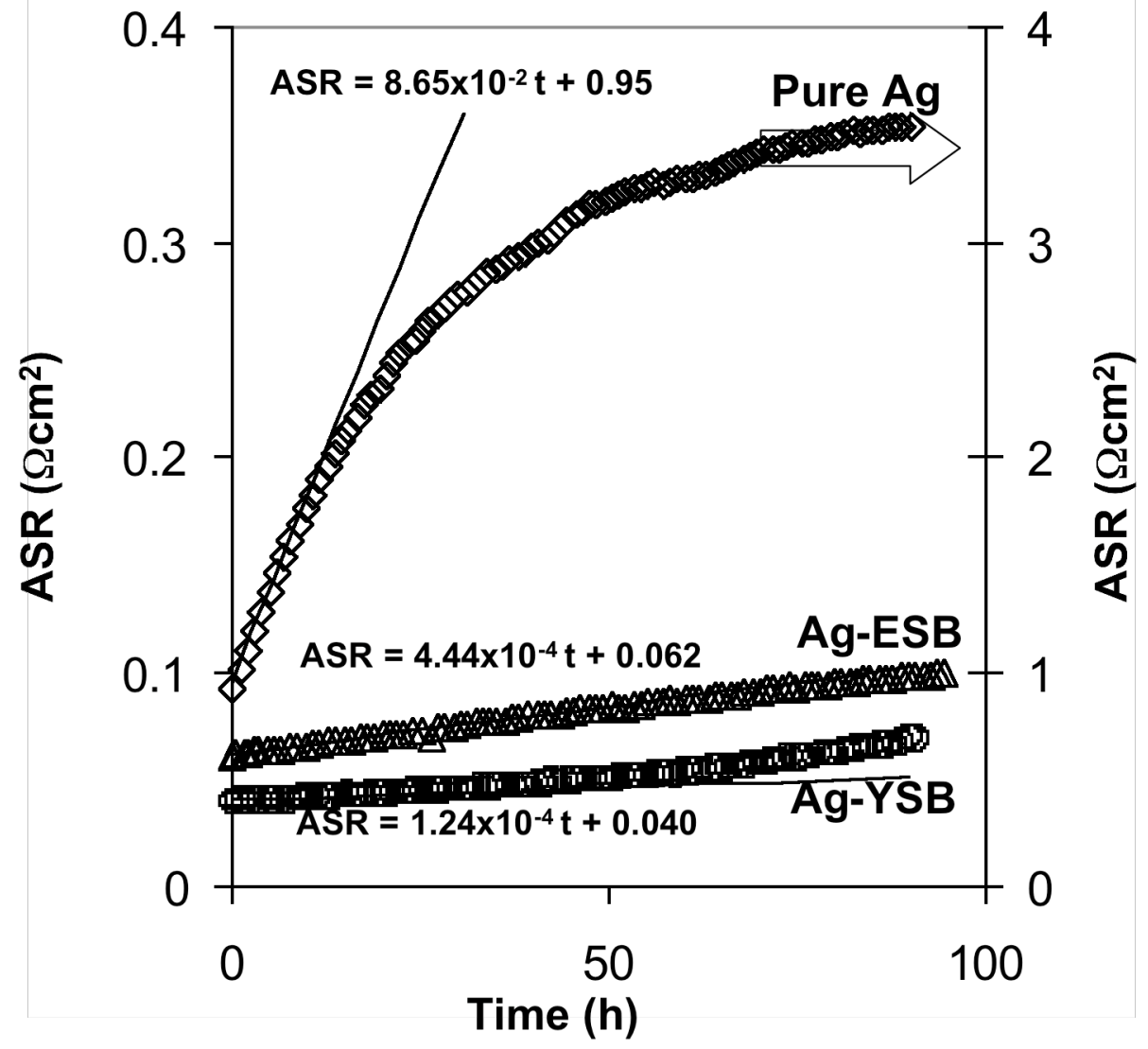

Figure 7. Electrode ASR vs. time for Ag-ESB, Ag-YSB, and pure Ag at $650{ }^{\circ} \mathrm{C}$.

to $0.07 \Omega \mathrm{cm}^{2}$ (75\%) and from $0.06 \Omega \mathrm{cm}^{2}$ to $0.10 \Omega \mathrm{cm}^{2}$ (67\%) for Ag-YSB and Ag-ESB respectively), while the pure Ag system experiences a near fourfold increase (from $0.92 \Omega \mathrm{cm}^{2}$ to $3.55 \Omega \mathrm{cm}^{2}$ ) during the same length of time. Linear regression of the data (based on the first $10 \mathrm{~h}$ of testing) yields a degradation rate of $4.4 \times 10^{-4} \Omega \mathrm{cm}^{2} / \mathrm{h}$ for Ag-ESB and $1.2 \times 10^{-4} \Omega \mathrm{cm}^{2} / \mathrm{h}$ for AgESB. The pure Ag electrode degrades at a rate more than two orders of magnitude faster$8.7 \times 10^{-2} \Omega \mathrm{cm}^{2} / \mathrm{h}$. It should also be mentioned that the rate of change in ASR with time is linear for Ag-ESB electrodes, while for the Ag-YSB system deviates slightly from linearity beginning approximately $50 \mathrm{~h}$ after commencement of testing. For the pure Ag system, this rate of change is strongly non-linear and is in the opposite direction compared to the Ag-YSB system.

Figure 8 is a plot of the time-dependent relative conductivity (from $R_{s}$ ) for both bismuth oxide electrolyte systems. Relative conductivity is the ratio of the electrolyte conductivity (determined from impedance spectra high-frequency intercepts) at time, t, to the initial conductivity value at $\mathrm{t}=0$. Both electrolytes seem to be relatively stable — both maintaining over 


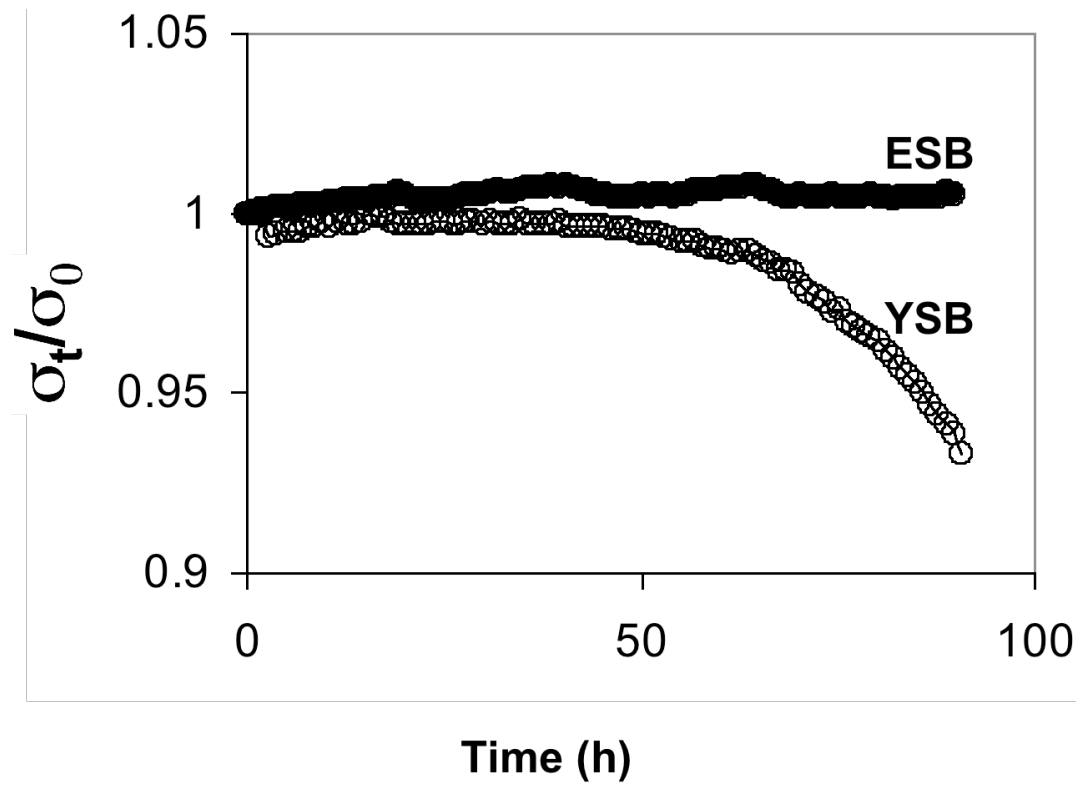

Figure 8. Change in electrolyte relative conductivity vs. time for ESB and YSB at $650{ }^{\circ} \mathrm{C}$.

$90 \%$ of their initial conductivities - however, YSB experiences significant decay in conductivity starting $50 \mathrm{~h}$ into testing, while ESB underwent a slight increase in conductivity $\left(+3.0 \times 10-5 \mathrm{Scm}^{-}\right.$ $1 / h)$. The trend for YSB is consistent with results reported by Fung and Virkar ${ }^{35}$ where YSB undergoes a cubic-rhombohedral phase transformation at this temperature. Post-mortem XRD studies confirm formation of a rhombohedral phase. Jiang and Wachsman ${ }^{36}$ showed that ESB undergoes no such phase transformation, which is consistent with the trend for ESB in Fig. 8.

Since the resistance of bulk-related phenomena of both systems remained relatively constant during the first half of the stability test, it may be concluded that little if any defect ordering has occurred in the YSB and ESB electrolytes. It follows that minimal defect ordering has occurred in the bismuth oxide phase of each cathode. Further, during this initial $50 \mathrm{~h}$ regime, the trend in electrolyte conductivity is slightly upward for ESB, and slightly downward for YSB. This trend is opposite to that observed for cathode ASR values, where the cathode containing YSB decayed at a slower rate than that containing ESB, suggesting the impact of the bismuth oxide phase on cathode degradation is minor at this temperature. In addition, the ASR of the pure Ag electrode rises at a much faster rate than either composite system. Thus, it is suspected that the silver phase is the major source of the observed increase in electrode polarization. However, the more dramatic decay in YSB conductivity at longer times may cause the observed non-linear increase in ASR with time for the Ag-YSB system (Fig. 7). 


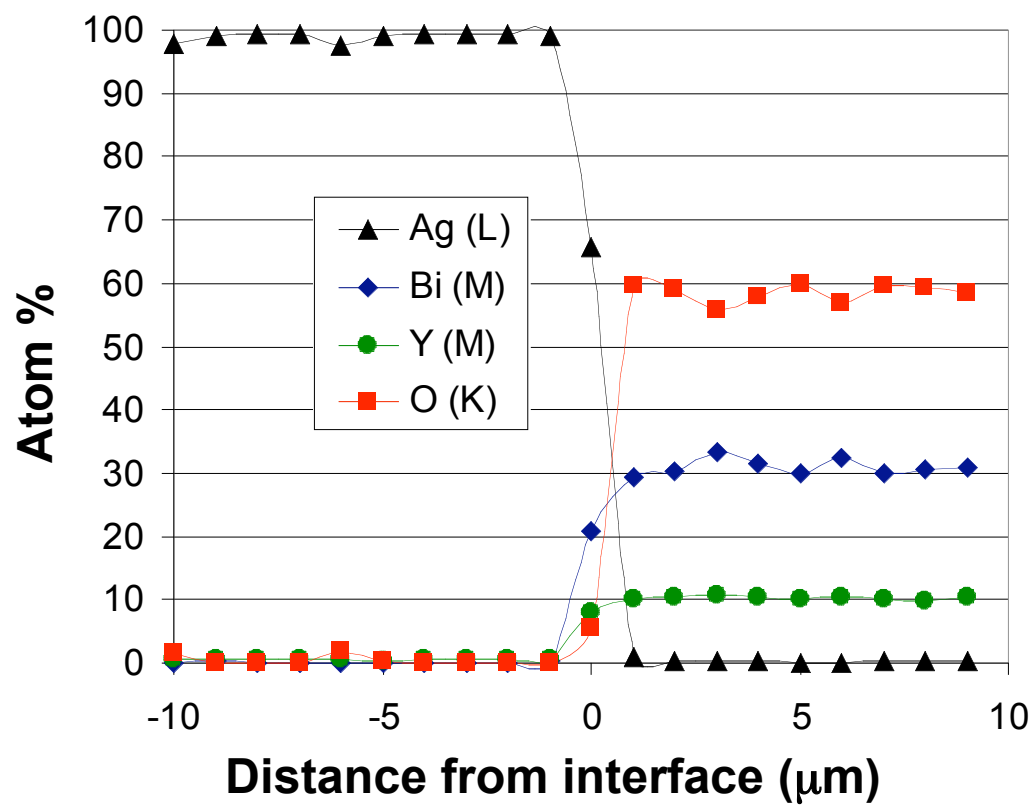

Figure 9. EPMA line-scan of a sample with pure Ag electrodes, annealed at $750{ }^{\circ} \mathrm{C}$ for $48 \mathrm{~h}$.

EPMA, XRD, and SEM analysis were performed on several samples to elucidate the compositional and microstructural changes that might transpire during testing. Figure 9 shows the results of EPMA testing on a YSB sample prepared with a pure silver electrode and annealed at $750{ }^{\circ} \mathrm{C}$ for $48 \mathrm{~h}$. The atomic percent of all elements is consistent with what is expected on both sides of the interface. Thus, it is concluded that silver did not diffuse across the interface into the electrolyte.

X-ray diffraction patterns of mixed silver and erbium-stabilized bismuth oxide powders (ESB) before and after heat treatment at $750{ }^{\circ} \mathrm{C}$ for $48 \mathrm{~h}$ are shown in Fig. 10. The patterns reveal no evidence of inter-phase reactivity after heat treatment. Since silver neither diffused into nor reacted with the electrolyte phase at $750{ }^{\circ} \mathrm{C}$, it is reasonable to assume the same is true for all samples tested at $650{ }^{\circ} \mathrm{C}$.

Microstructural comparisons of the three different electrode systems before firing, after firing, and after testing at $650{ }^{\circ} \mathrm{C}$ for $100 \mathrm{~h}$ are shown in Figs. 11-13. All three systems exhibit a dramatic growth of the silver phase after firing at $750{ }^{\circ} \mathrm{C}$ for $1 \mathrm{~h}$. However, the silver phase in the composite electrodes show significantly less growth and coalescence compared to the pure Ag system, as the ceramic phase helps restrict the migration of the silver phase. After $100 \mathrm{~h}$ of testing at $650{ }^{\circ} \mathrm{C}$, the pure $\mathrm{Ag}$ electrode appears fully dense. 


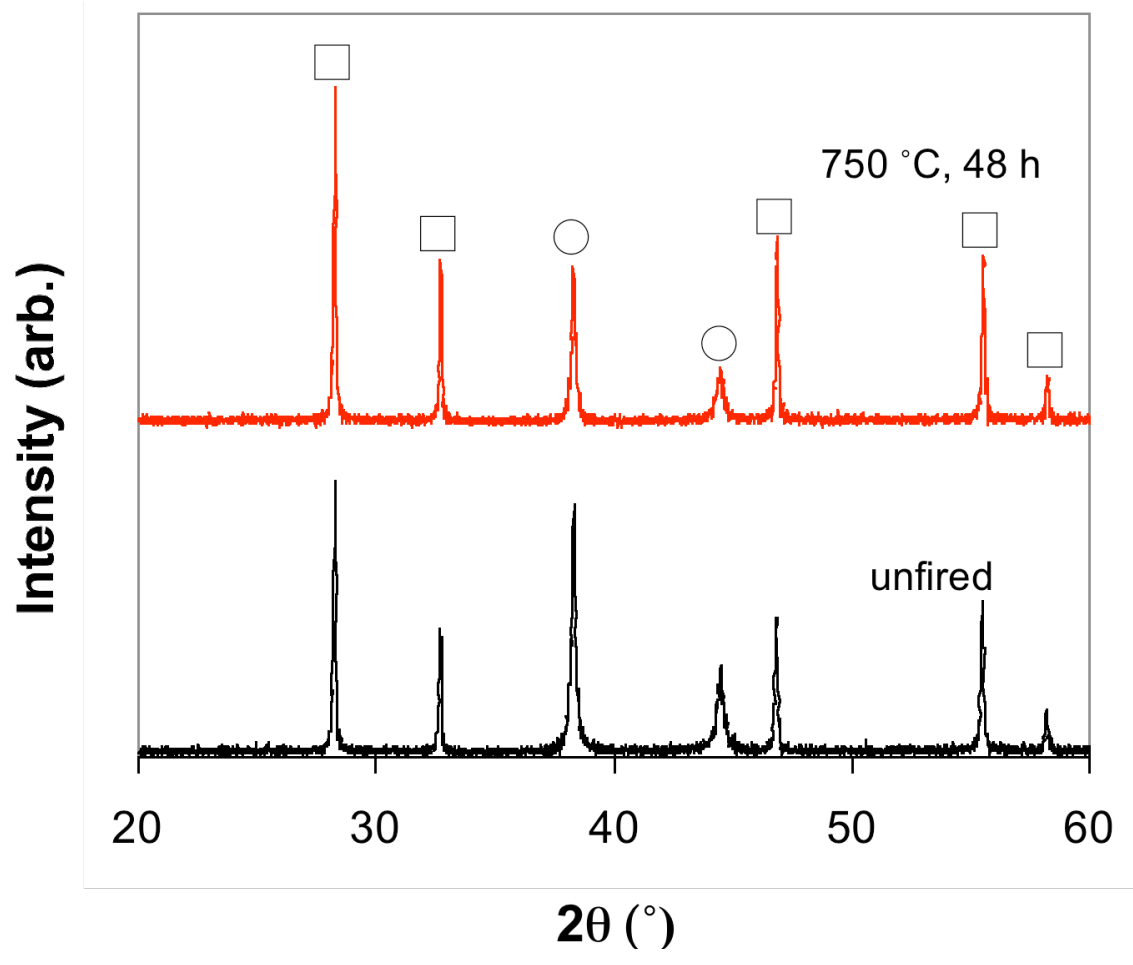

Figure 10. XRD spectra of Ag-ESB powder mixtures before and after co-firing at $750{ }^{\circ} \mathrm{C}$ for $48 \mathrm{~h}$. Square markers identify cubic fluorite peaks of the ESB phase, circle markers identify silver peaks.

The porosity of the Ag-ESB electrode decreased significantly after testing. Domains of coalesced silver are evident, and ESB particles between these domains have been forced closer together, further reducing porosity and TPBs. Growth and coalescence of the silver phase is also evident in the Ag-YSB electrode though to a lesser extent. It is believed that the smaller starting size of the YSB particles (as evidenced in the unfired electrode micrographs) helped to lower the mobility of the silver phase by providing the electrode with a higher surface area.

Increased grain size correlates with reduced TPB lengths, and hence a smaller reaction zone for oxygen reduction. Increased density can lead to concentration polarization effects, where the reaction species (oxygen ad-molecules) are being supplied to the reaction sites more slowly than they are being consumed. The trends in electrode ASR shown in Fig. 7 can be rationalized in terms of these microstructural observations. Pure Ag undergoes the most dramatic densification during testing, and also exhibits the most dramatic rise in ASR with time. It is reasonable to expect that as the densification process of Ag nears completion, changes in porosity and TPB lines will slow, and hence the electrode ASR will level off at longer times, as was observed. The composite electrodes experience a much less severe change in microstructure 

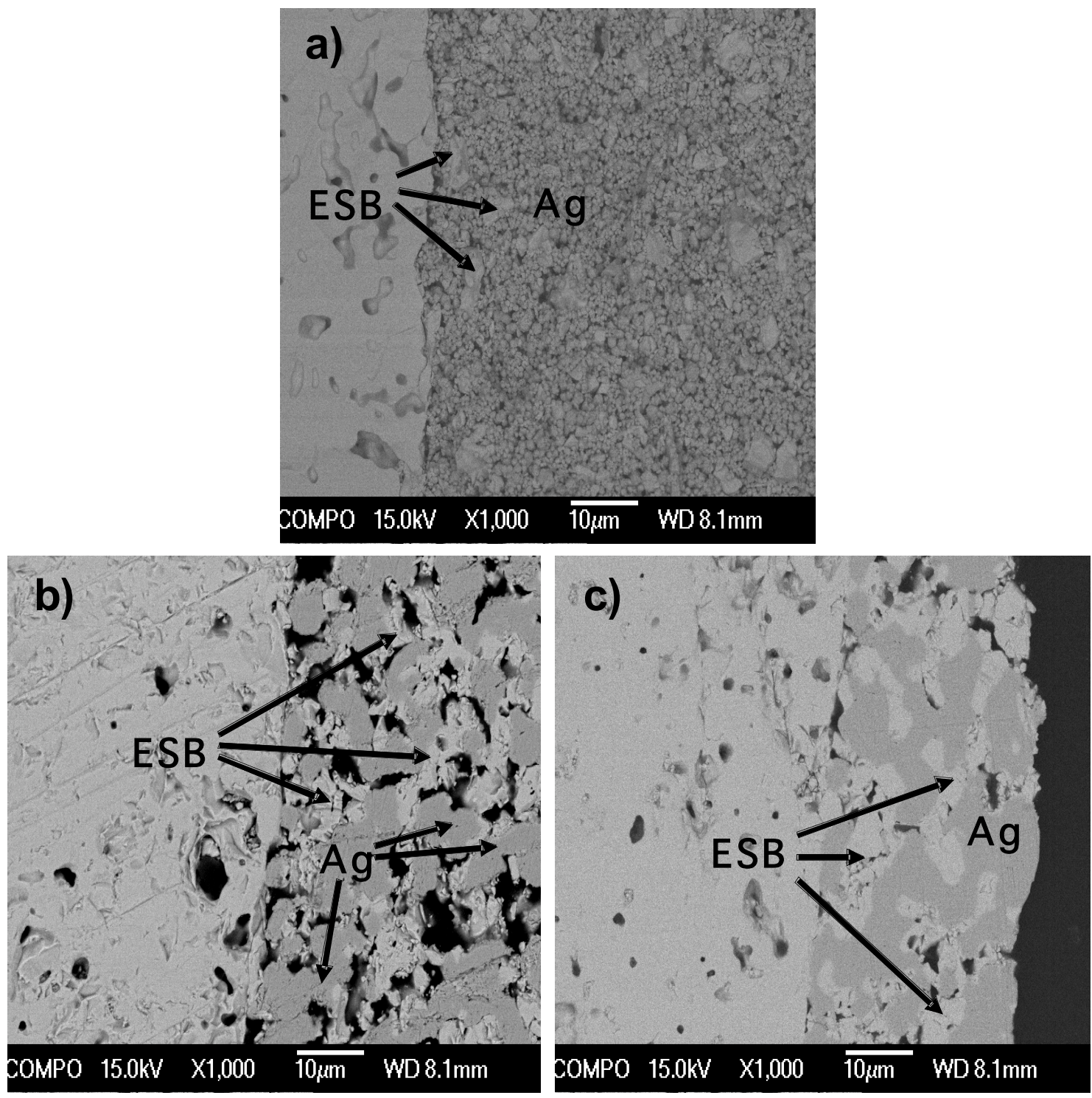

Figure 11. SEM micrographs comparing the morphology of Ag-ESB electrodes before (a) and after (b) firing at $750{ }^{\circ} \mathrm{C}$ for $1 \mathrm{~h}$ and (c) after testing at $650{ }^{\circ} \mathrm{C}$ for $100 \mathrm{~h}$.

after firing and during testing, particularly the Ag-YSB system. This is reflected in the more than two orders-of-magnitude slower rate of ASR increase for these composite systems, and the slightly slower rate for Ag-YSB compared with Ag-ESB. The finer silver phase microstructure of the fired, untested Ag-YSB electrode relative to the untested Ag-ESB electrode may also explain why the electrode containing YSB exhibited the lower initial zero time ASR value despite the higher ionic conductivity of ESB. Trans-granular platelet structures similar to those observed by Fung and Virkar ${ }^{34,35}$ were found in the YSB phase of the electrode and in the electrolyte near the electrode interface, supporting the assertion that some cubic-rhombohedral 

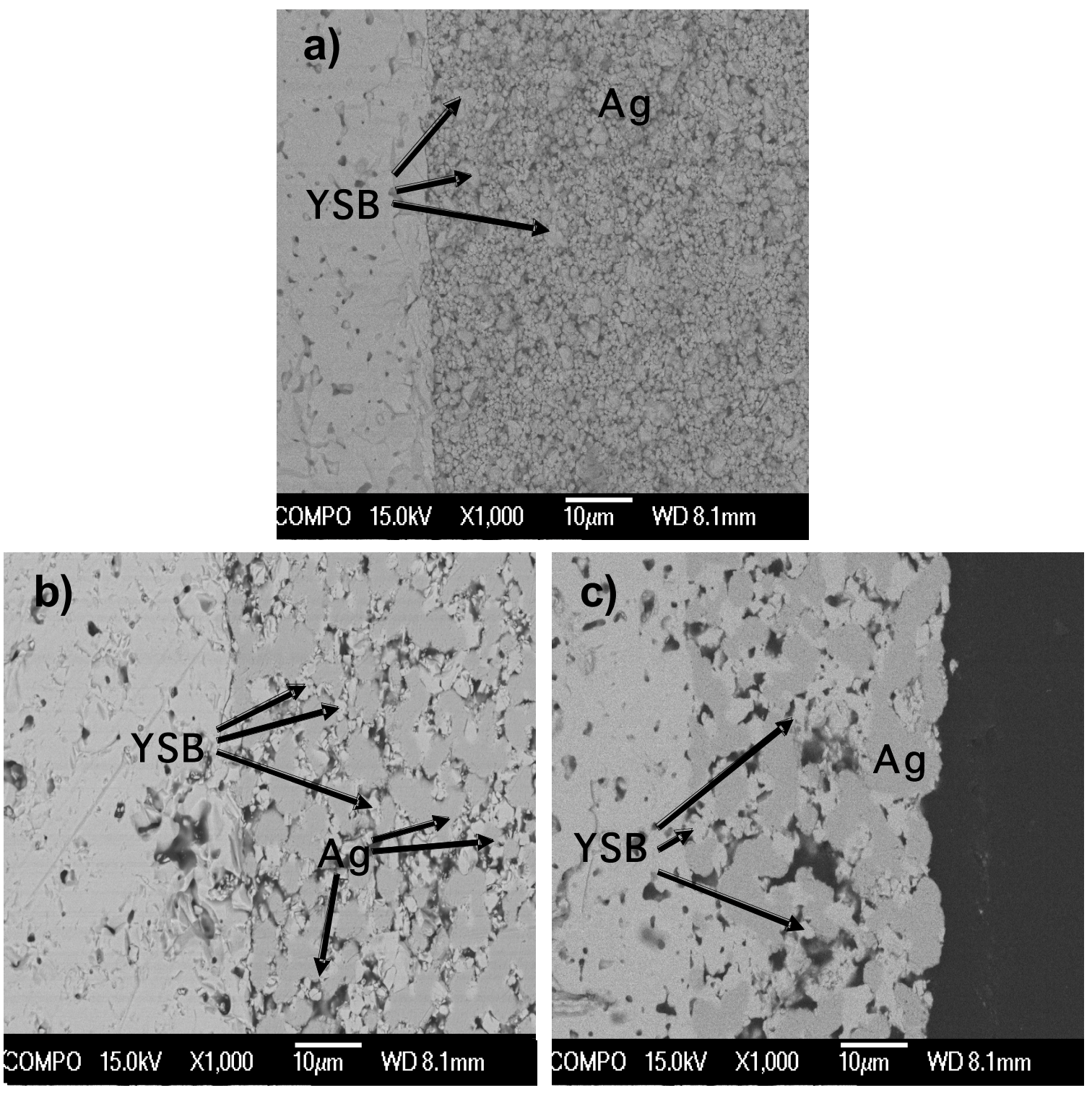

Figure 12. SEM micrographs comparing the morphology of Ag-YSB electrodes before (a) and after (b) firing at $750{ }^{\circ} \mathrm{C}$ for $1 \mathrm{~h}$ and (c) after testing at $650{ }^{\circ} \mathrm{C}$ for $100 \mathrm{~h}$.

phase transformation occurred during testing. This phase transformation likely led to the observed drop in electrolyte conductivity and rise in electrode ASR at longer times.

From the above observations, it is concluded that the main source of instability of the composite Ag-bismuth oxide electrodes is the migration of the silver phase, rather than reactivity or defect ordering of the stabilized bismuth oxide phase. Moreover, as demonstrated in the following section, silver migration is even more severe when operating under an applied bias ${ }^{37,38}$. 

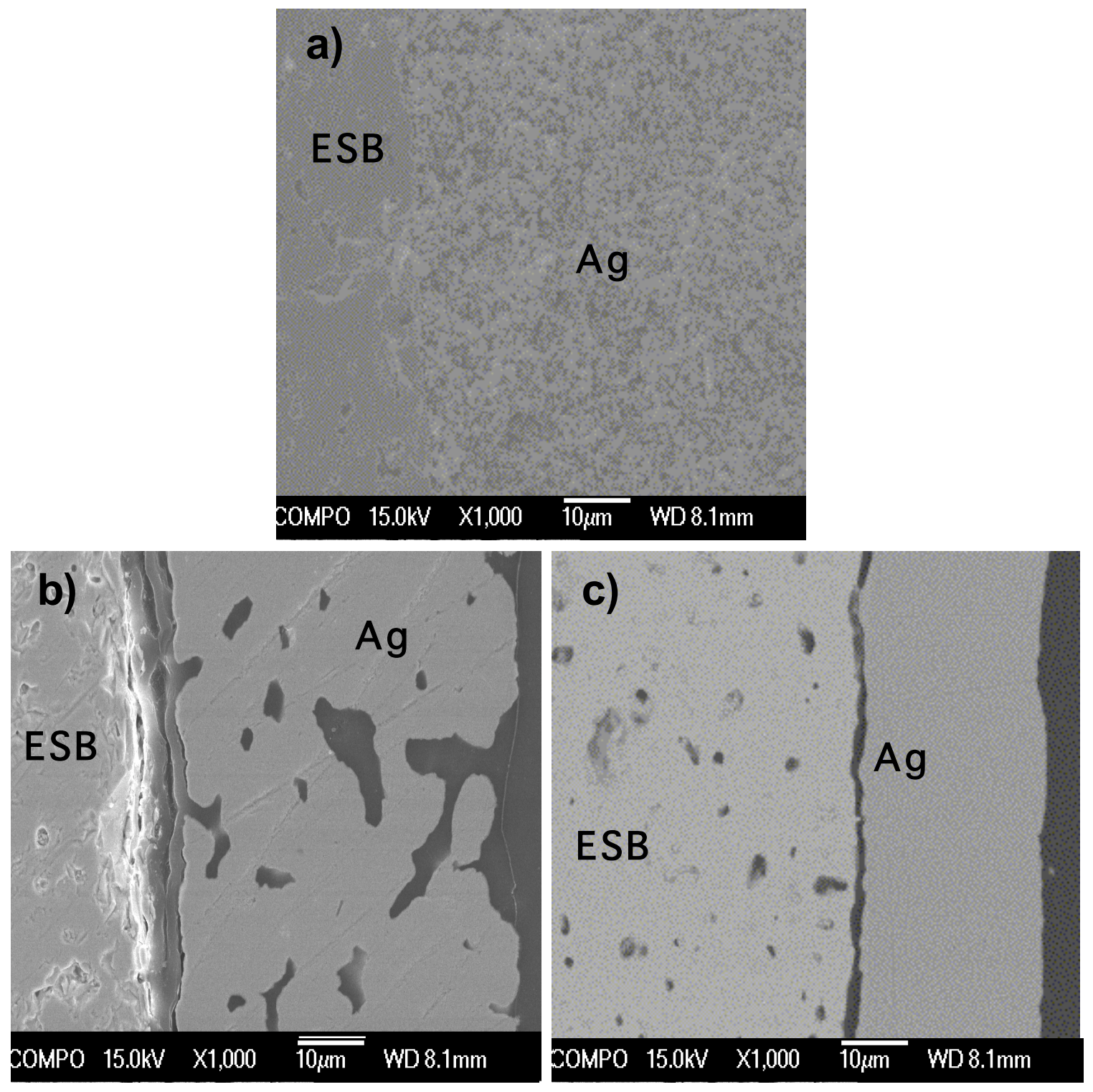

Figure 13. SEM micrographs comparing the morphology of pure Ag electrodes before (a) and after (b) firing at $750{ }^{\circ} \mathrm{C}$ for $1 \mathrm{~h}$ and (c) after testing at $650{ }^{\circ} \mathrm{C}$ for $100 \mathrm{~h}$. Delamination caused by fracturing for SEM analysis.

On the basis of electrochemical impedance and microstructural analysis, it is concluded that as-prepared Ag-bismuth oxide composites have inadequate microstructural stability for longterm, IT-SOFC cathode applications. The silver phase is deemed to be responsible for degradation in performance over time due to grain growth and electrode densification. 


\section{Stability: Performance Decay Under Applied D.C. Bias}

Impedance plots of the electrode at $500{ }^{\circ} \mathrm{C}$ under $0-72 \mathrm{~mA}$ current bias are shown in Fig. 14. Under bias, the electrode impedance will consist of contributions from anode and cathode reactions, and a three-electrode cell is required to separate the two. In the present study with symmetrical cells, the electrode performance is analyzed with the assumption that the oxygen reduction reaction at the cathode is the dominant contribution.
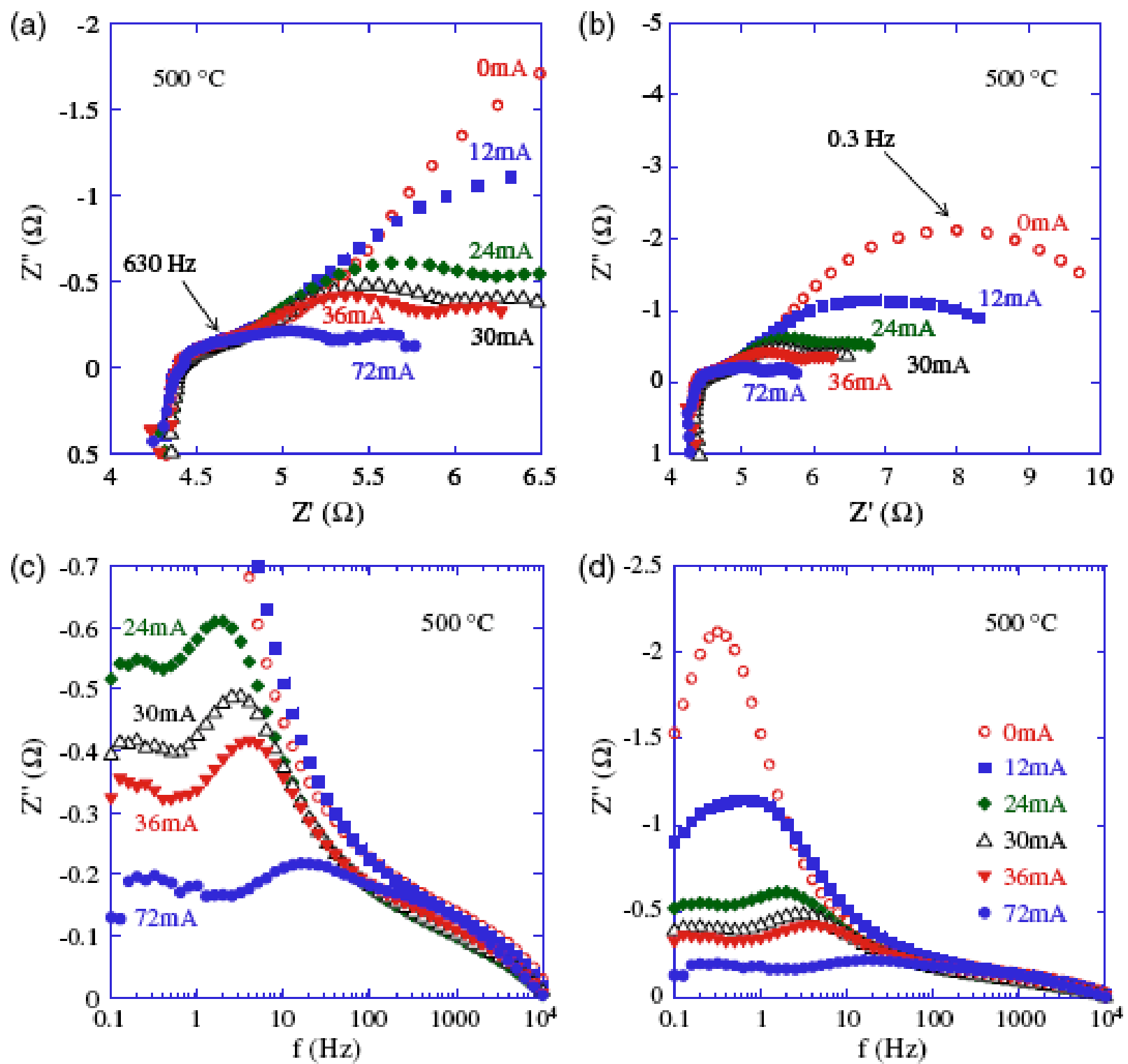

Figure 14. Impedance plots of Ag-ESB electrode at $500{ }^{\circ} \mathrm{C}$ under different bias currents (a) and (b) imaginary vs. real impedance (c) and (d) imaginary impedance vs. frequency. 


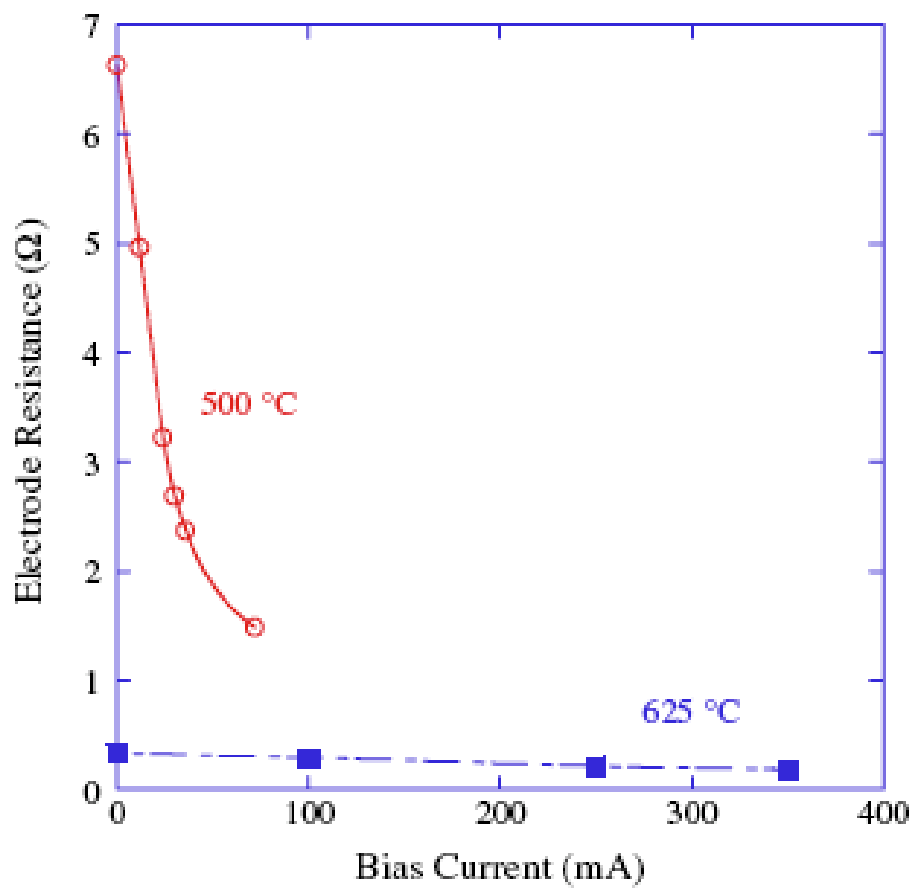

Figure 15. $\mathrm{Ag}-\mathrm{ESB}$ electrode resistance vs. bias current at 500 and $625^{\circ} \mathrm{C}$.

The electrode impedance decreased with bias current as shown in Fig. 15, which suggests that within the current range studied the electrode impedance is dominated by activation polarization. The electrode impedance consisted of at least two arcs: a low frequency arc with a characteristic frequency at $\sim 0.3 \mathrm{~Hz}$ and a high frequency arc with characteristic frequency at $\sim 630 \mathrm{~Hz}$. The plot of the imaginary part of impedance $\left(Z^{\prime \prime}\right)$ vs. log frequency (f) provides a better representation of the frequency distribution in the impedance data. On application of the bias current, the dominant low frequency arc divided into two arcs with significantly smaller impedance, while the impedance of the high frequency arc remained unaffected. The characteristic frequency of the middle arc increased with the bias current, while on the other hand the characteristic frequency of the low and high frequency arcs appear to be independent of the applied current bias. The electrode arcs represent the different reaction steps in the electrode reaction, and it is suggested that the low and middle frequency arcs are related to charge transfer step, while the high frequency arc is related to the bulk transport in the electrode.

Impedance plots of the electrode at $625{ }^{\circ} \mathrm{C}$ under different current biases are shown in Fig. 16. As expected, the activation polarization at $625^{\circ} \mathrm{C}$ is much smaller in comparison to 500 ${ }^{\circ} \mathrm{C}$ as shown in Fig. 15. The electrode impedance consisted of at least two arcs: a low frequency 

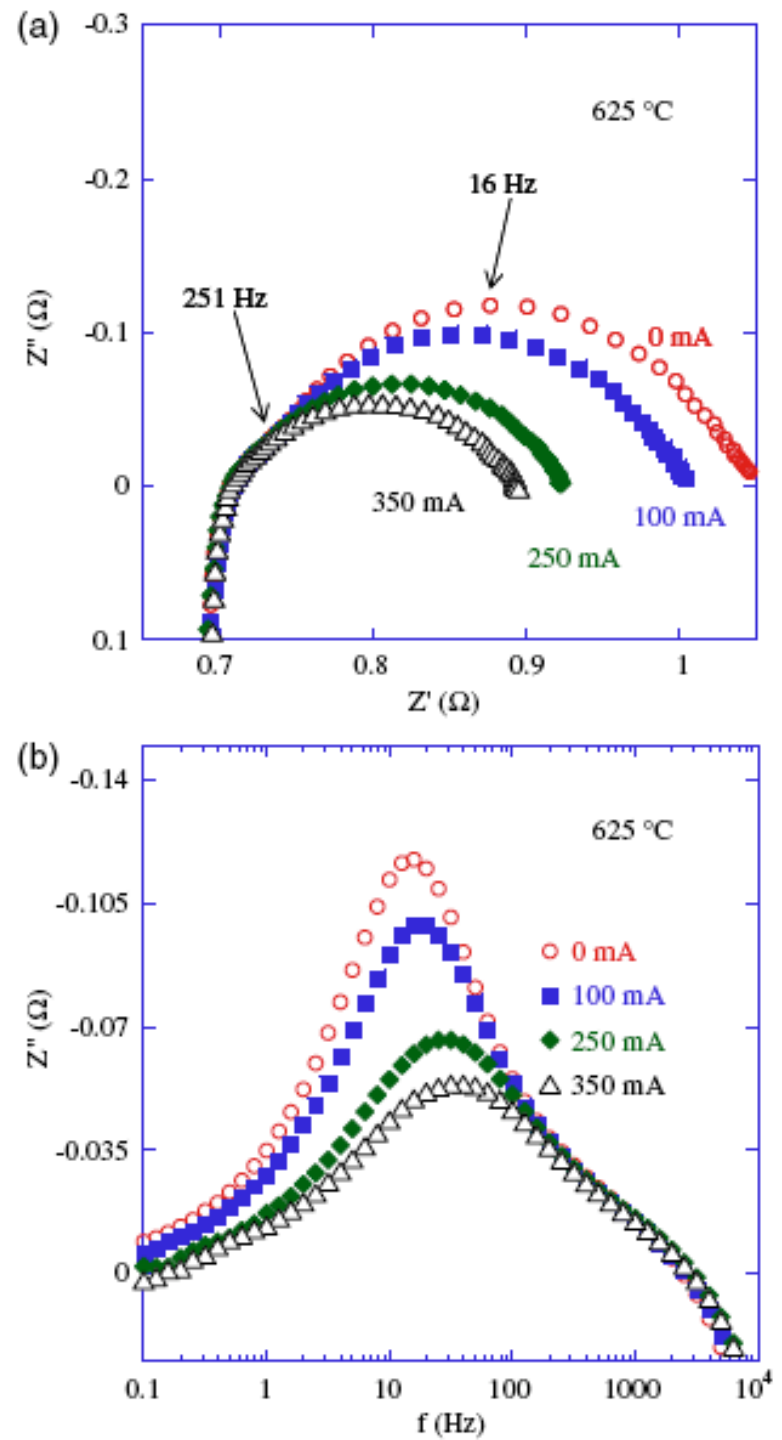

Figure 16. Impedance plots of $\mathrm{Ag}-\mathrm{ESB}$ electrode at $625^{\circ} \mathrm{C}$ under different bias currents (a) imaginary vs. real impedance (b) imaginary impedance vs. frequency.

arc with a characteristic frequency at $\sim 16 \mathrm{~Hz}$ and a high frequency arc with a characteristic frequency at $\sim 251 \mathrm{~Hz}$. As in the case of $500{ }^{\circ} \mathrm{C}$, impedance of the dominant low frequency arc decreased with the bias current, while the impedance of the high frequency arc remained unaffected. However, at $625^{\circ} \mathrm{C}$ the electrode performance was not stable under $250 \mathrm{~mA}$ bias, and the electrode resistance increased by six times after $\sim 22 \mathrm{~h}$ as shown in Fig. 17.

The magnitude of the high frequency electrode impedance arc increased with time and eventually became the dominant arc, which indicates that it might be related to some sort of concentration polarization. Interestingly, the magnitude of the high frequency arc reduced on 

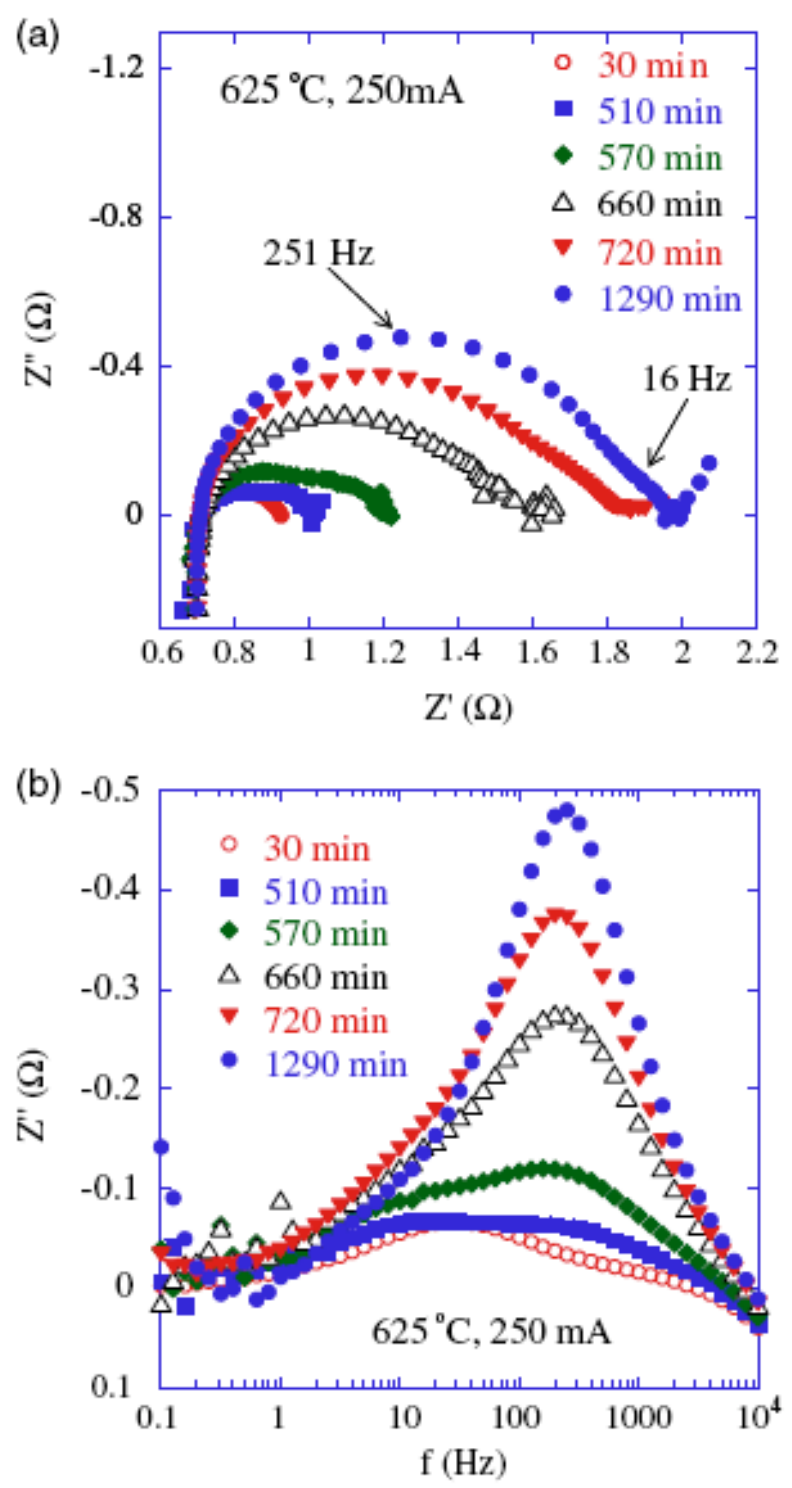

Figure 16. Impedance plots of Ag-ESB electrode under $250 \mathrm{~mA}$ bias at $625^{\circ} \mathrm{C}$ (a) imaginary vs. real impedance (b) imaginary impedance vs. frequency.

removing the bias at the end of the experiment, and once again, the low frequency arc became the dominant arc.

After the experiment at $625^{\circ} \mathrm{C}$ under $250 \mathrm{~mA}$ bias, the top surface of the anode looked silvery which was initially light brown in color, and the cathode peeled off very easily with a silver layer at the electrolyte interface. SEM micrographs of the electrode/electrolyte interface at the anode and cathode after $\sim 26 \mathrm{~h}$ at $625{ }^{\circ} \mathrm{C}$ under $250 \mathrm{~mA}$ bias are shown in Fig. 18. Significant electro-migration of Ag occurred along with the oxygen flux to the 

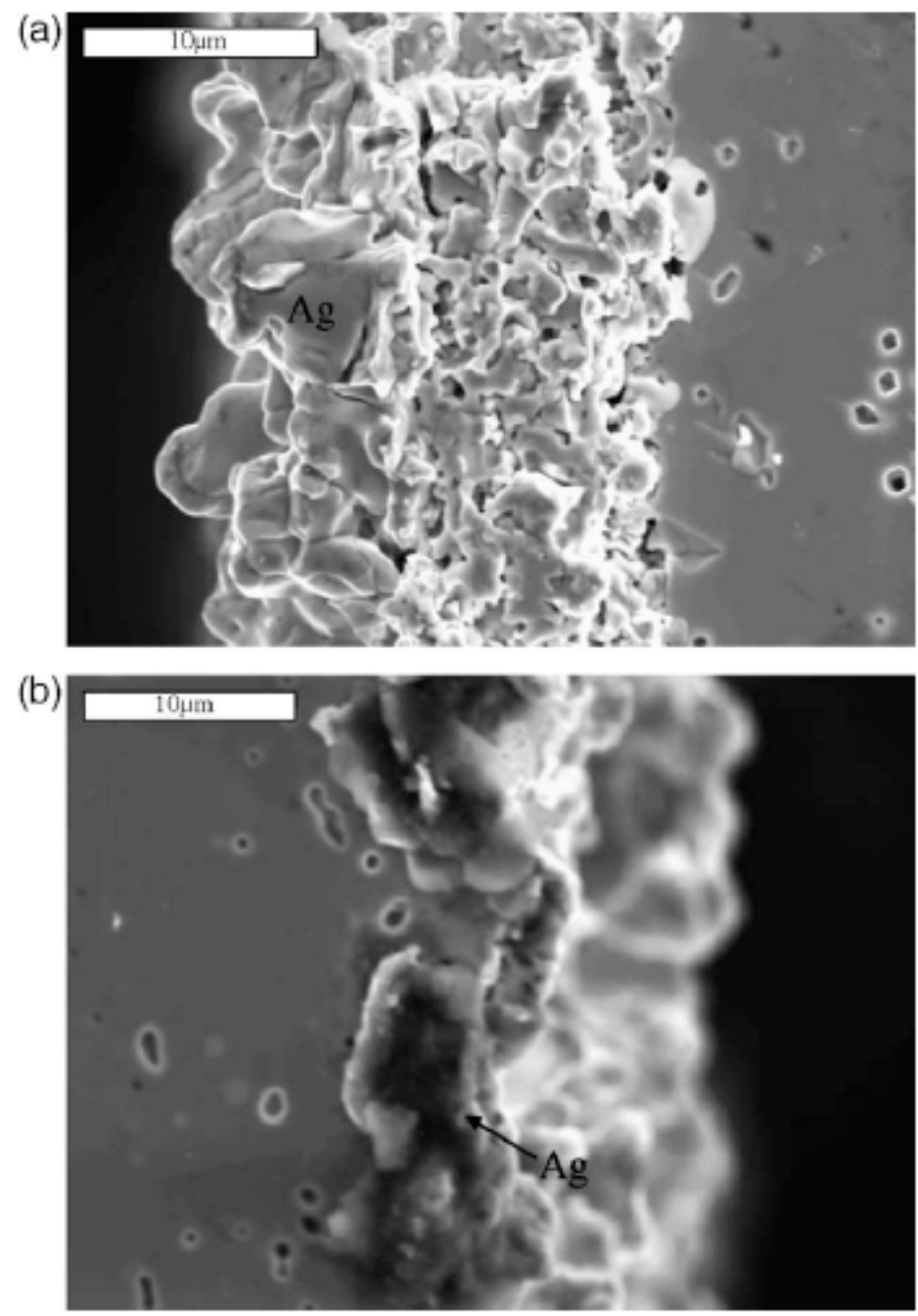

Figure 18. Cross-section of the electrolyte/electrode interface after annealing experiments at $625{ }^{\circ} \mathrm{C}$ under $250 \mathrm{~mA}$ bias for $\sim 26 \mathrm{~h}$ (a) anode (b) electrolyte interface after cathode peeled off.

electrode/electrolyte interface at the cathode and to the top surface at the anode. In fact, the samples tested at $625^{\circ} \mathrm{C}$ under $100 \mathrm{~mA}$ also showed electro-migration but to a comparatively less extent, whereas the other samples tested at $300{ }^{\circ} \mathrm{C}$ and $500{ }^{\circ} \mathrm{C}$ under bias maintained a uniform mixture of $\mathrm{Ag}$ and ESB phase in both electrodes after the test.

A schematic of the proposed electrode reaction mechanism is shown in Fig. 19. It is suggested that the low frequency arc is related to the charge transfer step, while the high frequency arc is related to the bulk transport of oxygen in the silver particles. The electrode response under no bias is limited by the charge transfer step, and on application of the bias the charge transfer resistance decreases, though along with Ag electro-migration in the electrode. 


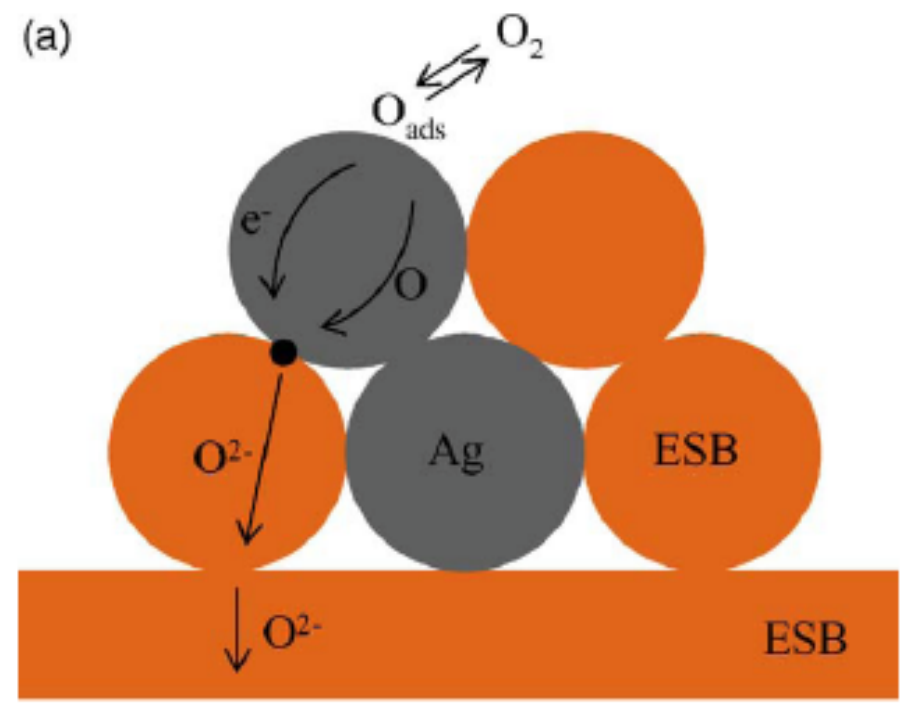

(b)
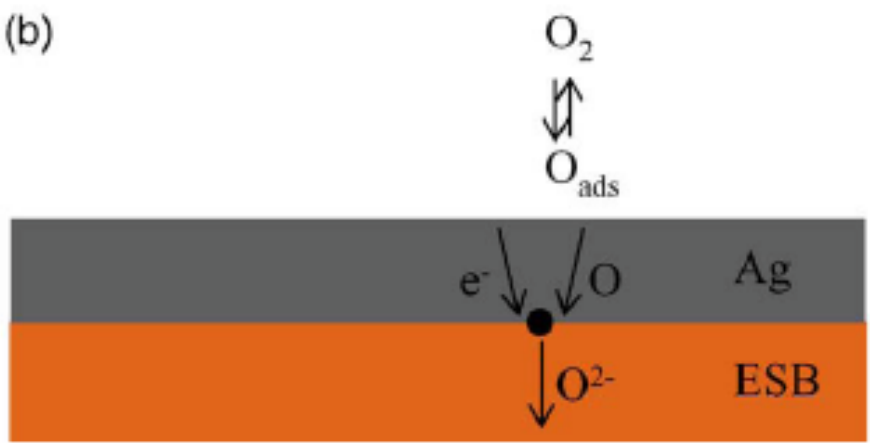

Figure 19. Proposed electrode reaction mechanism for Ag-ESB electrodes under (a) no bias and (b) bias.

The migration with time results in the formation of a dense Ag layer at the cathode/electrolyte interface and in the bulk transport contribution in the electrode impedance. As mentioned earlier, the formation of the dense Ag layer resulted in the eventual reduction of the electrolyte at the cathode; however, it was not detected in the impedance plots.

Oxygen diffusivity $\left(\mathrm{D}_{0}\right)$ and solubility $\left(\mathrm{C}_{0}\right)$ in $\mathrm{Ag}$ layer for the case of finite Warburg diffusion could be calculated using the following equations

$$
\begin{gathered}
\pi \delta^{2} \omega_{\text {max }}=8 D_{0} \\
Z_{D}(\omega \rightarrow 0)=\frac{R T}{n^{2} F^{2} C_{0} D_{0}}
\end{gathered}
$$


where $\omega_{\max }$ is the frequency at the maximum value of the imaginary component, ${ }^{\text {тм }}$ is the diffusion length, and $\mathrm{Z}_{\mathrm{D}}(\omega \rightarrow 0)$ is the real intercept $\mathrm{t}^{39}$. For $\mathrm{Ag}-\mathrm{ESB}$ electrode at $625^{\circ} \mathrm{C}, 250 \mathrm{~mA}$ after $\sim 26 \mathrm{~h}$, the calculated values for $\mathrm{D}_{0}$ and $\mathrm{C}_{0}$, assuming $1 \mathrm{fm}$ diffusion length, are $6.2 \times 10^{-6}$ $\mathrm{cm}^{2} / \mathrm{s}$ and $2.9 \times 10^{-6}$ moles $/ \mathrm{cm}^{3}$, respectively. The calculated values match well with experimental values for $\mathrm{D}_{0}\left(7.4 \times 10^{-6} \mathrm{~cm}^{2} / \mathrm{s}\right)$ and $\mathrm{C}_{0}\left(1.9 \times 10^{-6} \mathrm{moles} / \mathrm{cm}^{3}\right)$ reported in the literature $^{40}$, which supports the argument that the high frequency arc in the electrode impedance is related to the oxygen diffusion in Ag.

Phase equilibria between $\mathrm{Ag}$ and $\mathrm{Ag}_{2} \mathrm{O}$ has been studied by Assal et al. ${ }^{41}$. Ag forms a eutectic with $\mathrm{Ag}_{2} \mathrm{O}$ at $530{ }^{\circ} \mathrm{C}$ and 519 atm $\mathrm{O}_{2}$. The liquidus temperature in an oxygen-free atmosphere is $962{ }^{\circ} \mathrm{C}$, which is lowered to $951{ }^{\circ} \mathrm{C}$ and $939^{\circ} \mathrm{C}$ in air and 1 atm $\mathrm{O}_{2}$, respectively. The high performance of the Ag electrodes for oxygen reduction is because of its oxygen solubility which also results in the formation of the eutectic, and as found in this study will consequently lead to electro-migration of Ag along with the oxygen flux above the eutectic temperature. Therefore, electrodes containing Ag in sufficient proportions should not be expected to be microstructurally stable for long periods of time even at intermediate temperatures. $\mathrm{Ag}-\mathrm{Pt}$ and $\mathrm{Ag}-\mathrm{Pd}$ alloys with higher melting points can be better than $\mathrm{Ag}$, though they will be much costlier alternatives.

\section{Improving Stability and Area Specific Resistance through Microstructural Control.}

As discussed above, microstructural evolution of the silver phase leads to substantial reduction in the performance of these electrode systems. In order to improve the stability of these electrodes we investigated two approaches as described below.

Addition of Nano-Sized YSZ Particles. The first attempt to improve stability involved the use of nano-sized ceramic particles. In theory, the increased surface area provided by these particles should increase the energy required for silver to migrate over a given distance inside the electrode. Nano-sized $8 \mathrm{~mol} \%$ YSZ powder was used in this study as it is readily available and non-reactive toward $\mathrm{Ag}$ and $\mathrm{ESB}$ in the temperature range of interest. Various YSZ/ESB compositions were tested, keeping the Ag volume fraction constant. That is, cathodes with composition $\mathrm{Ag}_{\mathrm{x}}-\left(\mathrm{YSZ}_{\mathrm{y}}-\mathrm{ESB}_{1-\mathrm{y}}\right)_{1-\mathrm{x}}$ were prepared, where $\mathrm{x}=0.5$, and $\mathrm{y}=0,0.05,0.10$, and 0.15 represent fractions of the total cathode solids volume. 

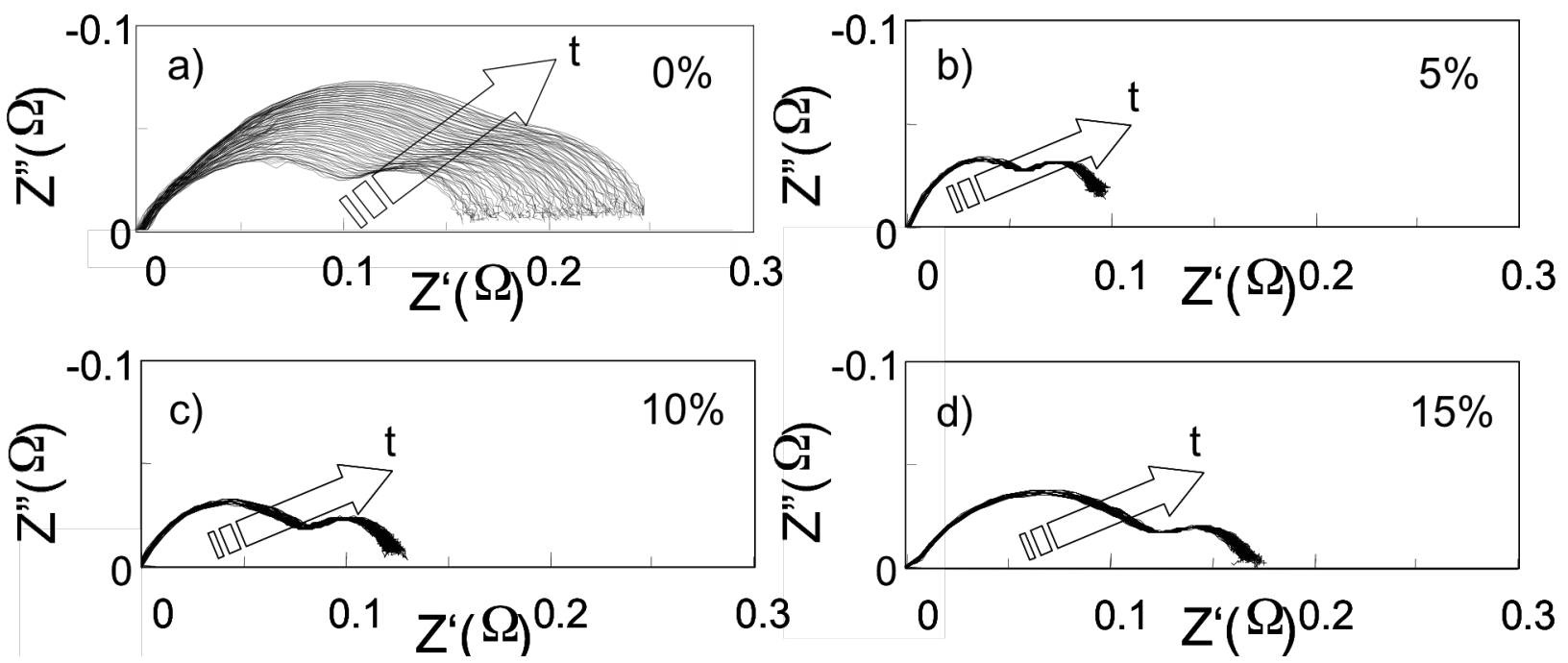

Figure 20. Nyquist plots for silver-ESB composite electrodes containing 0 vol\% (a), 5 vol\% (b), 10 vol\% (c), and $15 \mathrm{vol} \%$ (d) 8 YSZ nanoparticles. Samples were tested at $650{ }^{\circ} \mathrm{C}$ in air for $100 \mathrm{~h}$ under no applied bias. Note that the electrolyte resistance has been subtracted from all Nyquist plots.

Impedance spectra and electrode ASR versus time under no applied bias are shown in Figs. 20 and 21. It is clear from the impedance spectra that all samples containing the nano-sized YSZ powder additions were relatively stable compared to the YSZ-free sample. The electrode ASR degraded at a rate of $4.1 \times 10^{-4} \Omega \mathrm{cm}^{2} / \mathrm{h}, 1.3 \times 10^{-5} \Omega \mathrm{cm}^{2} / \mathrm{h}, 2.5 \times 10^{-5} \Omega \mathrm{cm}^{2} / \mathrm{h}$ and $3.1 \times 10^{-5}$ $\Omega \mathrm{cm}^{2} / \mathrm{h}$ for $0 \%, 5 \%, 10 \%$, and $15 \%$ YSZ, respectively. The largest stability improvement (a $97 \%$ reduction in ASR vs. time slope) was achieved at the lowest YSZ loading, $5 \%$. In addition, the initial zero-time ASR value of this composition was $31 \%$ less than that of the YSZfree composition $\left(0.043 \Omega \mathrm{cm}^{2}\right.$ and $0.062 \Omega \mathrm{cm}^{2}$ for $5 \%$ and $0 \% \mathrm{YSZ}$, respectively), despite the substitution of $5 \mathrm{vol} \%$ YSZ for the high conductivity ESB phase. Samples with higher concentrations of YSZ exhibited higher initial ASR values, as expected $-0.057 \Omega \mathrm{cm}^{2}$ and 0.077 $\Omega \mathrm{cm}^{2}$ for $10 \%$ and $15 \%$, respectively-but showed electrode stability improvement over the non-YSZ composite. However, the ASR vs. time slopes increased as YSZ content increased.

In Fig. 22, a comparison between backscattered SEM images of tested samples shows how the silver particles have been restrained from coalescence, allowing porosity to remain open and three phase boundaries (TPBs) to remain high, compared to the case with no YSZ additions. Further, the size of the silver grains decreases with increased YSZ content. 


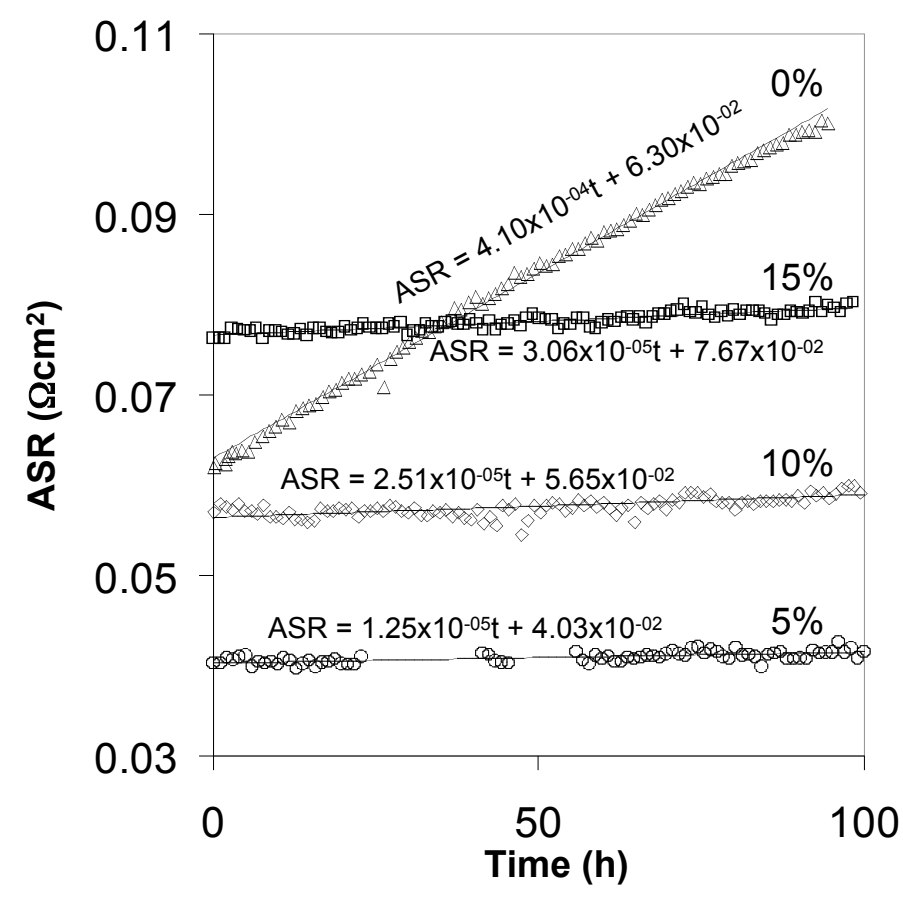

Figure 21. Effect of time on ASR of silver-ESB composite electrodes containing various volumetric amounts of $8 \mathrm{~mol} \%$ YSZ nano-particles. Measurements taken at $650{ }^{\circ} \mathrm{C}$ in air under no applied bias.
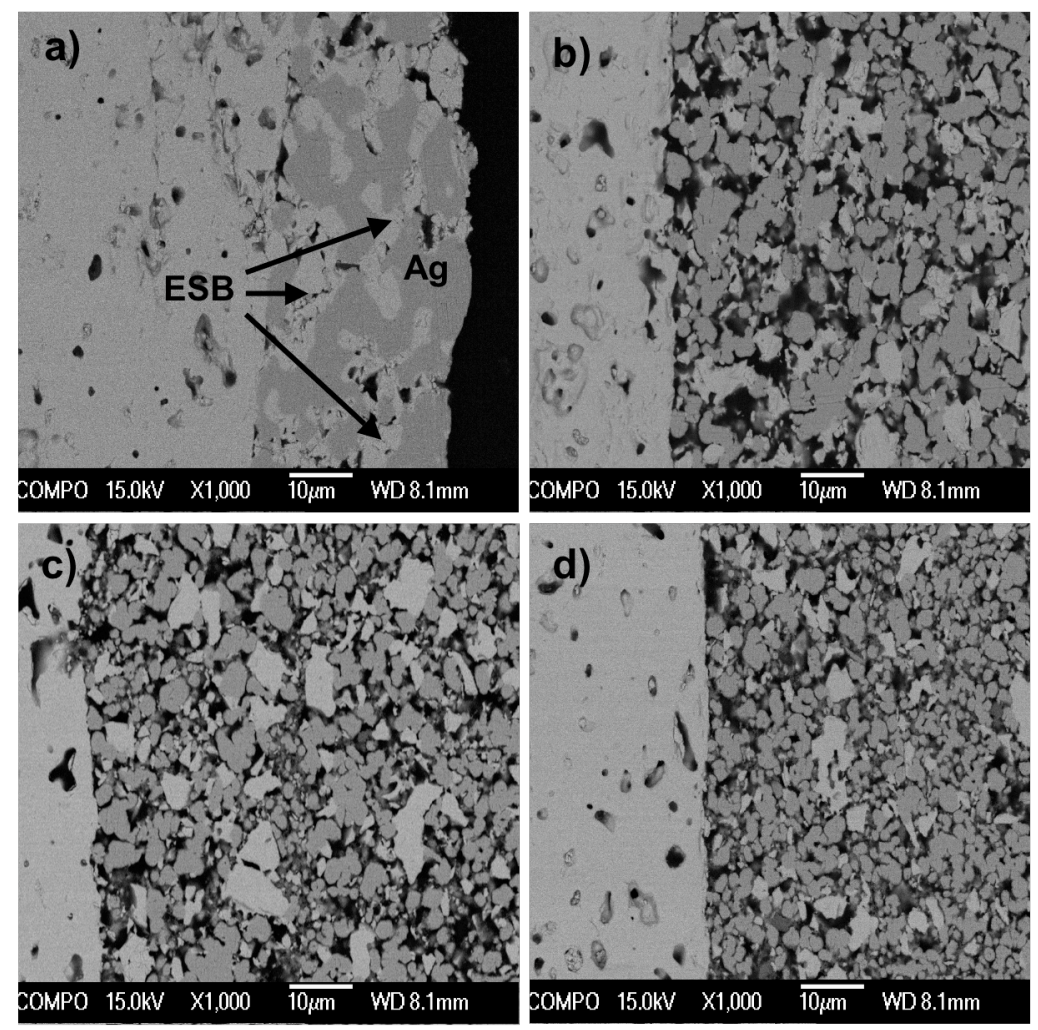

Figure 22. Backscattered electron SEM images of tested $\left(650^{\circ} \mathrm{C}, 100 \mathrm{~h}\right.$ in air under no applied bias) $\mathrm{Ag}$ ESB electrodes containing 0 vol\% (a), 5 vol\% (b), 10 vol\% (c), and 15 vol\% (d) YSZ nano-particles. 


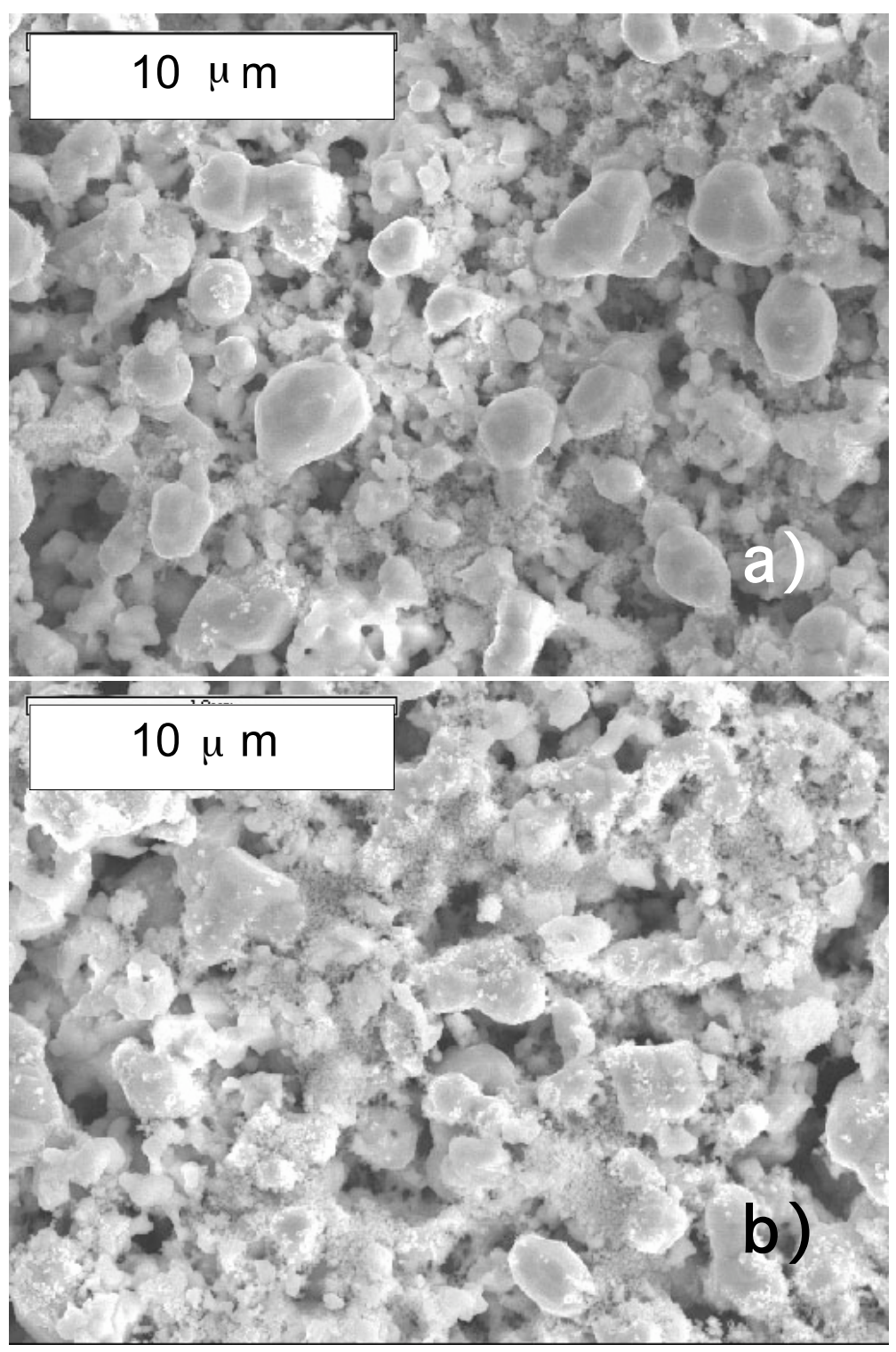

Figure 23. SEM images of an untested (a) and tested $\left(600{ }^{\circ} \mathrm{C}, 48 \mathrm{~h}\right.$ in air under no applied bias) (b) silver-ESB electrodes containing 15 vol $\% 8$ YSZ nano-particles.

Figure 23 is a secondary electron image comparing the $15 \%$ YSZ sample before and after testing. Grain size and porosity appear to be comparable before and after testing. However, the edges of the silver particles in the as-fired sample are smooth, while in the tested sample, the edges are rough, due to envelopment of YSZ into the silver particles. It is possible that this effect further reduces the TPB length between metallic, gaseous, and ESB phases, contributing to the observed increase in ASR with time for these electrodes. This could also explain the observed increased ASR vs. time slopes with increasing YSZ content. 

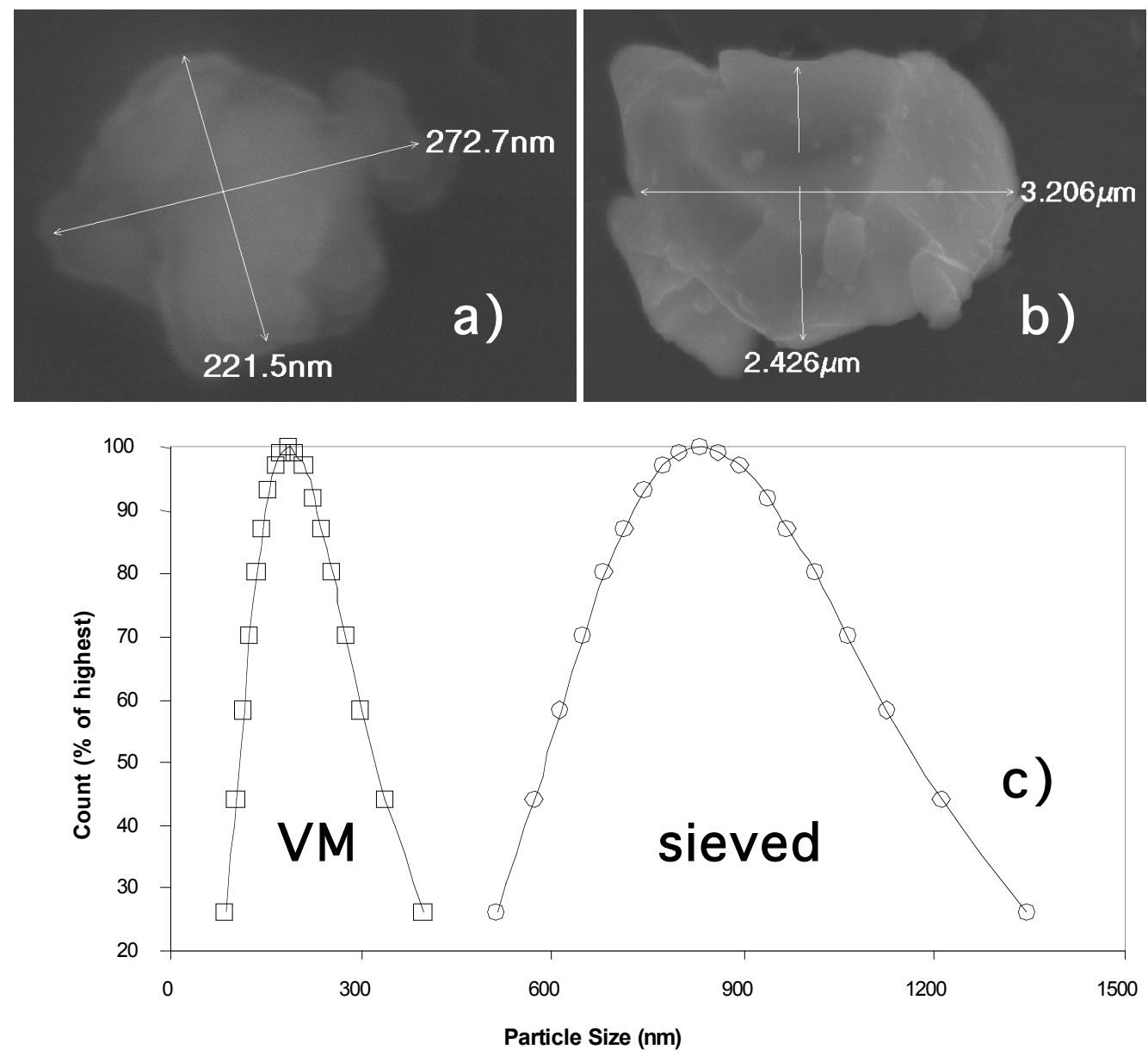

Figure 24. Electron micrographs of typical ESB powder after sieving, with (a) and without (b) vibratory milling, and particle size analysis (PSA) results (c). PSA results for the sieved ESB powders may be skewed to lower particle sizes since larger particles settle out of suspension quickly, and consequently may be omitted from the measurement count.

ESB Particle Size Reduction. The second attempt to improve electrode ASR and stability involved reduction of initial particle size of the ESB powder. This strategy is similar to the addition of nano-YSZ particles - more energy is required for the silver phase to migrate over a given distance in the electrode. However, the overall ionic conductivity of the cathode as well as the reactive TPB lines should not be compromised, unlike YSZ additions. This is also a more cost-effective approach than strategies involving alloying silver with precious metals to reduce Ag mobility, as suggested by Jaiswal et. al. ${ }^{42}$. Figure 23 shows the reduction in particle size that was obtained from the use of vibratory milling. SEM imagery reveals that particle size was reduced by about an order of magnitude after seven days of vibratory milling-from several microns to several hundreds of nanometers. 


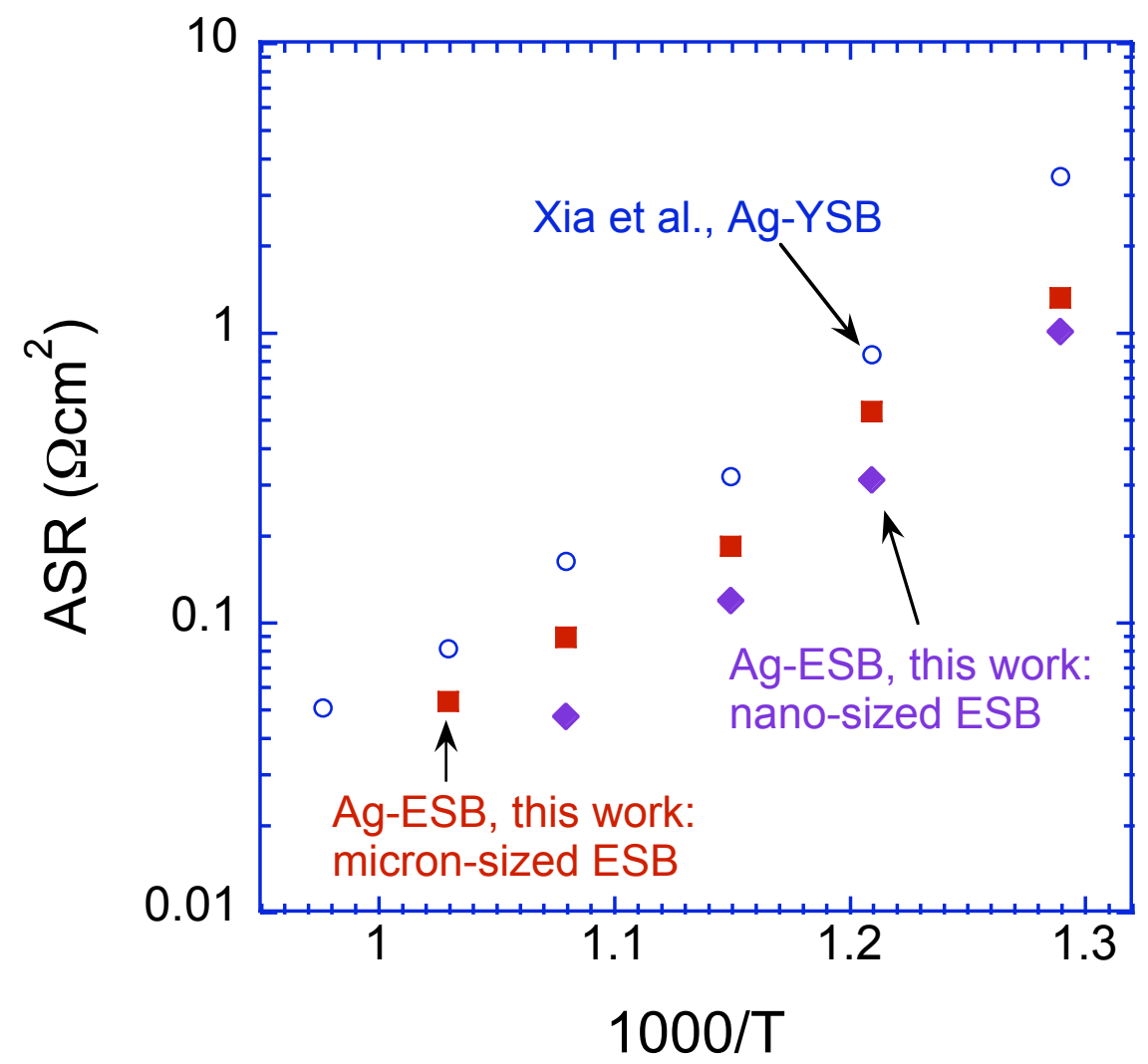

Figure 24. Comparison of ASR vs. reciprocal temperature for Ag-YSB (Xia et. al.) and Ag-ESB (this work) with micron-sized and nano-sized ESB particles.

Figure 25 shows a comparison of the performance of this microstructurally improved electrode with our other electrode and that of Xia et. $a l .{ }^{16}$ from the literature. The initial, zero time ASR for the Ag-ESB ${ }_{V M}$ composite at $650{ }^{\circ} \mathrm{C}$ was $0.048 \Omega \mathrm{cm}^{2}-70 \%$ lower than the 0.16 $\Omega \mathrm{cm}^{2}$ reported for Ag-YSB and $25 \%$ lower than the already-low $0.062 \Omega \mathrm{cm}^{2}$ for the Ag-ESBS composite. This is most likely due to enhanced TPB created by the use of smaller ESB particles, and may also be attributed to suppression of silver migration during electrode sintering, leaving both porosity and TPB length high.

The long term, unbiased impedance study comparing composites prepared with (ESB $\left.\mathrm{VM}_{\mathrm{M}}\right)$ and without $\left(\mathrm{ESB}_{\mathrm{S}}\right)$ vibratory milling of the ESB phase, shown in Figs. 26 and 27, reveal the vast improvement in stability the reduction in ESB particle size imparts on this system. As shown earlier, linear trends in ASR with time are observed, and the degradation rate of silver-ESB composites at $650{ }^{\circ} \mathrm{C}$ was reduced from $4.10 \times 10^{-4} \Omega \mathrm{cm}^{2} / \mathrm{h}$ to $1.91 \times 10^{-5} \Omega \mathrm{cm}^{2} / \mathrm{h}-\mathrm{a} 95 \%$ drop with the reduced ESB particle size. 

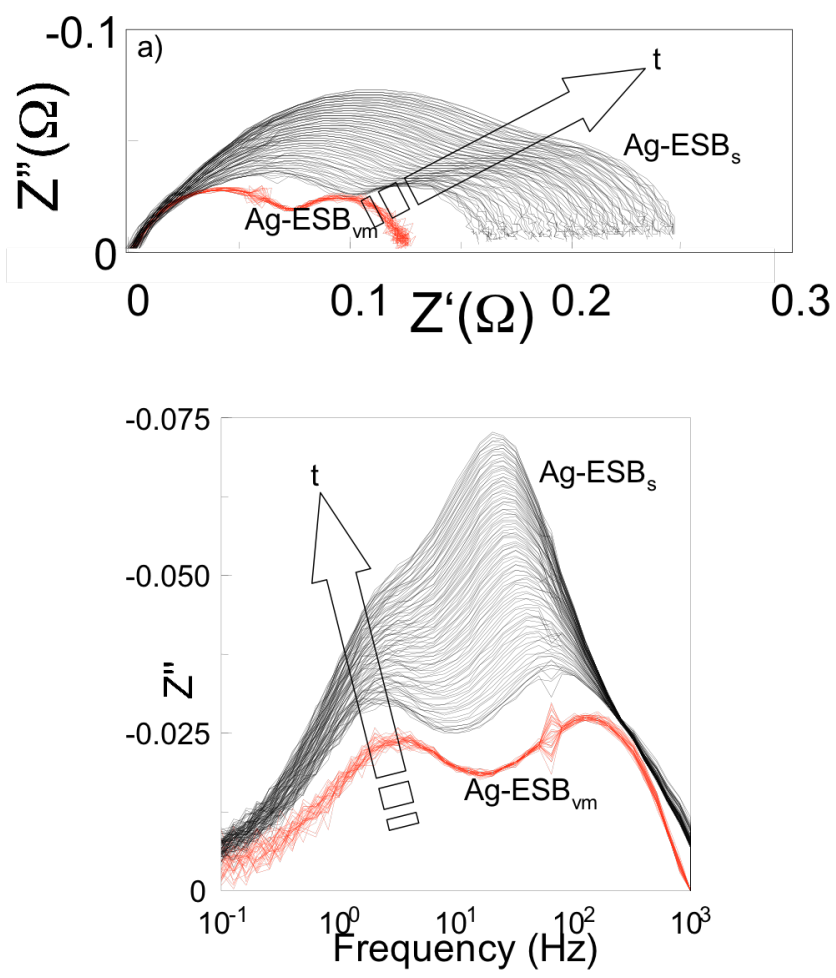

Figure 26. Nyquist plots (a) and imaginary part of impedance vs. log-scale frequency (b) for 50-50 vol\%

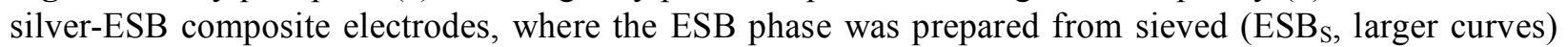
and vibratory milled (ESB $\mathrm{VM}_{\mathrm{M}}$, smaller curves) powders. Samples were tested at $650{ }^{\circ} \mathrm{C}$ in air for $100 \mathrm{~h}$ under no applied bias. Note that the electrolyte resistance has been subtracted from all Nyquist plots.

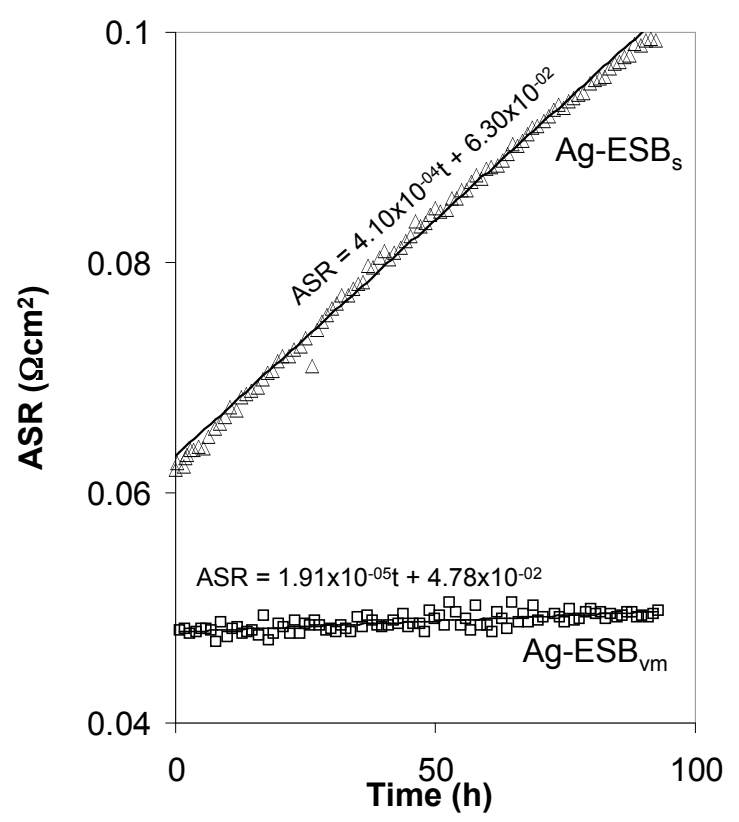

Figure 27. Electrode ASR vs. time for 50-50 vol\% silver-ESB composite electrodes, where the ESB phase was prepared from sieved $\left(\mathrm{ESB}_{\mathrm{S}}\right.$, triangles) and vibratory milled (ESB $\mathrm{VM}_{\mathrm{V}}$, squares) powders. Samples were tested at $650{ }^{\circ} \mathrm{C}$ in air for $100 \mathrm{~h}$ under no applied bias. 
Stability Under D. C. Bias. The above experiment was repeated with an external $0.25 \mathrm{~V}$ D. C. bias applied across the cells to simulate operating conditions, and the results are shown in Figures 28 and 29. The improvement in performance and stability is evident, though not as pronounced as the unbiased case. After $\sim 15 \mathrm{~h}$ of testing, the ASR increases linearly with time. The ASR vs. time slope under $0.25 \mathrm{~V}$ bias at $650{ }^{\circ} \mathrm{C}$ is reduced by $50 \%$ (from $1.6 \times 10^{-3} \Omega \mathrm{cm}^{2} / \mathrm{h}$ to $8.0 \times 10^{-4} \Omega \mathrm{cm}^{2} / \mathrm{h}$ ) when smaller ESB particles are used to prepare the composite electrodes.

Both macroscopic and microscopic changes in the electrodes prepared with larger ESB particles before and after bias testing are immediately recognized (Fig. 30). After testing, the electrode surface of the working electrode appears more silver in color when compared to the surface of an untested electrode. The counter-electrode of the tested cell appears more reddish in color, and a ring of silver color can be seen along its edge. The microstructural changes are also dramatic. A cross-sectional view of the counter electrode shows silver dendrite-like structures at the electrolyte interface, and nearly pure ESB at the electrode surface. The silver phase clearly migrates in one direction - towards the electrode/electrolyte interface in the counter electrode and towards the surface of the working electrode. Oxygen is reported to have high solubility and
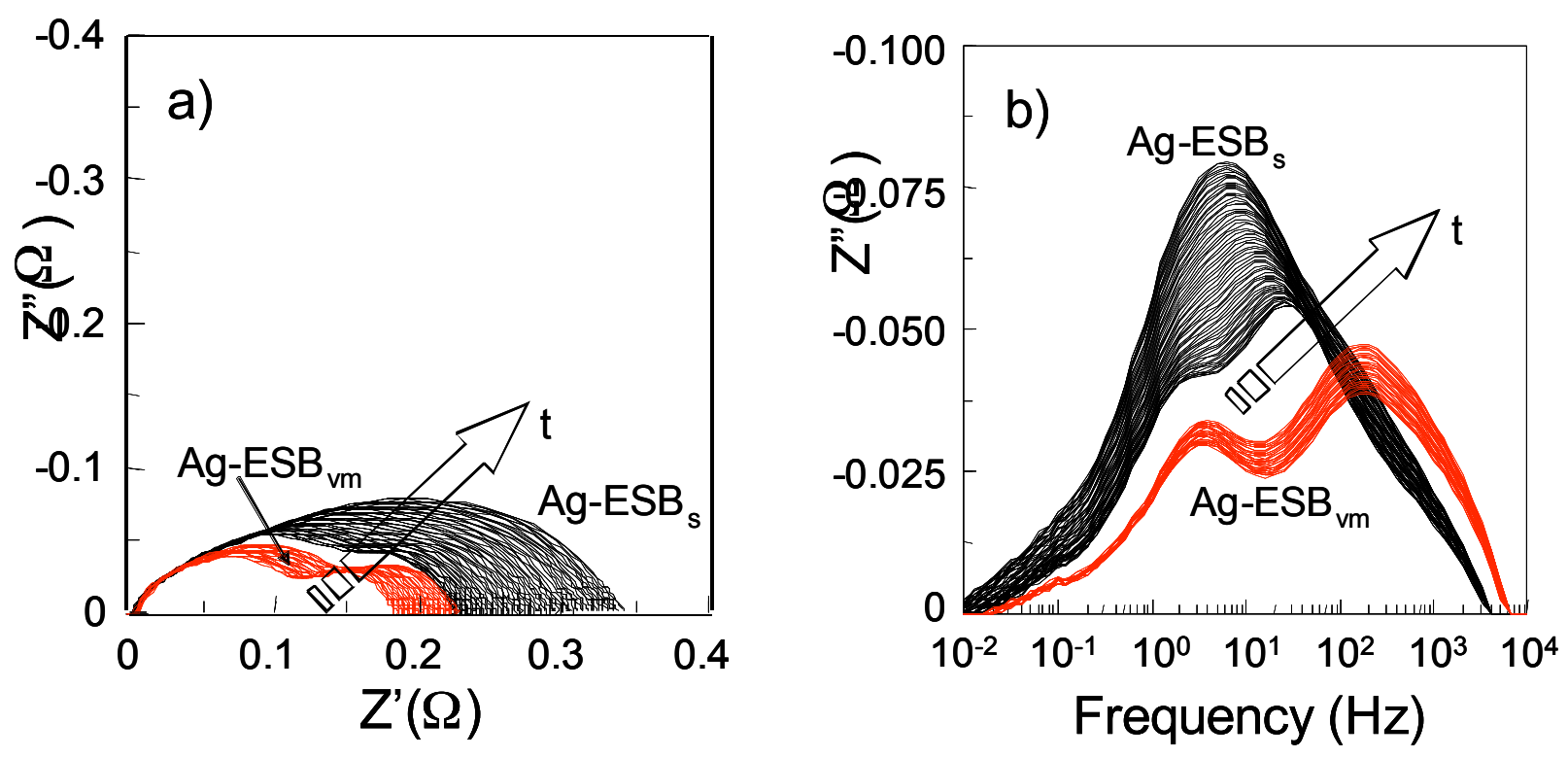

Figure 28. Nyquist plots (a) and imaginary part of impedance plotted vs. log-scale frequency (b) for 50$50 \mathrm{vol} \%$ silver-ESB composite electrodes, where the ESB phase was prepared from sieved (ESB , larger $^{2}$ curves) and vibratory milled (ESB $\mathrm{VM}$, smaller curves) powders. Samples were tested at $650{ }^{\circ} \mathrm{C}$ in air for $40 \mathrm{~h}$ under a $250 \mathrm{mV}$ bias. Note that the electrolyte resistance has been subtracted from all Nyquist plots. 


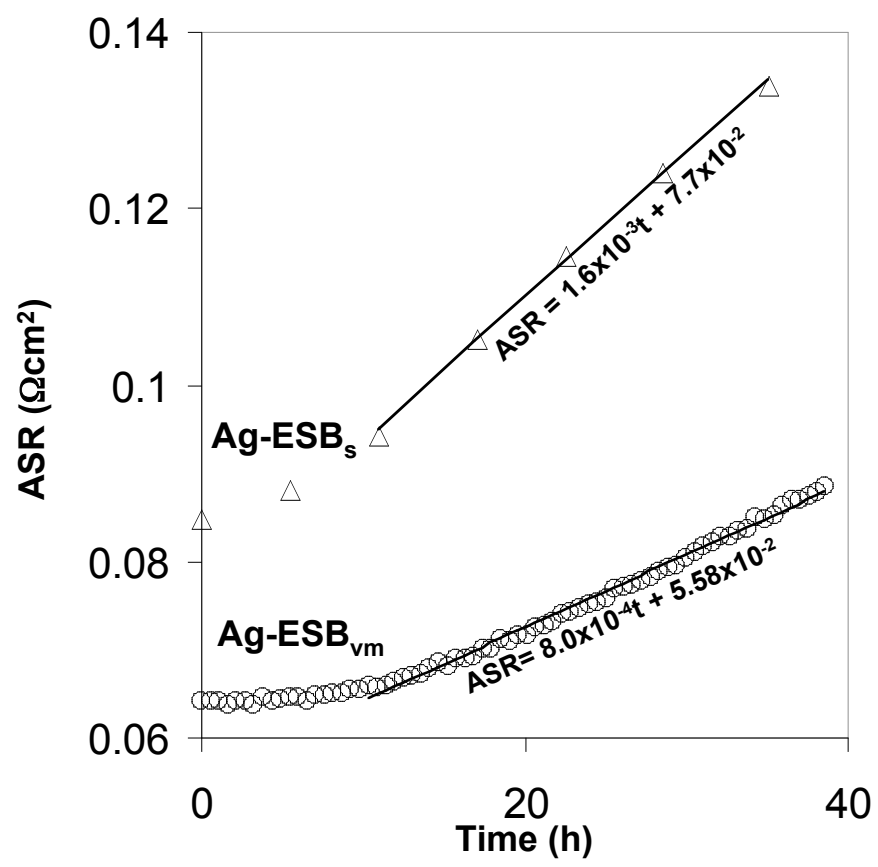

Figure 29. Electrode ASR vs. time for $50-50$ vol\% silver-ESB composite electrodes, where the ESB phase was prepared from sieved $\left(\mathrm{ESB}_{\mathrm{S}}\right.$, triangles) and vibratory milled (ESB $\mathrm{ES}_{\mathrm{VM}}$, circles) powders. Samples were tested at $650{ }^{\circ} \mathrm{C}$ in air for $40 \mathrm{~h}$ under a $250 \mathrm{mV}$ bias.

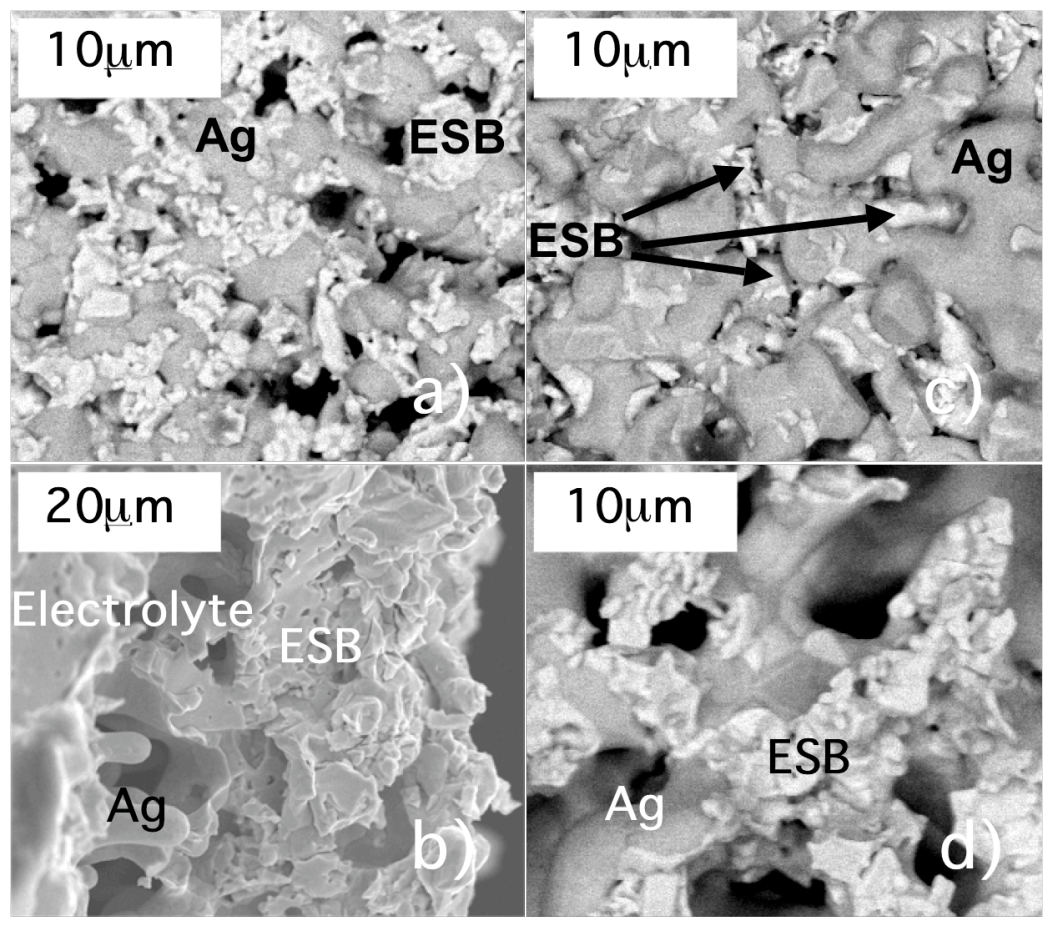

Figure 30. Microstructural images of silver-ESB composite electrodes, where the ESB phase was prepared from sieved powders - surface before testing (a) and cross-section of the counter electrode (b), working electrode surface (c), and counter electrode surface (d) of a cell after $48 \mathrm{~h}$ of testing at $650{ }^{\circ} \mathrm{C}$ under a $250 \mathrm{mV}$ applied bias. 

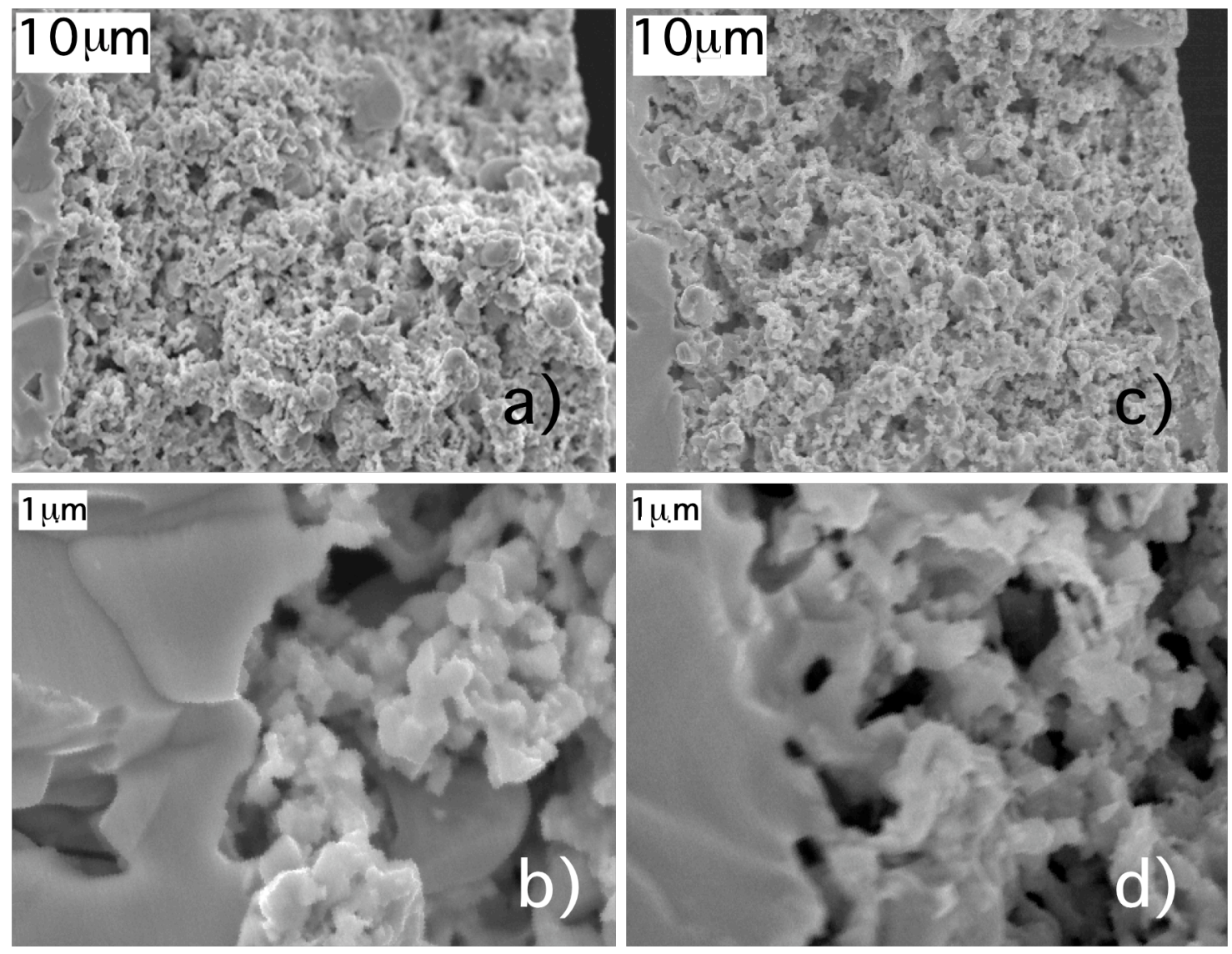

Figure 31. Cross-sectional microstructural images of silver-ESB composite electrodes, where the ESB phase was prepared from vibratory milled powders, after $48 \mathrm{~h}$ of testing at $650{ }^{\circ} \mathrm{C}$ under a $250 \mathrm{mV}$ applied bias - working electrode (a) with close-up view of the working electrode/electrolyte interface (b) and counter electrode (c) with close-up view of the counter electrode/electrolyte interface (d).

mobility in silver ${ }^{40,41}$ and, as shown earlier, the application of a bias across the cell leads to an electro-migration effect where the silver phase is dragged along in the direction of oxygen flux.

In contrast, the microstructure of the counter and working electrodes prepared with vibratory milled ESB particles after bias testing are quite comparable and no segregation of silver phase at the counter electrode/electrolyte interface is detected (Fig. 31), indicating silver phase migration was significantly suppressed by the smaller particle size. So, not only did the small ESB particles reduce initial ASR, and enhance microstructural stability with no bias, but also improved microstructural stability under bias testing.

Addition of 5 vol\% 8YSZ nano powders significantly improved unbiased electrode stability by $97 \%$, and reduced the initial, zero time ASR value by $31 \%$. Similar results were 
obtained when YSZ-free electrodes were prepared from ESB powders composed of particles hundreds of nanometers in size as opposed to electrodes prepared from ESB powders composed of micron-sized particles - the zero time ASR value was reduced by $25 \%$, and ASR vs. time slope during unbiased testing of the silver-ESB system at $650{ }^{\circ} \mathrm{C}$ was reduced by $95 \%$.

Finally, ASR vs. time slopes during testing under a $250 \mathrm{mV}$ external applied bias were lowered by $50 \%$ using the smaller ESB particles due to suppression silver phase electromigration. The stability of composite silver-ESB electrodes under an applied bias still needs some improvement. Improvements are likely with further reduction in ESB particle size down to several tens of nanometers. Also, as the operating temperature of SOFCs is reduced, the migration of the silver phase will be suppressed even further. These electrodes perform well even in the $500-550{ }^{\circ} \mathrm{C}$ range, but defect ordering in the bismuth oxide phase becomes an issue at these temperatures. Currently we are investigating ways to overcome this issue as well ${ }^{43,18}$.

\section{Summary}

Ag-ESB cermet electrodes showed good electrochemical performance. Our Ag-ESB composite cathode has an ASR of $0.18 \Omega \mathrm{cm}^{2}$ at $600{ }^{\circ} \mathrm{C}$, making it one of the lowest-resistance electrode systems reported to date and a significant improvement over that produced by Xia et. $a l^{16}$, Fig. 5, who obtained an ASR of $0.3 \Omega \mathrm{cm}^{2}$ at $600{ }^{\circ} \mathrm{C}$ for their Ag-YSB composite (our benchmark).

However, impedance studies under a bias current showed that the electrode microstructure was unstable at high bias currents at $625{ }^{\circ} \mathrm{C}$, primarily due to the electromigration of Ag along with the oxygen flux. The high oxygen solubility in Ag results in good performance of the electrode, but it also results in the lowering of the melting point of Ag and its consequent electro-migration.

Addition of 5 vol\% YSZ nano-powders significantly improved unbiased electrode stability by $97 \%$, and reduced the initial, zero time ASR value by $31 \%$. Similar results were obtained when YSZ-free electrodes were prepared from ESB powders composed of particles hundreds of nanometers in size as opposed to electrodes prepared from ESB powders composed of micron-sized particles - the zero time ASR value was reduced by $25 \%$, and ASR vs. time slope during unbiased testing of the silver-ESB system at $650{ }^{\circ} \mathrm{C}$ was reduced by $95 \%$. 
Finally, ASR vs. time slopes during testing under a $250 \mathrm{mV}$ external applied bias were lowered by $50 \%$ using the smaller ESB particles due to suppression silver phase electromigration. The stability of composite Ag-ESB electrodes under an applied bias still needs some improvement. Improvements are likely with further reduction in ESB particle size down to several tens of nanometers. Also, as the operating temperature of SOFCs is reduced, the migration of the silver phase will be suppressed even further. These electrodes perform well even in the $500-550{ }^{\circ} \mathrm{C}$ range, but defect ordering in the bismuth oxide phase becomes an issue at these temperatures. Currently, we are doing research to overcome this issue as well ${ }^{18}$. 


\section{PYROCHLORE RUTHENATE BASED CATHODES}

\section{Lead Ruthenate, $\mathrm{Pb}_{2} \mathrm{Ru}_{2} \mathrm{O}_{6.5}(\mathrm{PRO})$, Cathodes}

Pyrochlore-structured lead ruthenate $\left(\mathrm{Pb}_{2} \mathrm{Ru}_{2} \mathrm{O}_{6.5}, \mathrm{PRO}\right)$ was obtained at very low temperatures by using the direct condensation method. Figure 32 shows the diffraction patterns of the precipitate dried overnight at $80{ }^{\circ} \mathrm{C}$ and calcined at various temperatures for $6 \mathrm{~h}$. The PRO phase was observed after heating to only $400{ }^{\circ} \mathrm{C}$. The pyrochlore single phase was still observed even after a 6-hours long calcination at $900{ }^{\circ} \mathrm{C}$, without the presence of impurities. It must be emphasized that the stability of pyrochlore phase at $\mathrm{T}=900{ }^{\circ} \mathrm{C}$ is a way to obtain a better thermal stability of Ru oxides, which are volatile at high temperatures.

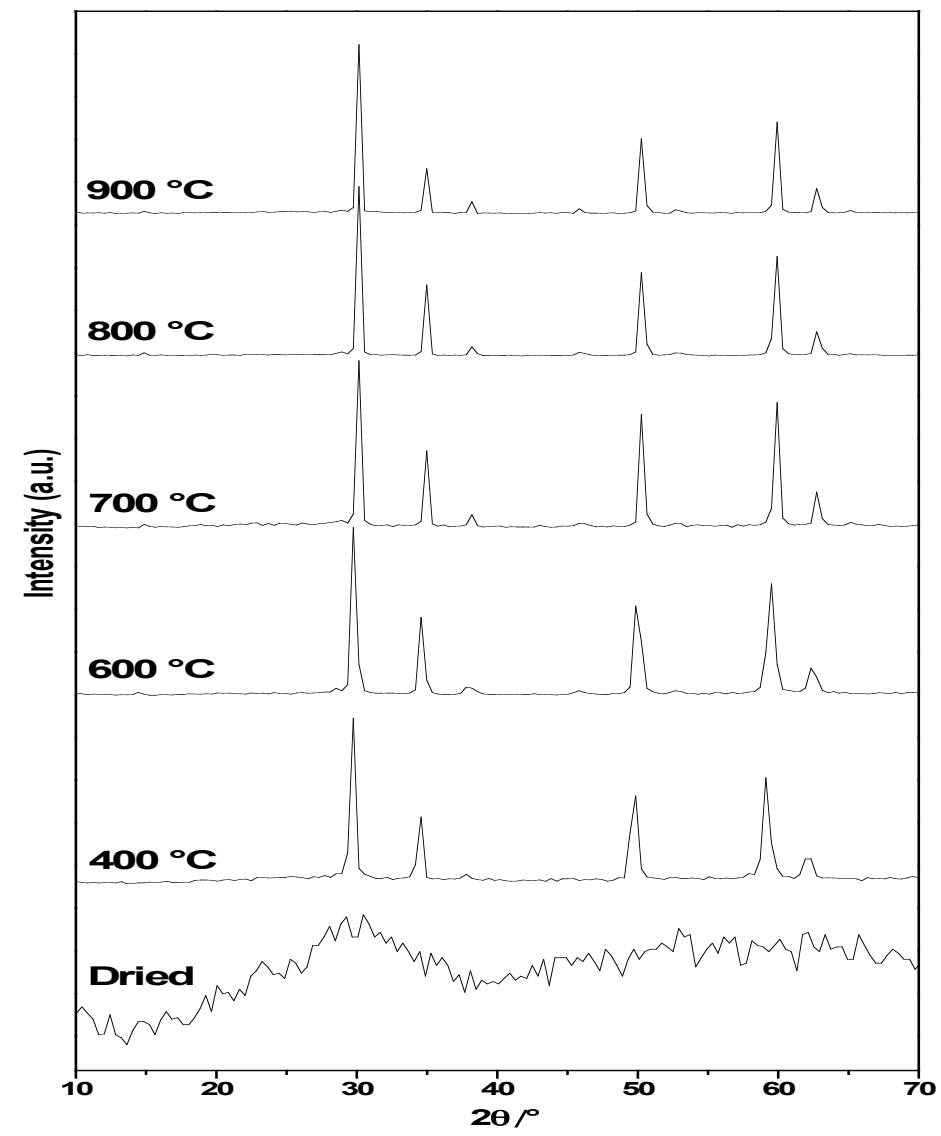

Figure 32. $\mathrm{XRD}$ patterns of $\mathrm{Pb}_{2} \mathrm{Ru}_{2} \mathrm{O}_{6.5}$ (PRO) gel precursor dried $80{ }^{\circ} \mathrm{C}$, and calcined at $400,600,700$, 800 , and $900{ }^{\circ} \mathrm{C}$ for 6 hours. 


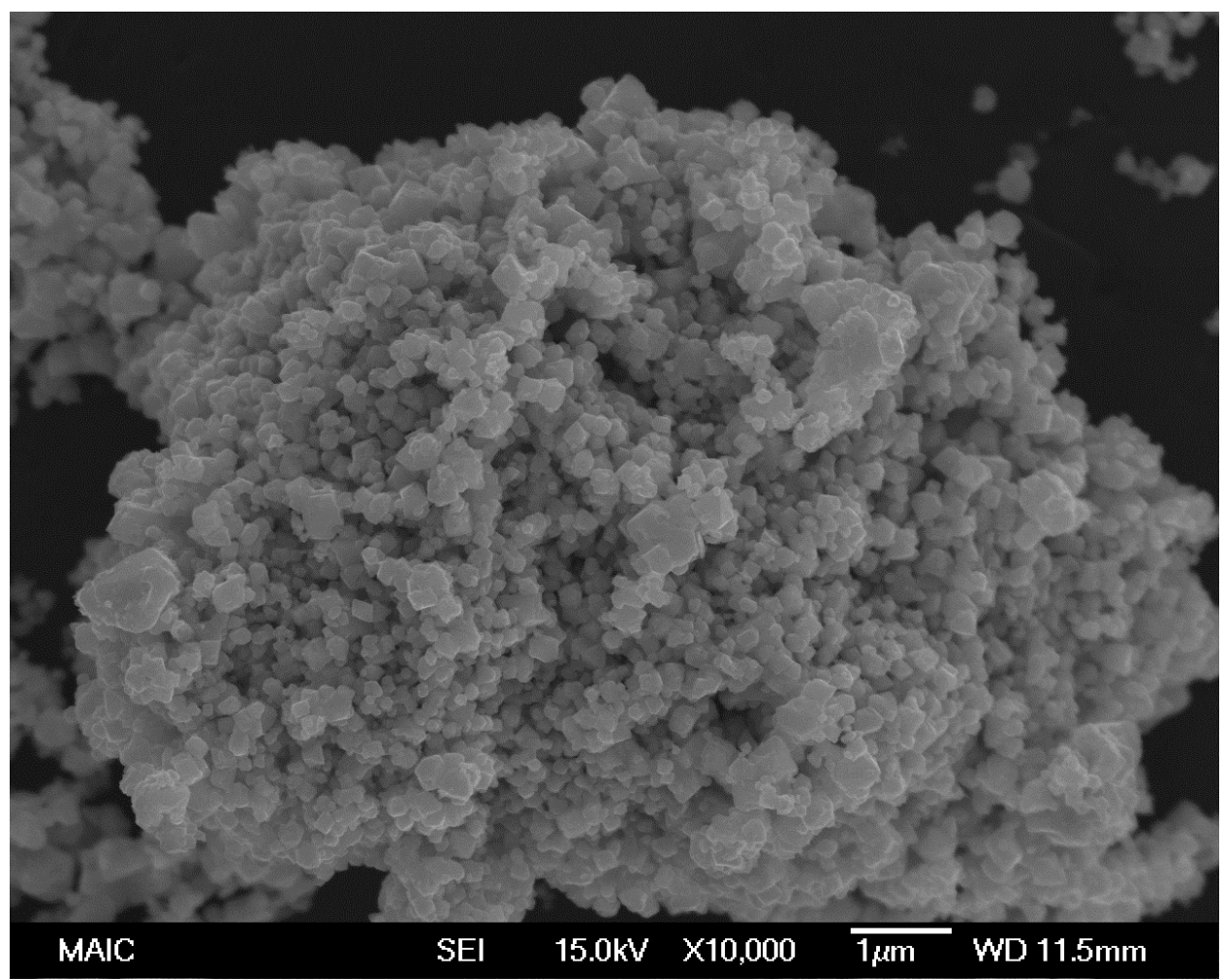

Figure 33. FE-SEM micrograph of $\mathrm{Pb}_{2} \mathrm{Ru}_{2} \mathrm{O}_{6.5}(\mathrm{PRO})$ powder prepared at $700{ }^{\circ} \mathrm{C}$ for 6 hours.

Figure 33 shows the FE-SEM of the pyrochlore calcined at $700{ }^{\circ} \mathrm{C}$ for 6 hours. The powder was made of agglomerated crystals around $50 \mathrm{~nm}$ in size. FE-SEM observations showed the presence of both isometric hexoctahedral $(4 / \mathrm{m}$ and $32 / \mathrm{m})$ and isometric hextetrahedral $(43 \mathrm{~m})$ crystals, which can be correlated with stoichiometric and defective arrangement of PRO, respectively. It was also observed that the various grains were connected to each other by sharing crystal corners ${ }^{44}$.

To determine the effect of sintering/microstructure on cathode performance, samples were prepared by screen printing PRO onto ESB disks and sintering the cathode at $700{ }^{\circ} \mathrm{C}$ (PRO700), $800{ }^{\circ} \mathrm{C}(\mathrm{PRO} 800)$ and $875^{\circ} \mathrm{C}(\mathrm{PRO} 875)$. The resulting electrodes were porous and uniform with thickness around $20 \mu \mathrm{m}$. Figures 34 and 35 show FE-SEM micrographs of lead ruthenate electrodes sintered at $700{ }^{\circ} \mathrm{C}$ and $875{ }^{\circ} \mathrm{C}$ respectively. Both thermal treatments led to an open porosity with a different degree of sintering and PRO crystal growth. The film heated to $700{ }^{\circ} \mathrm{C}$ showed that the sintering process was at its beginning stage (Fig. 34). The electrode surface obtained by the deposition was large because of both open porosity and the use of nanocrystalline pyrochlore powder. 


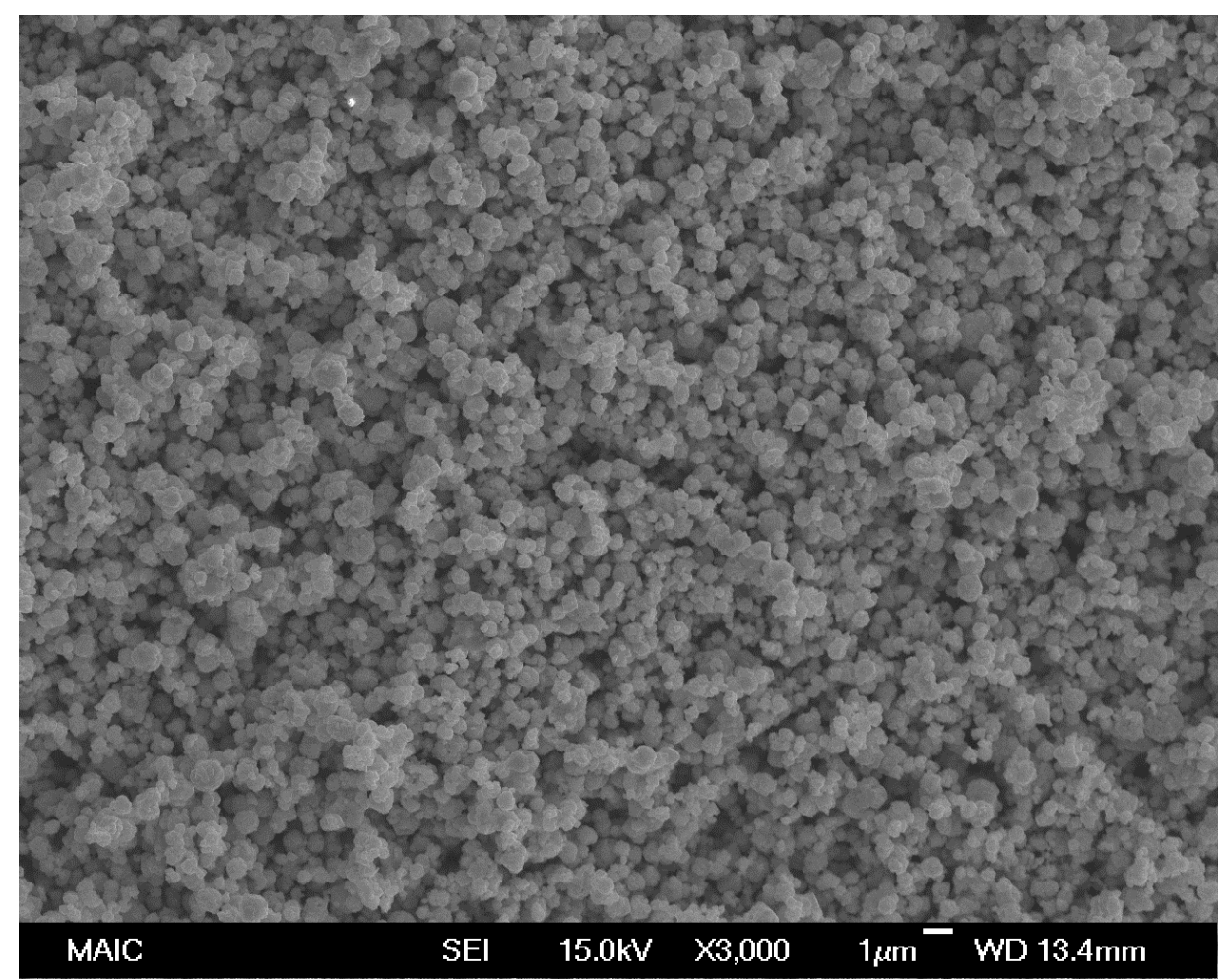

Figure 34. FE-SEM micrograph of the surface of $\mathrm{Pb}_{2} \mathrm{Ru}_{2} \mathrm{O}_{6.5}$ electrodes sintered at $700{ }^{\circ} \mathrm{C}$ for 3 hours.

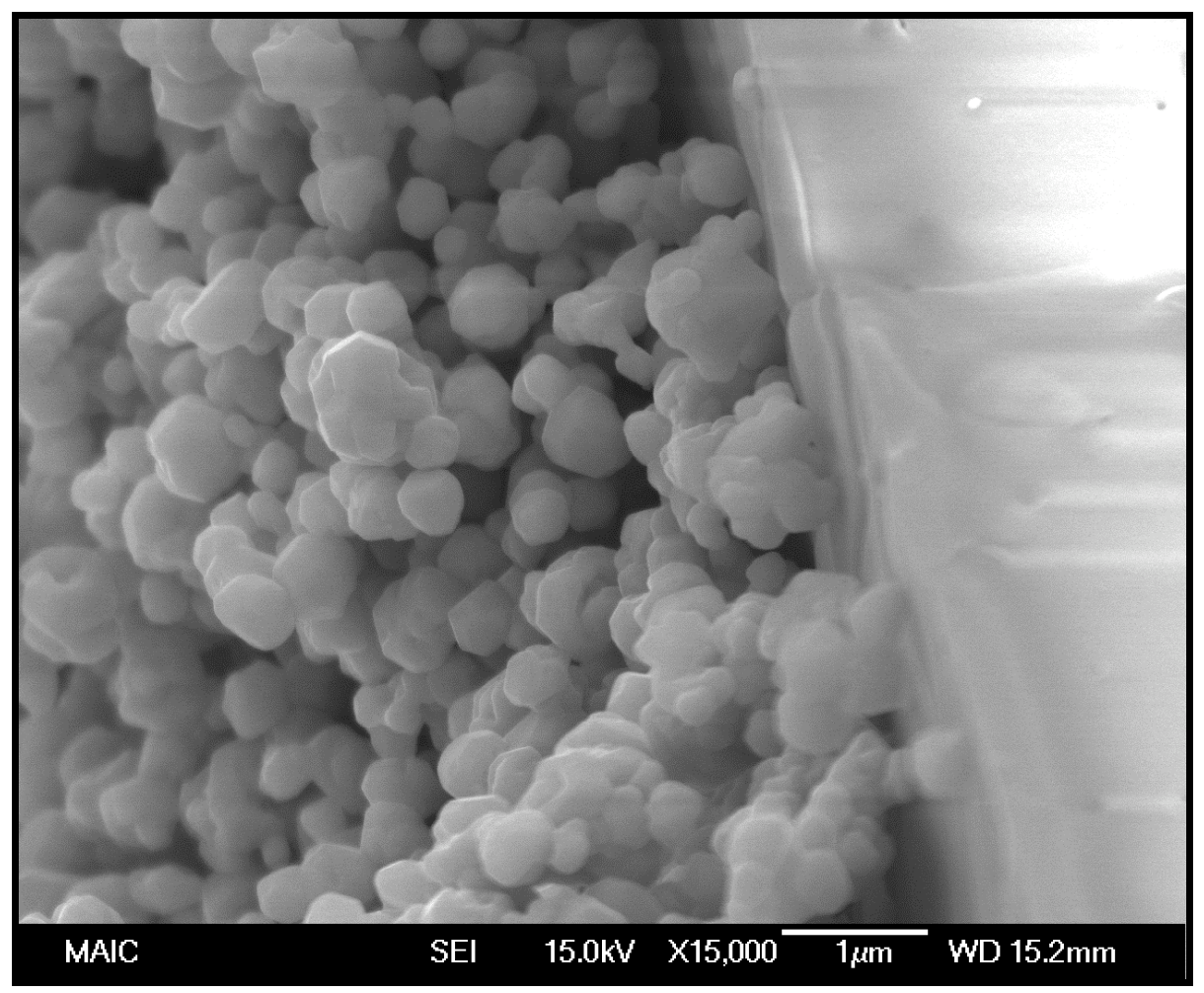

Figure 35. FE-SEM micrograph of the fractured cross-section of $\mathrm{Pb}_{2} \mathrm{Ru}_{2} \mathrm{O}_{6.5}(\mathrm{PRO})$ electrodes sintered at $875^{\circ} \mathrm{C}$ for 3 hours. 


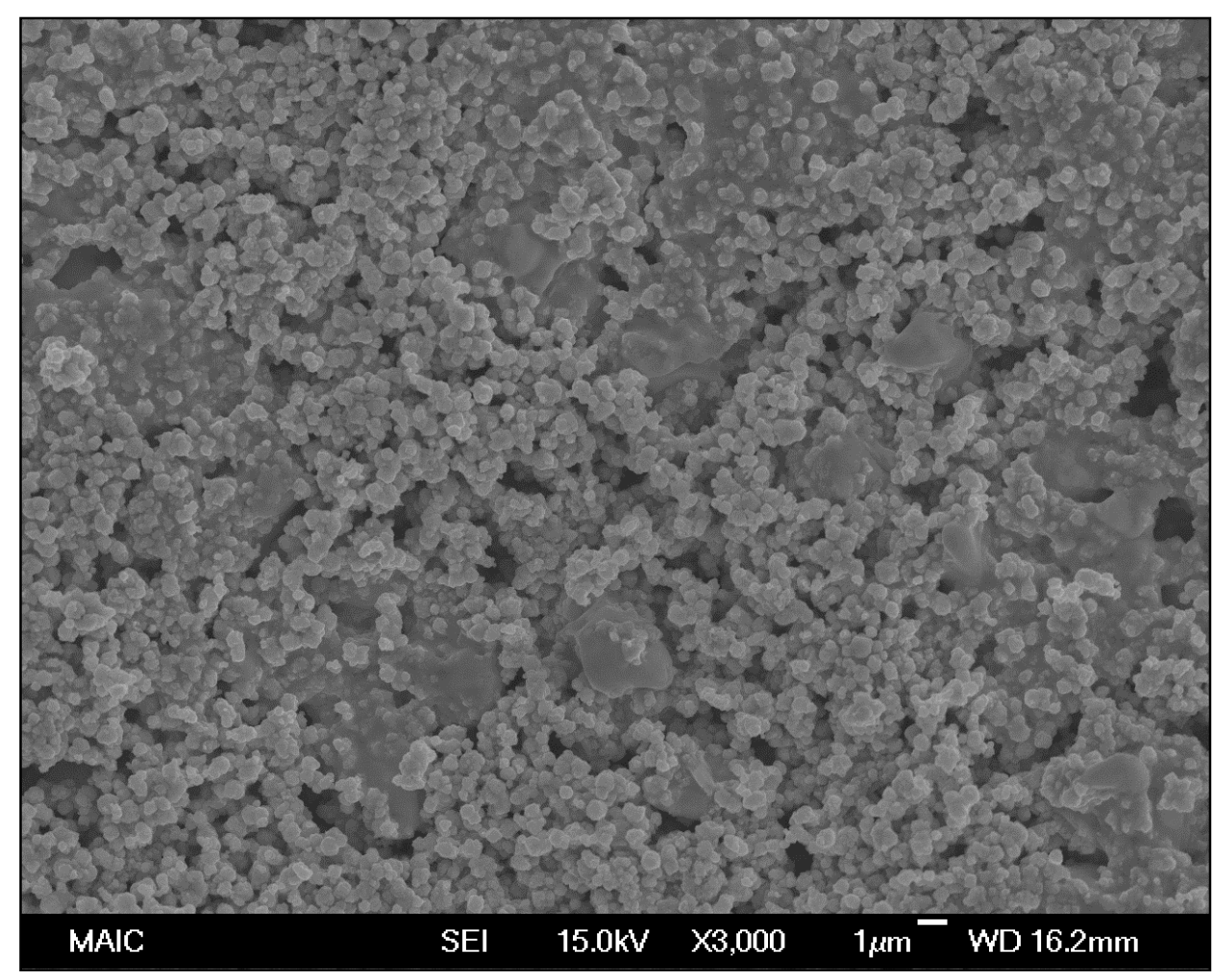

Figure 36. FE-SEM micrograph of PRO-ESB composite electrodes sintered at $800{ }^{\circ} \mathrm{C}$ for 3 hours.

Figure 35 shows the fractured cross section of at the lead ruthenate electrode at the electrolyte interface. Pyrochlore particles are well sintered and attached onto the electrolyte pellet. Lead ruthenate crystals were still submicron in size. FE-SEM observations showed that lead ruthenate particle growth increased significantly for sintering temperature around $800{ }^{\circ} \mathrm{C}$ $900{ }^{\circ} \mathrm{C}$ to reach grain size of about $1 \mu \mathrm{m}$.

Composite PRO-ESB cathodes were prepared by screen-printing a 50 vol\% PRO-ESB slurry on ESB disks which were then sintered at $700{ }^{\circ} \mathrm{C}$ (PRO-ESB700) and $800{ }^{\circ} \mathrm{C}$ (PROESB800) for 3 hours each. Figure 36 shows the FE-SEM micrograph of the composite electrodes prepared. The formation of a glassy phase was detected (as earlier for composite PRO-ESB electrodes sintered at $700^{\circ} \mathrm{C}$ ). EDS analysis confirmed the presence of $\mathrm{Bi}, \mathrm{Pb}$ and $\mathrm{Ru}$ in the glassy regions. The formation of this glassy phase can be explained by reaction of $\mathrm{Bi}$ oxide and $\mathrm{Pb}$ oxide forming a eutectic phase ${ }^{45}$. The occurrence of this reaction between ESB and lead ruthenate required keeping the composite electrode sintering temperature below $800{ }^{\circ} \mathrm{C}$. The formation of this phase can occur also at the interface between the pyrochlore electrodes and 
the ESB electrolyte. The presence of this additional phase can lead to a decrease in the TPB length for the composite electrodes.

Electrochemical impedance spectroscopy (EIS) analysis was used to study the electrochemical properties of both $\mathrm{PRO} / \mathrm{ESB} / \mathrm{PRO}$ and PRO-ESB/ESB/PRO-ESB symmetric cells. Two different temperature ranges were used to characterize symmetric cells. EIS analysis at low temperatures $\left(\mathrm{T}<400{ }^{\circ} \mathrm{C}\right)$, for high cell component resistance values $(\mathrm{R}>1 \mathrm{k} \Omega)$, enables to resolve electrolyte and interfacial impedance elements ${ }^{46}$; EIS analysis at high temperatures ( $\mathrm{T}$ $>500^{\circ} \mathrm{C}$ ), close to SOFC operating temperatures, gives information about total cell resistance (R $<1 \mathrm{k} \Omega$ ) and electrode polarization impedance ${ }^{47}$. EIS analysis at low frequencies and at high $\mathrm{T}$, is particularly interesting because it gives information on the impedance values correlated with chemical-physical processes, such as gas sorption-desorption and gas ionization ${ }^{47}$. Finite and infinite Warburg elements are the physical models applicable to the electrode polarization ${ }^{48}$. Voigt elements and/or resistance in parallel with constant phase elements (CPE) represent electrolyte charge transfer. Typical electrolyte capacitances values are around $10^{-9} \mathrm{~F}$ and they can be appraised from the $\mathrm{CPE}^{48}$.

Figure 37a shows the impedance plot and fitting of the PRO/ESB/PRO cell sintered at $700{ }^{\circ} \mathrm{C}$ for 6 hours (PRO700), measured at $300{ }^{\circ} \mathrm{C}$ in air, while Fig. $37 \mathrm{~b}$ shows detail at the low frequency range $(100 \mathrm{~Hz}-0.1 \mathrm{~Hz})$. One can observe a depressed semicircle, which can be related to the ESB electrolyte impedance contribution and the line for low frequencies is related to the electrode polarization. Only a single depressed semicircle was fitted and no other impedance contributions were measured at intermediate frequencies ${ }^{47}$. Electrode polarization (Fig. 37b) can be fitted by an infinite Warburg element. Ionic transfer at the TBP is influenced by the metallic nature of the electrodes, which are basically blocking because of the different nature of the charge carriers with respect to the ionic conducting electrolyte. Moreover, low thermal energy limits oxygen redox processes at the electrodes leading to the increment of the Nernst charge layers at low frequencies.

Figure 38a shows the impedance plot and fitting of the PRO/ESB/PRO cell sintered at $875^{\circ} \mathrm{C}$ for 6 hours (PRO875), measured at $350{ }^{\circ} \mathrm{C}$ in air, while Fig. 38b shows detail at the low frequency range $(100 \mathrm{~Hz}-0.1 \mathrm{~Hz})$. The measured EIS plot was similar to that observed for the cell using pyrochlore electrodes sintered at lower temperature. Higher sintering temperature 

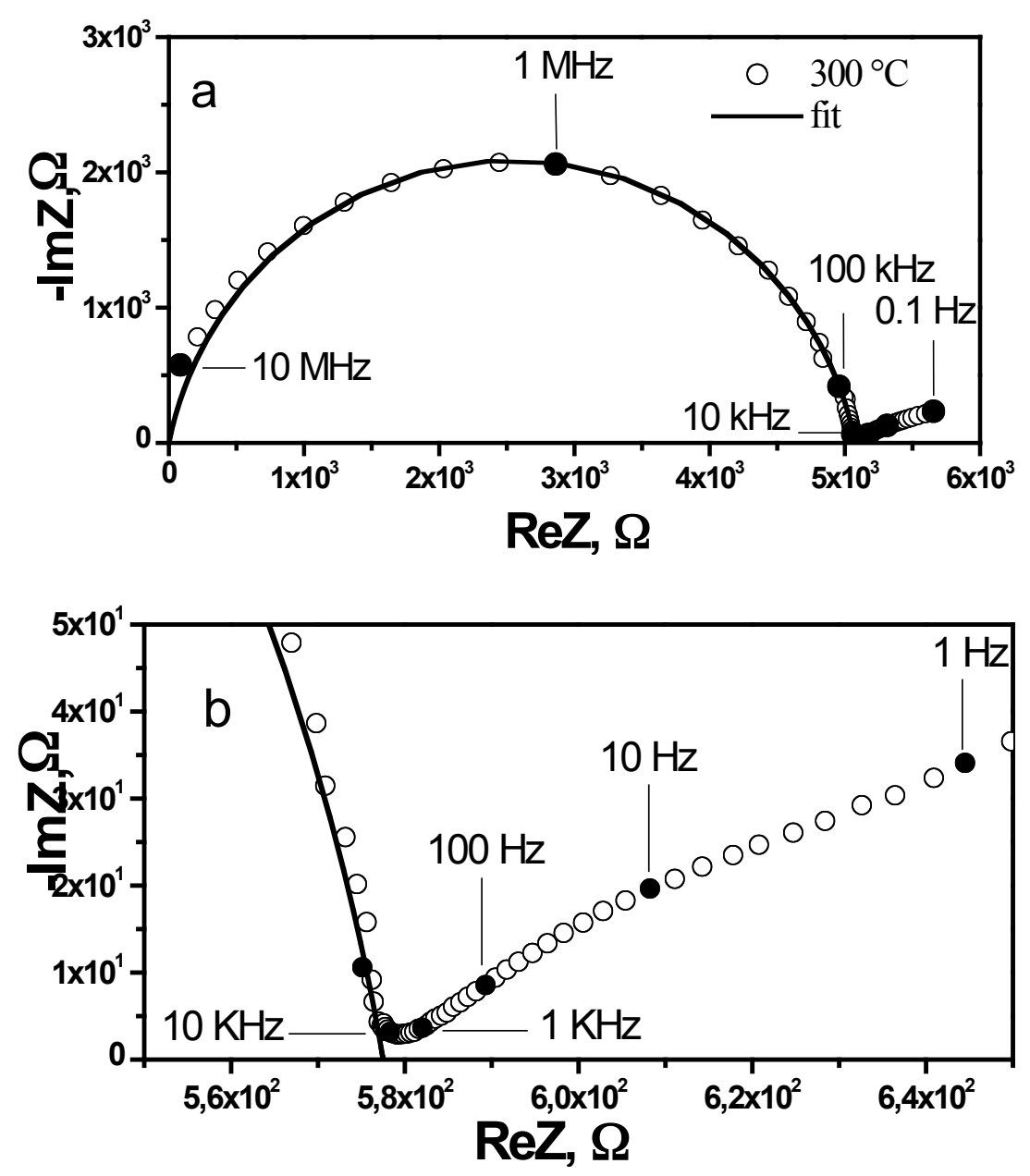

Figure 37. Complex impedance plot of PRO700 sample, measured at $300{ }^{\circ} \mathrm{C}$ in air (a); detail at low frequencies (b).

apparently did not change the equivalent circuit related to the symmetric cell. Nevertheless, a lower electrode polarization (Fig. 38b) contribution was measured at $0.1 \mathrm{~Hz}$ with respect to that observed for the PRO700 sample, showing a better performance.

Figures 39 and 40 show the impedance plots of PRO875 sample, measured in air at selected temperatures between $550{ }^{\circ} \mathrm{C}$ and $780{ }^{\circ} \mathrm{C}$. For temperatures above $500{ }^{\circ} \mathrm{C}$, the equivalent circuit related to the total impedance of the cell can be still related to a R//CPE in series to Warburg elements. The resistance of the R//CPE element is defined as Ohmic resistance $\mathrm{R}_{\mathrm{Ohmic}}{ }^{47}$. Figures 39 and 40 point out the variation of the capacitive polarization contribution from intermediate temperature $\left(550^{\circ} \mathrm{C}\right)$ to high temperature $\left(780^{\circ} \mathrm{C}\right)$. In fact, it can be observed that capacitance, resulting in blocking effect, of the PRO electrodes decreased with 

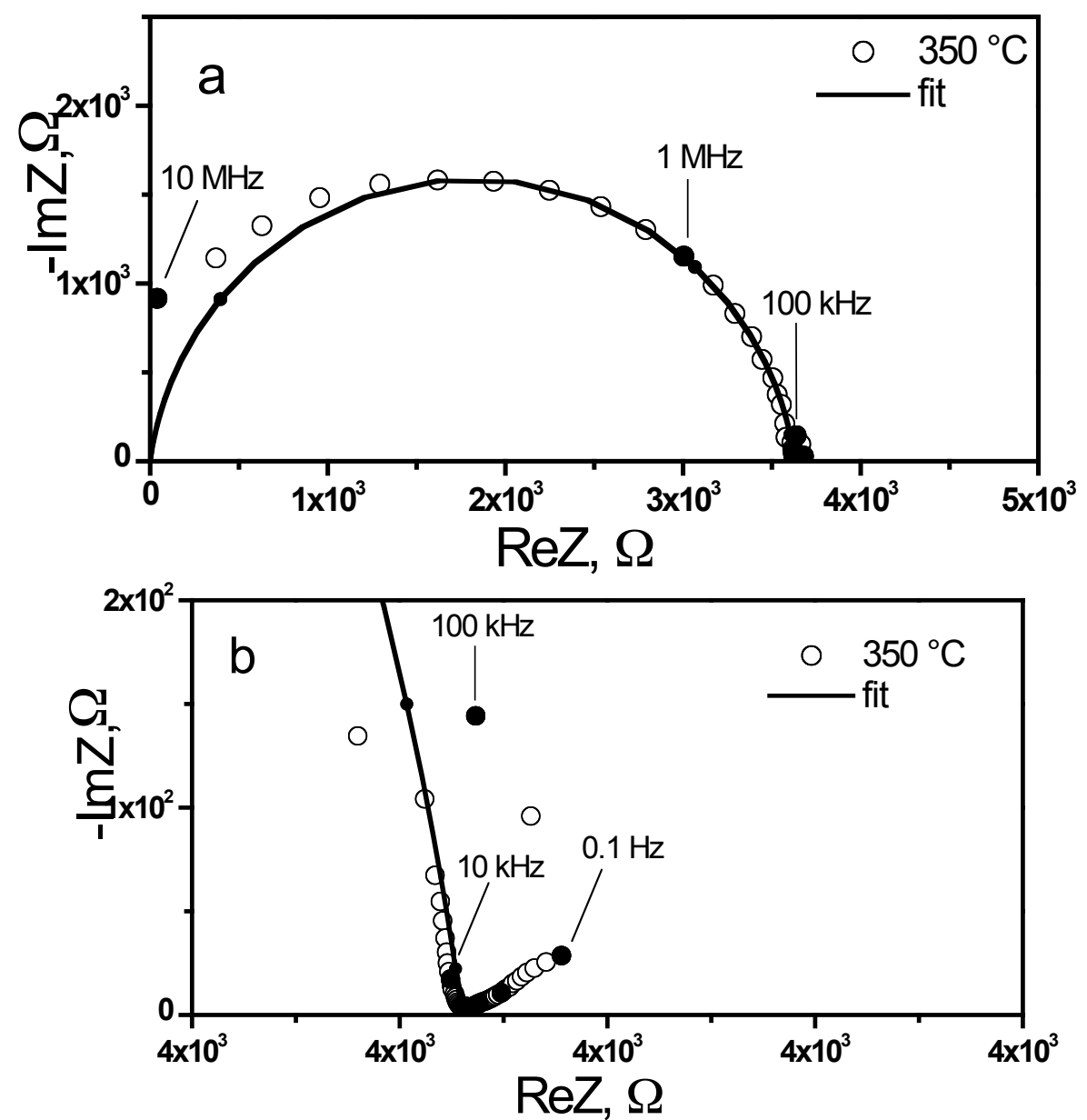

Figure 38. Complex impedance plot of PRO875 sample, measured at $350{ }^{\circ} \mathrm{C}$ in air (a); detail at low frequencies (b).

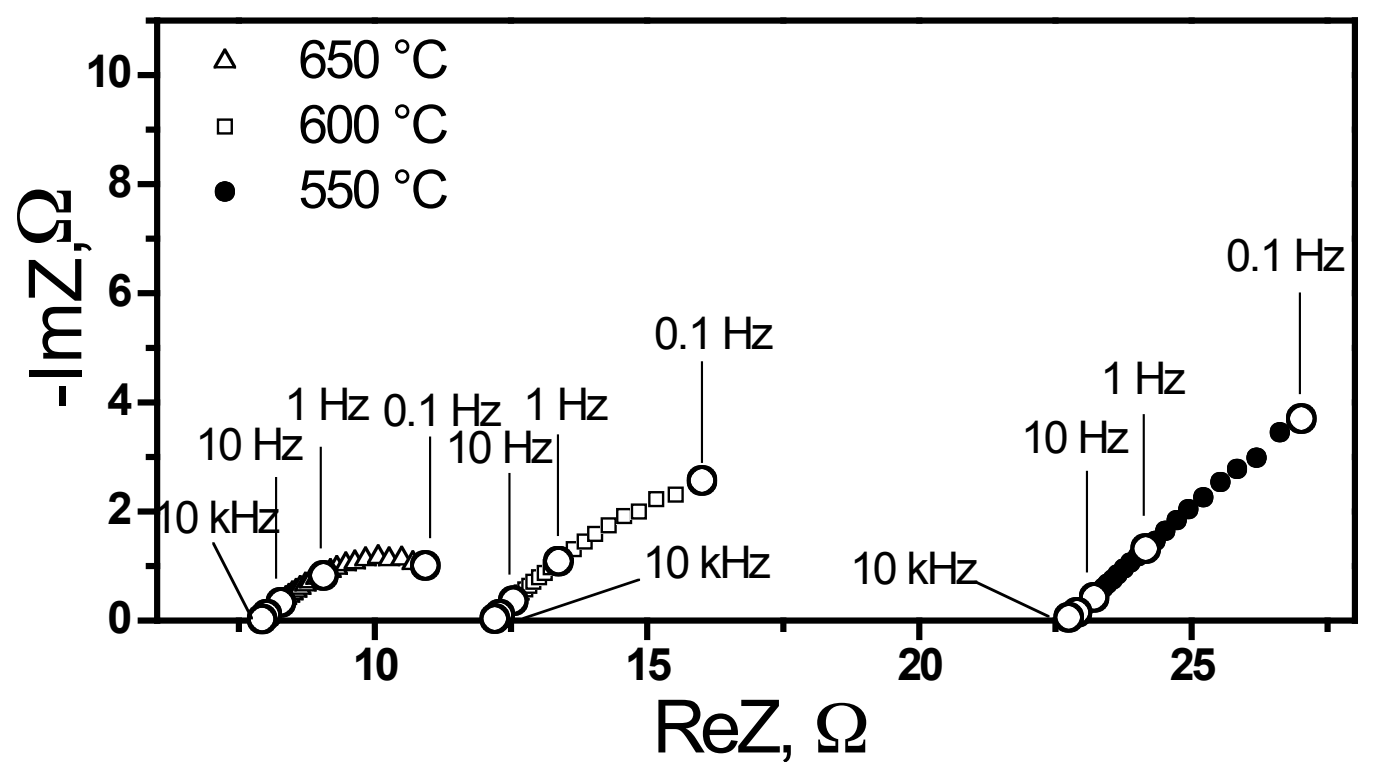

Figure 39. Complex impedance plots of PRO875 sample, measured at 550,600 and $650{ }^{\circ} \mathrm{C}$ in air. 


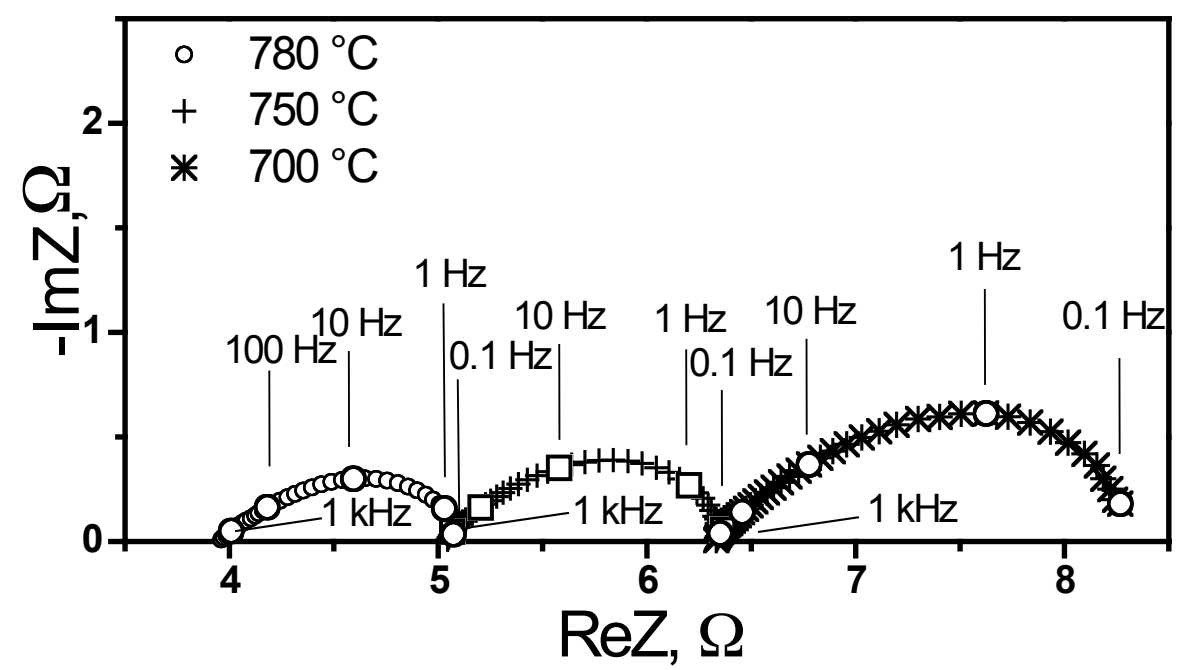

Figure 40. Complex impedance plots of PRO875 sample, measured at 700,750 and $780{ }^{\circ} \mathrm{C}$ in air.

increasing the temperature. At temperatures around $700{ }^{\circ} \mathrm{C}$ and above, the electrodes can be modelled as finite Warburg elements ${ }^{48}$. In ruthenate based electrodes, temperature controls the electrode polarization and the electrochemical activity for oxygen reduction reaction. Such different electrochemical behaviour at high $\mathrm{T}$ is a consequence of a discharging of the cell at the TPB that can be described by Eq. (1) where electrolyte oxygen vacancies, electrons from the electrodes, and adsorbed oxygen are the reactant species in the TPB region.

Figure 41 shows the comparison between impedance plots of the PRO samples sintered at the selected temperatures, measured at $650{ }^{\circ} \mathrm{C}$ in air. The observed shift in the high frequency intercept is primarily due to differences in the sample geometry. However, different sintering temperatures lead to different electrode polarization effects. For lower sintering temperatures $\left(700^{\circ} \mathrm{C}\right)$, the electrodes were blocking (polarization was fitted by a line) so extrapolation to the low frequency intercept was not possible. In contrast, a non-blocking electrode behaviour was observed for higher sintering temperatures $\left(800\right.$ and $\left.875^{\circ} \mathrm{C}\right)$ as consequence of better connection and contact between electrode particles and the electrolyte surface.

For the cells with composite electrodes EIS plots measured at low $\mathrm{T}\left(\mathrm{T}<500{ }^{\circ} \mathrm{C}\right)$, showed results similar to those observed for the samples of the PRO series. The single semi arc at high frequencies was related to the ionic conduction through the ESB electrolyte. No interfacial contribution were detected by EIS at intermediate frequencies and the polarization at 


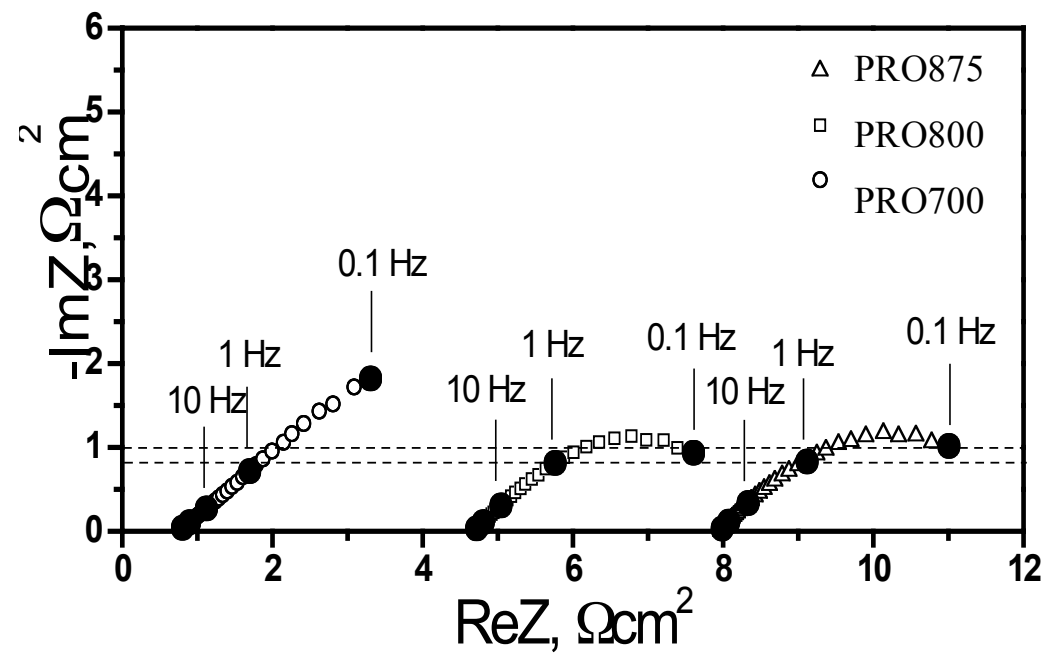

Figure 41. Complex impedance plot of PRO700, PRO800 and PRO875 samples, at $650{ }^{\circ} \mathrm{C}$ in air.

low frequencies can be associated to a infinite Warburg element. Moreover, all these features are common to both sintering thermal treatments at $700{ }^{\circ} \mathrm{C}$ and $800{ }^{\circ} \mathrm{C}$.

Figure 42 shows the impedance plots of the PRO-ESB800 sample measured at $700{ }^{\circ} \mathrm{C}$ and $750{ }^{\circ} \mathrm{C}$ in air. For non-blocking electrode behavior, chemical and ohmic resistances $\left(\mathrm{R}_{\text {chem }}\right.$ and $\mathrm{R}_{\mathrm{ohmic}}$ ) can be defined as the low and high frequency real axis intercepts, respectively, from complex impedance plots ${ }^{47}$. $\mathrm{R}_{\text {chem }}$ values were fitted by the finite Warburg model while $\mathrm{R}_{\text {ohmic }}$ is essentially the ESB electrolyte resistance.

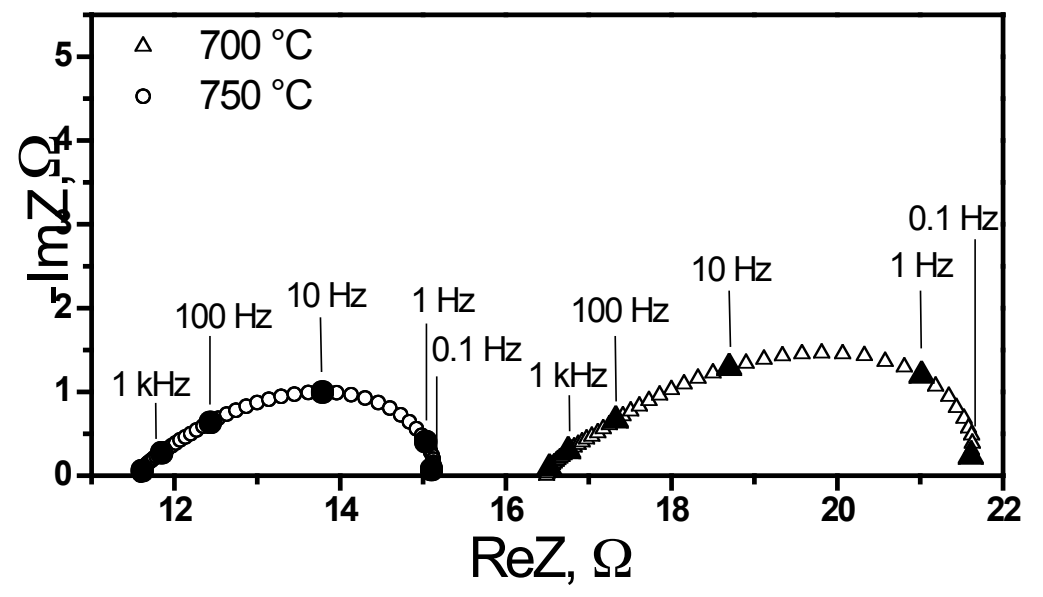

Figure 42. Complex impedance plot of PRO-ESB800 sample, measured at 700 and $750{ }^{\circ} \mathrm{C}$ in air. 


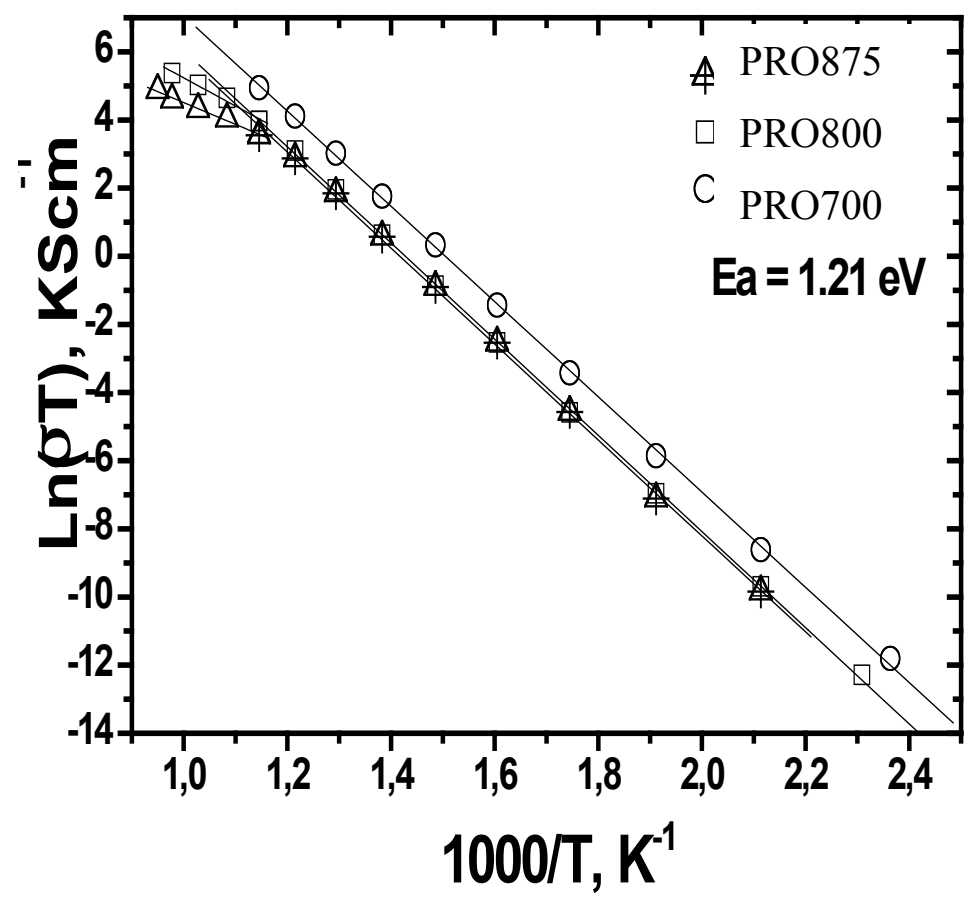

Figure 43. Arrhenius plots of $\mathrm{R}_{\text {Ohmic }}$ for PRO700, PRO800 and PRO875 samples.

Figure 43 shows the Arrhenius plot for the series of PRO samples. $\mathrm{R}_{\text {ohmic }}$ values were normalized to the geometrical parameters of the cells to evaluate conductivity of the samples. Two activation energies were observed for two different temperature ranges. For temperatures around $600{ }^{\circ} \mathrm{C}$ and below, $\mathrm{R}_{\text {Ohmic }}$ values lead to $\mathrm{E}_{\mathrm{a}}=1.18-1.21 \mathrm{eV}$. For temperatures $>600{ }^{\circ} \mathrm{C}$, the $E_{a}$ is $0.5-0.6 \mathrm{eV}$. The presence of two different activation energies in the ESB ionic conduction is attributed to a disorder-order transition of the vacancies in the fluoritic $\delta-\mathrm{Bi}_{2} \mathrm{O}_{3}$ lattice $^{32}$. Measured conductivity values and activation energies of ESB were found to be in agreement with the values reported in the literature ${ }^{32}$.

Electrode polarization is related to the cell area specific resistance (ASR), Eq. (2) and low values of ASR are desirable in SOFC cathode performance because they lead to lower electrode polarization. In SOFCs, the ASR parameter is directly dependent on the rate limiting step of the electrochemical processes involved in the oxygen reduction reaction at the cathode ${ }^{49}$.

Figure 44 shows the Arrhenius plot of the ASR values collected for the PRO800 and PRO875 samples and for the PRO-ESB700 and PRO-ESB800 samples. PRO800 showed the lowest ASR values. For this sample, the combination of lead ruthenate as electrodes and ESB as electrolyte led to ASR $=0.41 \Omega \mathrm{cm}^{2}$ at $750{ }^{\circ} \mathrm{C}$. Unexpectedly, larger ASR values were found for 


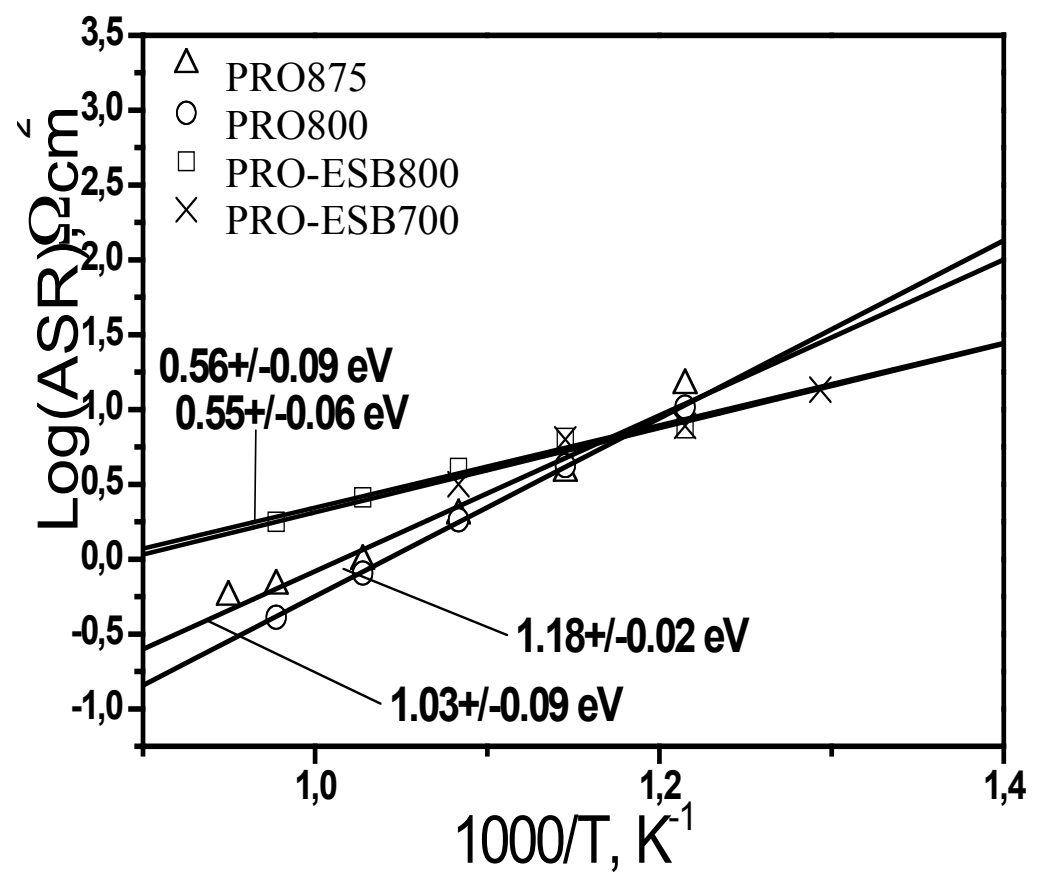

Figure 44. ASR Arrhenius plots of $\mathrm{R}_{\text {chem }}$ for PRO800, PRO875, PRO-ESB700 and PRO-ESB800 samples.

PRO-ESB samples at higher temperature: ASR for the PRO-ESB800 sample measured at $750{ }^{\circ} \mathrm{C}$ was estimated to be $\sim 1.70 \Omega \mathrm{cm}^{2}$. The best performance was found for thermal treatment around $800{ }^{\circ} \mathrm{C}$ in both PRO and PRO-ESB samples. ASR values for the PRO700 sample were not evaluated because of its electrode-blocking behaviour in the whole operating temperatures range.

Figure 44 also shows that for temperatures below $600{ }^{\circ} \mathrm{C}$ (lines intercept at 1000/T=1.15), the PRO-ESB700 and PRO-ESB800 samples had ASR values lower than the PRO800, PRO875 samples. These values are around $7 \Omega \mathrm{cm}^{2}$. These lower ASR values pointed out the role of ionic conduction in the electrode polarization.

Two different $R_{\text {chem }}$ activation energy values are observed (Fig. 44). For composite electrodes $\mathrm{E}_{\mathrm{a}}$ is around $0.5 \mathrm{eV}$ and for PRO samples an activation energy around $1 \mathrm{eV}$ is observed. This behavior can be explained in terms of $\mathrm{R}_{\text {chem }}$ limited by reaction at the TPB for the PRO samples vs. limited by solid state transport for the PRO-ESB samples. The electronic conductivity of lead ruthenates being much greater than the ionic conductivity of ESB.

Tests were performed to evaluate the reactivity between PRO, ESB and $\mathrm{RuO}_{2}$ by sintering at $850{ }^{\circ} \mathrm{C}$. During electrode fabrication, it was observed that PRO and ESB react at 


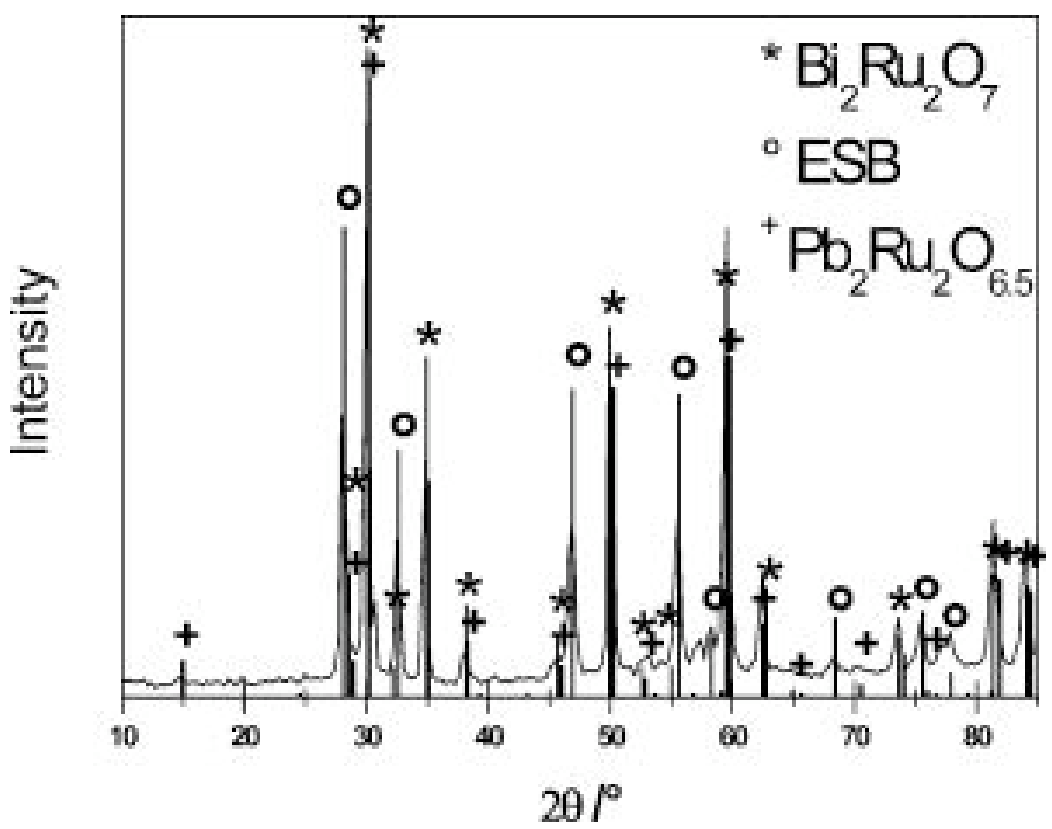

Figure 45. $\mathrm{XRD}$ patterns of $\mathrm{Pb}_{2} \mathrm{Ru}_{2} \mathrm{O}_{6.5}$-ESB (molar ratio $1: 1$ ) sintered at $850{ }^{\circ} \mathrm{C}$ for 12 hours.

intermediate temperature. In fact, for symmetrical cells heated at $600{ }^{\circ} \mathrm{C}$ and above, a black thin coating was observed on the ESB electrolyte pellets coming from the lead ruthenate electrodes. Thermal treatment at higher temperatures $\left(850^{\circ} \mathrm{C}\right)$ led to the possible formation of new phases. Figure 45 shows the XRD pattern of an ESB-PRO composite in 1:1 molar ratio sintered at 850 ${ }^{\circ} \mathrm{C}$ for 12 hours. Strong ESB peaks remain in the diffraction pattern and a generic pyrochlore structure diffraction pattern is also revealed. Bismuth ruthenate can be matched from the diffraction pattern but such a diffraction pattern could also be attributed to a generic solid solution of $\mathrm{Pb}, \mathrm{Bi}$ and Er ruthenates, while noise in the background may relate to intermediate bismuth based compounds formed during the sintering. $\mathrm{Bi}_{2} \mathrm{O}_{3}-\mathrm{PbO}$ phase diagram indicates that some low melting glassy compounds are possible ${ }^{45}$.

ESB-PRO- $\mathrm{RuO}_{2}\left(\right.$ molar ratio 4:1:8) and $\mathrm{ESB}-\mathrm{RuO}_{2}$ (molar ratio 1:3) composites sintered at $850{ }^{\circ} \mathrm{C}$ for 12 hours were analyzed by $\mathrm{XRD}$ and showed similar results. Bismuth ruthenate $\mathrm{Bi}_{2} \mathrm{Ru}_{2} \mathrm{O}_{7}$ was detected with these composites. However, since bismuth ruthenate is also considered a promising material for cathodic application for IT-SOFCs, its presence at the electrode/electrolyte interface does not give an additional resistive contribution. 


\section{Yttrium Ruthenate, $\mathrm{Y}_{2} \mathrm{Ru}_{2} \mathrm{O}_{7}(\mathrm{YRO})$, Cathodes}

$\mathrm{Y}_{2} \mathrm{Ru}_{2} \mathrm{O}_{7}$ was evaluated as a possible candidate for IT-SOFC because of its stability in a wide range of temperatures. For example, it exhibits a lack of reactivity in contact with gadolinium-doped ceria (GDC) electrolyte, in contrast to $\mathrm{Bi}_{2} \mathrm{Ru}_{2} \mathrm{O}_{7}$ and $\mathrm{Pb}_{2} \mathrm{Ru}_{2} \mathrm{O}_{6.5}$ powders ${ }^{50,51}$. However, $\mathrm{Y}_{2} \mathrm{Ru}_{2} \mathrm{O}_{7}$ is a semiconductor, which makes it less amenable as a cathodic material at low temperatures.

In order to increase the electrical conductivity, Pr was chosen as the A-site dopant. It has been hypothesized that the electrical conductivity is enhanced by the multivalent character of $\operatorname{Pr}$, which would allow the formation of additional holes, and increase its charge-carrying capacity. The following hypothetical mechanism shows the change of oxidation state of Pr allowing the oxygen incorporation into the cathodic surface.

$$
\begin{gathered}
2 \mathrm{Pr}_{\mathrm{Y}}^{\times}+2 \mathrm{~h}^{\bullet} \rightarrow 2 \operatorname{Pr}_{\mathrm{Y}}^{\bullet} \\
\frac{1}{2} \mathrm{O}_{2}+\mathrm{V}_{\mathrm{O}}^{\bullet \bullet} \rightarrow \mathrm{O}_{\mathrm{O}}^{\times}+2 \mathrm{~h}^{\bullet} \\
\frac{1}{2} \mathrm{O}_{2}+\mathrm{V}_{\mathrm{O}}^{\bullet \bullet}+2 \mathrm{Pr}_{\mathrm{Y}}^{\times} \rightarrow 2 \operatorname{Pr}_{\mathrm{Y}}^{\bullet}+\mathrm{O}_{\mathrm{O}}^{\mathrm{x}}
\end{gathered}
$$

Nanocrystalline powders of $\mathrm{Y}_{2} \mathrm{Ru}_{2} \mathrm{O}_{7}$ and $\mathrm{Y}_{2-\mathrm{x}} \mathrm{Pr}_{\mathrm{x}} \mathrm{Ru}_{2} \mathrm{O}_{7}$ were synthesized and characterized as an electrode on ESB electrolytes at temperatures of $300-700^{\circ} \mathrm{C}$. A comparison of their electrochemical performance is presented.

Figure 46 shows the $\mathrm{X}$-ray diffraction patterns of $\mathrm{Y}_{2} \mathrm{Ru}_{2} \mathrm{O}_{7}$ and $\mathrm{Y}_{2-\mathrm{x}} \mathrm{Pr}_{\mathrm{x}} \mathrm{Ru}_{2} \mathrm{O}_{7}$ powders after crystallization at $1050^{\circ} \mathrm{C}$; the formation of the single pyrochlore cubic phase for both the un-doped and doped powders was observed. Figure 47 shows the FE-SEM micrograph of the same powders, showing a mean particle size of about $100 \mathrm{~nm}$, and the SEM-EDS measurements, shown in Fig. 48, confirmed the presence of the dopant in the final product. Since the electrochemical activity of a cathode depends on the reaction area where three-phase boundaries (TPBs) of air (pore)/cathode/electrolyte are in contact, expanding the length of TPB in a cathode is crucial for IT-SOFCs. Therefore, the obtained nanocrystalline size seems very promising for the TPB tailoring to reduce power loss. 


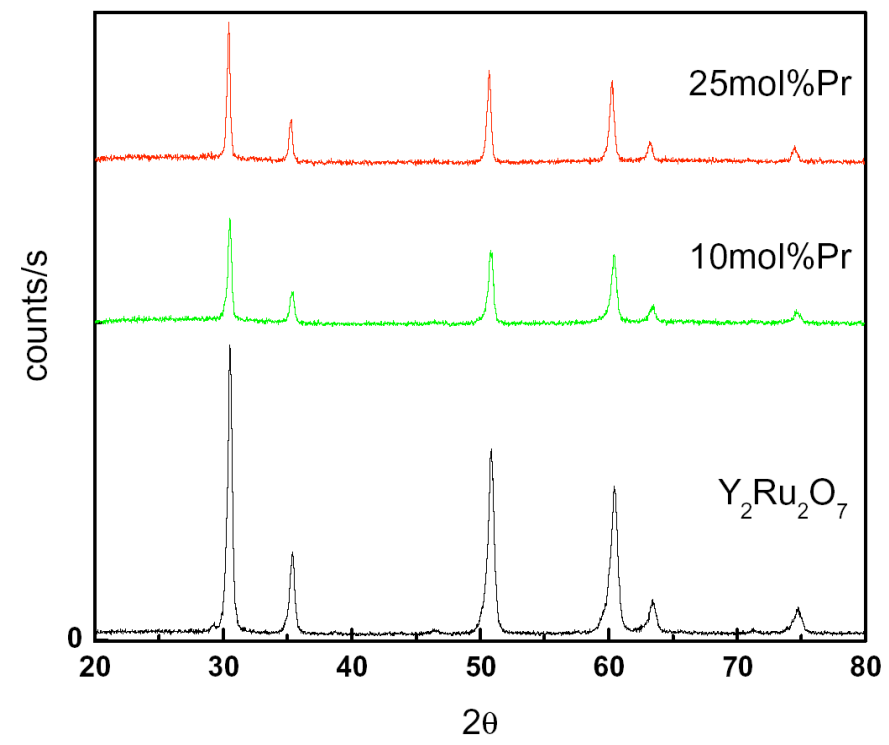

Figure 46. $\mathrm{XRD}$ pattern of $\mathrm{Y}_{1-\mathrm{x}} \mathrm{Pr}_{\mathrm{x}} \mathrm{Ru}_{2} \mathrm{O}_{7}$ powders after crystallization at $1050^{\circ} \mathrm{C}$.
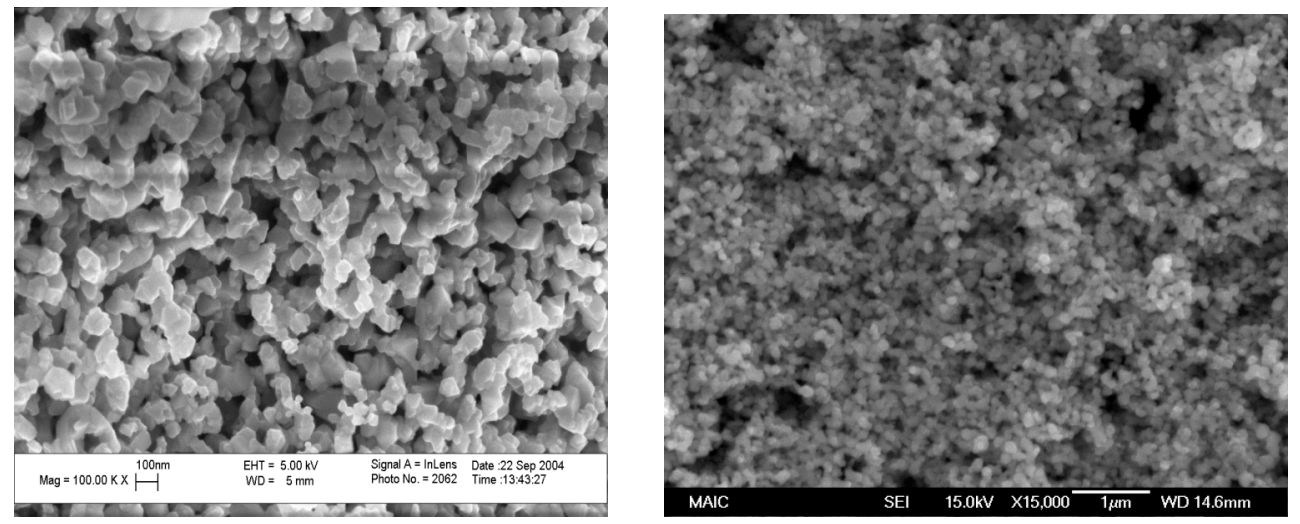

Figure 47. FE-SEM image of (a) $\mathrm{Y}_{2} \mathrm{Ru}_{2} \mathrm{O}_{7}$ after crystallization at $1050^{\circ} \mathrm{C}$ and (b) $\mathrm{Y}_{1.8} \mathrm{Pr}_{0.2} \mathrm{Ru}_{2} \mathrm{O}_{7}$ after crystallization at $1050^{\circ} \mathrm{C}$.

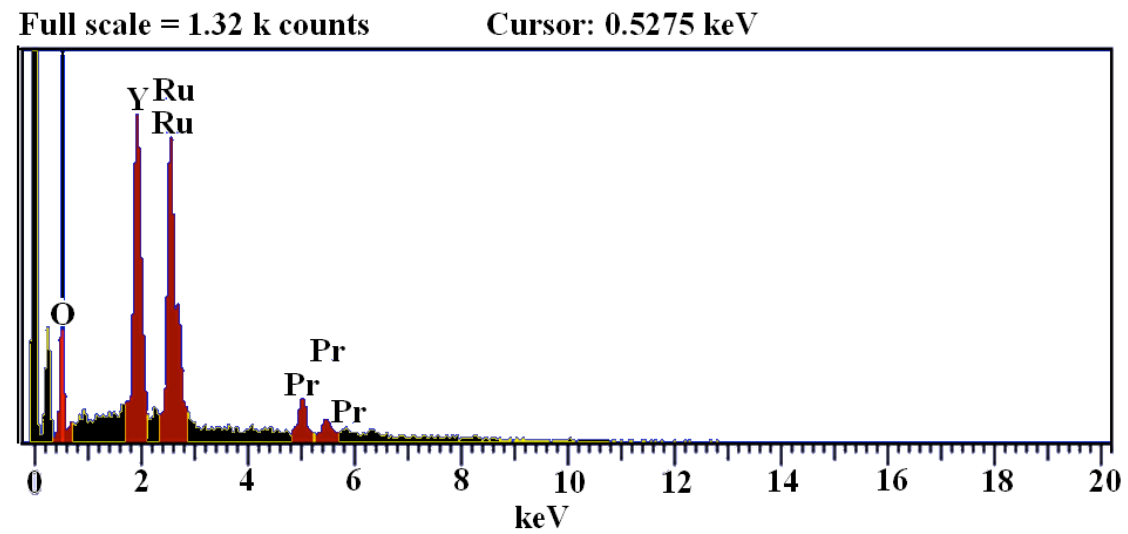

Figure 48. SEM-EDS image of the Pr-doped pyrochlore powder after crystallization at $1050^{\circ} \mathrm{C}$. 


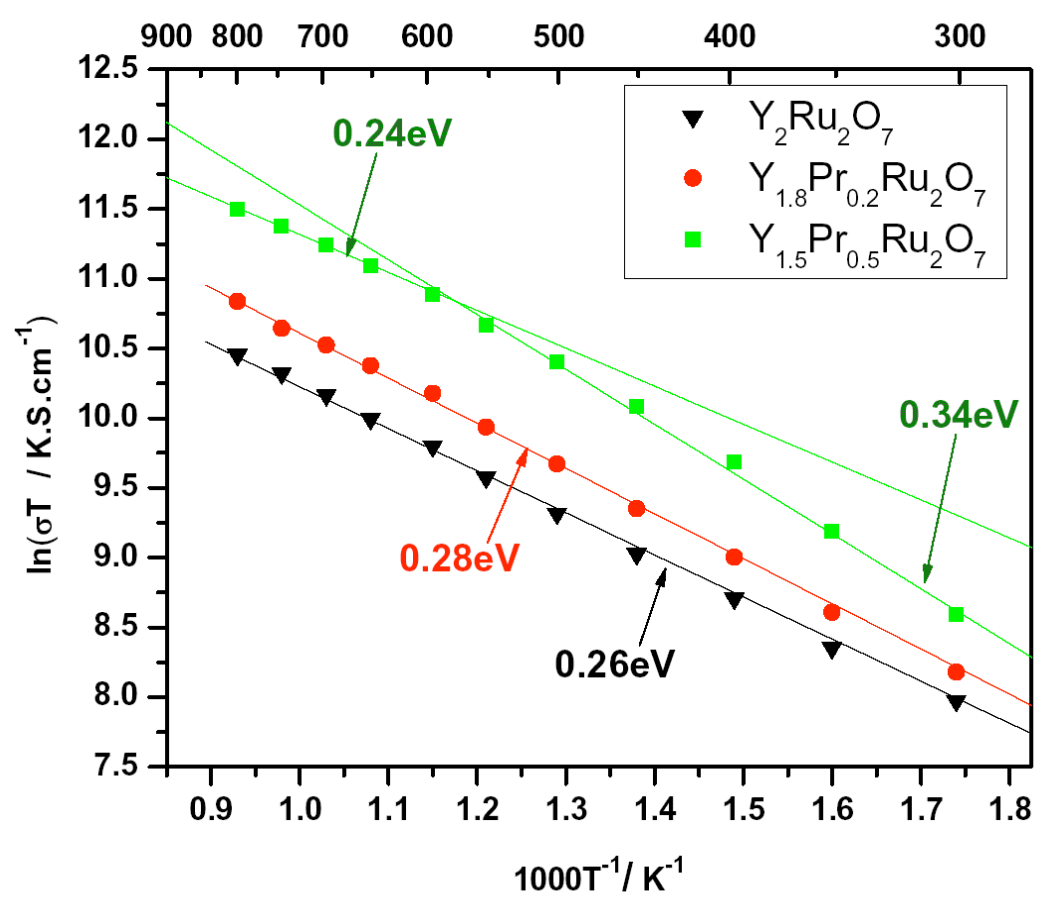

Figure 49. Temperature dependence of the electrical conductivity of $\mathrm{Y}_{2-\mathrm{x}} \mathrm{Pr}_{\mathrm{x}} \mathrm{Ru}_{2} \mathrm{O}_{7}$.

The electrical performance of the materials was studied by the d.c. 4-probe method. Figure 49 is an Arrhenius plot that shows the temperature dependence of the electrical conductivity, $\sigma$; this is indicative of a semi-conductive behavior The $\sigma$ values increased with increasing dopant concentration. At $500^{\circ} \mathrm{C}$ the electrical conductivity of $25 \mathrm{~mol} \% \mathrm{Pr}$ concentration is three times larger than the conductivity of the un-doped sample, and at $700^{\circ} \mathrm{C} \sigma$ increased from $26.7 \mathrm{~S} / \mathrm{cm}$ to $38.3 \mathrm{~S} / \mathrm{cm}$ to $78.6 \mathrm{~S} / \mathrm{cm}$ for samples with $0,10 \mathrm{~mol} \%$, and $25 \mathrm{~mol} \%$ dopant concentration, respectively.

The material with higher praseodymium content shows significantly higher temperature dependency, and its activation energy changes at a temperature above $600^{\circ} \mathrm{C}$. However, its activation energy is not higher than the activation energy of the undoped material in the range of IT-SOFCs operating temperatures. These results confirm that the introduction of praseodymium, into the pyrochlore structure, induces the formation of additional holes and enhances the electrical conductivity of the material.

The electrochemical properties of nanocrystalline $\mathrm{Y}_{2} \mathrm{Ru}_{2} \mathrm{O}_{7}$ and $\mathrm{Y}_{2-\mathrm{x}} \mathrm{Pr}_{\mathrm{x}} \mathrm{Ru}_{2} \mathrm{O}_{7}$ pyrochlore were tested on ESB substrates, using EIS in air, in the $300-700^{\circ} \mathrm{C}$ temperature range. Figure 50 shows a typical complex impedance plane plot of the $\mathrm{Y}_{2} \mathrm{Ru}_{2} \mathrm{O}_{7} / E S B / \mathrm{Y}_{2} \mathrm{Ru}_{2} \mathrm{O}_{7}$ symmetric cell at 

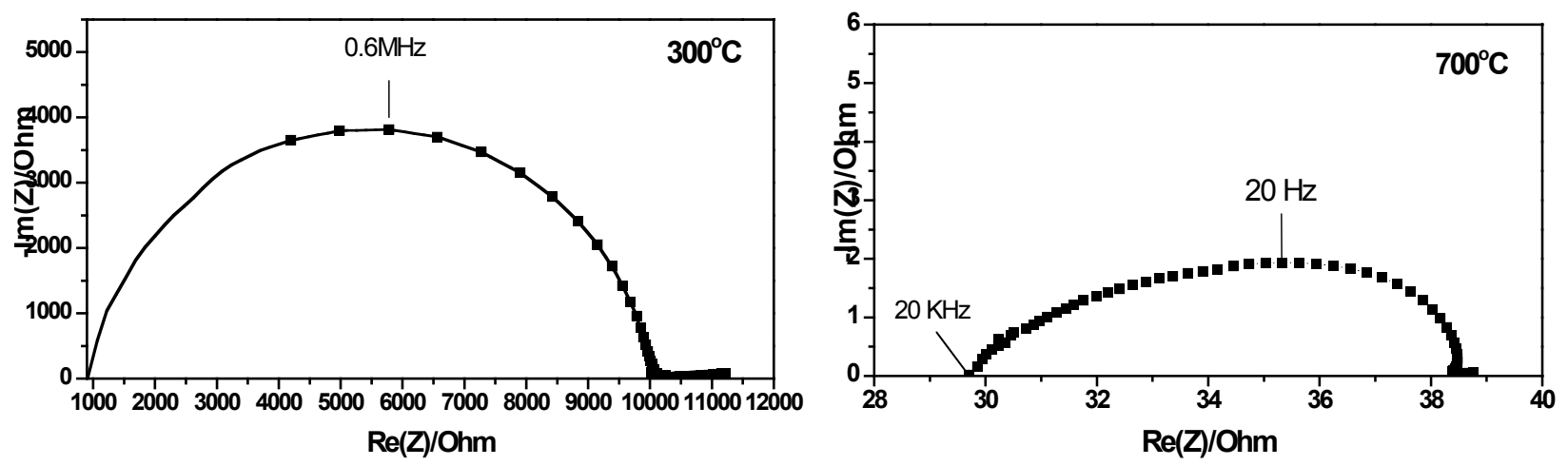

Figure 50. Typical complex impedance plot of $\mathrm{Y}_{2} \mathrm{Ru}_{2} \mathrm{O}_{7} / \mathrm{ESB} / \mathrm{Y}_{2} \mathrm{Ru}_{2} \mathrm{O}_{7}$ cell, in air at $300^{\circ} \mathrm{C}$ and $700^{\circ} \mathrm{C}$.

$300^{\circ} \mathrm{C}$ and at $700^{\circ} \mathrm{C}$. The plot at low temperature $\left(300^{\circ} \mathrm{C}\right)$ showed a semi-arc at high frequency, while no additional features were observed at low frequencies. The plot at $700^{\circ} \mathrm{C}$ is only due to electrode/electrolyte interfacial impedance, and the high frequency intercept can be attributed to the electrolyte bulk impedance because of the high testing temperature. No additional polarization resistance is shown at cathode/electrolyte interface.

The performance of the $\mathrm{Y}_{2} \mathrm{Ru}_{2} \mathrm{O}_{7} / E S B / \mathrm{Y}_{2} \mathrm{Ru}_{2} \mathrm{O}_{7}$ symmetric cell is better than the performance reported by Bae \& Steele ${ }^{51}$ for $\mathrm{Y}_{2} \mathrm{Ru}_{2} \mathrm{O}_{7}$ electrodes on GDC electrolyte. For example, at $627{ }^{\circ} \mathrm{C}$, they reported an ASR of about $4000 \Omega \mathrm{cm}^{2}$, compared to $\sim 9 \mathrm{\Omega cm}^{2}$ in this study on ESB electrolyte. Better performance of $\mathrm{Y}_{2} \mathrm{Ru}_{2} \mathrm{O}_{7}$ electrode on ESB electrolyte, compared to that on GDC electrolyte, demonstrated the role played by the electrolyte in the electrode polarization. The ionic conductivity of ESB is higher than GDC ${ }^{52}$ which allows for faster kinetics at the active triple phase boundaries, where the electrode reaction takes place. Furthermore, the electrode morphology plays a key role in the magnitude of the electrode polarization, which is further lowered because of the nano-crystalline size of the electrode.

Since the electrical conductivity of $\mathrm{Y}_{2} \mathrm{Ru}_{2} \mathrm{O}_{7}$ is increased by doping with praseodymium, it was expected to obtain an improvement of the performance of the cell using $Y_{2-x} \operatorname{Pr}_{x} \mathrm{Ru}_{2} \mathrm{O}_{7}$ in contact to the ESB electrolyte. Figure 51 shows typical EIS plots of $\mathrm{Y}_{1.8} \operatorname{Pr}_{0.2} \mathrm{Ru}_{2} \mathrm{O}_{7} / \mathrm{ESB} /$ $\mathrm{Y}_{1.8} \mathrm{Pr}_{0.2} \mathrm{Ru}_{2} \mathrm{O}_{7}$ and $\mathrm{Y}_{1.5} \operatorname{Pr}_{0.5} \mathrm{Ru}_{2} \mathrm{O}_{7} / \mathrm{ESB} / \mathrm{Y}_{1.5} \operatorname{Pr}_{0.5} \mathrm{Ru}_{2} \mathrm{O}_{7}$ cells tested in air at $700^{\circ} \mathrm{C}$. The electrode impedance of Pr doped yttrium ruthenium oxide on ESB electrolyte is lower than the electrode impedance of the undoped sample. 

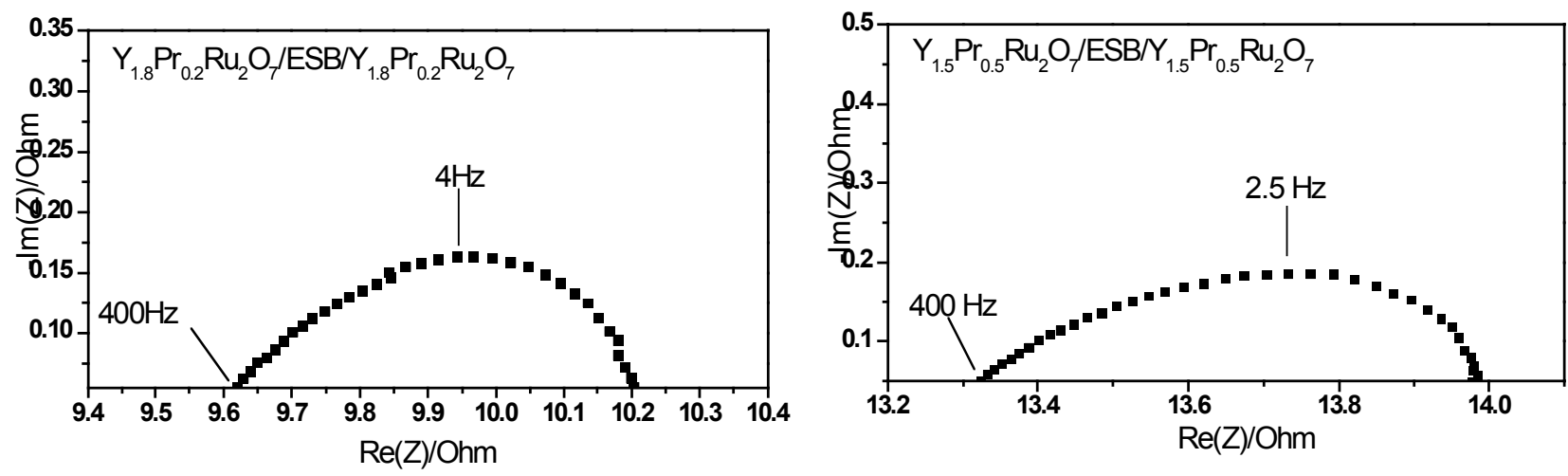

Figure 51. Typical complex impedance plots for $\mathrm{Y}_{1.8} \mathrm{Pr}_{0.2} \mathrm{Ru}_{2} \mathrm{O}_{7} / E S B / \mathrm{Y}_{1.8} \operatorname{Pr}_{0.2} \mathrm{Ru}_{2} \mathrm{O}_{7}$ and $\mathrm{Y}_{1.5} \mathrm{Pr}_{0.5} \mathrm{Ru}_{2} \mathrm{O}_{7}$ $/ \mathrm{ESB} / \mathrm{Y}_{1.5} \mathrm{Pr}_{0.5} \mathrm{Ru}_{2} \mathrm{O}_{7}$ cells, measured in air at $700{ }^{\circ} \mathrm{C}$.

These measurements were used to calculate the electrode ASR from the electrode/electrolyte features. Figure 52 shows the Arrhenius plots of the electrode ASR $(\Omega$ $\mathrm{cm}^{2}$ ) for the symmetrical cells. The ASR values of the $\mathrm{Y}_{2-\mathrm{x}} \operatorname{Pr}_{\mathrm{x}} \mathrm{Ru}_{2} \mathrm{O}_{7} / \mathrm{ESB} / \mathrm{Y}_{2-\mathrm{x}} \mathrm{Pr}_{\mathrm{x}} \mathrm{Ru}_{2} \mathrm{O}_{7}$ cells were significantly smaller than the ASR values of the undoped $\left(\mathrm{Y}_{2} \mathrm{Ru}_{2} \mathrm{O}_{7} / \mathrm{ESB} / \mathrm{Y}_{2} \mathrm{Ru}_{2} \mathrm{O}_{7}\right)$ symmetric cell. Moreover, the Arrhenius plot clearly shows that $10 \mathrm{~mol} \%$ dopant is sufficient to reduce the ARS and additional Pr does not exhibit an additional decrease in ASR.

The improvement of the ASR can be attributed to the Pr. It is presumed that Pr increases the electrical conductivity of the material due to the enhanced hole concentration or mobility. The increase of electrical conductivity permits lowered electrode resistance and may promote faster kinetics of the oxygen reduction reaction at the electrodes.

Further optimization of the dopant concentration is underway. Furthermore, investigations on the ionic conductivity of yttrium ruthenates as well as on the mechanism of the oxygen reduction reaction at the electrode are currently being performed.

In summary, doping the A-site of the pyrochlore structure with praseodymium increased the electrical conductivity of the material and emphasized its semi-conductor behavior. The $\mathrm{Y}_{2} \mathrm{Ru}_{2} \mathrm{O}_{7}$ on ESB electrolyte solid-state cell shows an $\mathrm{ASR}=4.4 \Omega \mathrm{cm}^{2}$ at $700^{\circ} \mathrm{C}$, which is already lower than the values reported in the literature, but it is further reduced by using Prdoped $\mathrm{Y}_{2} \mathrm{Ru}_{2} \mathrm{O}_{7}$. The $\mathrm{Y}_{1-\mathrm{x}} \mathrm{Pr}_{\mathrm{x}} \mathrm{Ru}_{2} \mathrm{O}_{7}$ on ESB electrolyte solid-state cells results in significant decrease in the electrode impedance and $\mathrm{Y}_{1.5} \operatorname{Pr}_{0.5} \mathrm{Ru}_{2} \mathrm{O}_{7}$ shows an ASR $=0.34 \Omega \mathrm{cm}^{2}$ at $700^{\circ} \mathrm{C}$. This study showed that the performance of $\operatorname{Pr}$ doped $\mathrm{Y}_{2} \mathrm{Ru}_{2} \mathrm{O}_{7}$ cathodes is very promising for 


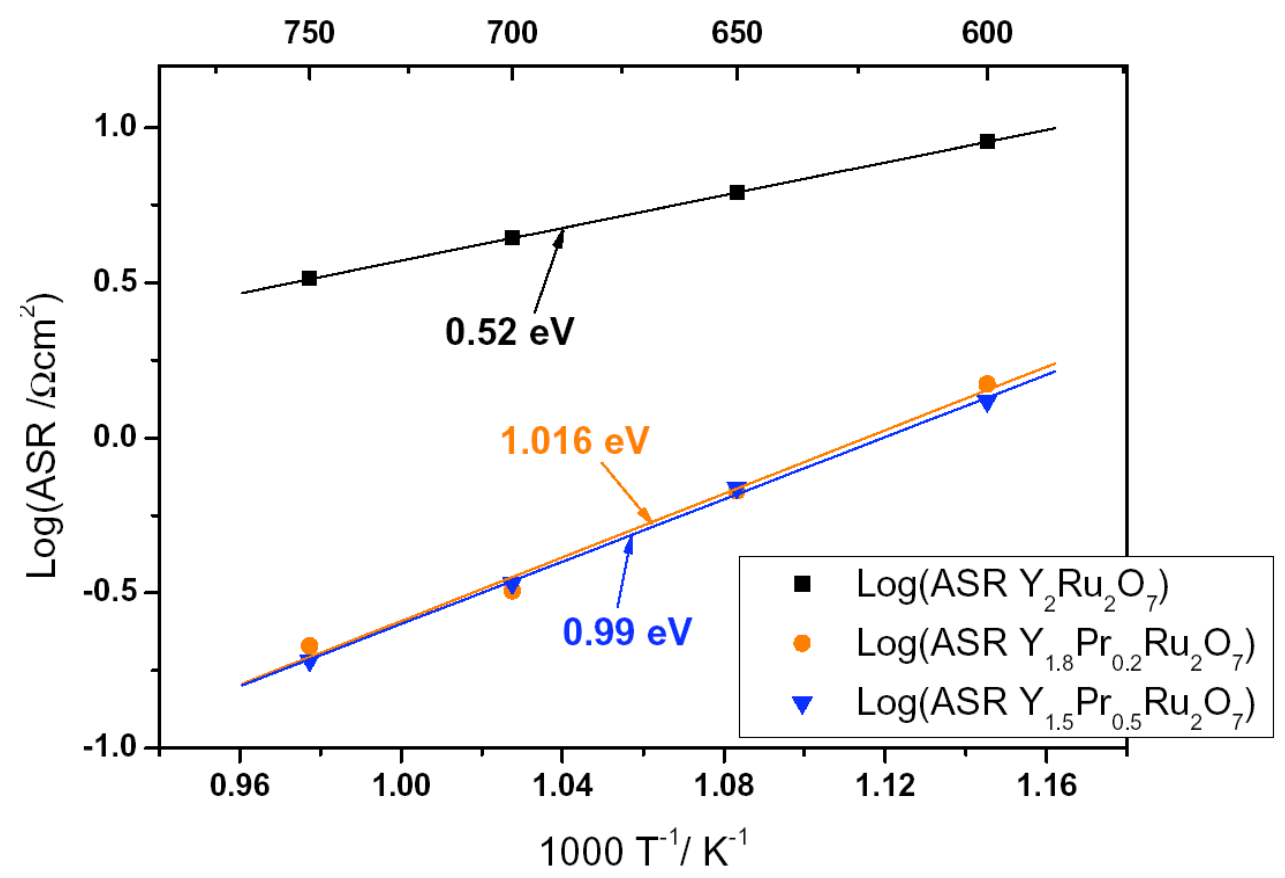

Figure 52. Arrhenius plot of the electrode $\operatorname{ASR}\left(\Omega \mathrm{cm}^{2}\right)$.

application in IT-SOFCs, and further improvements of its performance by using composite cathodes are expected.

The chemical compatibility of the cathode material with the solid electrolyte was evaluated using $\mathrm{X}$-ray diffraction. Mixtures of $\mathrm{Y}_{2-\mathrm{x}} \mathrm{Pr}_{\mathrm{x}} \mathrm{Ru}_{2} \mathrm{O}_{7}$ and ESB powders (weight ratio 1:1) were thoroughly pressed and treated at $800{ }^{\circ} \mathrm{C}$ for 24 hours. The XRD analysis did not reveal any presence of unidentified extra peaks (Fig. 53). Similar measurements were performed on mixtures of $\mathrm{Y}_{2-\mathrm{x}} \mathrm{Pr}_{\mathrm{x}} \mathrm{Ru}_{2} \mathrm{O}_{7}$ and GDC powders, and again no extra peaks were revealed. Thus, it was deduced that no chemical reaction occurred between these compounds.

The electrochemical properties of nanocrystalline $\mathrm{Y}_{2-\mathrm{x}} \mathrm{Pr}_{\mathrm{x}} \mathrm{Ru}_{2} \mathrm{O}_{7}$ pyrochlore were tested in contact to both ESB and GDC electrolytes, using Electrochemical Impedance Spectroscopy (EIS) in air from $300{ }^{\circ} \mathrm{C}$ to $750{ }^{\circ} \mathrm{C}$. Figure 54 shows EIS data from (I) $\mathrm{Y}_{1.5} \mathrm{Pr}_{0.5} \mathrm{Ru}_{2} \mathrm{O}_{7} / \mathrm{ESB} / \mathrm{Y}_{1.5} \operatorname{Pr}_{0.5} \mathrm{Ru}_{2} \mathrm{O}_{7}$ and (II) $\mathrm{Y}_{1.5} \mathrm{Pr}_{0.5} \mathrm{Ru}_{2} \mathrm{O}_{7} / \mathrm{GDC} / \mathrm{Y}_{1.5} \operatorname{Pr}_{0.5} \mathrm{Ru}_{2} \mathrm{O}_{7}$ cells tested in air at $700{ }^{\circ} \mathrm{C}$. The high frequency intercepts of the EIS plots can be attributed to the electrolyte bulk impedance due to the high temperature of the test. Thus, the semicircles observed in the plots are due to electrode/electrolyte interfacial impedance. The electrode ASR was calculated by multiplying the electrode resistance by the electrode area, and dividing by two to account for the 

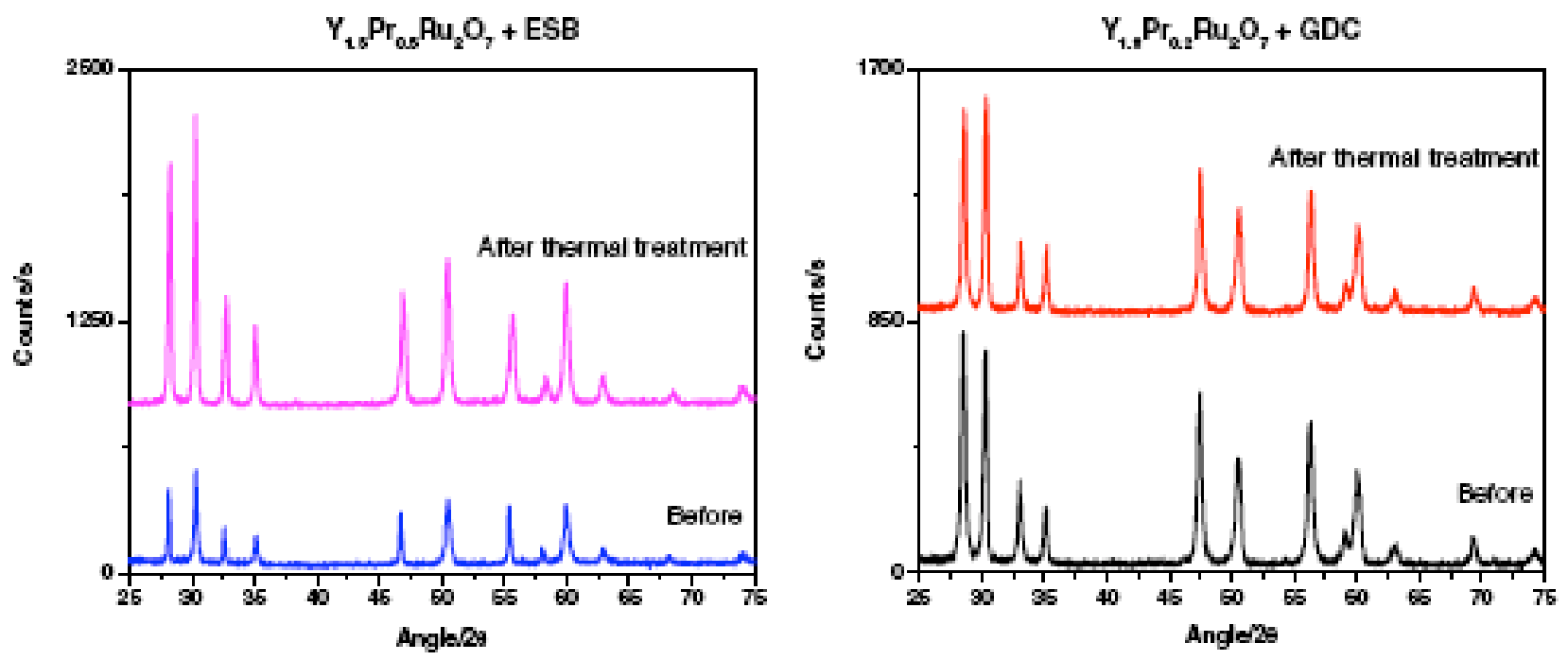

Figure 53. $\mathrm{X}$-ray spectra of $\mathrm{Y}_{2-\mathrm{x}} \mathrm{Pr}_{\mathrm{x}} \mathrm{Ru}_{2} \mathrm{O}_{7} / \mathrm{ESB}$ mixture and $\mathrm{Y}_{2-\mathrm{x}} \mathrm{Pr}_{\mathrm{x}} \mathrm{Ru}_{2} \mathrm{O}_{7} /$ GDC mixture that were pressed and treated at $800^{\circ} \mathrm{C}$ for $24 \mathrm{~h}$.

symmetric cell. At $700{ }^{\circ} \mathrm{C}$ the ASR of $25 \% \operatorname{Pr}$-doped $\mathrm{Y}_{2} \mathrm{Ru}_{2} \mathrm{O}_{7}$ on ESB was $0.19 \Omega \mathrm{cm}^{2}$ while on GDC the ASR was $4.23 \Omega \mathrm{cm}^{2}$. The factor of forty reduction in ASR of $25 \%$ Pr-doped $\mathrm{Y}_{2} \mathrm{Ru}_{2} \mathrm{O}_{7}$ on ESB versus $\mathrm{GDC}$ is a significant result that is being investigated further. Nevertheless, it suggests that the high conductivity and oxygen affinity of ESB plays an important role in cathode performance. The performance of the $\mathrm{Y}_{1.5} \mathrm{Pr}_{0.5} \mathrm{Ru}_{2} \mathrm{O}_{7} / \mathrm{ESB} / \mathrm{Y}_{1.5} \mathrm{Pr}_{0.5} \mathrm{Ru}_{2} \mathrm{O}_{7}$ symmetric cell was significantly better than the performance of the $\mathrm{Y}_{1.5} \mathrm{Pr}_{0.5} \mathrm{Ru}_{2} \mathrm{O}_{7} / \mathrm{GDC} / \mathrm{Y}_{1.5} \mathrm{Pr}_{0.5} \mathrm{Ru}_{2} \mathrm{O}_{7}$ symmetric cell. However, the performance of $\mathrm{Y}_{1.5} \mathrm{Pr}_{0.5} \mathrm{Ru}_{2} \mathrm{O}_{7}$ on GDC electrolyte was better than that previously reported in the literature for Strontium-doped pyrochlore compounds ${ }^{50}$. In fact, Steele ${ }^{53}$ reported an ASR value of $47 \Omega \mathrm{cm}^{2}$
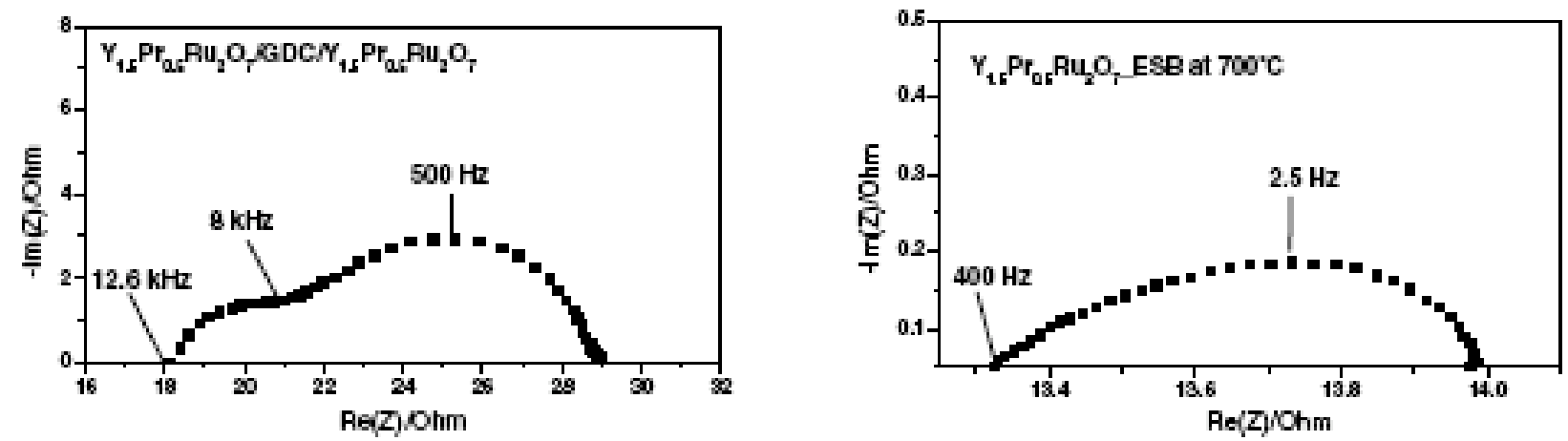

Figure 54. Typical complex impedance plots for $\mathrm{I}$. Y $1.5 \mathrm{Pr} 0.5 \mathrm{Ru} 2 \mathrm{O} 7 / \mathrm{GDC} / \mathrm{Y} 1.5 \mathrm{Pr} 0.5 \mathrm{Ru} 2 \mathrm{O}_{7}$, and II. $\mathrm{Y}_{1.5} \mathrm{Pr} 0.5 \mathrm{Ru} 2 \mathrm{O} 7 / \mathrm{ESB} / \mathrm{Y} 1.5 \mathrm{Pr} 0.5 \mathrm{Ru} 2 \mathrm{O}_{7}$ cells, measured in air at $700_{\circ} \mathrm{C}$. 

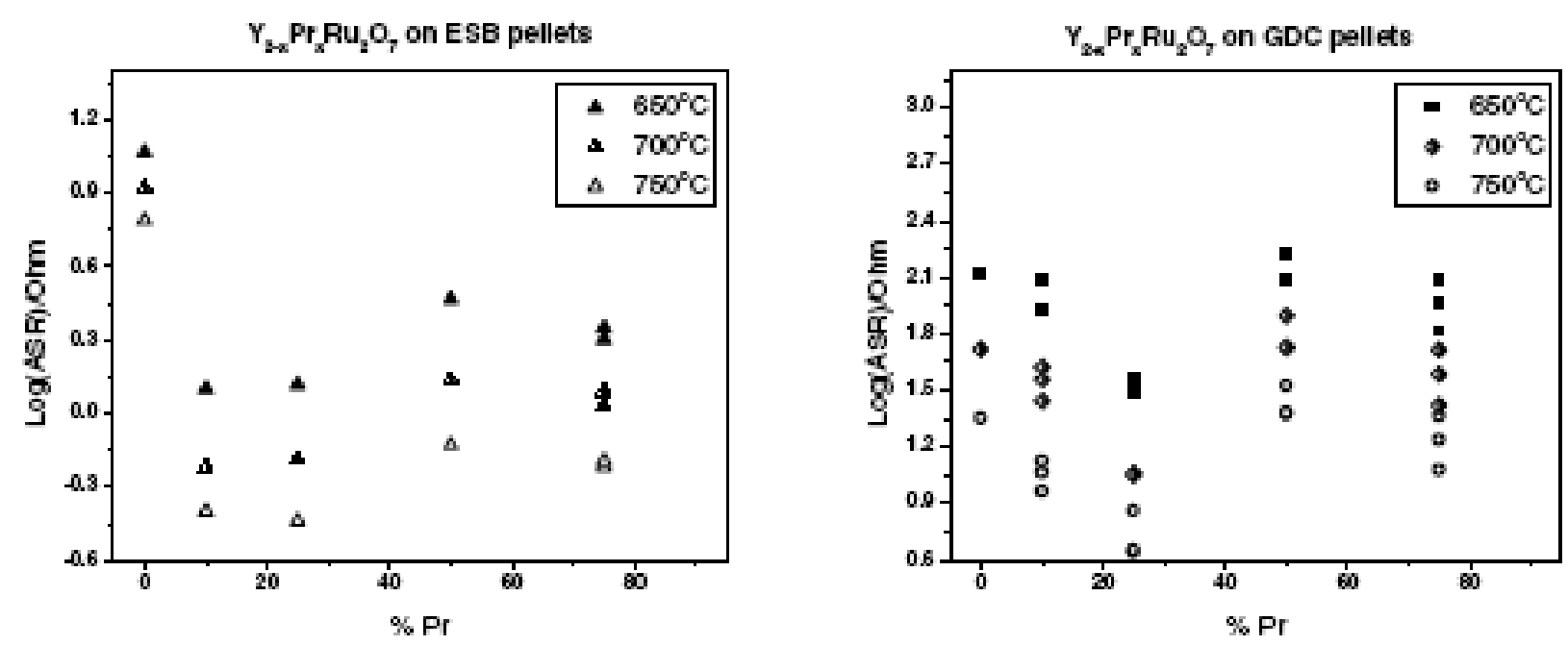

Figure 55. ASR values of $\mathrm{Y}_{2-\mathrm{x}} \mathrm{Pr}_{\mathrm{x}} \mathrm{Ru}_{2} \mathrm{O}_{7}$ on ESB and on GDC pellets as function of $\mathrm{Pr}$ content.

for 5 mole $\%$ Sr-doped $\mathrm{Y}_{2} \mathrm{Ru}_{2} \mathrm{O}_{7}$ cathode on GDC at $627{ }^{\circ} \mathrm{C}$; in contrast, $25 \%$ Pr-doped $\mathrm{Y}_{2} \mathrm{Ru}_{2} \mathrm{O}_{7}$ showed an ASR value of $10.72 \Omega \mathrm{cm}^{2}$ at $650{ }^{\circ} \mathrm{C}$ and $31.98 \Omega \mathrm{cm}^{2}$ at $600{ }^{\circ} \mathrm{C}$.

Figure 55 shows EIS data from $\mathrm{Y}_{2-\mathrm{x}} \mathrm{Pr}_{\mathrm{x}} \mathrm{Ru}_{2} \mathrm{O}_{7} / \mathrm{ESB} / \mathrm{Y}_{2-\mathrm{x}} \mathrm{Pr}_{\mathrm{x}} \mathrm{Ru}_{2} \mathrm{O}_{7}$ and $\mathrm{Y}_{2-}$ ${ }_{x} \mathrm{Pr}_{\mathrm{x}} \mathrm{Ru}_{2} \mathrm{O}_{7} / \mathrm{GDC} / \mathrm{Y}_{2-\mathrm{x}} \mathrm{Pr}_{\mathrm{x}} \mathrm{Ru}_{2} \mathrm{O}_{7}$ cells as a function of the $\mathrm{Pr}$ concentration, measured in a temperature range of $650{ }^{\circ} \mathrm{C}-750{ }^{\circ} \mathrm{C}$. The samples tested on ESB electrolytes showed the same ASR variation of the samples tested on GDC electrolyte. The ASR values decreased with increasing $\mathrm{Pr}$ amount until a minimum at $25 \% \operatorname{Pr}$-doped $\mathrm{Y}_{2} \mathrm{Ru}_{2} \mathrm{O}_{7}$, and then increased again. Thus, both systems showed their best performance with the $\mathrm{Y}_{1.5} \operatorname{Pr}_{0.5} \mathrm{Ru}_{2} \mathrm{O}_{7}$ cathode. These results were reproduced several times and on different samples. Hence, this behavior can be attributed to the electrical properties of the cathode. Further investigation is needed for a better understanding of how electrical properties of this material depend on dopant concentration.

In order to understand the mechanism of oxygen reduction at the electrodes, EIS measurements were carried out as a function of oxygen partial pressure. Figure 56a showed the variation of the ASR for $\mathrm{Y}_{1.5} \mathrm{Pr}_{0.5} \mathrm{Ru}_{2} \mathrm{O}_{7} / \mathrm{GDC} / \mathrm{Y}_{1.5} \mathrm{Pr}_{0.5} \mathrm{Ru}_{2} \mathrm{O}_{7}$ cell in function of the oxygen partial pressure. The impedance measurements on GDC electrolyte are described by two semicircles, which are partially overlapping. By decreasing the oxygen partial pressure, the semicircle at low frequencies showed a large variation, while the shape of the semicircle at high frequencies did not vary. Moreover, Fig. 56b shows the values of the ASR as a function of the oxygen partial pressure, at different temperatures. 

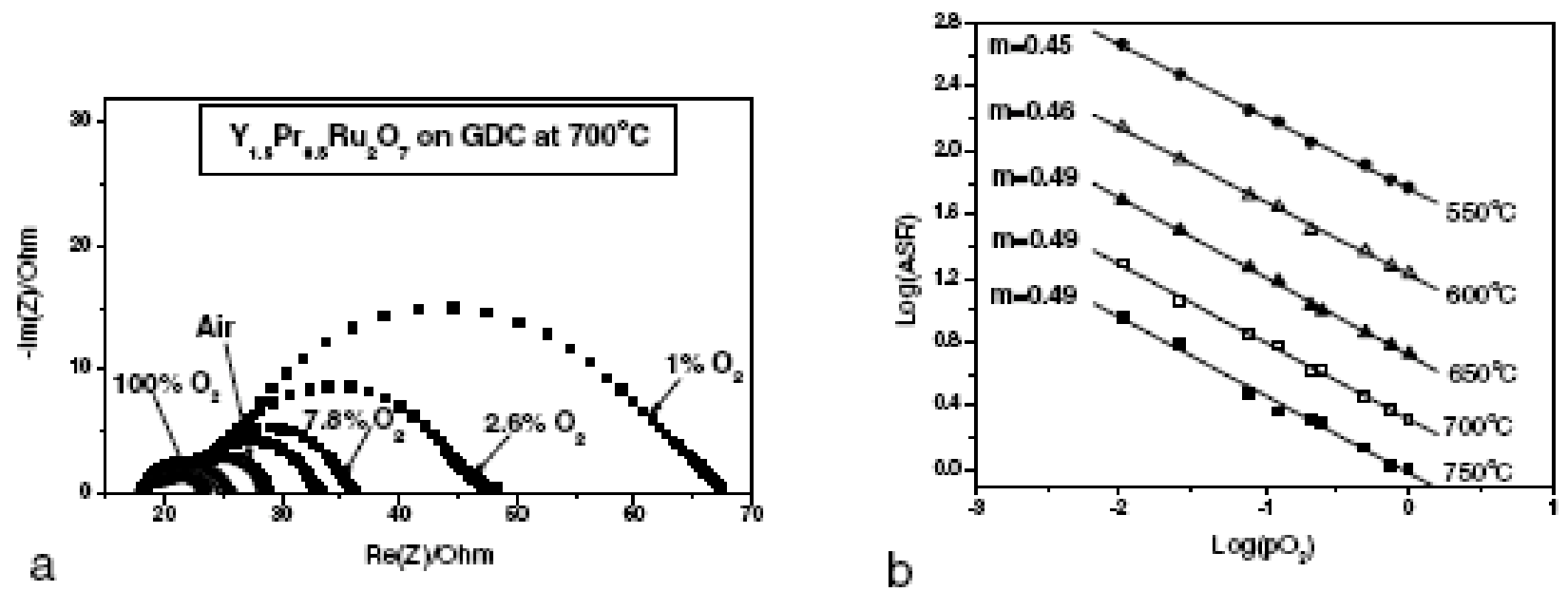

Figure 56. ASR values of $\mathrm{Y}_{1.5} \mathrm{Pr}_{0.5} \mathrm{Ru}_{2} \mathrm{O}_{7}$ on GDC electrolyte as function of oxygen partial pressure.

To understand the mechanism of oxygen reduction at the electrodes, impedance measurements were done as a function of oxygen partial pressure. Generally, ASR of the electrode varies with the oxygen partial pressure according to the following equation

$$
A S R=A S R_{0} \times P_{O_{2}}^{-m}
$$

The magnitude of $m$ provides an insight into the rate-limiting step in the oxygen reduction reaction at the electrodes. With metal and metal oxide electrodes on solid electrolytes, $m=0.25$ has been associated with the charge-transfer reaction at the triple-phase boundary, $m=0.5$ with the surface diffusion of the dissociatively adsorbed oxygen at the electrodes to the triple phase boundaries TPBs, and $m=1$ with gaseous diffusion of oxygen molecules in the electrode structure. In addition, the electrode-electrolyte combination along with the microstructure plays a key role in determining the rate-limiting step ${ }^{62,54,55,56,57}$.

For an operating temperature range of $550{ }^{\circ} \mathrm{C}-750{ }^{\circ} \mathrm{C}$, the value of $\mathrm{m}$ for $\mathrm{Y}_{1.5} \mathrm{Pr}_{0.5} \mathrm{Ru}_{2} \mathrm{O}_{7} / \mathrm{GDC} / \mathrm{Y}_{1.5} \operatorname{Pr}_{0.5} \mathrm{Ru}_{2} \mathrm{O}_{7}$ cell was about 0.5. This suggests that the rate-limiting step is surface diffusion of the adsorbed oxygen at the electrode surface to the TPB.

Finally, the semicircle at low frequencies, showed by the impedance spectroscopy on the GDC electrolyte, is indicative of the mass transport resistance. Hence, the semicircular arc at high frequencies is representative of charge transfer resistance. In contrast, the impedance on ESB electrolyte is characterized by one single elongated semicircle, and it showed a very low 
charge transfer resistance. This can be the primary reason for the higher performance of this electrode on the ESB electrolyte.

A chemical analysis of the interface was performed by SEM-EDS line scan measurements of $\mathrm{Y}_{1.5} \mathrm{Pr}_{0.5} \mathrm{Ru}_{2} \mathrm{O}_{7} / \mathrm{ESB}$ sample. This showed a partial solid diffusion of the cations at the electrode/electrolyte interface (figure not shown). Thus, the enhanced performance of $\mathrm{Y}_{1.5} \mathrm{Pr}_{0.5} \mathrm{Ru}_{2} \mathrm{O}_{7}$ on ESB may also be caused by the formation of a new conductive phase at the electrode/electrolyte interface that lowers the interfacial polarization, as reported elsewhere ${ }^{58}$ [7].

In summary, no detrimental reaction products between the pyrochlore and either GDC or ESB electrolytes were found by XRD analysis after heat-treatment at $800{ }^{\circ} \mathrm{C}$ for $24 \mathrm{~h}$. Both systems showed a similar variation of ASR depending on the amount of $\operatorname{Pr}$ in the cathode material. The performance on ESB electrolyte is much better than the performance on the GDC electrolyte. Since the oxygen mass diffusion is the limiting step of the electrode kinetics, the enhanced performance on ESB electrolyte is probably due to a partial solid diffusion at the electrode/electrolyte interface that lower the interfacial polarization. However, the low value of resistivity of the $\mathrm{Y}_{1.5} \mathrm{Pr}_{0.5} \mathrm{Ru}_{2} \mathrm{O}_{7} / \mathrm{ESB} / \mathrm{Y}_{1.5} \mathrm{Pr}_{0.5} \mathrm{Ru}_{2} \mathrm{O}_{7}$ symmetric cell indicated that the nanocrystalline powders of $\mathrm{Y}_{1.5} \mathrm{Pr}_{0.5} \mathrm{Ru}_{2} \mathrm{O}_{7}$ electrode are promising materials for intermediate temperature solid oxide fuel cell (IT-SOFC) cathode applications where ESB is either the electrolyte or a constituent of a composite cathode structure.

\section{Bismuth Ruthenate, $\mathrm{Bi}_{2} \mathrm{Ru}_{2} \mathrm{O}_{7}(\mathrm{BRO})$, Cathodes}

XRD patterns for $\mathrm{Bi}_{2} \mathrm{Ru}_{2} \mathrm{O}_{7}$ after calcination at $900{ }^{\circ} \mathrm{C}$ for $10 \mathrm{~h}$ and after leaching are shown in Fig. 57. We found that leaching with $\mathrm{HNO}_{3}$ is effective in removing the impurity sillenite type-phase, $\mathrm{Bi}_{12} \mathrm{RuO}_{20}$, resulting in a predominant single pyrochlore phase. Figure 58 shows the XRD pattern of BRO and GDC powders heat-treated at $850^{\circ} \mathrm{C}$ for $10 \mathrm{~h}$. There are no new peaks identifiable in the pattern, indicating that there is no reaction between BRO and GDC. Similarly, Hrovat et al. ${ }^{59}$ studied the subsolidus-phase equilibria in $\mathrm{RuO}_{2}-\mathrm{Bi}_{2} \mathrm{O}_{3}-\mathrm{CeO}_{2}$ system and no ternary compound was found at $800{ }^{\circ} \mathrm{C}$. The tie-line is between $\mathrm{BRO}$ and $\mathrm{Ce}_{1_{-} x} \mathrm{Bi}_{x} \mathrm{O}_{2-x / 2}$ $(0<x<0.33)$ solid solution. These results are in contrast with those of Bae and Steele ${ }^{60}$, where they found unknown reaction products between $\mathrm{Bi}_{2} \mathrm{Ru}_{2} \mathrm{O}_{7.3}$ and $\mathrm{GDC}$ at $800{ }^{\circ} \mathrm{C}$. It is possible that the presence of sillenite type-impurities in bismuth ruthenate could lead to a new product, as 


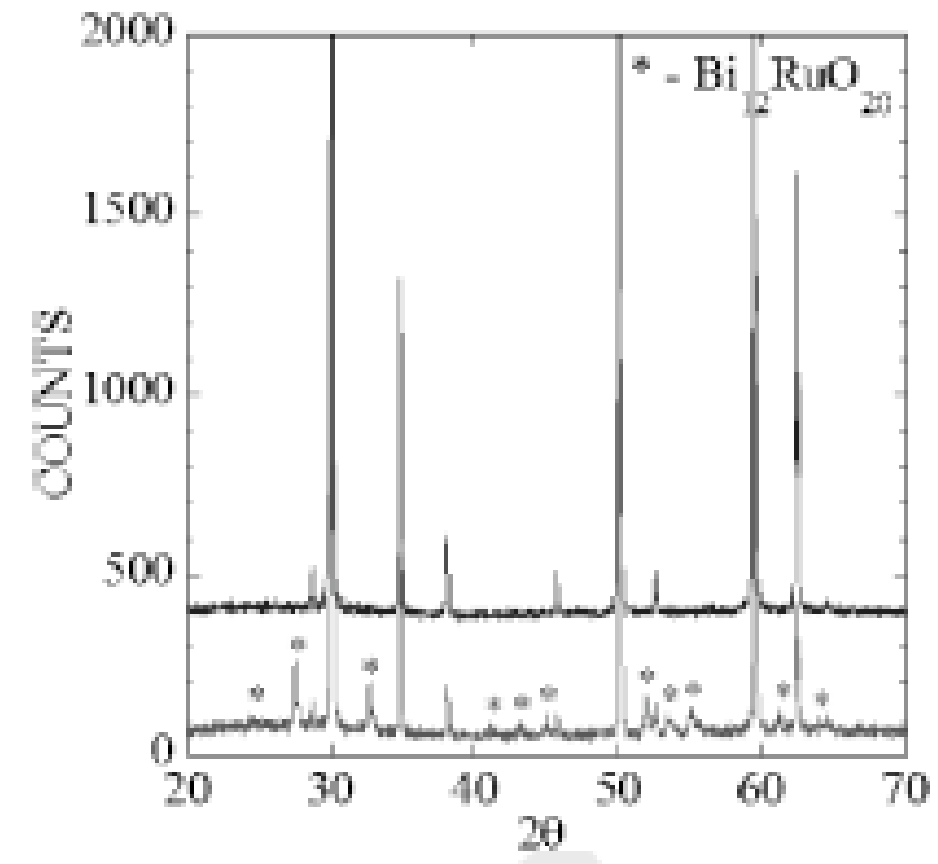

Figure 57. $\mathrm{XRD}$ patterns of $\mathrm{Bi}_{2} \mathrm{Ru}_{2} \mathrm{O}_{7}$ after calcination at $900{ }^{\circ} \mathrm{C}$ for $10 \mathrm{~h}$ before (top) and after (bottom) leaching.

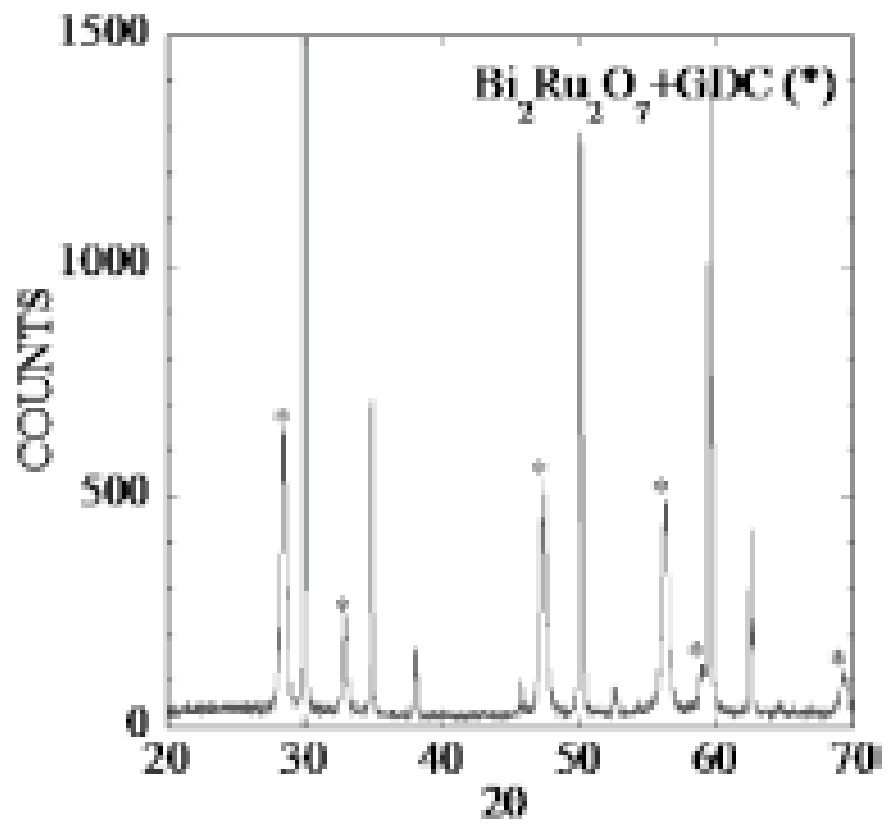

Figure 58. XRD pattern for $\mathrm{Bi}_{2} \mathrm{Ru}_{2} \mathrm{O}_{7}$ and $\mathrm{GDC}$ powder mixture after heat treatment at $850^{\circ} \mathrm{C}$ for $10 \mathrm{~h}$. 

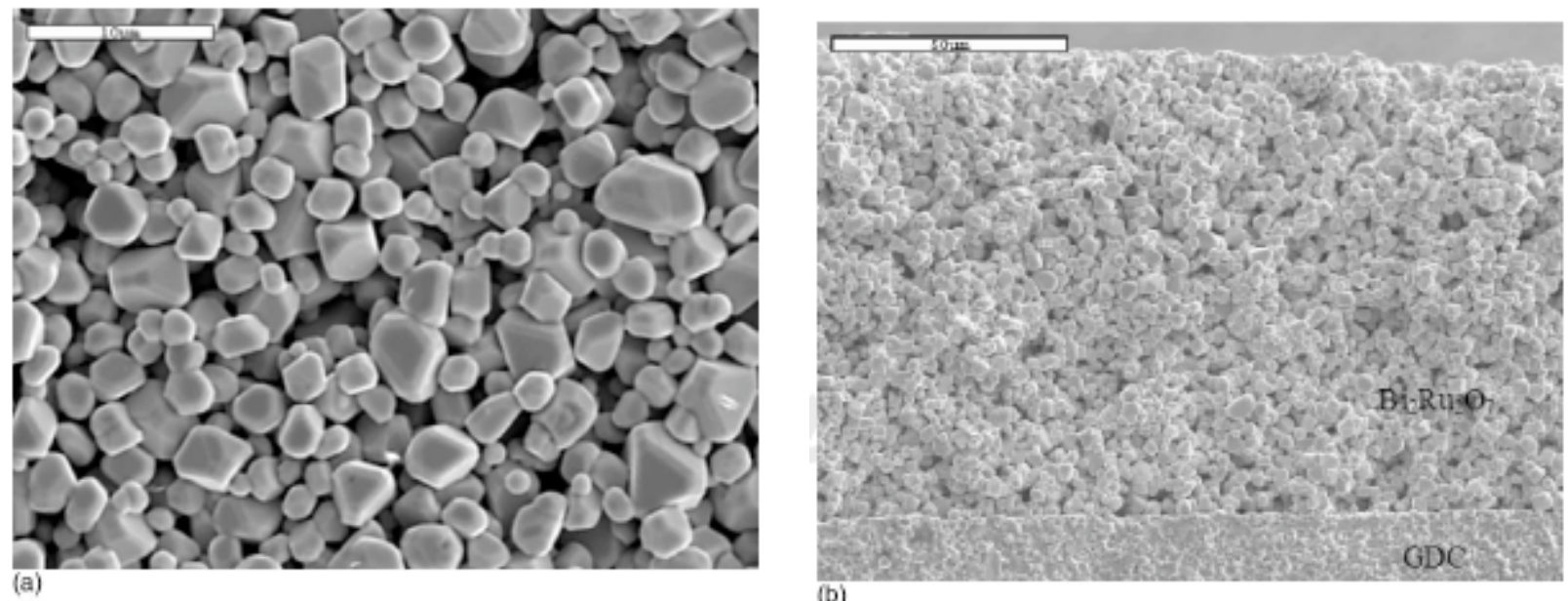

(b)

Figure 59. (a) Surface and (b) cross-sectional micrographs of $\mathrm{Bi}_{2} \mathrm{Ru}_{2} \mathrm{O}_{7}$ electrode on GDC electrolyte.

Takeda et $a l .{ }^{61}$ found in their work on $\mathrm{Bi}_{2} \mathrm{Ru}_{2} \mathrm{O}_{7}$ electrodes on YSZ where the presence of sillenite-type impurities lead to the transformation of monoclinic zirconia.

Figures 59a and 59b show the surface and cross-sectional micrographs of a BRO electrode on GDC electrolyte, respectively. Solid-state synthesis of BRO powders at $900{ }^{\circ} \mathrm{C}$ has resulted in a coarse particle size $(\sim 3 \mu \mathrm{m})$. After sintering at $850^{\circ} \mathrm{C}$, the electrode is porous with a thickness of $100 \mu \mathrm{m}$. Initial sintering experiments showed that lower sintering temperatures for the film resulted in poor adhesion with the substrate, while at higher temperatures there was evaporation of the electrode material.

Impedance plots of $\mathrm{BRO}$ electrodes on GDC at 500 and $700{ }^{\circ} \mathrm{C}$ are shown in Fig. 60 . The high frequency intercept corresponds to the bulk conductivity of the GDC electrolyte, which is comparable to values reported in the literature. The depressed semicircle at lower frequencies is due to the $\mathrm{Bi}_{2} \mathrm{Ru}_{2} \mathrm{O}_{7}$ electrode with resistances of $158.29 \Omega$ and $4.13 \Omega$ at $500{ }^{\circ} \mathrm{C}$ and $700{ }^{\circ} \mathrm{C}$, respectively. The electrode ASR was calculated by multiplying the electrode resistance by the electrode area $0.7 \mathrm{~cm}^{2}$ and dividing by two to account for the symmetric cell.

The Arrhenius plot of the electrode ASR (in $\Omega \mathrm{cm}^{2}$ ) is shown in Fig. 61. The ASR values are significantly smaller than those reported by Linquette-Mailley et al. ${ }^{62}$ for $\mathrm{Bi}_{2} \mathrm{Ru}_{2} \mathrm{O}_{7}$ electrodes on YSZ electrolytes. For example at $500^{\circ} \mathrm{C}$, they reported an ASR of $160 \Omega \mathrm{cm}^{2}$ compared to $55.64 \Omega \mathrm{cm}^{2}$ in this study on GDC and at $650{ }^{\circ} \mathrm{C}, 20 \Omega \mathrm{cm}^{2}$ compared to $3.03 \Omega \mathrm{cm}^{2}$ in this study. Also, they reported a kink in the Arrhenius plot with activation energies of $1.3 \mathrm{eV}$ 

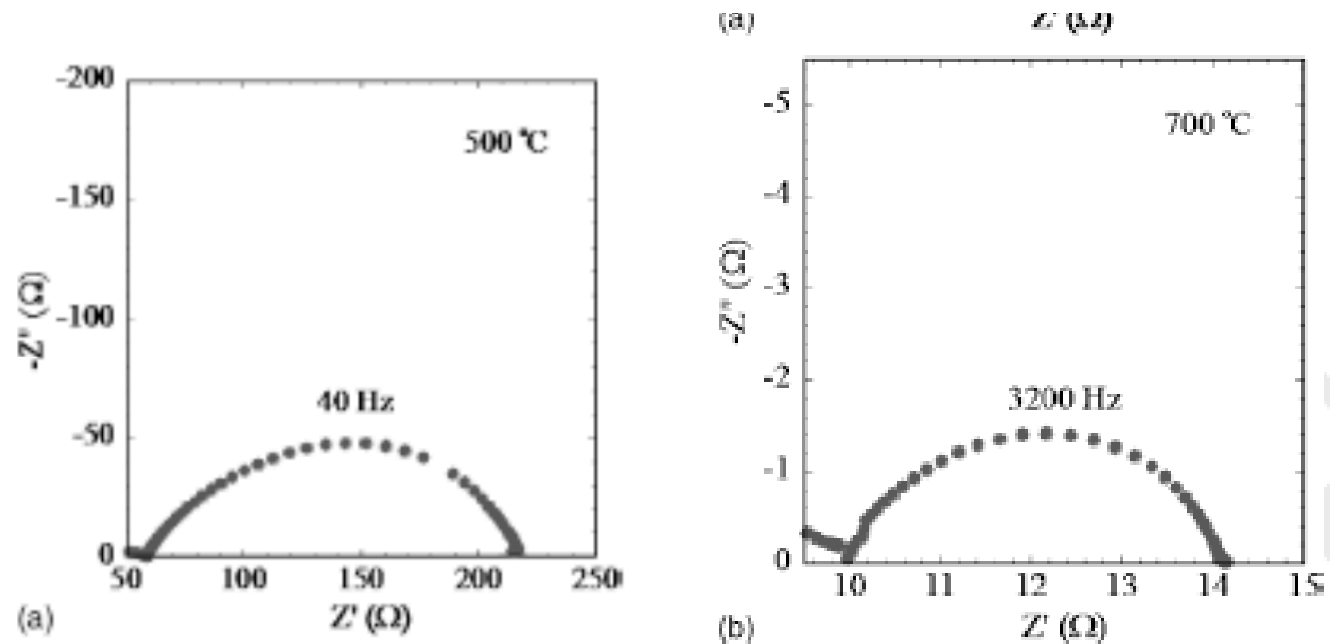

Figure 60. Impedance plots of $\mathrm{Bi}_{2} \mathrm{Ru}_{2} \mathrm{O}_{7}$ electrode on $\mathrm{GDC}$ at 500 (a), and $700^{\circ} \mathrm{C}(\mathrm{b})$.

below $567{ }^{\circ} \mathrm{C}$ and $1.0 \mathrm{eV}$ above $567^{\circ} \mathrm{C}$, suggesting that two different reaction mechanisms were dominant at the electrodes in the temperature range studied. However, in this study a single activation energy of $1.26 \mathrm{eV}$ in the temperature range of $450-700{ }^{\circ} \mathrm{C}$ was observed.

To understand the mechanism of oxygen reduction at the electrodes, impedance measurements were done as a function of oxygen partial pressure. Generally, ASR of the electrode varies with the oxygen partial pressure according to Eq. (4). Figure 62 is a graph between $\ln$ ASR vs. $\ln \mathrm{P}_{\mathrm{O}_{2}}$. The values of $m$ range between 0.5 and 0.6 , which suggests that the

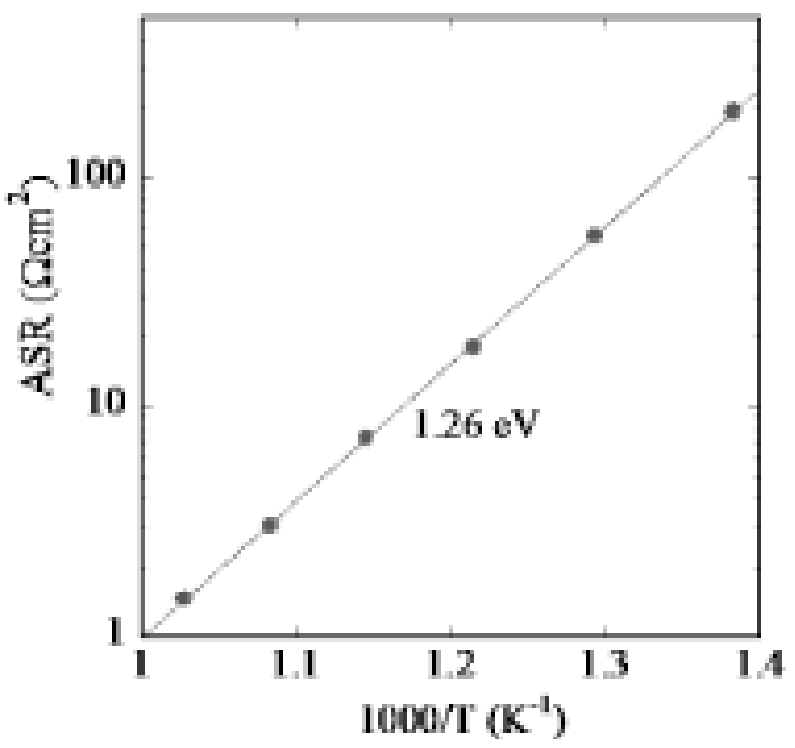

Figure 61. Arrhenius plot of the electrode ASR $\left(\Omega \mathrm{cm}^{2}\right)$. 


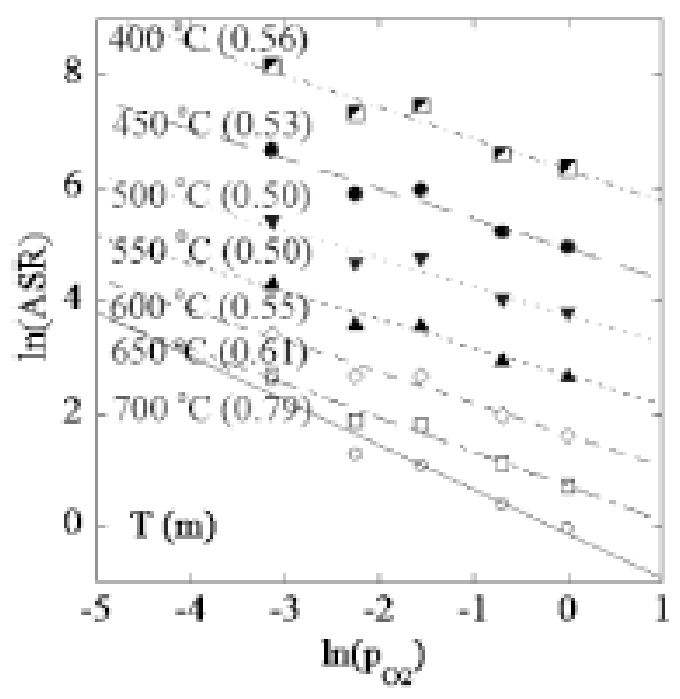

Figure 62. $\ln$ ASR vs. $\ln p_{02}$ at different temperatures with $m$ in parenthesis $T m$.

rate-limiting step in the present case is surface diffusion of the dissociatively adsorbed oxygen at the electrode surface to the TPBs. In contrast, Linquette-Mailley et al. ${ }^{63}$ reported values of $m=$ 0.25 at temperatures less than $567{ }^{\circ} \mathrm{C}$ and continuously increasing values for temperatures greater than $567^{\circ} \mathrm{C}$ for $\mathrm{Bi}_{2} \mathrm{Ru}_{2} \mathrm{O}_{7}$ electrodes on YSZ electrolytes. The rate-limiting step at lower temperatures was attributed to the charge-transfer step and at higher temperatures a transition to surface diffusion was suggested.

Better performance of the $\mathrm{Bi}_{2} \mathrm{Ru}_{2} \mathrm{O}_{7}$ electrode on a GDC electrolyte compared to that on a YSZ electrolyte, along with different rate-limiting steps again demonstrate the role played by the electrolyte in the electrode polarization. For predominant electronically conducting electrodes with negligible ionic conductivity such as in the case of $\mathrm{Bi}_{2} \mathrm{Ru}_{2} \mathrm{O}_{7}$ at low polarizations, the interface between the electrode and electrolyte are the active triple phase boundaries TPBs for electrode reaction to take place. Hence, it can be expected that the bulk and surface properties of the electrolyte can have significant effects on the overall performance of the electrode. GDC has higher ionic conductivity than YSZ, along with the capability of cerium to exist in multiple valence states to provide sufficient electronic charge carriers which can result in improved charge transfer and better electrode performance ${ }^{64}$. The lack of sillenite-type impurities could also have a possible role in the better performance. 
Apart from the electrical properties of the electrode-electrolyte combination, electrode morphology also plays a key role in determining the rate-limiting step for the electrode reaction and the magnitude of the electrode polarization. The electrode polarization in the present case can be expected to be reduced by using finer electrode particles, which would provide parallel surface diffusion paths to the TPBs. Further, composite cathodes consisting of $\mathrm{Bi}_{2} \mathrm{Ru}_{2} \mathrm{O}_{7}$ and an ionic conductive phase can increase the concentration of the TPBs and improve performance, effectively spreading the reaction zone from the electrode-electrolyte interface into the electrode.

This preliminary study showed that the performance of $\mathrm{Bi}_{2} \mathrm{Ru}_{2} \mathrm{O}_{7}$ cathodes is very promising, and it is expected that with improved electrode morphology and with composite cathodes, high performance cathodes can be developed for IT-SOFCs. These studies follow below.

\section{Doping Strategies to Increase Ionic Conductivity in Bismuth Ruthenates}

The $\mathrm{A}_{2} \mathrm{~B}_{2} \mathrm{O}_{7}$ pyrochlore structure is essentially derived from an oxygen deficient cubic fluorite structure with both ordered cation and anion sub-lattice. It exhibits $\mathrm{Fd} \overline{3} \mathrm{~m}$ space group with eight formula units within a cubic unit cell. ${ }^{65}$. The cation sublattice consists of bigger $\mathrm{A}^{3+}$ and smaller $\mathrm{B}^{4+}$ which order into alternate (110) rows in every other (001) plane and in alternate ( 110$)$ rows in the other $(001)$ planes. This cation ordering provides three distinguishable tetrahedral sites for the oxygen ions: 8a-sites surrounded by $4 \mathrm{~A}^{3+}$ cations, $8 \mathrm{~b}$-sites surrounded by $4 \mathrm{~B}^{4+}$ cations, and $48 \mathrm{f}$-sites surrounded by $2 \mathrm{~A}^{3+}$ and $2 \mathrm{~B}^{4+}$ cations. $8 \mathrm{a}$ and $48 \mathrm{f}$-sites are occupied, while $8 \mathrm{~b}$-sites are vacant resulting in an ordered oxygen ion sub-lattice. The formula unit of the pyrochlore can also be written as $\mathrm{A}_{2} \mathrm{~B}_{2} \mathrm{O}_{6} \mathrm{O}$ ' to distinguish between the oxygen ions occupying the $48 \mathrm{f}$-site as $\mathrm{O}$ and those occupying the $8 \mathrm{a}$-sites as $\mathrm{O}^{\prime}$.

Although bismuth ruthenate has sufficient electronic conductivity to perform as a good cathode, it will be beneficial to introduce oxygen ion conductivity in the structure. The oxygen ion vacancies in the pyrochlore structure are ordered but still result in an ionic conductivity, which is larger than that of undoped fluorites. It is expected that the pyrochlore structure may exhibit a transition temperature above which the oxygen ion sub-lattice will disorder, leading to enhanced oxygen ion conductivity ${ }^{65}$. As the anion ordering is related to the cation ordering, the transition temperature could be lowered by manipulating the ion radii of the two cations. The 
smaller is $r_{A} / r_{B}$, the lower is the expected transition temperature. As in the case of fluorites, oxygen ion conductivity can also be introduced into the pyrochlore structure by generating additional oxygen ion vacancies by doping with lower valent cations. These additional oxygen ion vacancies are expected to primarily occupy 8a- and 48f-sites, and hence, could contribute to oxygen ion conduction. However, one has to remember that depending on temperature and $\mathrm{p}_{\mathrm{O} 2}$ charge compensation can also take by valence change of $\mathrm{Ru}$. Further, apart from the concentration of mobile oxygen vacancies, the oxygen ion conductivity also depends on structure factors such as jump directions, jump paths, activation barrier for the oxygen ion motion, and on dopant-vacancy interactions.

Bismuth ruthenate forms solid solution, with large solubility, with a number of dopants on the A-site and the doping does not significantly affect the electronic conductivity at least at room temperature ${ }^{66,67}$. In the present work, $\mathrm{Ca}^{2+}(\mathrm{r}=1.12 \AA), \mathrm{Sr}^{2+}(\mathrm{r}=1.26 \AA)$, $\operatorname{and~}_{\mathrm{Ag}^{+}}(\mathrm{r}=$ $1.28 \AA)$ with fixed valence and comparable ionic radii with the host $\mathrm{Bi}^{3+}(\mathrm{r}=1.17 \AA)$ were studied as dopants on A-site. The solubility limit in $\left(\mathrm{Bi}_{1-\mathrm{x}} \mathrm{M}_{\mathrm{x}}\right)_{2} \mathrm{Ru}_{2} \mathrm{O}_{7-\delta}$ for $\mathrm{Ca}^{2+}, \mathrm{Sr}^{2+}$, and $\mathrm{Ag}^{+}$ was estimated to be 50,30, and 20 mol\%, respectively ${ }^{66,67}$. This strategy was used keeping in mind that, possibly as in fluorite systems, the dopant with better matched ionic radii with the host would generate lesser elastic strains in the lattice and would show higher oxygen ion conductivity. It was hoped that the presence of mixed ionic and electronic conduction in the electrode would activate the oxygen reduction reaction on the complete surface and would just not be limited to the TPBs at the electrode/electrolyte interface. Symmetrical cells with doped bismuth ruthenate electrodes were fabricated on gadolinium doped ceria electrolyte pellets and ASR of the electrodes was measured using electrochemical impedance spectroscopy as a function of temperature and oxygen partial pressure. The following nomenclature has been used to identify the oxide compositions: $\mathrm{Bi}_{2} \mathrm{Ru}_{2} \mathrm{O}_{7} \equiv \mathrm{BRO}$ and $\left(\mathrm{Bi}_{1-\mathrm{x}} \mathrm{M}_{\mathrm{x}}\right)_{2} \mathrm{Ru}_{2} \mathrm{O}_{7-\delta} \equiv \mathrm{BMRx} ; \mathrm{M}=\mathrm{C}$ for $\mathrm{Ca}^{2+}, \mathrm{S}$ for $\mathrm{Sr}^{2+}$, and $\mathrm{A}$ for $\mathrm{Ag}^{+} ; \mathrm{x}=$ dopant $\mathrm{mol} \%$.

XRD patterns of calcined and leached powders: BRO, BCRx with $\mathrm{x}$ between 5 and 30 mol\%, BARx with $x$ between 5 and $20 \mathrm{~mol} \%$, and BSRx with $x$ equal to 10 and $20 \mathrm{~mol} \%$ are shown in Figure 63. Leaching with dilute $\mathrm{HNO}_{3}$ has earlier been found to be effective in removing the sillenite type-impurity phase $\left(\mathrm{Bi}_{12} \mathrm{RuO}_{20}\right)$, which results in predominant single phase powders ${ }^{68}$. 


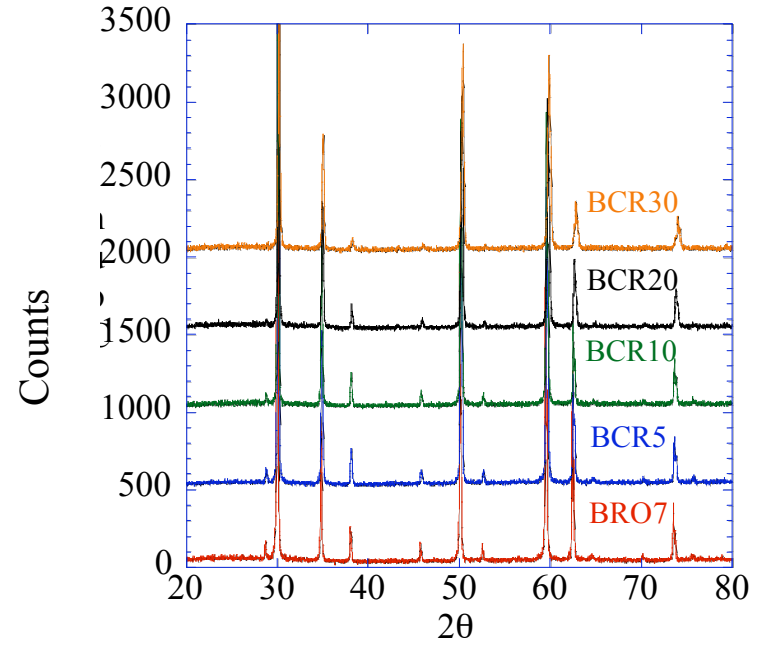

(a)

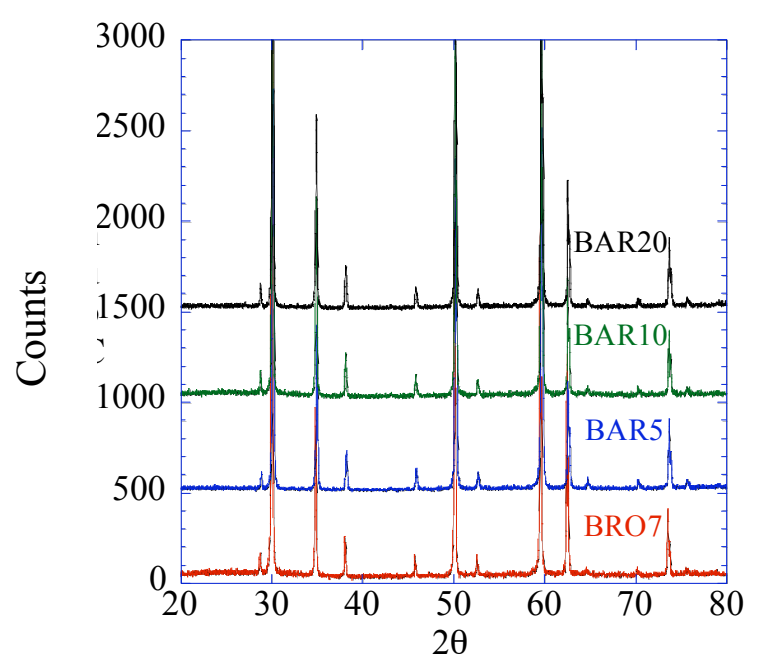

(b)

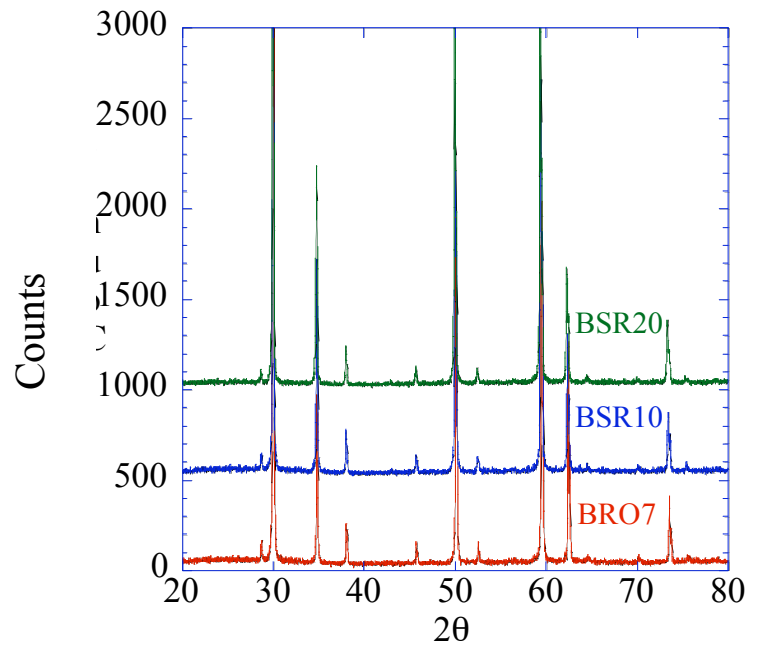

(c)

Figure 63. XRD patterns for (a) Ca doped bismuth ruthenate, (b) Ag doped bismuth ruthenate, and (c) $\mathrm{Sr}$ doped bismuth ruthenate powders. 
Table 1. Elemental composition of $\mathrm{Ca}$ and $\mathrm{Ag}$ doped bismuth ruthenates as measured by EDX.

\begin{tabular}{ccccc}
\hline & BCR5 & BCR20 & BAR5 & BAR20 \\
\hline Bi at $\%$ & 46.28 & 37.18 & 47.05 & 44.43 \\
Dopant at $\%$ & 2.59 & 10.41 & 1.73 & 4.54 \\
Ru at\% & 51.13 & 52.41 & 51.23 & 51.03 \\
Dopant $/(\mathrm{Bi}+$ Dopant $)$ & 0.05 & 0.22 & 0.04 & 0.09 \\
$(\mathrm{Bi}+$ Dopant $) / \mathrm{Ru}$ & 0.96 & 0.91 & 0.95 & 0.96 \\
\hline
\end{tabular}

EDX data for four different compositions are shown in Table 1. Due to the semiquantitative nature of EDX analysis, the compositions can be considered reasonably close to intended, apart from BAR20 which has Ag content lower than intended possibly due to leaching or Ag volatization during calcination. Lattice parameters of undoped and doped bismuth ruthenate powders, after calcination and leaching, are shown in Fig. 64; for comparison, lattice parameters from the study by Kemmler-Sack and co-workers are also shown ${ }^{66,67}$. Lattice parameter for undoped bismuth ruthenate matched well between the two studies; $10.292( \pm 0.002)$ $\AA$ in this study and $10.292( \pm 0.007) \AA$ reported previously ${ }^{66,67}$. The trends for change in lattice parameter with dopant type and concentration also matched well between the two data-sets;

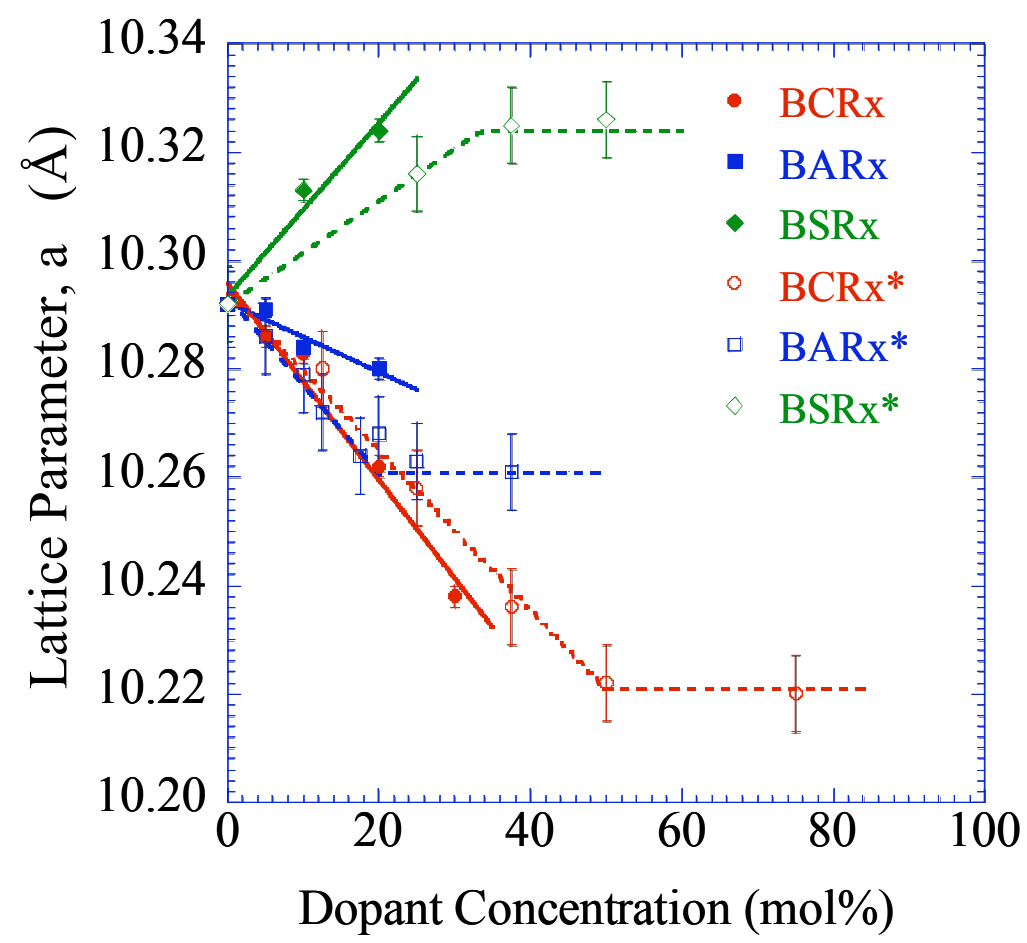

Figure 64. Lattice constants as a function of dopant concentration for $\mathrm{Ca}, \mathrm{Ag}$, and $\mathrm{Sr}$ doped bismuth ruthenate powders $(*$ - from reference 14 and 15$)$. 


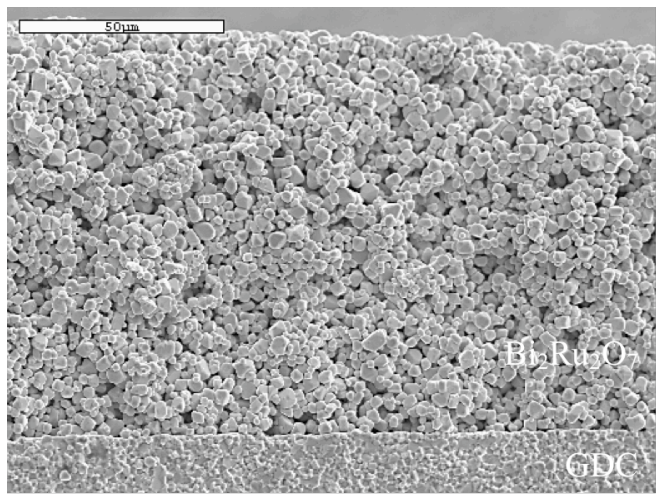

(a)

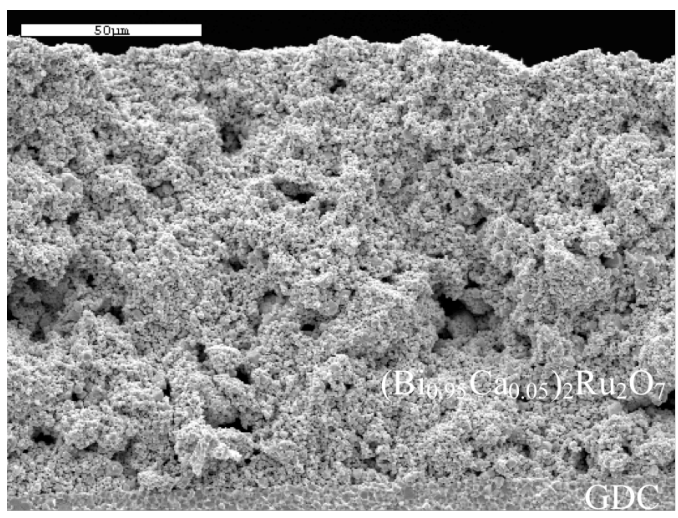

(b)

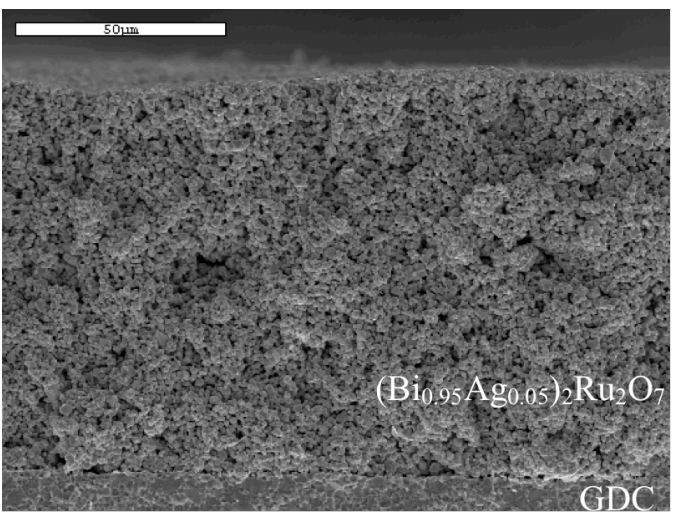

(c)

Figure 65. Cross-section micrographs of (a) $\mathrm{Bi}_{2} \mathrm{Ru}_{2} \mathrm{O}_{7}$, (b) $\left(\mathrm{Bi}_{0.95} \mathrm{Ca}_{0.05}\right)_{2} \mathrm{Ru}_{2} \mathrm{O}_{7}$, and (c) $\left(\mathrm{Bi}_{0.95} \mathrm{Ag}_{0.05}\right)_{2} \mathrm{Ru}_{2} \mathrm{O}_{7}$ electrodes on GDC electrolyte sintered at $850{ }^{\circ} \mathrm{C}$.

however, the magnitudes were found to be different for $\mathrm{Ag}$ and $\mathrm{Sr}$ doped bismuth ruthenate powders. As-expected on the basis of ionic radii, the lattice parameter increased and decreased on doping with $\mathrm{Sr}$ and $\mathrm{Ca}$, respectively. To account for the unexpected decrease in the lattice parameter for Ag-doped system $\left(\mathrm{Ag}^{+}\right.$has a larger ionic radii than $\left.\mathrm{Bi}^{3+}\right)$, it was suggested that $\mathrm{Ag}$ exists in $2+$ valence state in the lattice ${ }^{67}$. Lattice parameter difference between the two data-sets for the Ag-doped system could be partly attributed to the above mentioned Ag loss.

Representative cross-sectional micrographs of undoped and doped bismuth ruthenates electrodes on GDC electrolyte are shown in Fig. 65. After sintering at $850^{\circ} \mathrm{C}$, the electrodes are porous with thickness between 100-115 $\mu \mathrm{m}$.

Impedance plots of $\mathrm{Bi}_{2} \mathrm{Ru}_{2} \mathrm{O}_{7}$ and $\mathrm{Ca}$ doped $\mathrm{Bi}_{2} \mathrm{Ru}_{2} \mathrm{O}_{7}(\mathrm{BCRx} ; \mathrm{x}=5-30 \mathrm{~mol} \%)$ at $700{ }^{\circ} \mathrm{C}$ are shown in Figure 66. The electrode ASR was calculated by multiplying the electrode resistance by the electrode area $\left(\sim 0.7 \mathrm{~cm}^{2}\right)$ and dividing by 2 to account for the symmetric cell. 


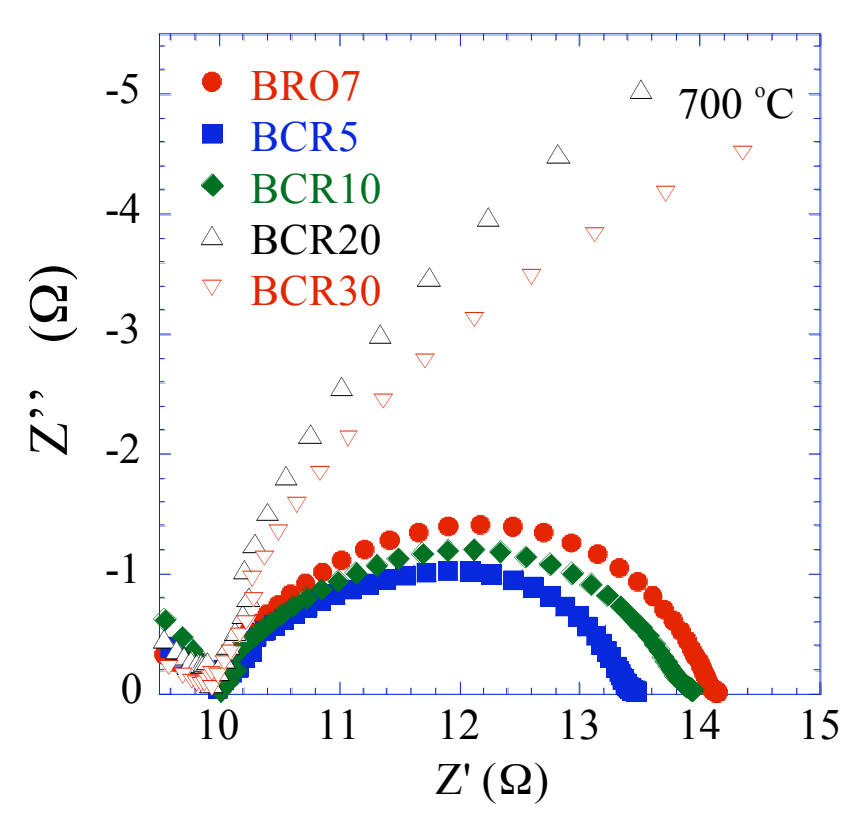

(a)

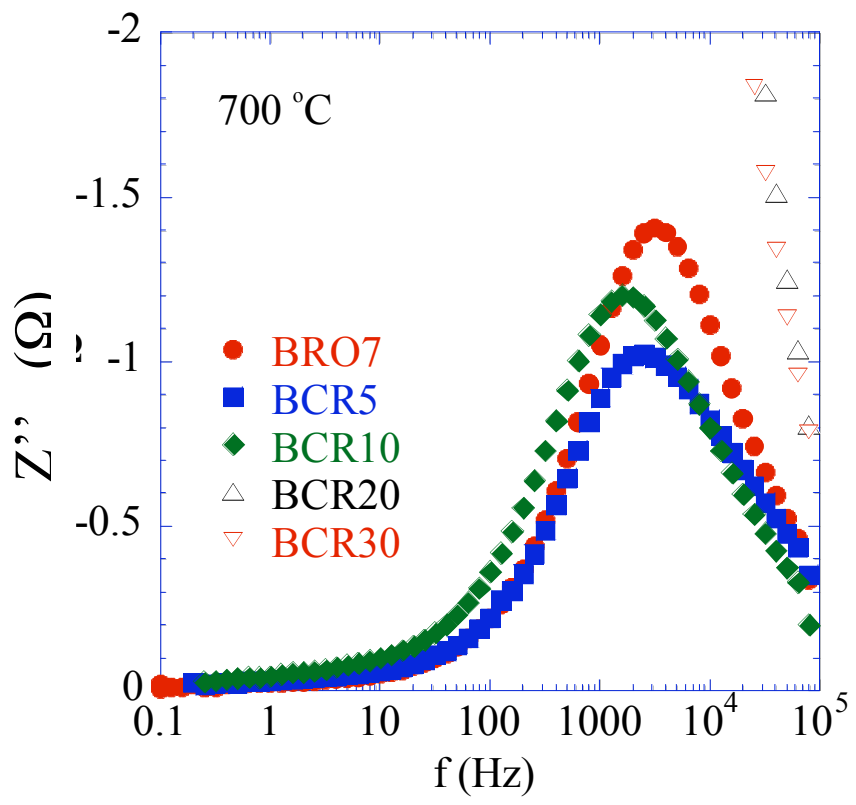

(c)

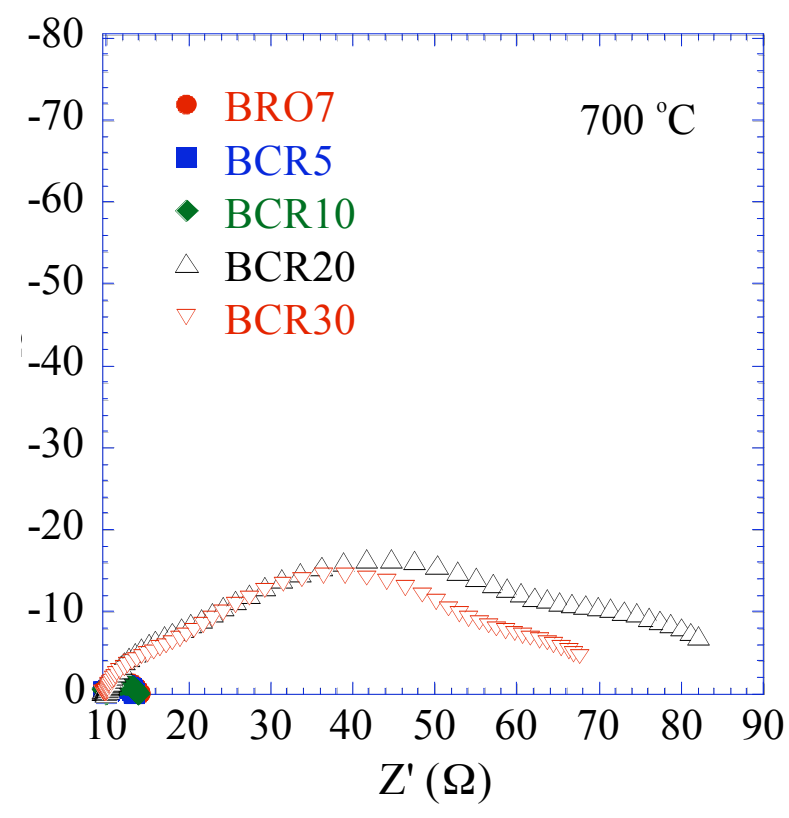

(b)

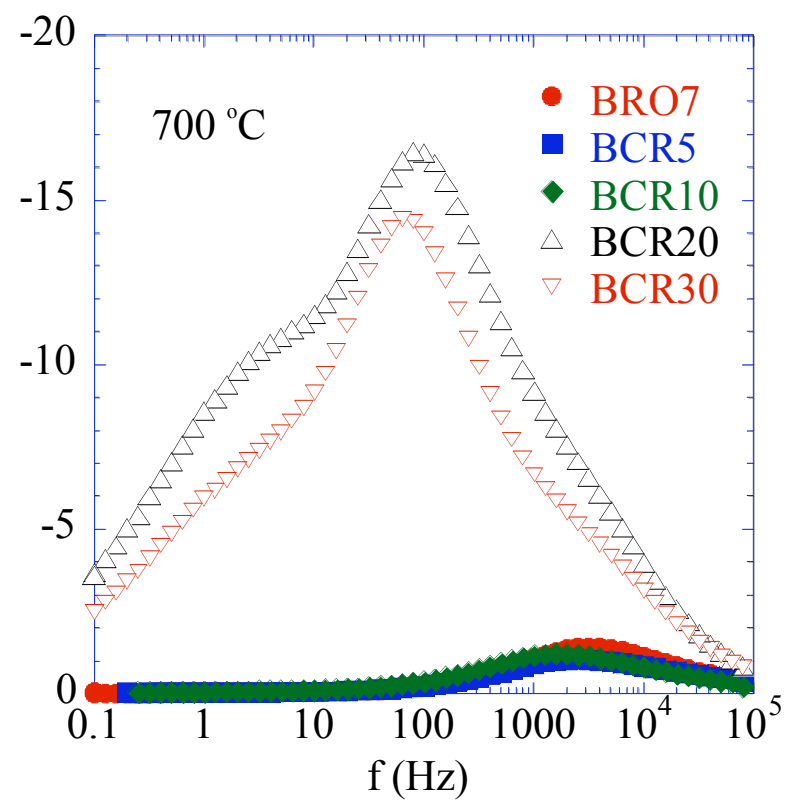

(d)

Figure 66. Impedance plots of $\mathrm{Ca}$ doped $\mathrm{Bi}_{2} \mathrm{Ru}_{2} \mathrm{O}_{7}$ electrodes on $\mathrm{GDC}$ at $700{ }^{\circ} \mathrm{C}$ (a) and (b) imaginary vs. real impedance, (c) and (d) imaginary impedance vs. frequency. 


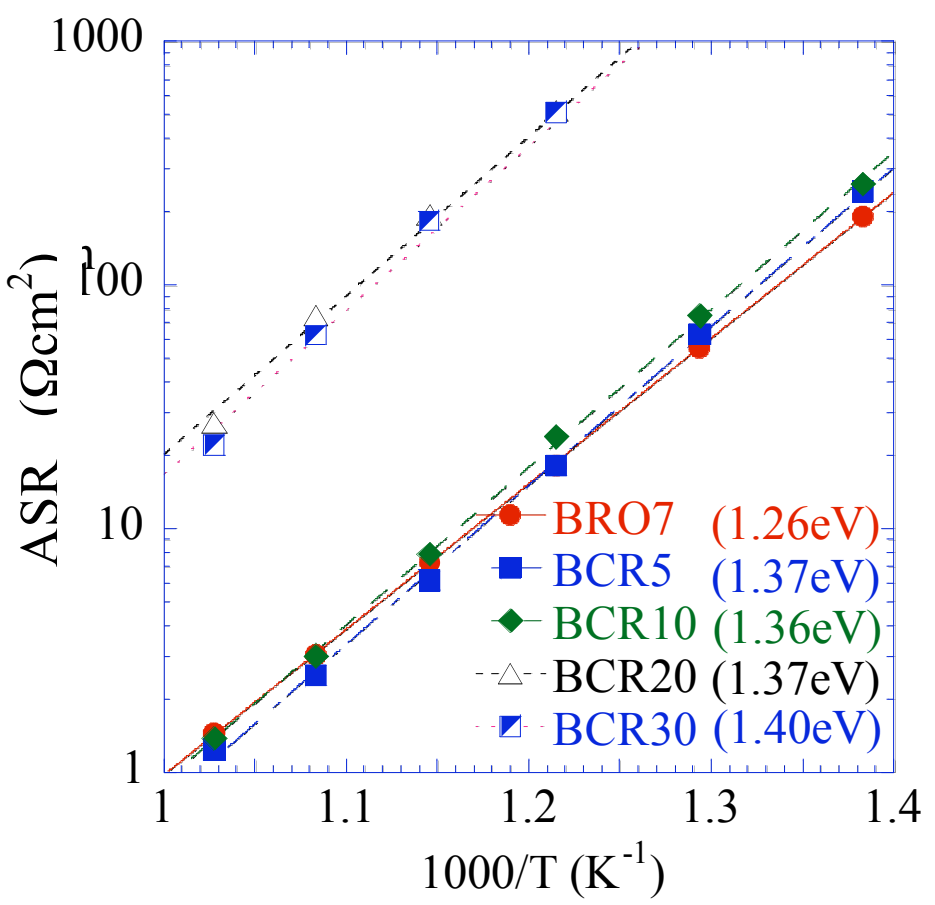

Figure 67. Arrhenius plot of $\mathrm{Ca}$ doped $\mathrm{Bi}_{2} \mathrm{Ru}_{2} \mathrm{O}_{7}$ electrode $\mathrm{ASR}\left(\Omega \mathrm{cm}^{2}\right)$ in air.

Arrhenius plot of the electrode ASR in air is shown in Figure 67. At $500{ }^{\circ} \mathrm{C}$, all dopant levels led to increase in the electrode polarization, while at $700{ }^{\circ} \mathrm{C}, 5$ and $10 \mathrm{~mol} \%$ doping resulted in decrease in the electrode polarization as compared to undoped bismuth ruthenate. At $700{ }^{\circ} \mathrm{C}$, ASR values for undoped, $5 \mathrm{~mol} \%$, and $10 \mathrm{~mol} \% \mathrm{Ca}$ doped bismuth ruthenate electrodes are $1.45,1.24$, and $1.38 \wedge \mathrm{cm}^{2}$, respectively. The electrode characteristic frequency, at which the magnitude of imaginary part of impedance (Z") is maximum, was same for undoped, $5 \mathrm{~mol} \%$, and $10 \mathrm{~mol} \% \mathrm{Ca}$ doped bismuth ruthenate, suggesting that the rate limiting steps in the electrode reaction has not changed with doping. However with $x \geq 20 \mathrm{~mol} \%$, the electrode polarization is an order of magnitude higher along with additional electrode arcs at lower frequencies. As the microstructure (particle size, porosity, and thickness) of electrodes are comparable, the drastic increase in polarization at high dopant levels is attributed primarily to compositional effects. Doping resulted in the increase in activation energy from $\sim 1.26 \mathrm{eV}$ for undoped $\mathrm{Bi}_{2} \mathrm{Ru}_{2} \mathrm{O}_{7}$ to $\sim 1.37 \mathrm{eV}$ for $\mathrm{Ca}$ doped $\mathrm{Bi}_{2} \mathrm{Ru}_{2} \mathrm{O}_{7}$, though 5 and $10 \mathrm{~mol} \% \mathrm{Ca}$ doped $\mathrm{Bi}_{2} \mathrm{Ru}_{2} \mathrm{O}_{7}$ showed better performance at higher temperatures. 

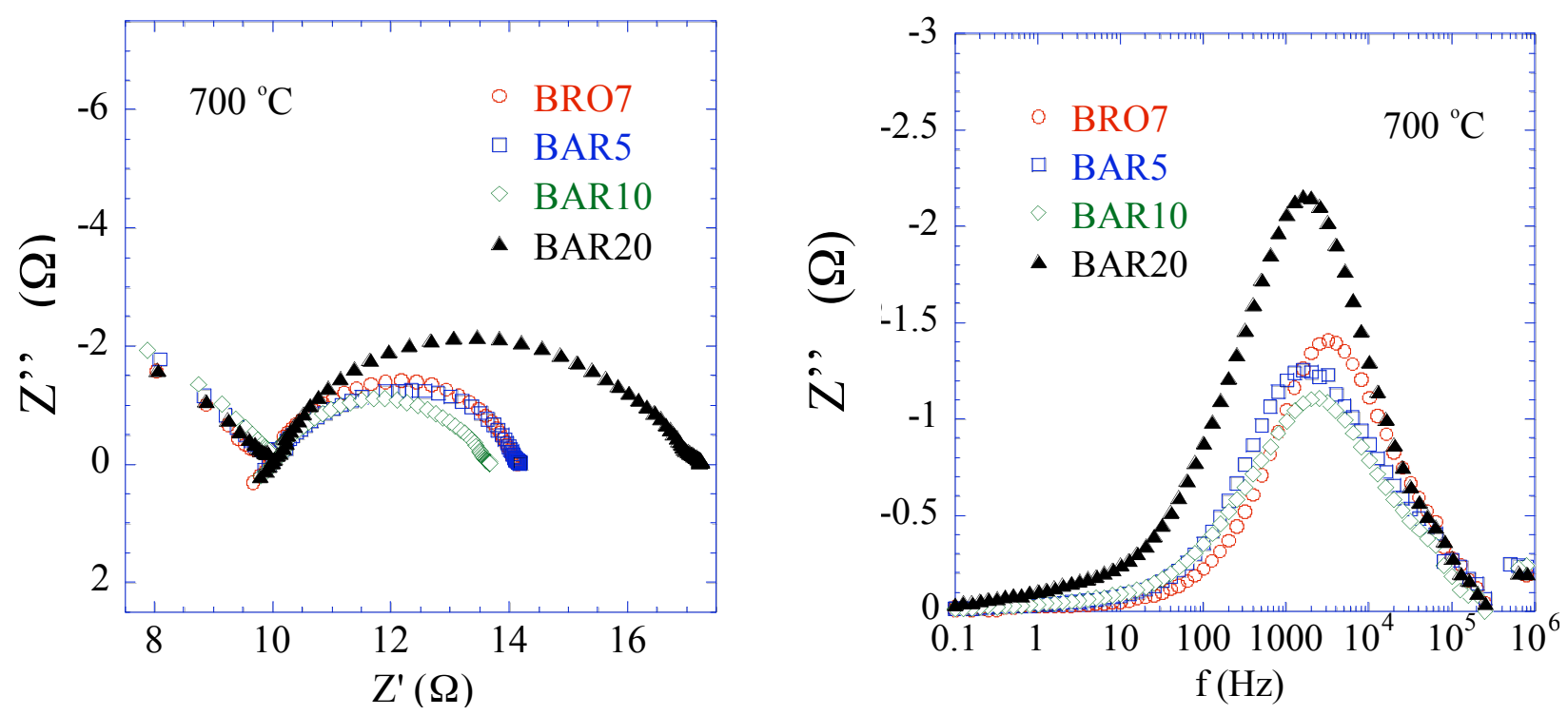

Figure 68. Impedance plots of $\mathrm{Ag}$ doped $\mathrm{Bi}_{2} \mathrm{Ru}_{2} \mathrm{O}_{7}$ electrodes on $\mathrm{GDC}$ at $700{ }^{\circ} \mathrm{C}$ (a) imaginary vs. real impedance, (b) imaginary impedance vs. frequency.

Impedance plots of $\mathrm{Ag}$ doped $\mathrm{Bi}_{2} \mathrm{Ru}_{2} \mathrm{O}_{7}(\mathrm{BARx} ; \mathrm{x}=5-20 \mathrm{~mol} \%)$ at $700{ }^{\circ} \mathrm{C}$ are shown in Fig. 68. The performance was similar to that of $\mathrm{Ca}$ doped systems: same characteristic frequency for undoped and doped electrodes, higher activation energy compared to undoped $\mathrm{Bi}_{2} \mathrm{Ru}_{2} \mathrm{O}_{7}$ and better performance at temperatures higher than $\sim 550{ }^{\circ} \mathrm{C}$ with 5 and $10 \mathrm{~mol} \% \mathrm{Ag}$ doped $\mathrm{Bi}_{2} \mathrm{Ru}_{2} \mathrm{O}_{7}$ as shown in Fig. 69.

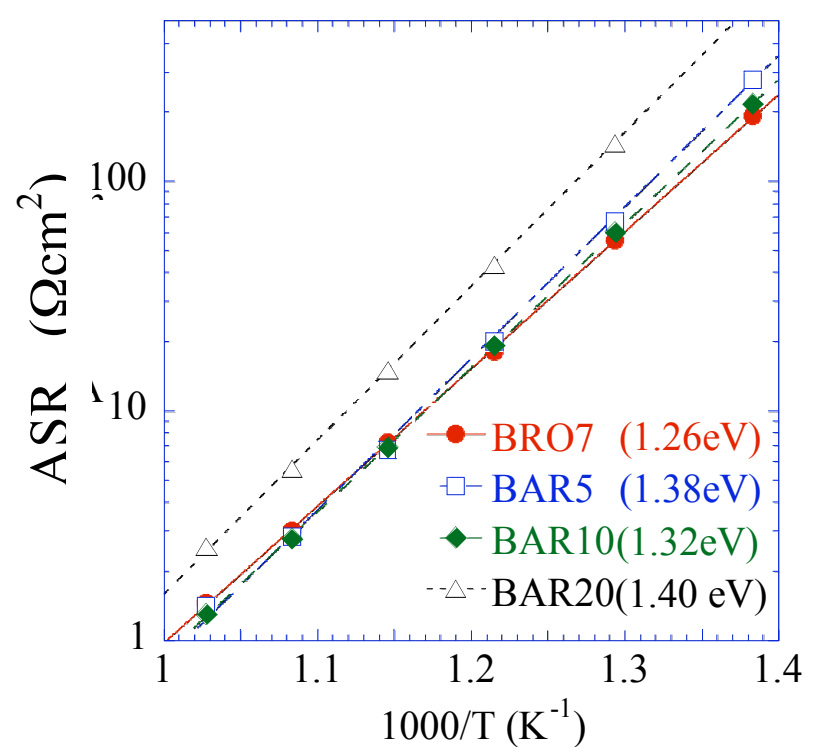

Figure 69. Arrhenius plot of $\mathrm{Ag}$ doped $\mathrm{Bi}_{2} \mathrm{Ru}_{2} \mathrm{O}_{7}$ electrode $\mathrm{ASR}\left(\Omega \mathrm{cm}^{2}\right)$ in air. 


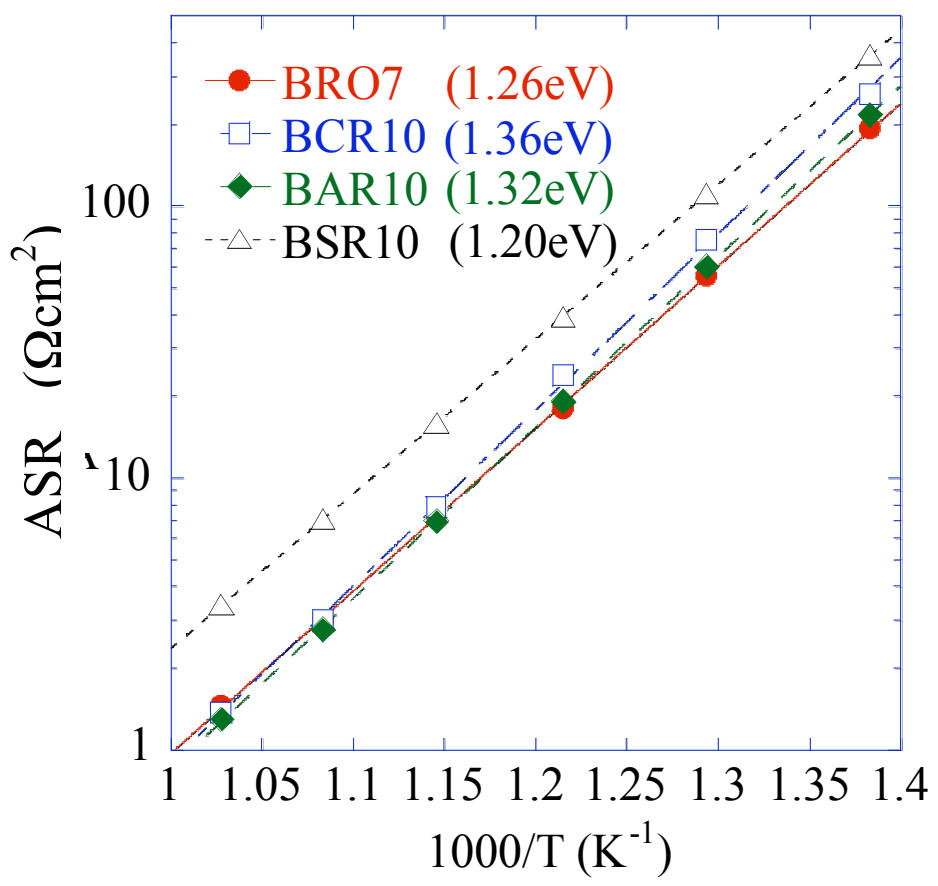

Figure 70. Arrhenius plot of undoped, $10 \mathrm{~mol} \% \mathrm{Ca}-$, Ag- and $\mathrm{Sr}$-doped $\mathrm{Bi}_{2} \mathrm{Ru}_{2} \mathrm{O}_{7}$ electrode ASR in air.

At $700{ }^{\circ} \mathrm{C}$, ASR values for 5 and $10 \mathrm{~mol} \%$ Ag-doped bismuth ruthenate electrodes are $1.41 \Omega \mathrm{cm}^{2}$ and $1.31 \Omega \mathrm{cm}^{2}$, respectively. $10 \mathrm{~mol} \% \mathrm{Sr}$-doped $\mathrm{Bi}_{2} \mathrm{Ru}_{2} \mathrm{O}_{7}(\mathrm{BSR} 10)$ showed inferior performance than undoped, $10 \mathrm{~mol} \% \mathrm{Ca}$, and $10 \mathrm{~mol} \% \mathrm{Ag}$-doped $\mathrm{Bi}_{2} \mathrm{Ru}_{2} \mathrm{O}_{7}$ as shown in Fig. 70, and hence systems with $\mathrm{Sr}$ as a dopant were not studied further.

Electrode polarization of $5 \mathrm{~mol} \% \mathrm{Ca}$ - and $5 \mathrm{~mol} \%$ Ag-doped $\mathrm{Bi}_{2} \mathrm{Ru}_{2} \mathrm{O}_{7}$ was studied as a function of $\mathrm{P}_{\mathrm{O}_{2}}$ in order to understand the rate limiting steps with these electrodes. Impedance plots for $5 \mathrm{~mol} \% \mathrm{Ca}$-doped system are shown in Fig. 71, while for $5 \mathrm{~mol} \%$ Ag-doped system are shown in Fig. 72. For both systems, electrode impedance decreased and characteristic frequency increased with increase in $\mathrm{P}_{\mathrm{O}_{2}}$. In general, the electrode ASR varies with the oxygen partial pressure according Eq. (4) where the magnitude of the exponent m provides an insight into the rate limiting step in the oxygen reduction reaction at the cathode. Plots of $\ln ($ ASR $)$ vs. $\ln \left(\mathrm{P}_{\mathrm{O}_{2}}\right)$ at temperatures between $400{ }^{\circ} \mathrm{C}-700{ }^{\circ} \mathrm{C}$ for $5 \mathrm{~mol} \% \mathrm{Ca}$ - and Ag-doped systems are shown in Figs. 73 and 74, respectively. The value of $\mathrm{m}$ for $5 \mathrm{~mol} \% \mathrm{Ca}$-doped $\mathrm{Bi}_{2} \mathrm{Ru}_{2} \mathrm{O}_{7}$ ranged between 0.6 and 0.8 at $0.11 \leq \mathrm{P}_{\mathrm{O}_{2}}(\mathrm{~atm}) \leq 1$ and at a lower $\mathrm{P}_{\mathrm{O}_{2}}$ of $0.04 \mathrm{~atm}$, the value of $\mathrm{m}$ increased indicating a change in the rate limiting step. On the other hand for $5 \mathrm{~mol} \% \mathrm{Ag}$ doped $\mathrm{Bi}_{2} \mathrm{Ru}_{2} \mathrm{O}_{7}$, the value of 


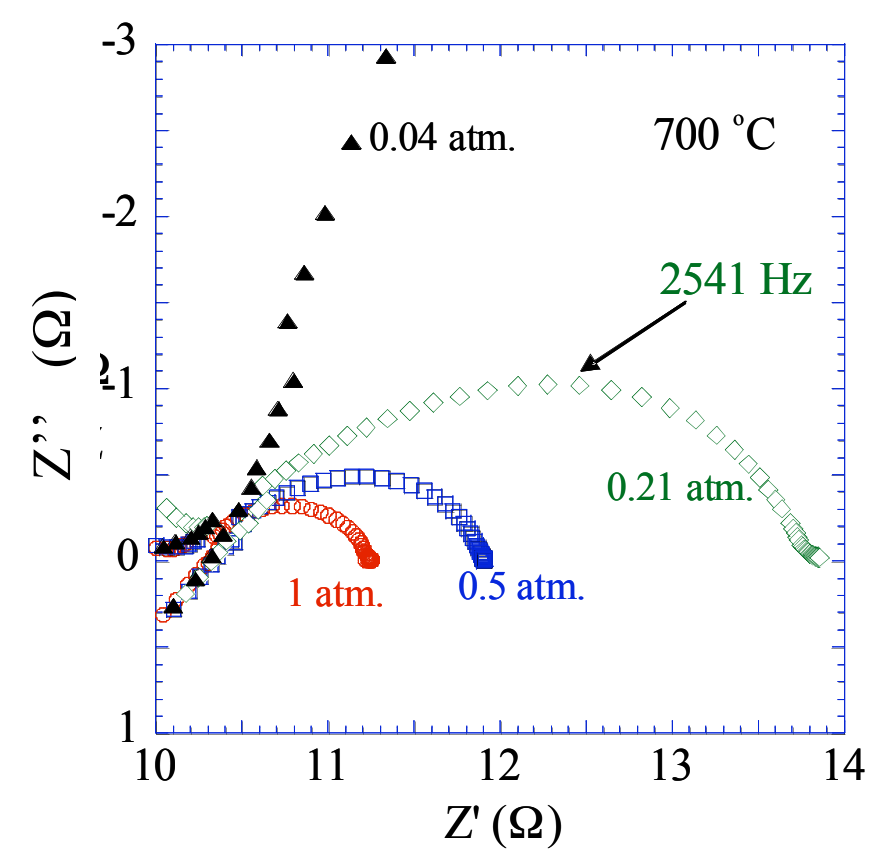

(a)

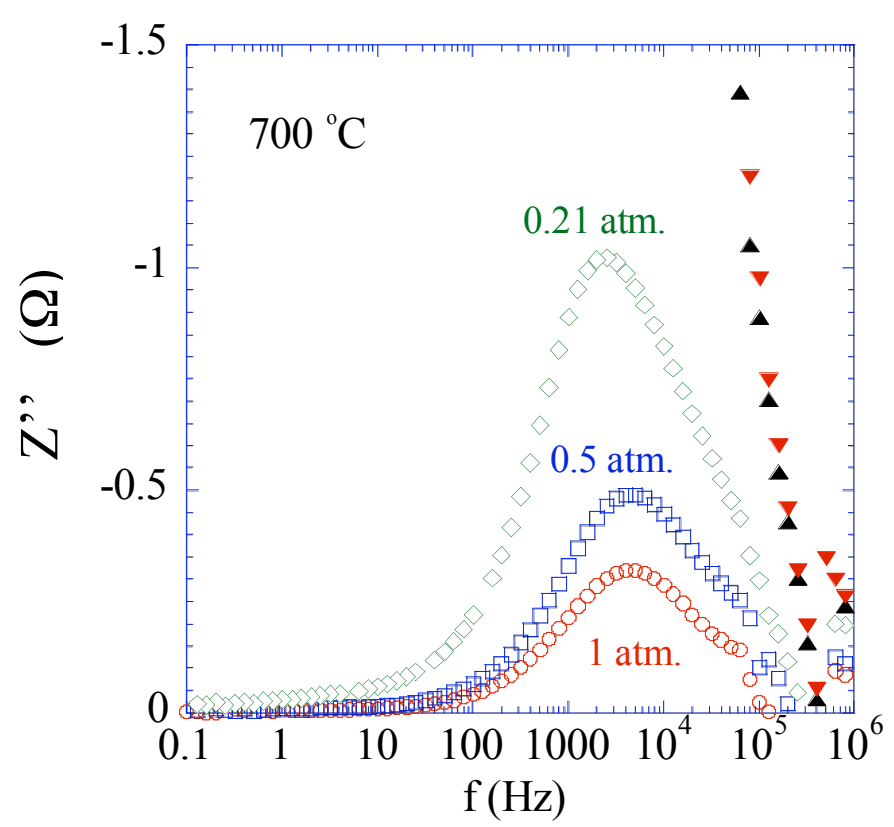

(c)

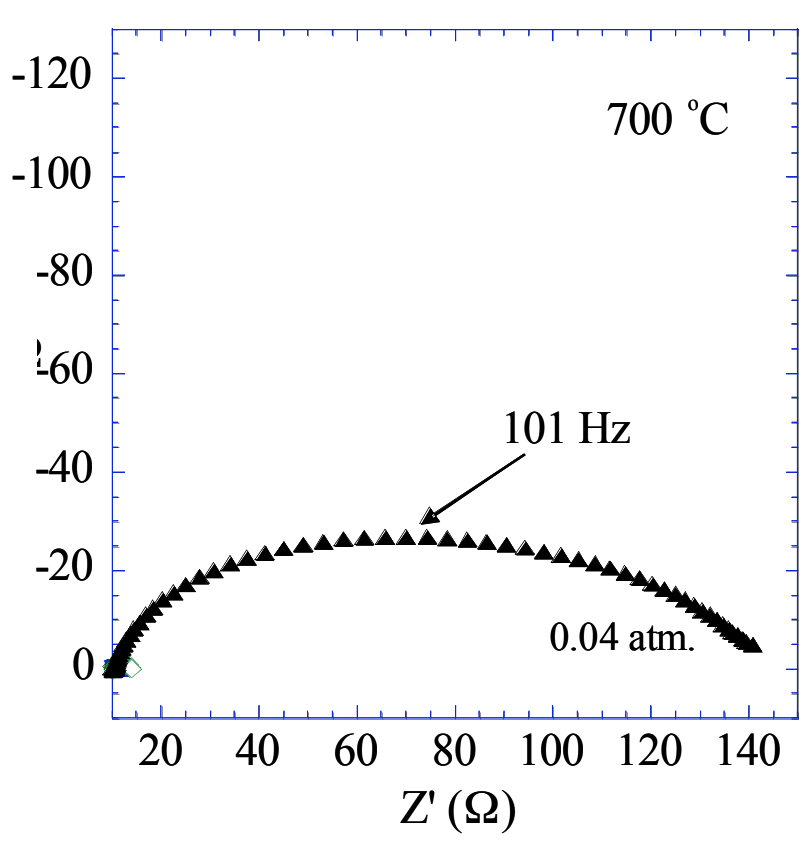

(b)

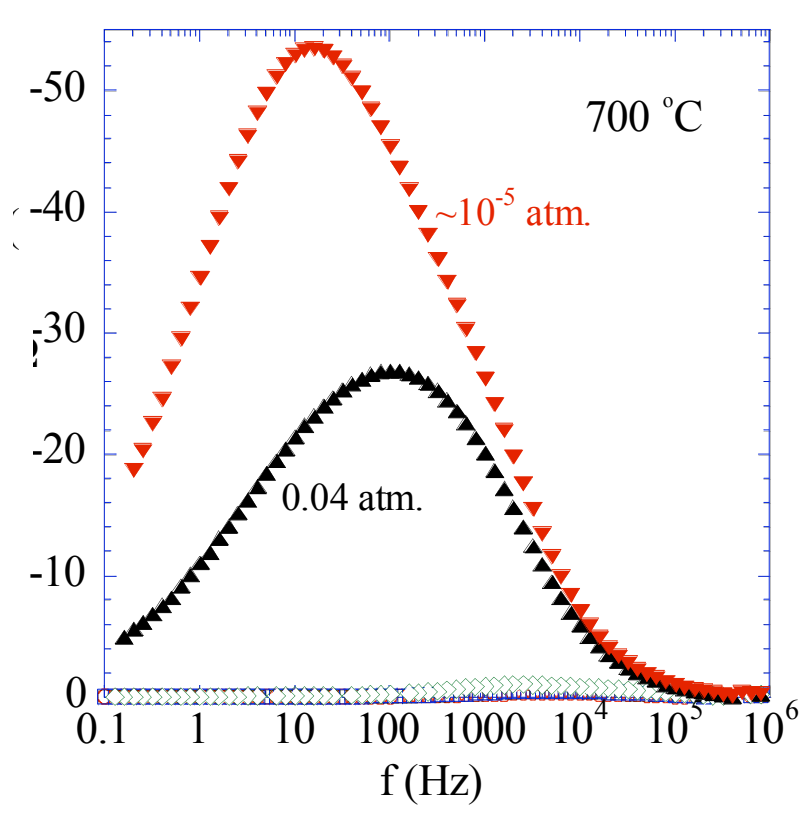

(d)

Figure 71. Impedance plots of 5 mol\% Ca-doped $\mathrm{Bi}_{2} \mathrm{Ru}_{2} \mathrm{O}_{7}$ electrodes on GDC at $700{ }^{\circ} \mathrm{C}$ (a) and (b) imaginary vs. real impedance, (c) and (d) imaginary impedance vs. frequency. 


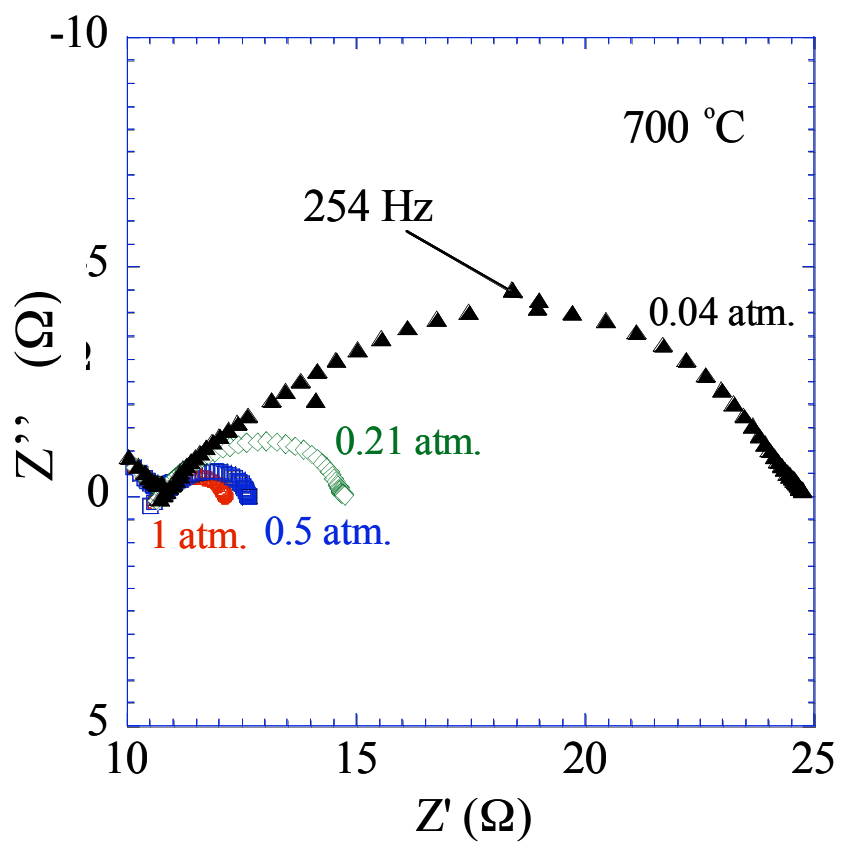

(a)
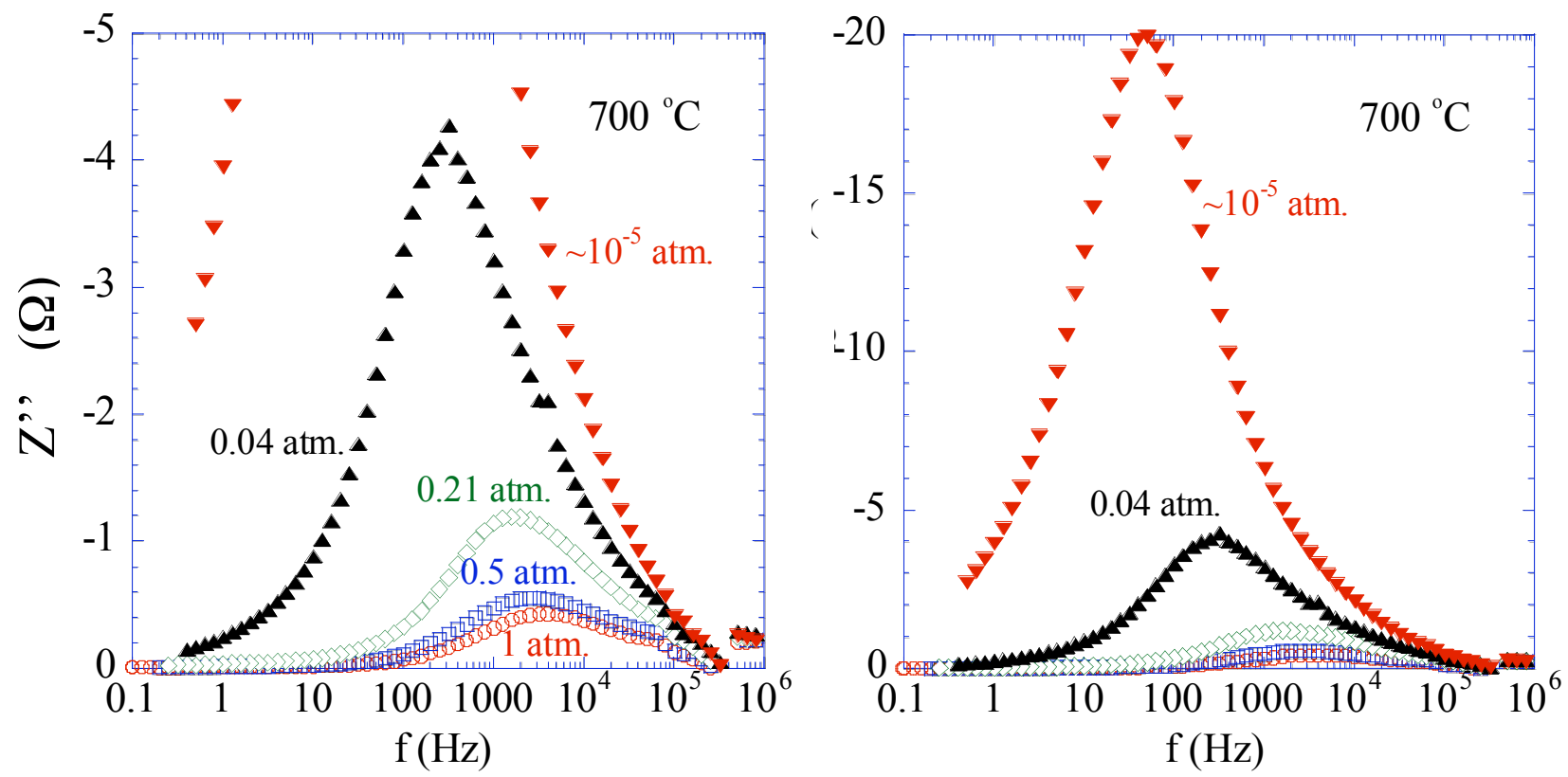

Figure 72. Impedance plots of $5 \mathrm{~mol} \% \mathrm{Ag}$-doped $\mathrm{Bi}_{2} \mathrm{Ru}_{2} \mathrm{O}_{7}$ electrodes on $\mathrm{GDC}$ at $700{ }^{\circ} \mathrm{C}$ (a) imaginary vs. real impedance, (b) and (c) imaginary impedance vs. frequency. 


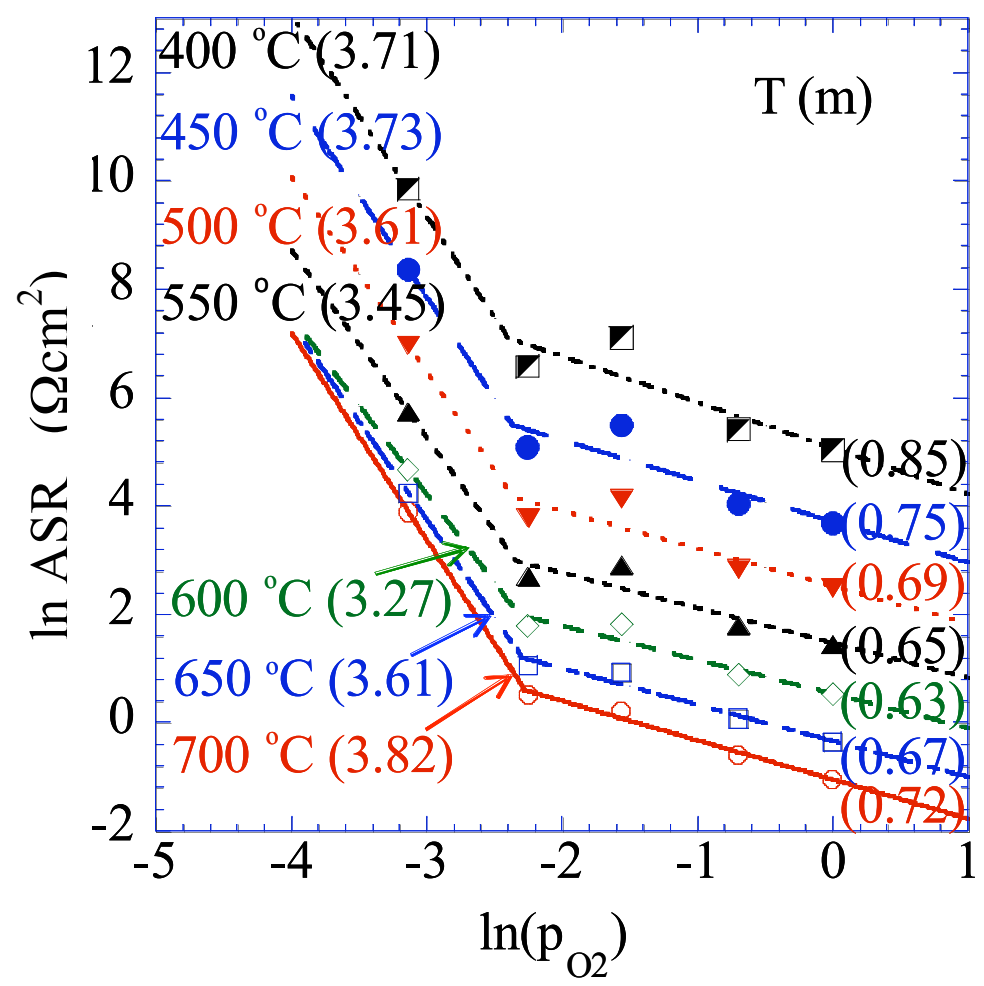

Figure 73. $\ln (\mathrm{ASR})$ vs. $\ln \left(\mathrm{P}_{\mathrm{O}_{2}}\right)$ of $5 \mathrm{~mol} \% \mathrm{Ca}$ doped $\mathrm{Bi}_{2} \mathrm{Ru}_{2} \mathrm{O}_{7}$ electrode at different temperatures with $\mathrm{m}$ in parenthesis, i.e., $\mathrm{T}(\mathrm{m})$.

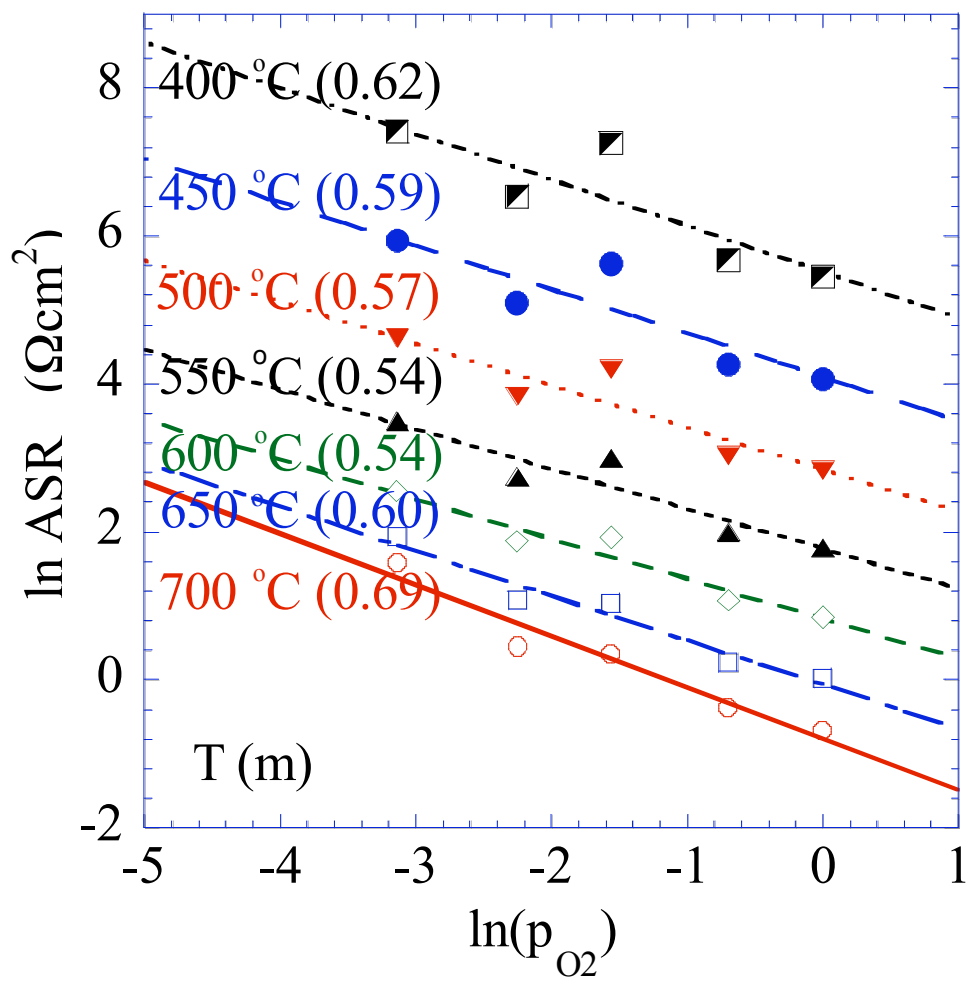

Figure 74. $\ln (\mathrm{ASR})$ vs. $\ln \left(\mathrm{P}_{\mathrm{O}_{2}}\right)$ of $5 \mathrm{~mol} \% \mathrm{Ag}$-doped $\mathrm{Bi}_{2} \mathrm{Ru}_{2} \mathrm{O}_{7}$ electrode at different temperatures with $\mathrm{m}$ in parenthesis, i.e., $\mathrm{T}(\mathrm{m})$. 


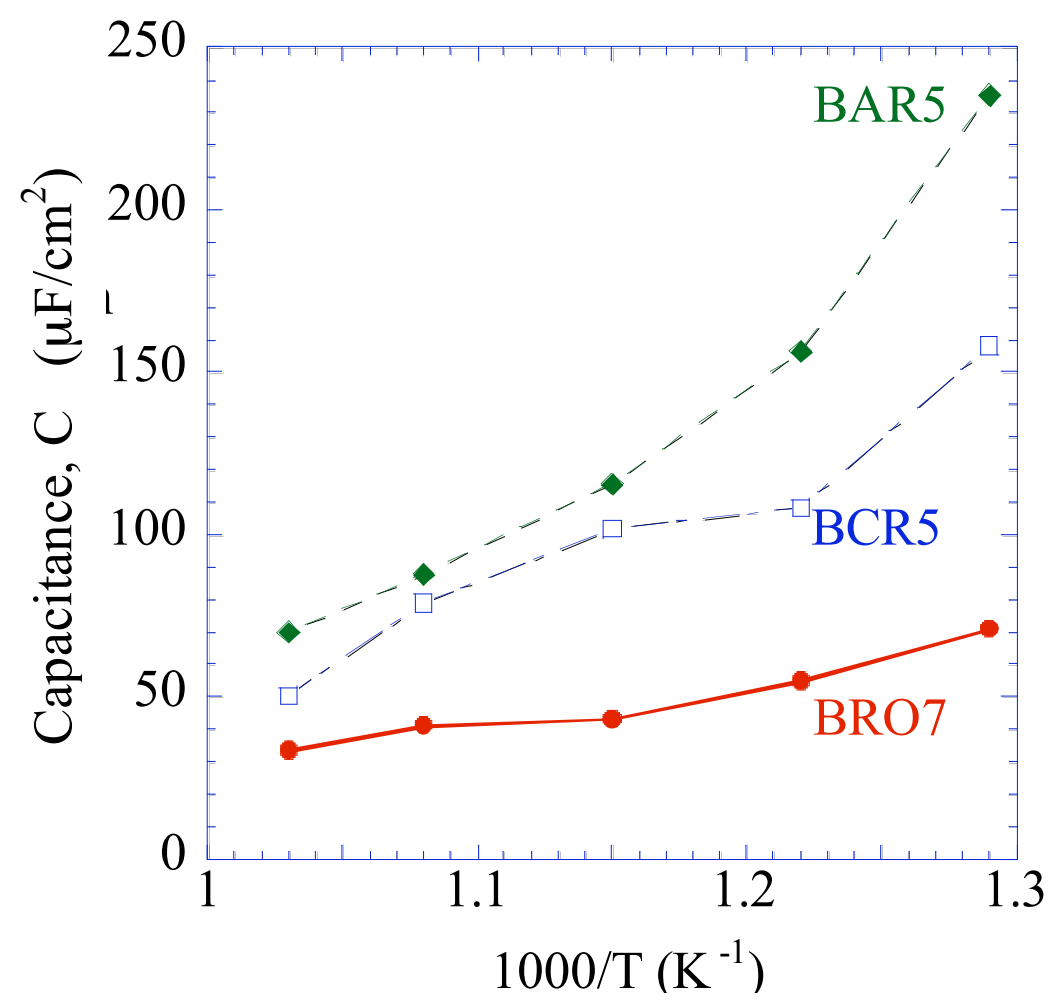

Figure 75. Capacitance $\left(\mu \mathrm{F} / \mathrm{cm}^{2}\right)$ in air of $\mathrm{Bi}_{2} \mathrm{Ru}_{2} \mathrm{O}_{7}, 5 \mathrm{~mol} \% \mathrm{Ca}$ - and $\mathrm{Ag}$-doped $\mathrm{Bi}_{2} \mathrm{Ru}_{2} \mathrm{O}_{7}$ electrodes.

$\mathrm{m}$ ranged consistently between 0.5 and 0.6 in the complete $\mathrm{p}_{\mathrm{O} 2}$ range of study. In an earlier study on undoped bismuth ruthenate electrodes, the value of $\mathrm{m}$ was found to be between 0.5 and 0.6 in the same temperature and $\mathrm{P}_{\mathrm{O}_{2}}$ range ${ }^{68}$. A magnitude of 0.5 for $\mathrm{m}$ was related in the literature to surface diffusion of the dissociatively adsorbed oxygen at the electrodes to the TPBs ${ }^{62,64,69}$, which appears to be one of the rate limiting steps for undoped, $5 \mathrm{~mol} \% \mathrm{Ca}$, and $5 \mathrm{~mol} \% \mathrm{Ag}$ doped bismuth ruthenate electrodes.

Electrode capacitance (in $\mathrm{F} / \mathrm{cm}^{2}$ ), $\mathrm{C}$, was calculated by using the following equation

$$
\mathrm{C}=1 /\left(2 \pi \mathrm{f}^{*} \mathrm{ASR}\right)
$$

where, $\mathrm{f}$ is electrode characteristic frequency in $\mathrm{Hz}$, and ASR is electrode area specific resistance in $\Omega \mathrm{cm}^{2}$. Electrode capacitance of undoped, $5 \mathrm{~mol} \% \mathrm{Ca}$, and $5 \mathrm{~mol} \% \mathrm{Ag}$-doped bismuth ruthenate electrodes in air as a function of temperature is shown in Fig. 75.

Capacitance of the electrodes as a function of $\mathrm{P}_{\mathrm{O}_{2}}$ at $500{ }^{\circ} \mathrm{C}$ and $700{ }^{\circ} \mathrm{C}$ is shown in Fig. 76. Electrode capacitance in air of the doped systems is higher and a stronger function of 


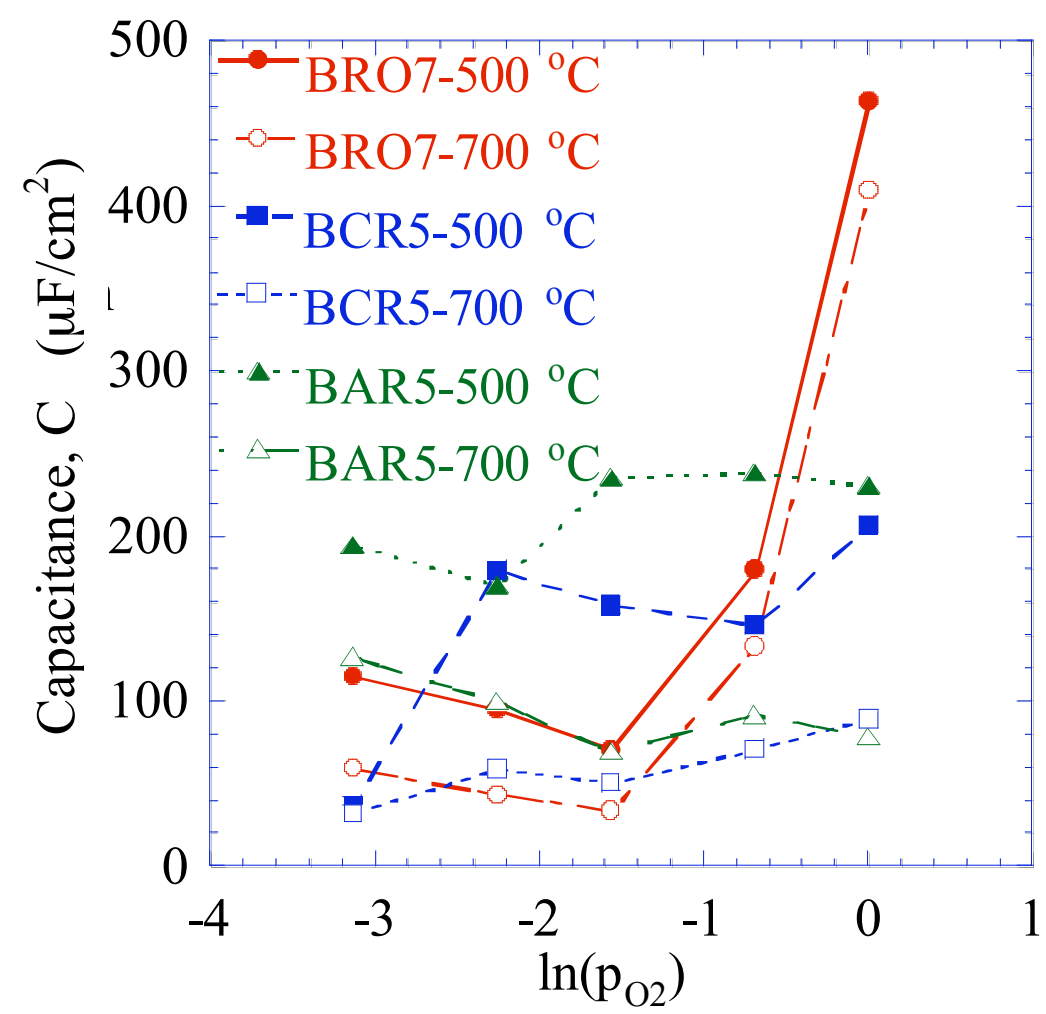

Figure 76. Electrode capacitance $\left(\mu \mathrm{F} / \mathrm{cm}^{2}\right)$ vs $\ln \left(\mathrm{P}_{\mathrm{O}_{2}}\right)$ of $\mathrm{Bi}_{2} \mathrm{Ru}_{2} \mathrm{O}_{7}, 5 \mathrm{~mol} \% \mathrm{Ca}$ and $\mathrm{Ag}$ doped $\mathrm{Bi}_{2} \mathrm{Ru}_{2} \mathrm{O}_{7}$ electrodes at 500 and $700{ }^{\circ} \mathrm{C}$.

temperature in comparison to the undoped bismuth ruthenate; for example, undoped, $5 \mathrm{~mol} \% \mathrm{Ca}$ and Sr-doped bismuth ruthenate electrodes showed capacitance of 70.99, 158.17, and 235.51 $\mu \mathrm{F} / \mathrm{cm}^{2}$ and $33.70,50.37$, and $70.16 \mu \mathrm{F} / \mathrm{cm}^{2}$ at 500 and $700{ }^{\circ} \mathrm{C}$, respectively. On the other hand, capacitance of undoped bismuth ruthenate is a strongly influenced by $\mathrm{P}_{\mathrm{O}_{2}}$ while the doped systems have a relatively flat profile; for $5 \mathrm{~mol} \% \mathrm{Ca}$ doped system, the sharp decrease in capacitance at $0.04 \mathrm{~atm} ., 500{ }^{\circ} \mathrm{C}$ correlates well with sharp increase in magnitude of $\mathrm{m}$ and a change in reaction mechanism. Electrode capacitance is a complex parameter affected by number of factors (including ionic and electronic conduction) and is indicative of the electrode reaction mechanism. Evidently, doping changed the electrode capacitance, both as a function of temperature and oxygen partial pressure, but not to an extent to alter the rate limiting step and to improve the electrode ASR significantly.

It was found that the performance of $\mathrm{Bi}_{2} \mathrm{Ru}_{2} \mathrm{O}_{7}$ electrode was also not influenced to a great degree by the electrode particle size and thickness. Electrode ASR, characteristic 
frequency, and activation energy of $\mathrm{Bi}_{2} \mathrm{Ru}_{2} \mathrm{O}_{7}$ electrode $(\sim 3 / \mathrm{m}$ particle size and $\sim 100 \quad \mathrm{~m})$ fabricated from as-calcined powders was comparable to $\mathrm{Bi}_{2} \mathrm{Ru}_{2} \mathrm{O}_{7}$ electrode $(\sim 1\lceil\mathrm{~m}$ particle size and $\sim 10$ ( $\mathrm{m}$ thick) fabricated from vibration milled powders as described in a later section.

The pyrochlore structure consists of $\mathrm{BO}_{6}$ trigonal antiprism and $\mathrm{A}_{2} \mathrm{O}^{\prime}$ anticyrstobalite chains. Vacancies are known to exist on both A- and $\mathrm{O}^{\prime}$-sites, as $\mathrm{A}_{2} \mathrm{O}$ ' sublattice is not essential for the stability of the oxide ${ }^{70}$. Doping with aliovalent cations and change in oxygen activity further complicates the defect chemistry of the system. The electronic properties of ruthenate pyrochlores has been correlated with the Ru-O bond length and Ru-O-Ru bond angle ${ }^{70,71,72}$. The bond length and bond angle in the $\mathrm{RuO}_{6}$ trigonal antiprism is related to the degree of the overlap between $\mathrm{Ru}-4 \mathrm{~d}$ and $\mathrm{O}-2 \mathrm{p}$ orbitals, and therefore, to the spitting of $\mathrm{t}_{2 \mathrm{~g}}$ and $\mathrm{e}_{\mathrm{g}}$ by the cubic field; $E_{F}$, the Fermi energy level, is mostly composed of anti-bonding states of Ru- $4 d$ and O- $2 p$ orbitals. As the Ru-O-Ru bond angle decreases, the orbital overlap also decreases, resulting in narrowed band and decreased mobility. Recently, it has been observed that apart from these two factors, the interaction of $\mathrm{A}$-ion orbitals with $\mathrm{Ru}-4 \mathrm{~d}$ and $\mathrm{O}-2 \mathrm{p}$ orbitals near $\mathrm{E}_{\mathrm{F}}$ plays a significant role in the observed drift in electronic properties of various ruthenate pyrochlores which are isostructural and iso-electronic; $\mathrm{Bi}_{2} \mathrm{Ru}_{2} \mathrm{O}_{7}$ and $\mathrm{Pb}_{2} \mathrm{Ru}_{2} \mathrm{O}_{6.5}$ are weakly metallic (temperature independent resistivity over broad temperature range) and $\mathrm{Y}_{2} \mathrm{Ru}_{2} \mathrm{O}_{7}$ and lanthanide ruthenate pyrochlores are semi-conductors ${ }^{73,74,75}$. It is possible that the introduction of dopants in $\mathrm{Bi}_{2} \mathrm{Ru}_{2} \mathrm{O}_{7}$ affects the Bi-6p orbital overlap along with the $\mathrm{Ru}-\mathrm{O}-\mathrm{Ru}$ bond angle and consequently the electrical conductivity. It is interesting to note that electrical conductivity of perovskite $\mathrm{CaRuO}_{3}$ and $\mathrm{SrRuO}_{3}$, although metallic, is lower than that of $\mathrm{Bi}_{2} \mathrm{Ru}_{2} \mathrm{O}_{7}$; at $727^{\circ} \mathrm{C}$, conductivity values of $\mathrm{Bi}_{2} \mathrm{Ru}_{2} \mathrm{O}_{7}, \mathrm{CaRuO}_{3}$, and $\mathrm{SrRuO}_{3}$ are $\sim 316,70$, and $28 \mathrm{~S} / \mathrm{cm}$, respectively ${ }^{61}$. Assuming a rule of mixtures, it can be expected that doped bismuth ruthenate will show lower electronic conductivity. Whether doping improves the ionic conductivity or not is unclear; the marked influence on the electrode capacitance behavior, both as a function of temperature and oxygen partial pressure, could be an indirect indication. In any case, doped $\mathrm{Bi}_{2} \mathrm{Ru}_{2} \mathrm{O}_{7}$ pyrochlore didn't improve the electrode performance as significantly as observed by Bae and Steele ${ }^{60}$ with their studies on $5 \mathrm{~mol} \% \mathrm{Sr}$ doped $\mathrm{Y}_{2} \mathrm{Ru}_{2} \mathrm{O}_{7}$ where doping could have improved the electronic and/or ionic conductivity. 


\section{Summary}

Lead ruthentae (PRO) was successfully synthesized by direct condensation method (DCM). Sintering of PRO electrodes was optimized at $800{ }^{\circ} \mathrm{C}$. Low ASR values, e.g., 0.41 $\Omega \mathrm{cm}^{2}$ at $750^{\circ} \mathrm{C}$, of these PRO electrodes confirmed the remarkable electrochemical properties of this material for cathodic application. Also, ESB and PRO were determined to be compatible and thus suitable constituents of composite electrodes. Hence, with ASR of $\sim 1.7 \Omega \mathrm{cm}^{2}$ at 750 ${ }^{\circ} \mathrm{C}$ and $7 \Omega \mathrm{cm}^{2}$ at $500{ }^{\circ} \mathrm{C}$, PRO-ESB can be used in intermediate temperature solid oxide fuel cells (IT-SOFCs).

Above $600^{\circ} \mathrm{C}$ where reaction at the TPB is not rate limiting PRO is a better cathode than PRO-ESB. However, below $600^{\circ} \mathrm{C}$ the extended TPB of the PRO-ESB composite results in a lower ASR cathode. Further optimization of the microstructure and $\mathrm{ESB} / \mathrm{Pb}_{2} \mathrm{Ru}_{2} \mathrm{O}_{6.5}$ ratio could result in even lower ASRs.

YRO is compatible with both GDC and ESB since no reaction products were found by $\mathrm{XRD}$ analysis after heat-treatment at $800{ }^{\circ} \mathrm{C}$ for $24 \mathrm{~h}$. The best performing electrode was $\mathrm{Y}_{1.5} \mathrm{Pr}_{0.5} \mathrm{Ru}_{2} \mathrm{O}_{7}$ with ASR, at $700{ }^{\circ} \mathrm{C}$, of $0.19 \Omega \mathrm{cm}^{2}$ on an ESB electrolyte and $4.23 \Omega \mathrm{cm}^{2}$ on a GDC electrolyte. The ASR increased for lower or higher PRO content. The performance of Prdoped YRO on ESB is much better than the performance on GDC. Since oxygen mass diffusion is the limiting step for the electrode kinetics, enhanced performance on ESB is probably due to partial solid diffusion at the electrode/electrolyte interface that lowered the interfacial polarization. The low value of resistivity of the $\mathrm{Y}_{1.5} \operatorname{Pr}_{0.5} \mathrm{Ru}_{2} \mathrm{O}_{7} / \mathrm{ESB} / \mathrm{Y}_{1.5} \operatorname{Pr}_{0.5} \mathrm{Ru}_{2} \mathrm{O}_{7}$ symmetric cell suggests that $\mathrm{Y}_{1.5} \mathrm{Pr}_{0.5} \mathrm{Ru}_{2} \mathrm{O}_{7}$ in a composite with ESB would be a promising cathode material for IT-SOFCs.

This study showed that the performance of BRO cathodes is very promising, and it is expected that with improved electrode morphology and with composite cathodes, high performance cathodes can be developed for IT-SOFCs. Doping with lower valent cations on Bisite, in order to improve the ionic conductivity, was not effective in improving the performance of bismuth ruthenate cathodes. $5 \mathrm{~mol} \% \mathrm{Ca}$ and $\mathrm{Ag}$ doping were found to slightly improve the electrode performance over undoped bismuth ruthenate pyrochlores above $\sim 550{ }^{\circ} \mathrm{C}$. At $700{ }^{\circ} \mathrm{C}$, the ASRs of undoped, $5 \mathrm{~mol} \% \mathrm{Ca}$, and $5 \mathrm{~mol} \% \mathrm{Sr}$ doped BRO electrode were $1.45 \Omega \mathrm{cm}^{2}, 1.24$ $\Omega \mathrm{cm}^{2}$, and $1.41 \Omega \mathrm{cm}^{2}$, respectively. The rate limiting step for the oxygen reduction reaction in 5 
mol\% Ag doped bismuth ruthenate electrode was found to be the surface diffusion of dissociatively adsorbed oxygen, while for $5 \mathrm{~mol} \% \mathrm{Ca}$ doped system multiple rate limiting steps were observed in the oxygen partial pressure range studied. Doping with $5 \mathrm{~mol} \% \mathrm{Ca}$ and $\mathrm{Ag}$ changed the electrode capacitance behavior, both as function of temperature and oxygen partial pressure. 


\section{PYROCHLORE RUTHENATE-BISMUTH OXIDE COMPOSTE CATHODES}

Since doping bismuth ruthenate did not impart the increase in ionic conductivity necessary for it to become mixed conducting (and hence provide greater performance), composite cathodes were explored as an alternative strategy.

Bismuth oxides stabilized by doping in fcc fluorite $\delta-\mathrm{Bi}_{2} \mathrm{O}_{3}$ structure are one of the highest known oxygen ion conductors ${ }^{76,77,78}$. At comparable temperatures, oxygen ion conductivity of $20 \mathrm{~mol} \%$ erbia stabilized bismuth oxide (ESB) is one to two orders of magnitude higher than that of YSZ. It is well known that a composite cathode, consisting of an electrocatalyst and an oxygen ion conductive phase, enhances the performance significantly by effectively extending the reaction zone from the electrode/electrolyte interface into the electrode. Composite cathodes based on LSM-YSZ and LSM-GDC for YSZ electrolytes and LSCF-GDC for GDC electrolytes have been very effective in reducing the polarization resistance compared to single phase cathodes ${ }^{79,80}$. Chemical compatibility between the two phases is critical in order to avoid the formation of resistive tertiary phases and to develop high performance electrodes.

$\mathrm{Bi}_{2} \mathrm{O}_{3}-\mathrm{RuO}_{2}$ phase diagrams were proposed by Prosychev et al. ${ }^{81}$ and Hrovat et al. ${ }^{82}$. Bismuth ruthenate, apart from the fcc pyrochlore structure $\mathrm{Bi}_{2} \mathrm{Ru}_{2} \mathrm{O}_{7}$, also exists in the oxygen enriched cubic $\mathrm{KSbO}_{3}$ structure as $\mathrm{Bi}_{2} \mathrm{Ru}_{2} \mathrm{O}_{7.3}\left(\text { or } \mathrm{Bi}_{3} \mathrm{Ru}_{3} \mathrm{O}_{11}\right)^{83}$. Both phase diagram studies show that $\mathrm{Bi}_{2} \mathrm{Ru}_{2} \mathrm{O}_{7.3}$ forms a eutectic with $\mathrm{Bi}_{2} \mathrm{O}_{3}$ at relatively low temperatures; however there is some discrepancy regarding the eutectic temperature and composition. There is also confusion regarding the transition temperature from the $\mathrm{KSbO}_{3}$ structure to the fcc pyrochlore structure

$\left(965{ }^{\circ} \mathrm{C}^{18}, 950{ }^{\circ} \mathrm{C}^{19}, 975^{\circ} \mathrm{C}^{20}\right)$; Hrovat et al. noted that the reaction of precursors with alumina crucible could have affected the transition temperature. According to Prosychev et al., the eutectic is between $\mathrm{Bi}_{2} \mathrm{Ru}_{2} \mathrm{O}_{7.3}$ and monoclinic $\alpha-\mathrm{Bi}_{2} \mathrm{O}_{3}$ at $\sim 37 \mathrm{~mol} \% \mathrm{RuO}_{2}$; the eutectic temperature is $730{ }^{\circ} \mathrm{C}$, which incidentally is also the transformation temperature from $\langle$ to fcc $\delta$ $\mathrm{Bi}_{2} \mathrm{O}_{3}$. Hrovat et al. instead proposed that the eutectic is between $\mathrm{Bi}_{2} \mathrm{Ru}_{2} \mathrm{O}_{7.3}$ and $\delta-\mathrm{Bi}_{2} \mathrm{O}_{3}$ at $\sim 20$ $\mathrm{mol} \% \mathrm{RuO}_{2}$; the eutectic is at $745^{\circ} \mathrm{C}$, above the $\alpha$ - to $\delta-\mathrm{Bi}_{2} \mathrm{O}_{3}$ transformation temperature. The presence of the eutectic could significantly undermine the microstructural stability of a 


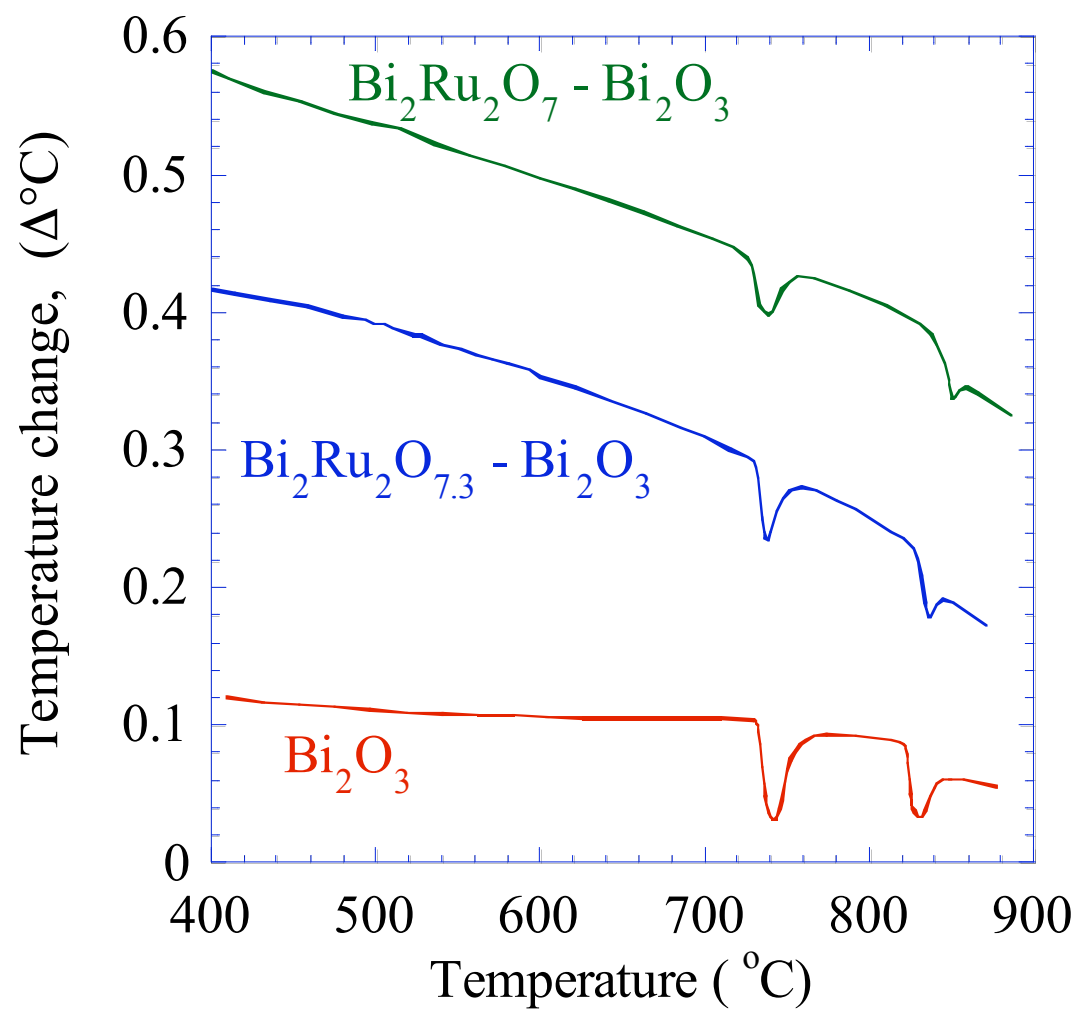

Figure 77. DTA plots of $\mathrm{Bi}_{2} \mathrm{O}_{3}, \mathrm{Bi}_{2} \mathrm{Ru}_{2} \mathrm{O}_{7.3}-\mathrm{Bi}_{2} \mathrm{O}_{3}\left(50 \mathrm{wt} \% \mathrm{Bi}_{2} \mathrm{O}_{3}\right)$, and $\mathrm{Bi}_{2} \mathrm{Ru}_{2} \mathrm{O}_{7}-\mathrm{Bi}_{2} \mathrm{O}_{3}\left(50 \mathrm{wt} \% \mathrm{Bi}_{2} \mathrm{O}_{3}\right)$ powders in heating cycle.

composite electrode, consisting of bismuth ruthenate and bismuth oxide, during processing and/or under operation. Differential thermal analysis (DTA) studies were done to study the eutectic temperature and composition.

DTA plots of powder mixtures of bismuth ruthenate and bismuth oxide in the heating cycle are shown in Figure 77. Two endotherms are observed for $\mathrm{Bi}_{2} \mathrm{O}_{3}, \mathrm{Bi}_{2} \mathrm{Ru}_{2} \mathrm{O}_{7.3}-\mathrm{Bi}_{2} \mathrm{O}_{3}$, and $\mathrm{Bi}_{2} \mathrm{Ru}_{2} \mathrm{O}_{7}-\mathrm{Bi}_{2} \mathrm{O}_{3}$ with onset temperatures at $731.2{ }^{\circ} \mathrm{C}, 729.7{ }^{\circ} \mathrm{C}, 725.8^{\circ} \mathrm{C}$ for the first transition and $821.7^{\circ} \mathrm{C}, 827.0^{\circ} \mathrm{C}, 837.9^{\circ} \mathrm{C}$ for the second transition, respectively. Based on the phase diagram proposed by Proshychev et al. ${ }^{81}$, the first transition is attributed to the transition from monoclinic $\alpha$ - to fcc $\delta-\mathrm{Bi}_{2} \mathrm{O}_{3}$ and the concomitant eutectic formation, while the second transition is attributed to the liquidus temperature. The above described transitions are absent in DTA plots for $\mathrm{ESB}, \mathrm{Bi}_{2} \mathrm{Ru}_{2} \mathrm{O}_{7.3}, \mathrm{Bi}_{2} \mathrm{Ru}_{2} \mathrm{O}_{7}, \mathrm{Bi}_{2} \mathrm{Ru}_{2} \mathrm{O}_{7.3}-\mathrm{ESB}$, and $\mathrm{Bi}_{2} \mathrm{Ru}_{2} \mathrm{O}_{7}$-ESB. $\mathrm{ESB}$ is stabilized at room temperature in fcc $\delta-\mathrm{Bi}_{2} \mathrm{O}_{3}$ structure by erbia doping, the melting point is elevated beyond the sintering temperature of ESB $\left(\sim 890{ }^{\circ} \mathrm{C}^{84}\right)$; hence, both $\alpha$ - to $\delta-\mathrm{Bi}_{2} \mathrm{O}_{3}$ and $\delta$ - to liquid- $\mathrm{Bi}_{2} \mathrm{O}_{3}$ 
transitions are not observed for ESB. Moreover, this also indicates that the eutectic is absent between BRO and ESB suggesting that the composite electrodes could be microstructurally stable during fabrication and under operation. One possible explanation for the absence could be that the eutectic is essentially between $\mathrm{Bi}_{2} \mathrm{Ru}_{2} \mathrm{O}_{7.3}$ and $\alpha-\mathrm{Bi}_{2} \mathrm{O}_{3}$, as proposed by Proshychev et al .

XRD patterns of powder mixtures of bismuth ruthenate with GDC and ESB after heattreatment are shown in Figs. 78 - 80. After firing at $850{ }^{\circ} \mathrm{C}$ for 10 hours, GDC does not show any reactivity with either the low-temperature $\mathrm{Bi}_{2} \mathrm{Ru}_{2} \mathrm{O}_{7.3}$ phase or the high-temperature $\mathrm{Bi}_{2} \mathrm{Ru}_{2} \mathrm{O}_{7}$ phase, as indicated by the absence of any unidentified peaks in the pattern. However with $\mathrm{ESB}$, both $\mathrm{Bi}_{2} \mathrm{Ru}_{2} \mathrm{O}_{7.3}$ and $\mathrm{Bi}_{2} \mathrm{Ru}_{2} \mathrm{O}_{7}$ after firing at $850{ }^{\circ} \mathrm{C}$ for 10 hours react to transform the fcc $\delta-\mathrm{Bi}_{2} \mathrm{O}_{3}$ phase to tetragonal $\beta-\mathrm{Bi}_{2} \mathrm{O}_{3}$ phase, as shown in Fig. 79c and $80 \mathrm{~b}$, respectively. Moreover, $\mathrm{Bi}_{2} \mathrm{Ru}_{2} \mathrm{O}_{7.3}$ transforms partly into the high-temperature pyrochlore phase at and above $800^{\circ} \mathrm{C}$, as shown in Figs. $79 \mathrm{~b}$ and $79 \mathrm{c}$. Note that the impurity sillenite type phase $\left(\mathrm{Bi}_{12} \mathrm{RuO}_{20}\right)$, present after calcination of bismuth ruthenates and removed by leaching with dilute $\mathrm{HNO}_{3}$, is isomorphous to bcc $\gamma-\mathrm{Bi}_{2} \mathrm{O}_{3}{ }^{78}$. Both $\beta$ - and $\gamma-\mathrm{Bi}_{2} \mathrm{O}_{3}$ are highly undesirable as they have an ordered oxygen ion sublattice and show oxygen ion conductivity up to three orders of magnitude

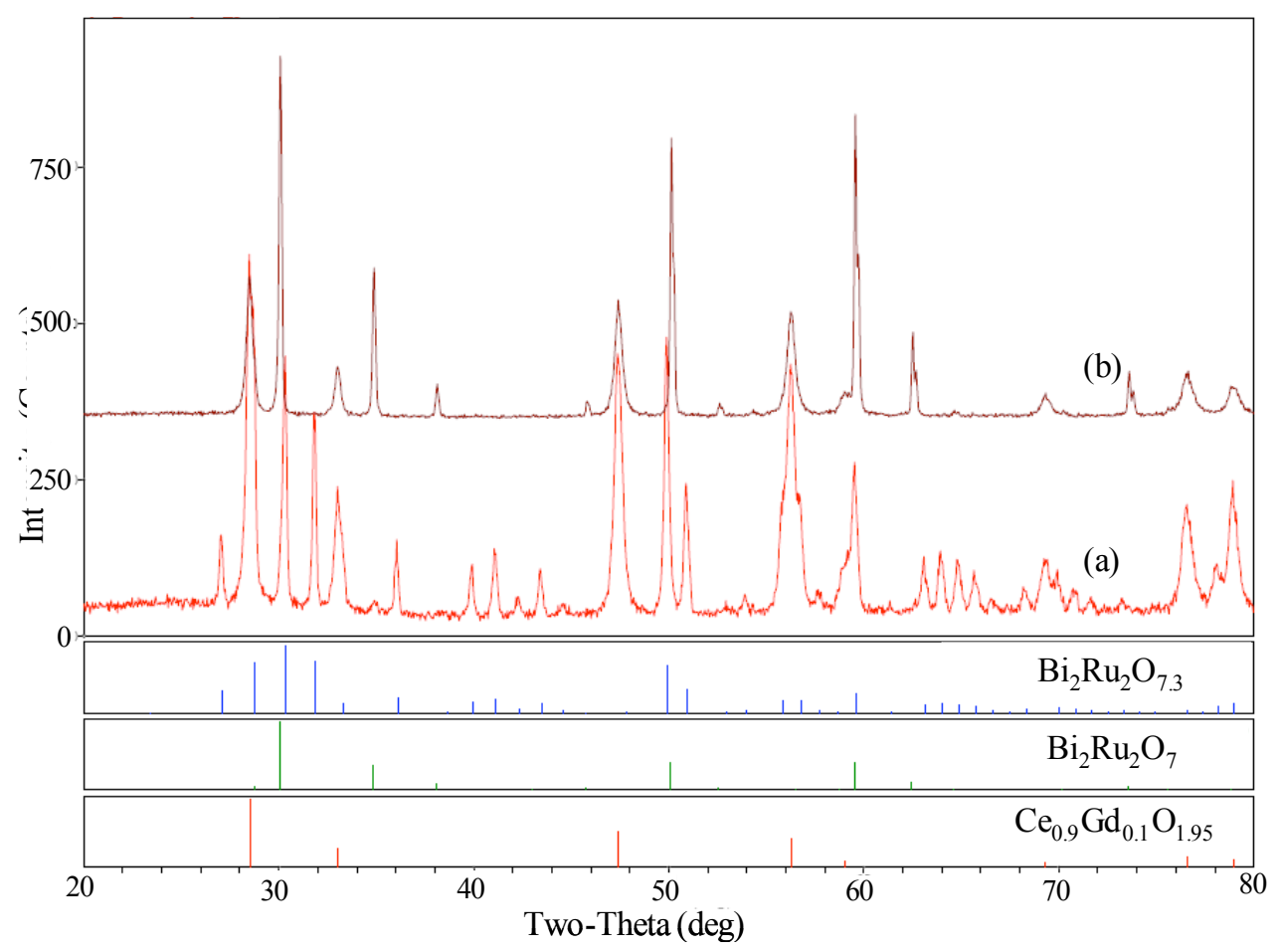

Figure 78. $\mathrm{XRD}$ patterns for powder mixture (a) $\mathrm{Bi}_{2} \mathrm{Ru}_{2} \mathrm{O}_{7.3}-\mathrm{GDC}$ and (b) $\mathrm{Bi}_{2} \mathrm{Ru}_{2} \mathrm{O}_{7}-\mathrm{GDC}$ fired at 850 ${ }^{\circ} \mathrm{C} / 10$ hours. 


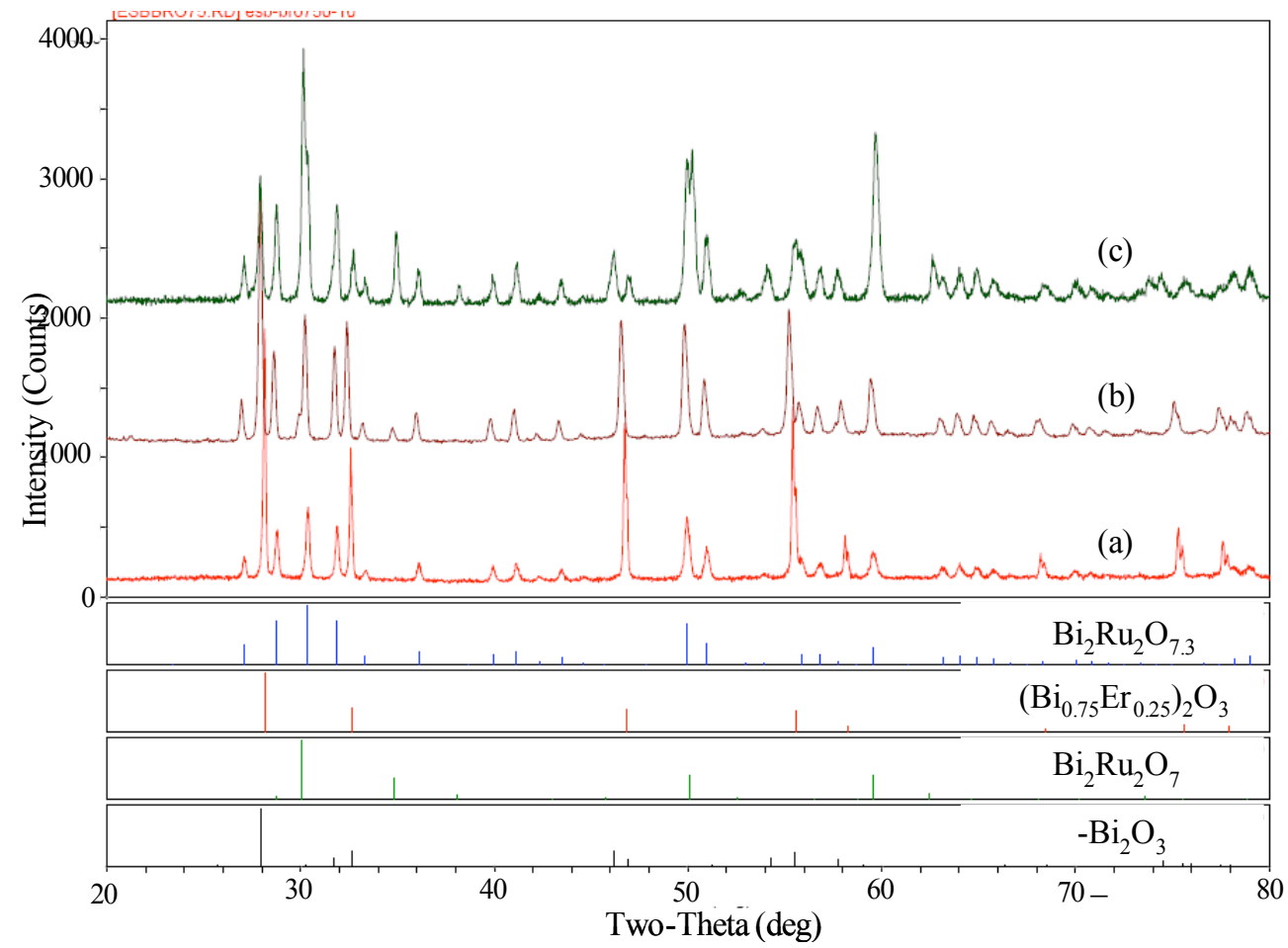

Figure 79. XRD patterns for powder mixture of $\mathrm{Bi}_{2} \mathrm{Ru}_{2} \mathrm{O}_{7.3}$-ESB fired at (a) $750{ }^{\circ} \mathrm{C} / 10$ hours, (b) 800 ${ }^{\circ} \mathrm{C} / 10$ hours, and (c) $850{ }^{\circ} \mathrm{C} / 10$ hours.

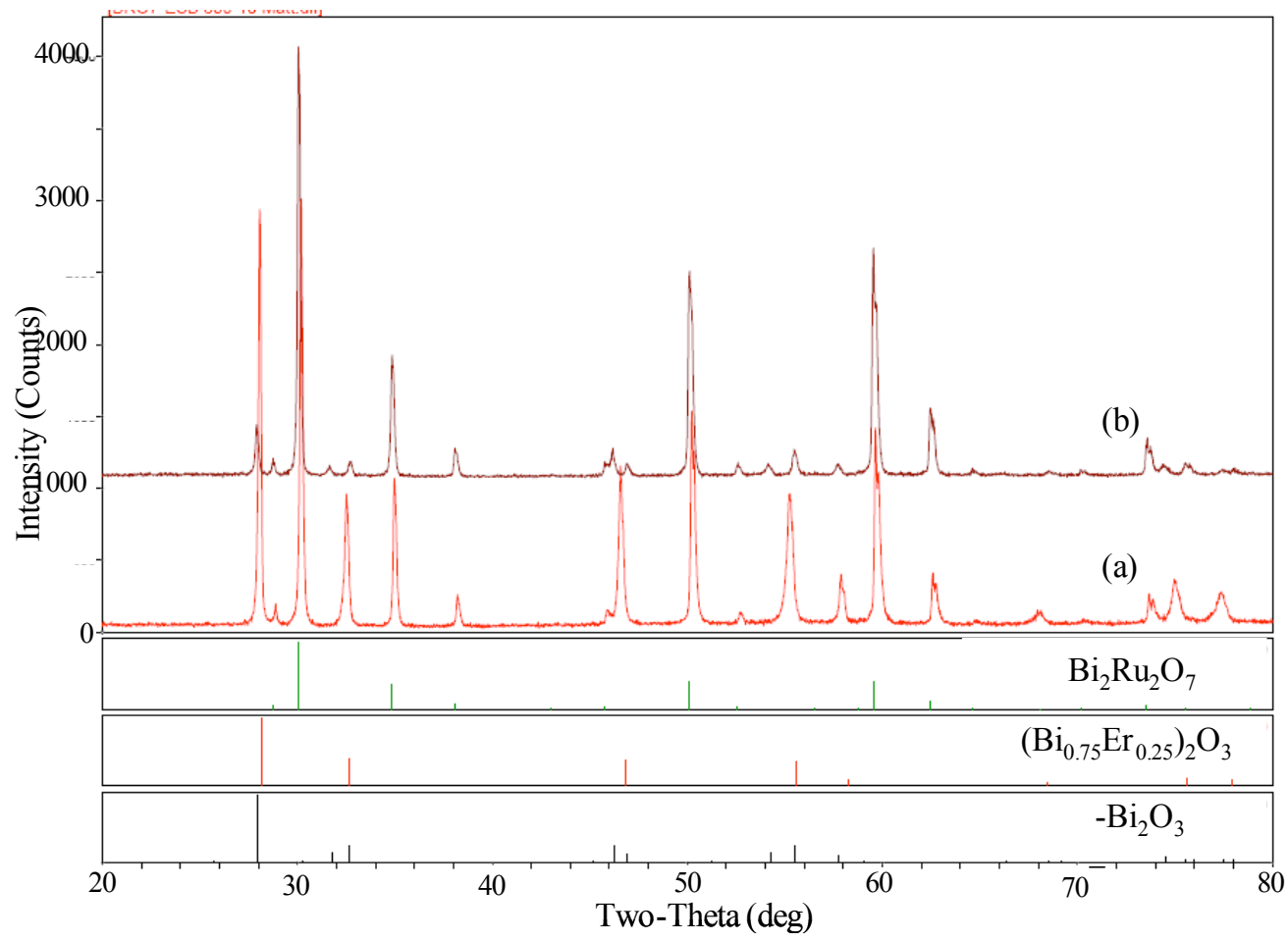

Figure 80. XRD patterns for powder mixture of $\mathrm{Bi}_{2} \mathrm{Ru}_{2} \mathrm{O}_{7}$-ESB fired at (a) $800{ }^{\circ} \mathrm{C} / 10$ hours and (b) 850 ${ }^{\circ} \mathrm{C} / 10$ hours. 
lower than that of $\delta-\mathrm{Bi}_{2} \mathrm{O}_{3}{ }^{88-90}$. Therefore, $\mathrm{Bi}_{2} \mathrm{Ru}_{2} \mathrm{O}_{7}$ and $\mathrm{ESB}$ composite electrodes for impedance spectroscopy studies were fired at $800{ }^{\circ} \mathrm{C}$ for 2 hours. No reaction was found to occur between bismuth ruthenate and ESB after firing at $750{ }^{\circ} \mathrm{C}$ for 10 hours and the composite was studied as a cathode for IT-SOFC ${ }^{85}$.

\section{Compositional Optimization}

Representative micrographs of surface and cross-section of different $\mathrm{Bi}_{2} \mathrm{Ru}_{2} \mathrm{O}_{7}$-ESB electrodes on GDC electrolyte are shown in Figs. 81 and 82, respectively. Vibration milling reduced the particle size of $\mathrm{Bi}_{2} \mathrm{Ru}_{2} \mathrm{O}_{7}$ powders, calcined at $900{ }^{\circ} \mathrm{C}$, from $\sim 3 \mu \mathrm{m}$ to $\sim 1 \mu \mathrm{m}$. Amorphous citrate route produced fine sub-micron ESB particles. It was expected that fine particle size would ensure homogenous mixing, high TPB concentration and good sinterability of the composite electrode. After sintering at $800^{\circ} \mathrm{C}$, the electrodes are $10-20 \mu \mathrm{m}$ thick.

Impedance plots of $\mathrm{Bi}_{2} \mathrm{Ru}_{2} \mathrm{O}_{7}$-ESB composite electrodes at $500{ }^{\circ} \mathrm{C}$ and $700{ }^{\circ} \mathrm{C}$ are shown in Figs. 83 and 84, respectively. The electrode ASR was calculated by multiplying the electrode resistance by the electrode area $\left(\sim 0.7 \mathrm{~cm}^{2}\right)$ and dividing by 2 to account for the symmetric cell. The performance, in terms of electrode ASR, characteristic frequency, and activation energy, of $\mathrm{Bi}_{2} \mathrm{Ru}_{2} \mathrm{O}_{7}$ electrodes $(\sim 1 \mu \mathrm{m}$ particle size and $\sim 10 \mu \mathrm{m}$ thick) fabricated from vibration milled powders is comparable to $\mathrm{Bi}_{2} \mathrm{Ru}_{2} \mathrm{O}_{7}$ electrodes $(\sim 3 \mu \mathrm{m}$ particle size and $\sim 100 \mu \mathrm{m})$ fabricated from as-calcined powders described earlier. This indicates that the rate limiting step in the

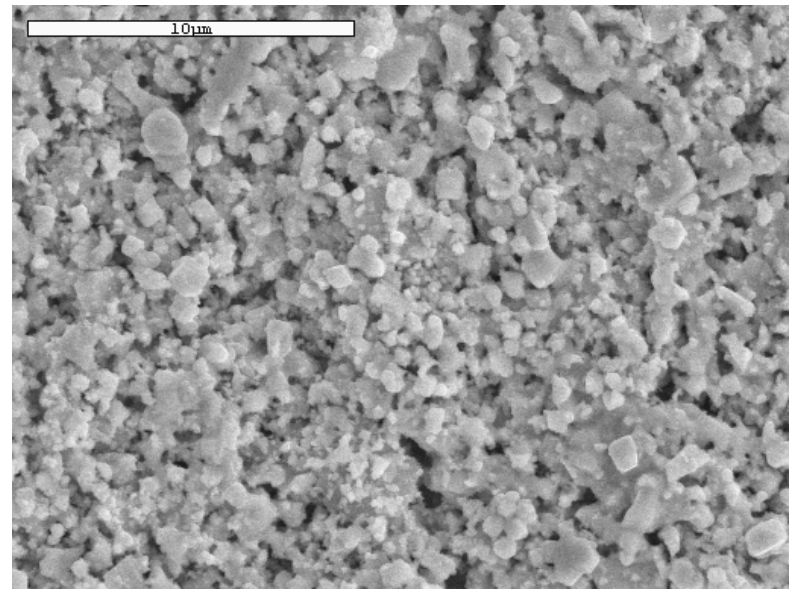

(a)

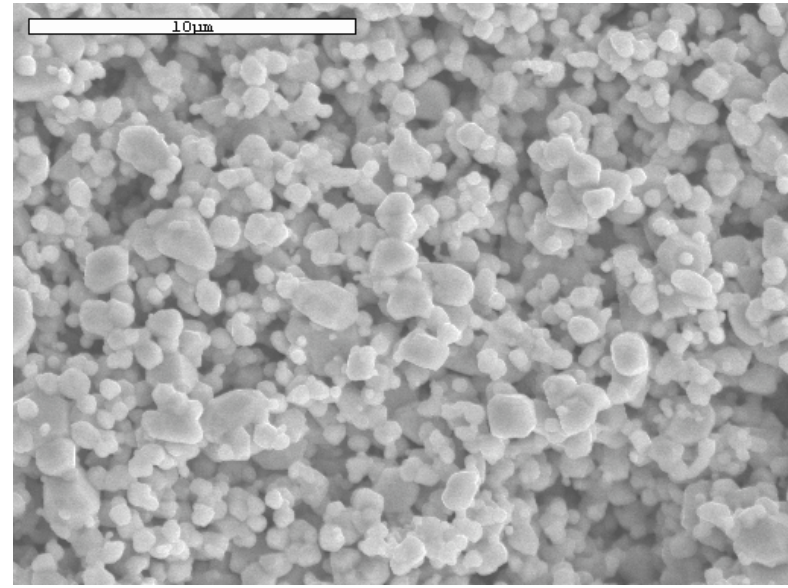

(b)

Figure 81. Surface micrographs of (a) $\mathrm{Bi}_{2} \mathrm{Ru}_{2} \mathrm{O}_{7}$, (b) $\mathrm{Bi}_{2} \mathrm{Ru}_{2} \mathrm{O}_{7}-\mathrm{ESB}$ (50 wt $\%$ ESB) electrodes on GDC electrolyte sintered at $800^{\circ} \mathrm{C}$ 


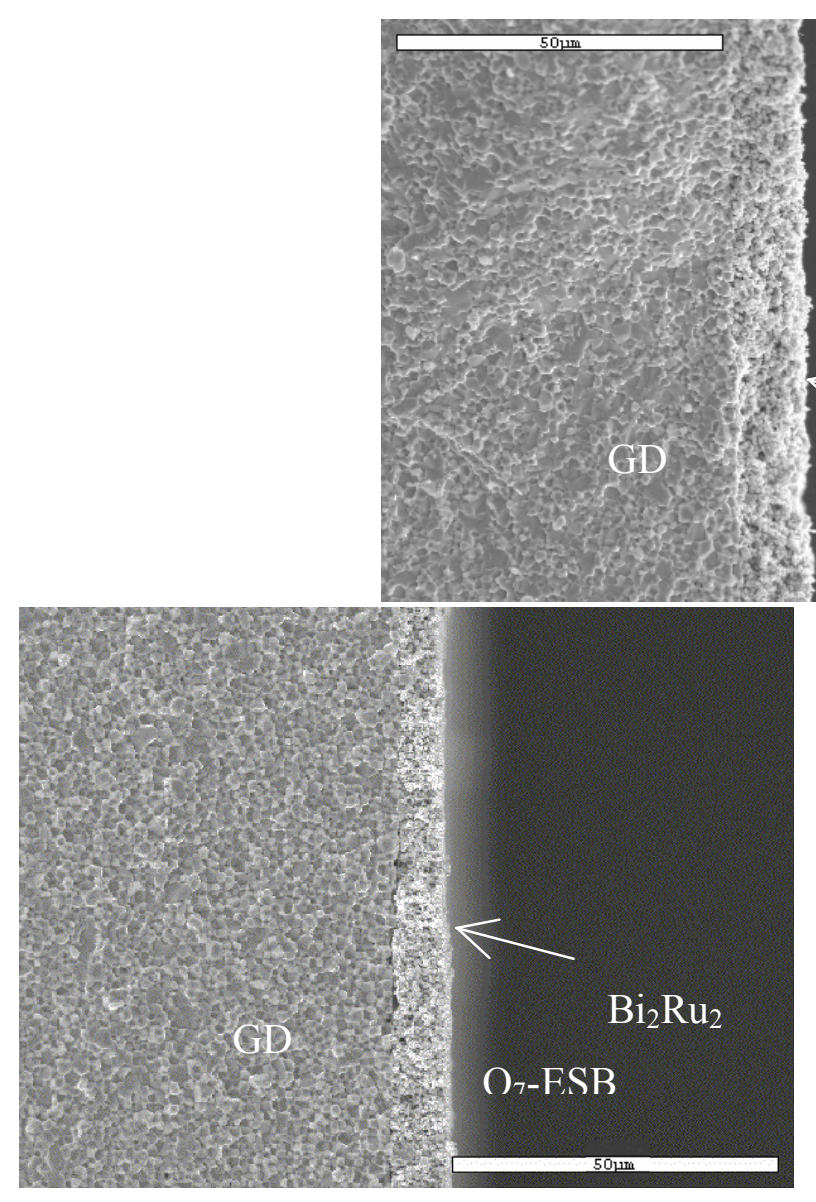

(b)

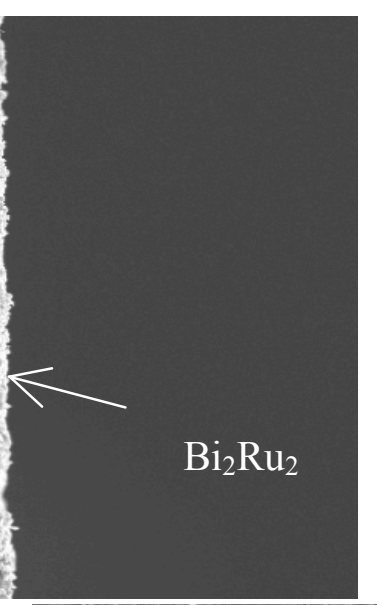

(a)

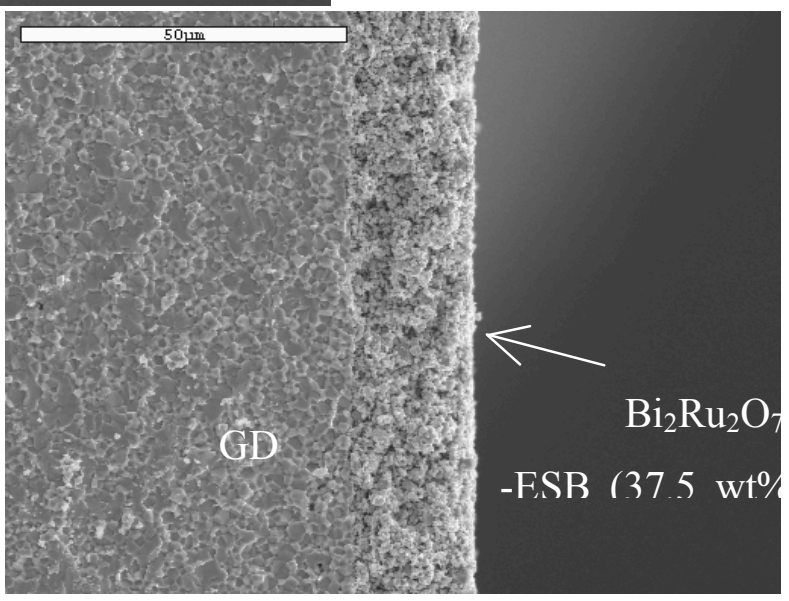

(c)

Figure 82. Cross-section micrographs of (a) $\mathrm{Bi}_{2} \mathrm{Ru}_{2} \mathrm{O}_{7}$, (b) $\mathrm{Bi}_{2} \mathrm{Ru}_{2} \mathrm{O}_{7}-\mathrm{Bi}_{2} \mathrm{O}_{3}$ (25 wt $\% \mathrm{ESB}$ ), and (c) $\mathrm{Bi}_{2} \mathrm{Ru}_{2} \mathrm{O}_{7}-\mathrm{Bi}_{2} \mathrm{O}_{3}\left(37.5 \mathrm{wt} \% \mathrm{ESB}\right.$ ) electrodes on GDC electrolyte sintered at $800{ }^{\circ} \mathrm{C}$.

oxygen reduction reaction for the single phase pyrochlore electrode is not influenced to a great degree by particle size and electrode thickness. On the other hand, introduction of the ESB phase in the electrode resulted in significant reduction of the electrode impedance at each temperature, along with a shift in the electrode's characteristic frequency towards lower values suggesting a change in electrode reaction mechanism. For all compositions, the electrode characteristic frequency increased with temperature.

As shown in Fig. 85, for the current particle-size distribution, composite cathodes with 31.25-43.75 wt\% ESB showed the lowest ASR values of $3.47-5.55 \Omega \mathrm{cm}^{2}$ and $0.08-0.11 \Omega \mathrm{cm}^{2}$ at $500{ }^{\circ} \mathrm{C}$ and $700{ }^{\circ} \mathrm{C}$, respectively. In comparison, single phase pyrochlore electrode showed ASR values of $74.15 \Omega \mathrm{cm}^{2}$ and $1.78 \Omega \mathrm{cm}^{2}$ at 500 and $700{ }^{\circ} \mathrm{C}$, respectively. Arrhenius plots of the composite electrodes are shown in Fig. 86 with activation energy between 1.20-1.34 eV. 


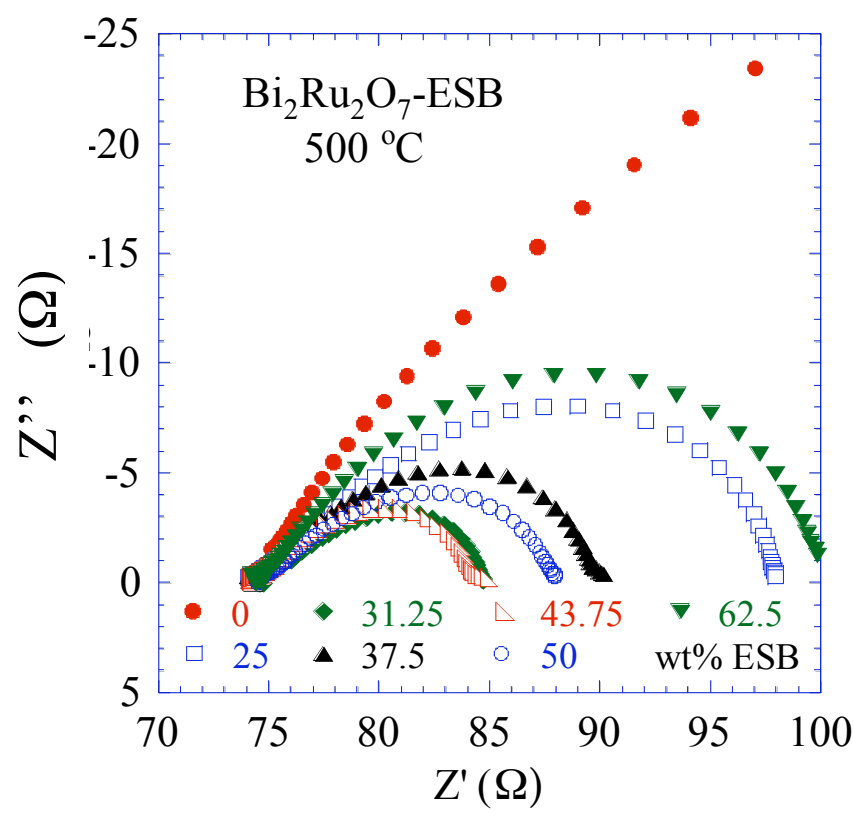

(a)

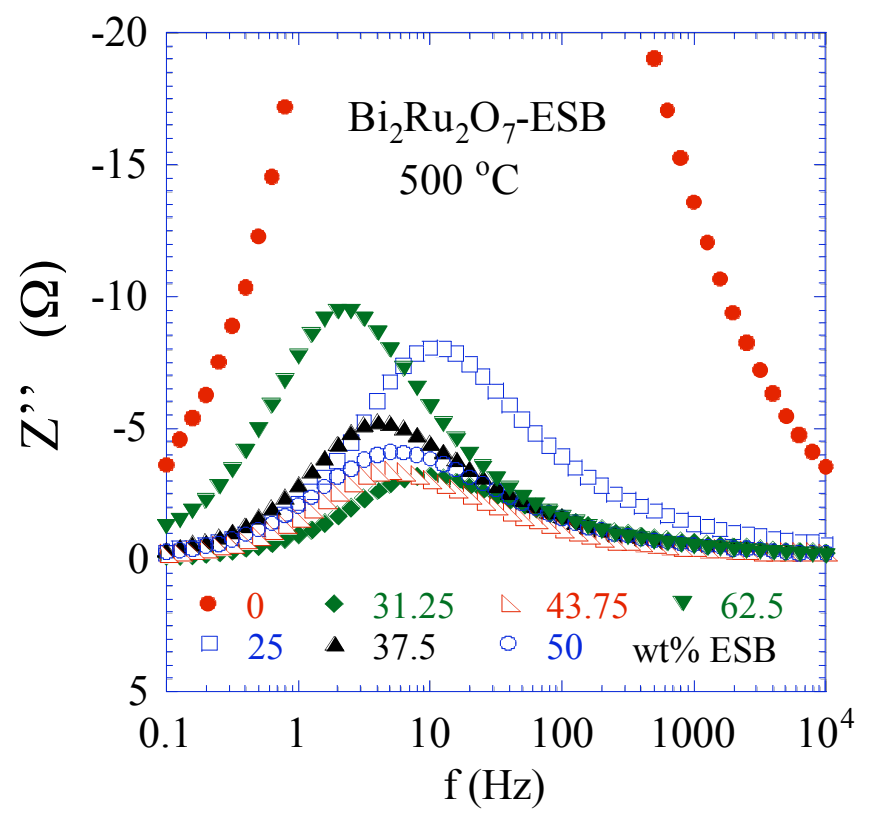

(c)

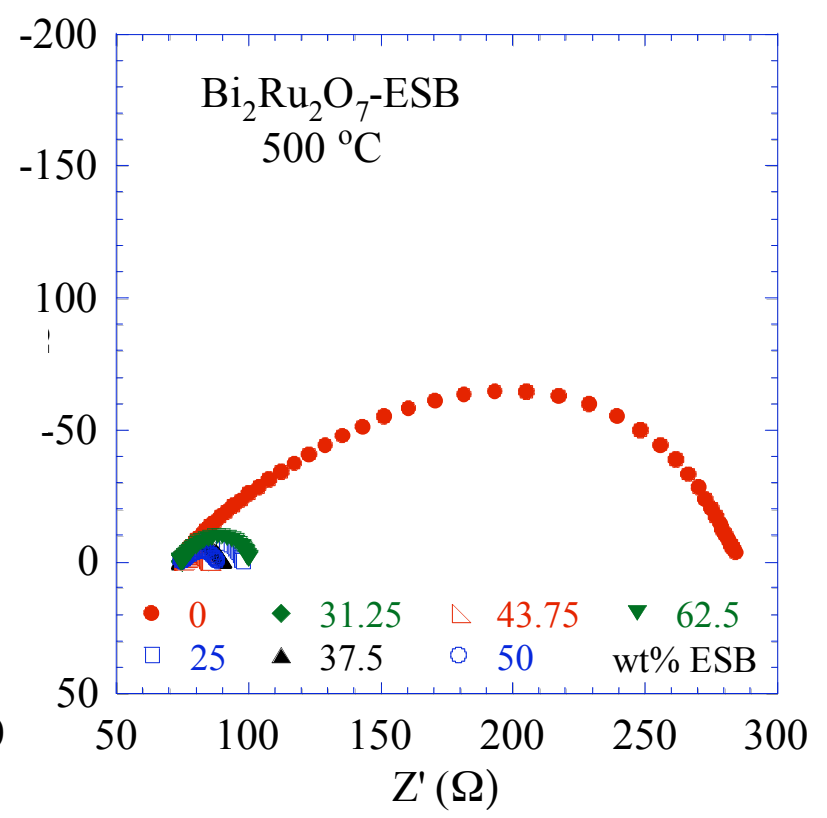

(b)

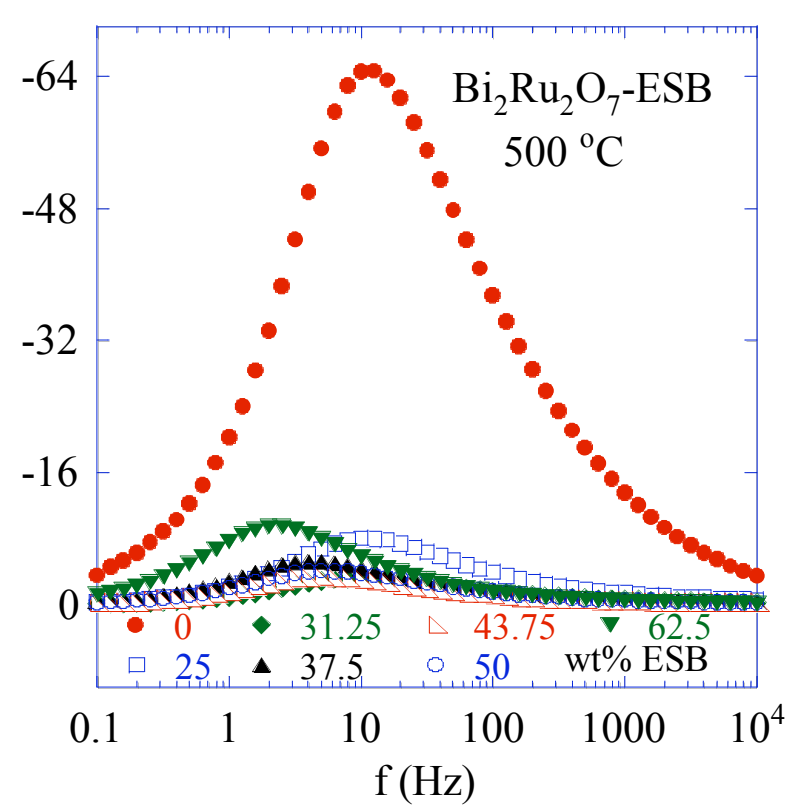

(d)

Figure 83. Impedance plots of $\mathrm{Bi}_{2} \mathrm{Ru}_{2} \mathrm{O}_{7}-\mathrm{ESB}$ electrodes on $\mathrm{GDC}$ at $500{ }^{\circ} \mathrm{C}$ (a) and (b) imaginary vs. real impedance, (c) and (d) imaginary impedance vs. frequency. 


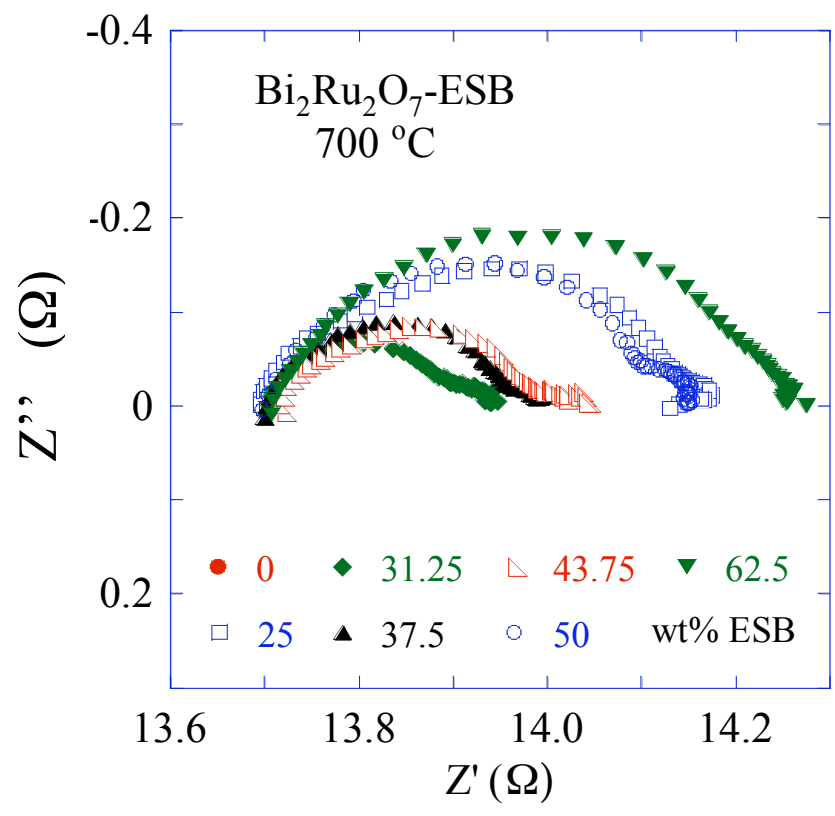

(a)

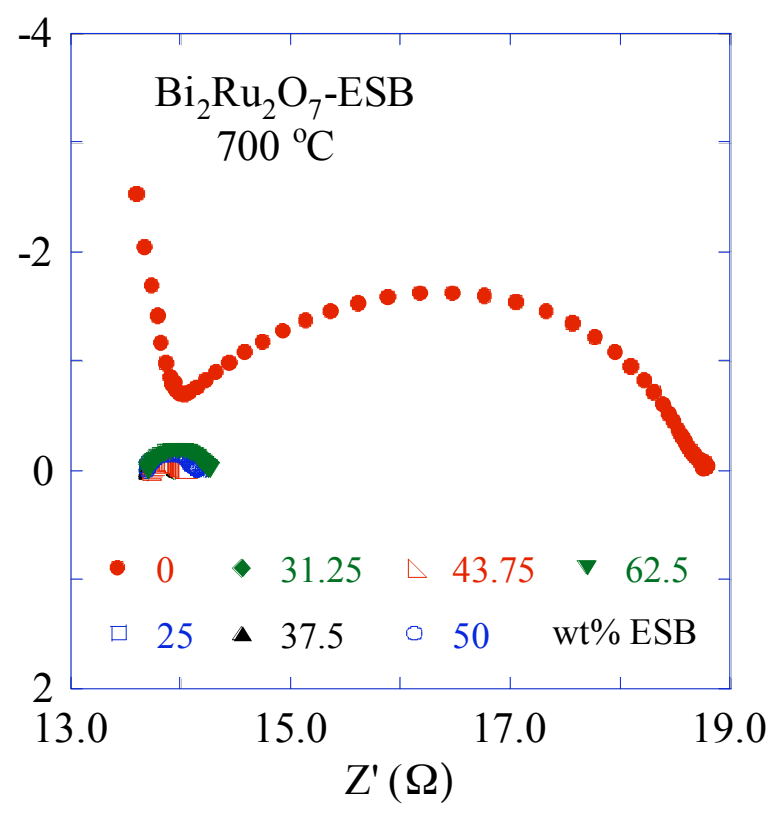

(b)

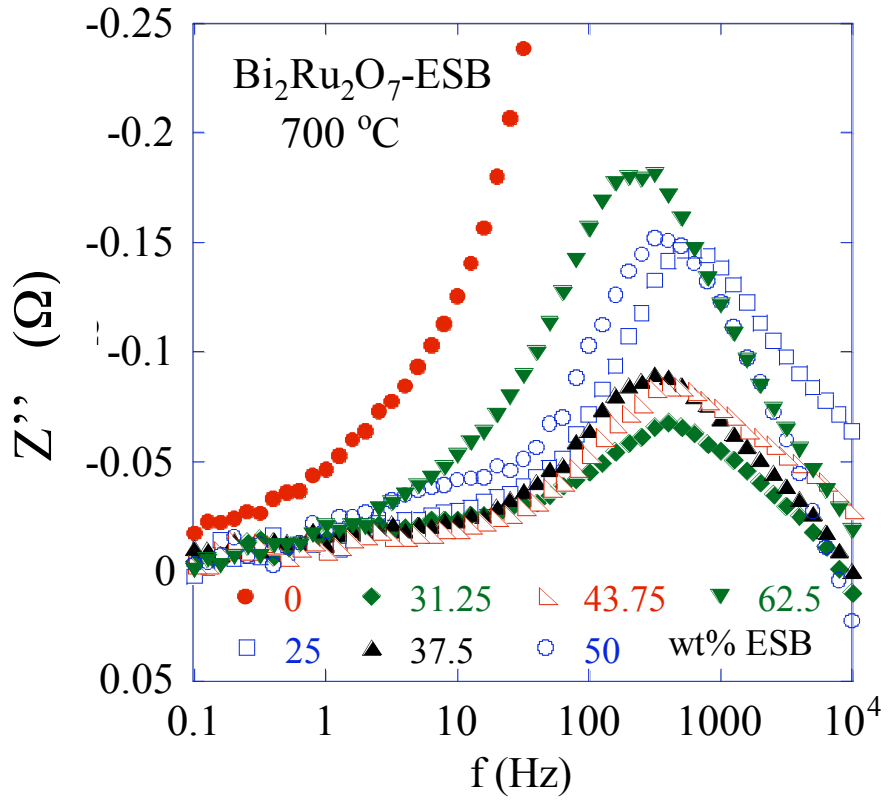

(c)

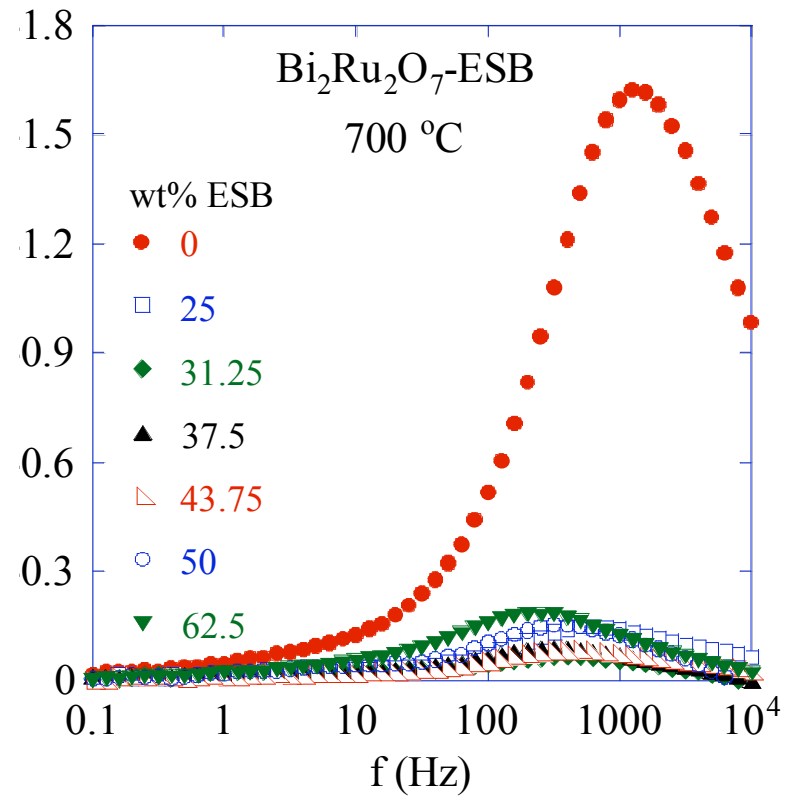

(d)

Figure 84. Impedance plots of $\mathrm{Bi}_{2} \mathrm{Ru}_{2} \mathrm{O}_{7}-\mathrm{ESB}$ electrodes on $\mathrm{GDC}$ at $700{ }^{\circ} \mathrm{C}$ (a) and (b) imaginary vs. real impedance, (c) and (d) imaginary impedance vs. frequency. 


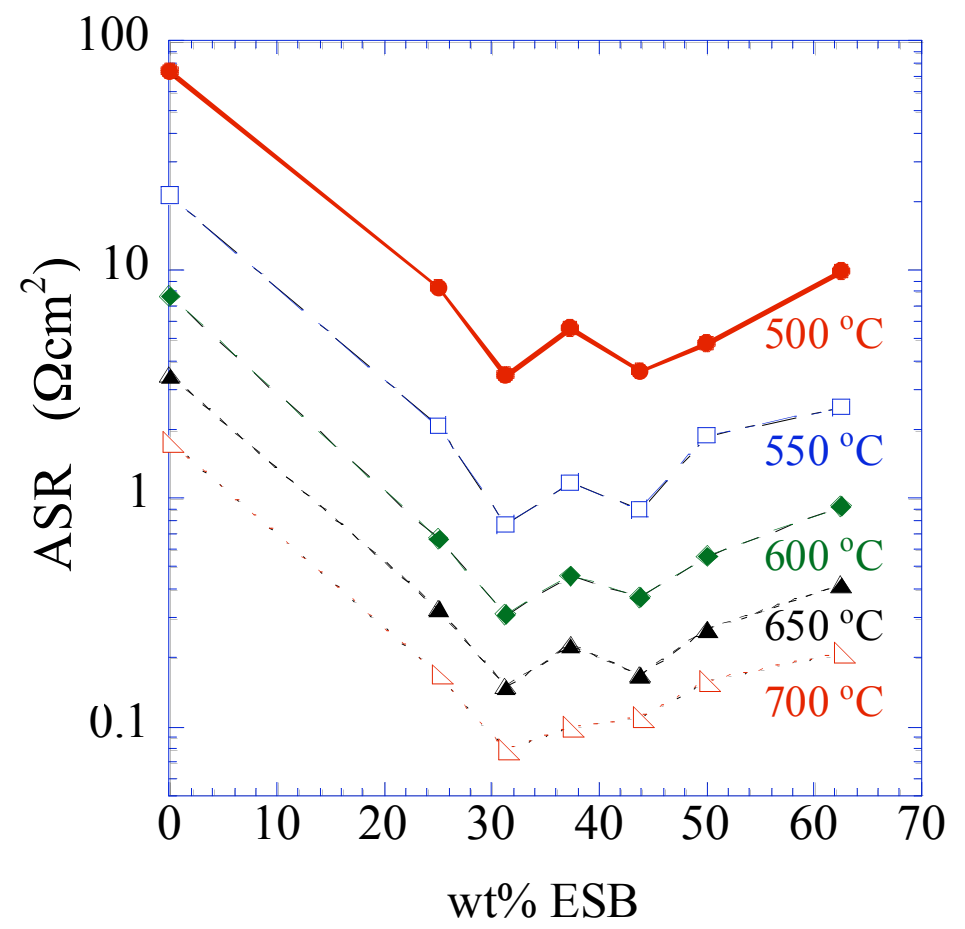

Figure 85. $\mathrm{ASR}\left(\Omega \mathrm{cm}^{2}\right)$ of $\mathrm{Bi}_{2} \mathrm{Ru}_{2} \mathrm{O}_{7}-\mathrm{ESB}$ composite electrodes as a function of $\mathrm{wt} \% \mathrm{ESB}$.

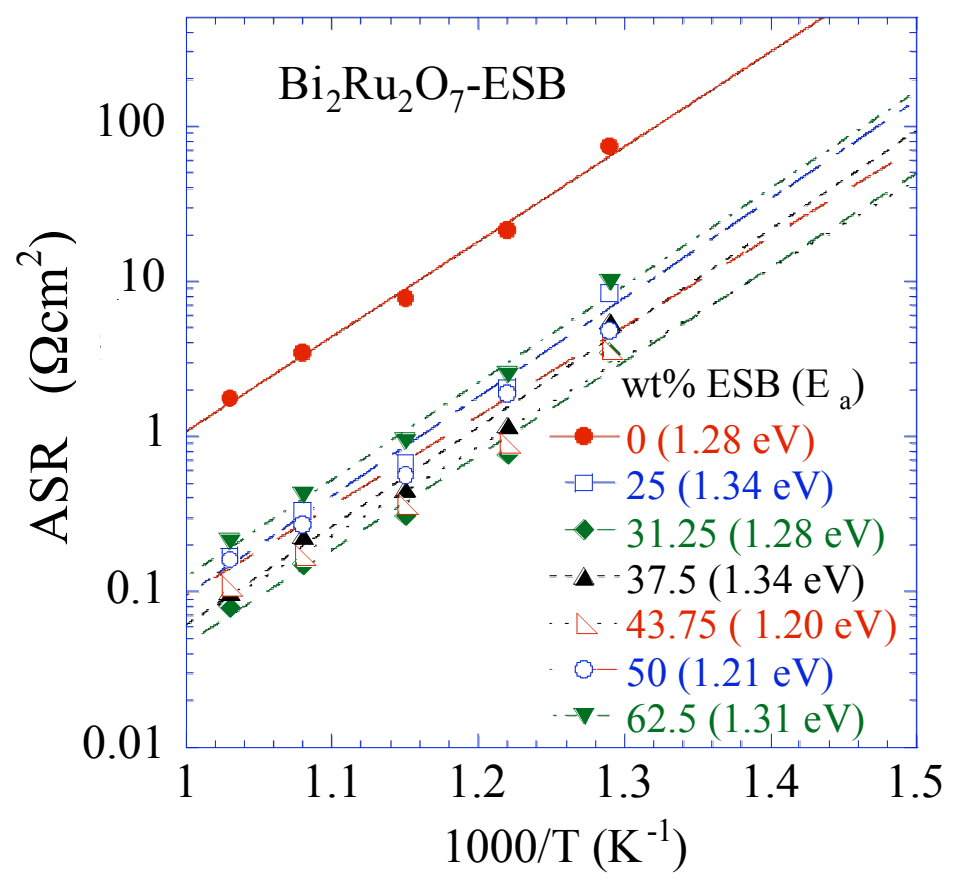

Figure 86. Arrhenius plot of $\mathrm{Bi}_{2} \mathrm{Ru}_{2} \mathrm{O}_{7}-\mathrm{ESB}$ composite electrode ASR $\left(\wedge \mathrm{cm}^{2}\right)$. 


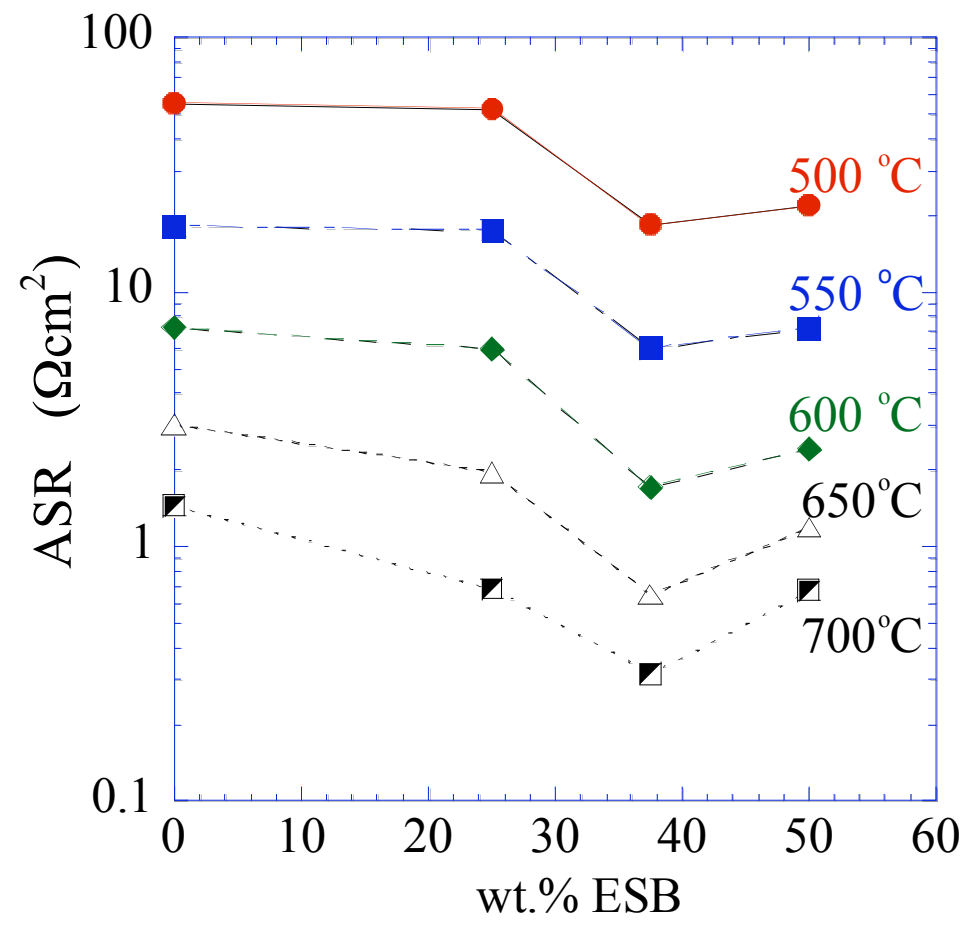

Figure 87. ASR $\left(\Omega \mathrm{cm}^{2}\right)$ of $\mathrm{Bi}_{2} \mathrm{Ru}_{2} \mathrm{O}_{7.3}$-ESB $(25,37.5,50 \mathrm{wt} \% \mathrm{ESB})$ composite electrodes in comparison to $\mathrm{Bi}_{2} \mathrm{Ru}_{2} \mathrm{O}_{7}$ electrode. As-calcined bismuth ruthenate powders used for fabrication.

The performance of $\mathrm{Bi}_{2} \mathrm{Ru}_{2} \mathrm{O}_{7}$-ESB electrodes is similar to composite electrodes consisting of low temperature phase $\mathrm{Bi}_{2} \mathrm{Ru}_{2} \mathrm{O}_{7.3}$ and $\mathrm{ESB}^{85}$. As shown in Fig. 87, the best performance of $18.40 \Omega \mathrm{cm}^{2}$ and $0.32 \Omega \mathrm{cm}^{2}$ was obtained with a composite containing $37.5 \mathrm{wt} \%$ ESB at $500{ }^{\circ} \mathrm{C}$ and $700{ }^{\circ} \mathrm{C}$, respectively. Moreover with $\mathrm{Bi}_{2} \mathrm{Ru}_{2} \mathrm{O}_{7.3}-\mathrm{ESB}$ composite electrodes, the characteristic frequency decreased by more than an order of magnitude in comparison to the single phase pyrochlore electrode ${ }^{85}$. Note that the electrodes were fabricated using as-calcined (without a milling step) bismuth ruthenate powders.

Electrode capacitance of $\mathrm{Bi}_{2} \mathrm{Ru}_{2} \mathrm{O}_{7}$-ESB electrodes as a function of temperature are shown in Fig. 88. Electrode capacitance was calculated from Eq. (5). For comparison, electrode capacitance of as-calcined $\mathrm{Bi}_{2} \mathrm{Ru}_{2} \mathrm{O}_{7},\left(\mathrm{Bi}_{0.95} \mathrm{Ca}_{0.05}\right)_{2} \mathrm{Ru}_{2} \mathrm{O}_{7},\left(\mathrm{Bi}_{0.95} \mathrm{Ag}_{0.05}\right)_{2} \mathrm{Ru}_{2} \mathrm{O}_{7}$, and $\mathrm{Bi}_{2} \mathrm{Ru}_{2} \mathrm{O}_{7.3}{ }^{-}$ ESB electrodes as a function of temperature are shown in Figs. 88 and 89. Doping with $5 \mathrm{~mol} \%$ $\mathrm{Ca}$ and $\mathrm{Ag}$ did not significantly increase the capacitance of bismuth ruthenate electrode, while introduction of ESB increased the capacitance by more than an order of magnitude; for example, $\mathrm{Bi}_{2} \mathrm{Ru}_{2} \mathrm{O}_{7}, \mathrm{Bi}_{2} \mathrm{Ru}_{2} \mathrm{O}_{7}$ (as-calcined), $\left(\mathrm{Bi}_{0.95} \mathrm{Ca}_{0.05}\right)_{2} \mathrm{Ru}_{2} \mathrm{O}_{7}$ (as-calcined), $\left(\mathrm{Bi}_{0.95} \mathrm{Ag}_{0.05}\right)_{2} \mathrm{Ru}_{2} \mathrm{O}_{7}$ (ascalcined), $\mathrm{Bi}_{2} \mathrm{Ru}_{2} \mathrm{O}_{7}-\mathrm{ESB}$ (37.5 wt $\% \mathrm{ESB}$ ), and $\mathrm{Bi}_{2} \mathrm{Ru}_{2} \mathrm{O}_{7.3}-\mathrm{ESB}$ (37.5 wt $\% \mathrm{ESB}$, as-calcined) 


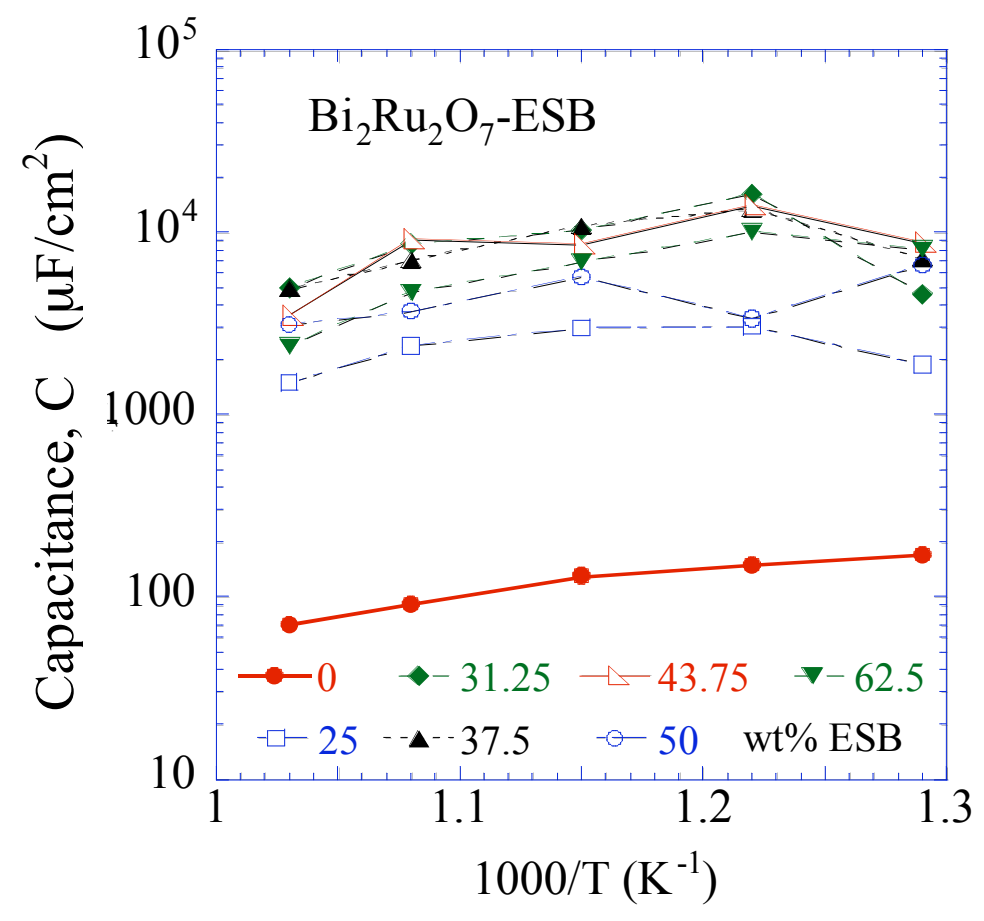

Figure 88. Electrode capacitance $\left(\mu \mathrm{F} / \mathrm{cm}^{2}\right)$ of $\mathrm{Bi}_{2} \mathrm{Ru}_{2} \mathrm{O}_{7}-\mathrm{ESB}$ composite electrodes.

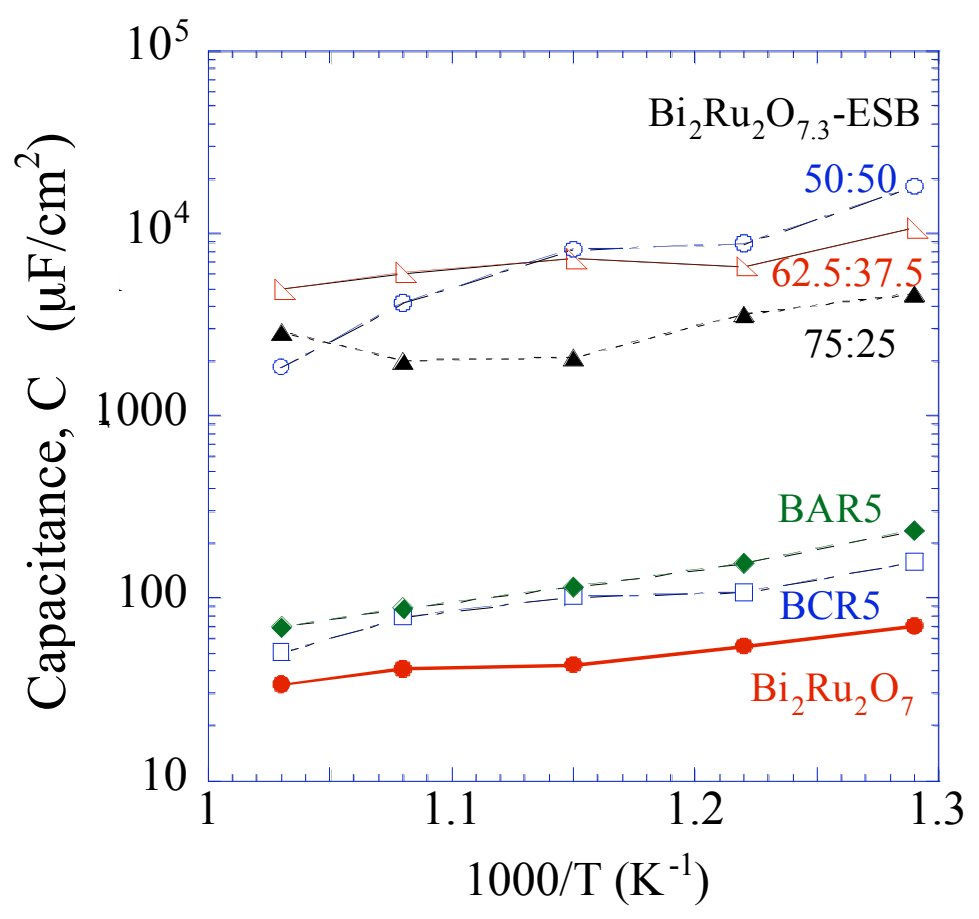

Figure 89. Electrode capacitance $\left(\mu \mathrm{F} / \mathrm{cm}^{2}\right)$ of $\mathrm{Bi}_{2} \mathrm{Ru}_{2} \mathrm{O}_{7}, 5 \mathrm{~mol} \% \mathrm{Ca}$ doped $\mathrm{Bi}_{2} \mathrm{Ru}_{2} \mathrm{O}_{7}$ (BCR5), $5 \mathrm{~mol} \%$ Ag doped $\mathrm{Bi}_{2} \mathrm{Ru}_{2} \mathrm{O}_{7}$ (BAR5), and $\mathrm{Bi}_{2} \mathrm{Ru}_{2} \mathrm{O}_{7.3}$-ESB composite electrodes. As-calcined bismuth ruthenate powders used for fabrication. 
electrodes showed capacitance of $70.83 \mu \mathrm{F} / \mathrm{cm}^{2}, 33.70 \mu \mathrm{F} / \mathrm{cm}^{2}, 50.37 \mu \mathrm{F} / \mathrm{cm}^{2}, 70.16 \mu \mathrm{F} / \mathrm{cm}^{2}$, $4928.90 \mu \mathrm{F} / \mathrm{cm}^{2}$ and $4960.97 \mu \mathrm{F} / \mathrm{cm}^{2}$ at $700{ }^{\circ} \mathrm{C}$, respectively.

The much improved performance along with an order of magnitude higher capacitance on addition of ESB phase in both $\mathrm{Bi}_{2} \mathrm{Ru}_{2} \mathrm{O}_{7}-\mathrm{ESB}$ and $\mathrm{Bi}_{2} \mathrm{Ru}_{2} \mathrm{O}_{7.3}$-ESB composite electrode systems indicate a change in electrode reaction mechanism. The presence of the ESB not only increases the concentration of TPBs and ionic conductivity of the electrode, but possibly also shortens the rate-limiting surface diffusion path to the TPBs observed in single phase bismuth ruthenate electrodes. Further impedance studies as a function of oxygen partial pressure could identify the rate limiting steps in the oxygen reduction reaction for the composite systems. The optimum composition in the vicinity of $37.5 \mathrm{wt} \%$ ESB for both composite systems could be explained on the basis of percolation theory, so as to provide contiguous pathways for both electrons and oxygen ions in the electrode; density of $\mathrm{Bi}_{2} \mathrm{Ru}_{2} \mathrm{O}_{7.3}, \mathrm{Bi}_{2} \mathrm{Ru}_{2} \mathrm{O}_{7}$, and ESB is $9.12 \mathrm{gm} / \mathrm{cm}^{3}, 8.92$ $\mathrm{gm} / \mathrm{cm}^{3}$ and $8.96 \mathrm{gm} / \mathrm{cm}^{3}$, respectively.

\section{Further Optimization of BRO-ESB Composites}

The initial results for BRO-ESB composites make it a promising candidate for reduced temperature SOFCs. Moreover, the dramatic impact microstructure has on composite electrode performance has already been established from Ag-ESB studies earlier in the report. TPB lengths can be affected by such microstructural factors as particle size, porosity, agglomeration and phase segregation. This section addresses some of these parameters in order to further improve the performance of BRO-ESB composite cathodes.

Reproducibility/Compositional Optimization. Before any microstructural optimization was conducted, BRO-ESB was first compositionally optimized on ESB electrolytes using readily available powders--ESB prepared from conventional solid-state synthesis and solid-state BRO powders which underwent an additional vibratory milling step. These powders being a different size than the abovementioned work would result in a different microstructure. (Further, this work was performed by a different student in the same laboratory.) Therefore, these "relatively" minor changes would also give an indication of the types of reproducibility issues inherent in comparing results between research groups. 

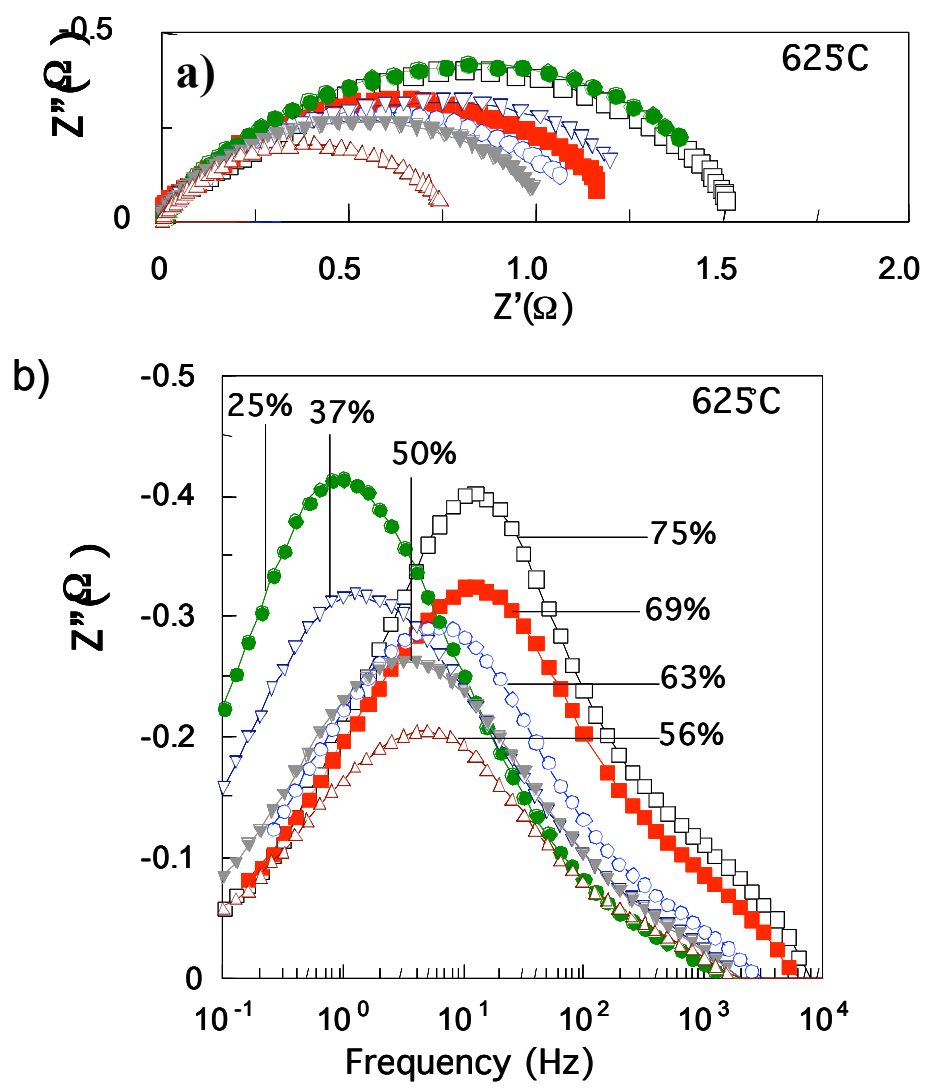

Figure 90. Nyquist (a) and bode (b) plots at $625^{\circ} \mathrm{C}$ for different compositions of $\mathrm{BRO}_{\mathrm{VM}, \mathrm{AP}}-\mathrm{ESB}_{\mathrm{S}, \mathrm{AP}}$ electrodes tested in air.

Figure 90 shows typical impedance and bode spectra obtained at $625{ }^{\circ} \mathrm{C}$ in air under no applied bias, and Fig. 91 shows the trend in cathode ASR vs. temperature over a range of composition for this system. Note that in these and all future impedance plots, the data has been $\mathrm{R}_{\mathrm{s}}$-corrected for ease in comparison-i.e., the high-frequency real-axis intercept, $\mathrm{R}_{\mathrm{s}}$, of each spectrum (composed of the bulk electrolyte resistance, electrode sheet resistance and lead contact resistance) was subtracted from the real component of each data point in the spectrum.

Plotted this way, the low-frequency real-axis intercept corresponds to electrode polarization resistance, $R_{p}$, and the cathode ASR can easily be calculated from Eq. (2), where $R_{p}$ is now simply the real-axis low-frequency intercept. At $625^{\circ} \mathrm{C}$, each impedance plot appears to be composed of a single arc, and the characteristic frequency increases with ESB content. It is interesting to note that the width of the imaginary impedance vs. frequency spectrum is narrower toward the extremes of the concentration range than at intermediate compositions, suggesting a mechanistic overlap at these intermediate compositions, and in fact, a minimum value is 


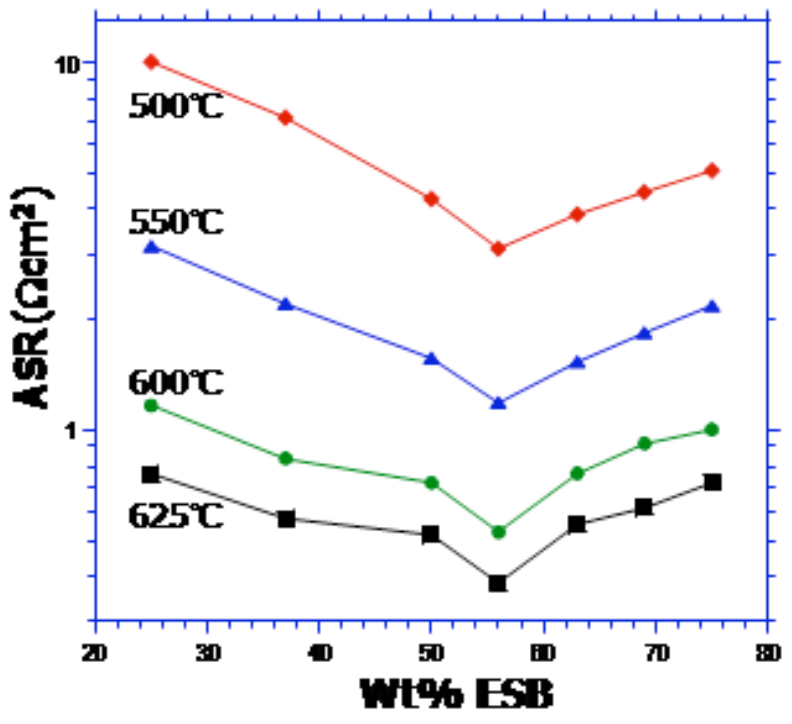

Figure 91. Effect of electrode composition for the $\mathrm{ESB}_{\mathrm{S}, \mathrm{AP}}-\mathrm{BRO}_{\mathrm{VM}, \mathrm{AP}}$ system.

observed at $56 \mathrm{wt} \%$ ESB over the range of temperatures tested. Since the densities of BRO and ESB are approximately the same $\left(\sim 8.9 \mathrm{~g} / \mathrm{cm}^{3}\right)$, this observation is consistent with the effective medium percolation theory and TPB maximization.

For a two-phase composite whose particle sizes are roughly the same, and assuming the solid phases and pores are randomly distributed and the porosity is open and sufficiently large, the TPB length should reach a maximum if the two solid phases are present in equal fractions of the overall electrode volume. In the present study, BRO particles are small relative to ESB particles hence percolation and TPB length maximization can occur at non-equal volume fractions of the two phases. As discussed above, TPB length is important in two-phase cathode systems since the oxygen reduction reaction that is occurring can only proceed at sites where all three reactants are present - as the cathode TPB length increases, so do the number of reaction sites, and hence cathode activation polarization decreases.

Note that this result differs from that obtained earlier, where a minimum was observed between 31-43 wt\% ESB. One possible explanation may be differences in powder synthesis techniques between the two studies. ESB was obtained through conventional solid state synthesis in this section (micron-sized particles), as opposed to a wet chemical route (yielding nano-sized particles) used in the previous section. Also, in the present study the BRO powders 
were vibratory milled for seven days versus thee days in the earlier study; hence, yielding, on average, larger BRO particles than in the present study. Consequently, the ESB-to-BRO particle size ratio in the present study is appreciably larger than for the earlier study. As the ESB-toBRO particle size ratio decreases, percolation of the ESB phase-and hence compositional optimization of the cermet cathode-becomes feasible at smaller ESB volume fractions.

Note that there appears to be a difference in activation energies between the electrodes obtained here $(1.02 \mathrm{eV})$ compared to the previous section $(\sim 1.3 \mathrm{eV})$. The electrode ASR at 500 ${ }^{\circ} \mathrm{C}$ are comparable $\left(3.11 \Omega \mathrm{cm}^{2}\right.$ for the present study compared to $3.37 \Omega \mathrm{cm}^{2}$ for the previous section), but are quite different at $700{ }^{\circ} \mathrm{C}\left(0.17 \Omega \mathrm{cm}^{2}\right.$ for the present study compared to 0.08 $\Omega \mathrm{cm}^{2}$ for the previous section). The lower activation energy in the present study is likely due to the matching ESB electrolyte and electrode ionic conducting phases in the present study (aforesaid study was conducted on a GDC electrolyte) and may indicate a contribution to cathode polarization arising from oxygen vacancy transport across the electrode/electrolyte interface.

Microstructural Optimization. Having shown an acceptable level of reproducibility-in performance, though not in optimal composition - microstructural optimization was next carried out. Given the difference in optimum concentration between the two compositional studies, careful consideration was given with respect to the choice of concentration to use for the microstrucural study. It was decided to fix the BRO-ESB composition at 50-50 wt\% (approximately 50-50 vol\%) so as to minimize any possible bias that might arise from skewing the composition toward either end of the spectrum.

Electrode microstructure was first optimized according to starting particle size ratio. Particle sizes of the constituent phases were altered using vibratory milling as well as a combination of sonication and sedimentation, as explained in the experimental section. Table 2 shows the subscripts and symbols used to represent the different starting powders used in the

Table 2. Subscript and symbolic designations for different sets of starting powders, orange and yellow represent ESB particles, black and gray represent BRO particles.

\begin{tabular}{cccc}
\hline Phase subscript designation & Type of powder & Avg. particle size rank & Symbol \\
\hline S,AP & Sieved, as-prepared & 1 (largest) & $\bigcirc \bigcirc$ \\
VM,AP & Vibratory-milled, as-prepared & 2 & 0 \\
VM,SUP & Vibratory-milled, supernatant & 3 (smallest) & 0 O \\
\hline
\end{tabular}



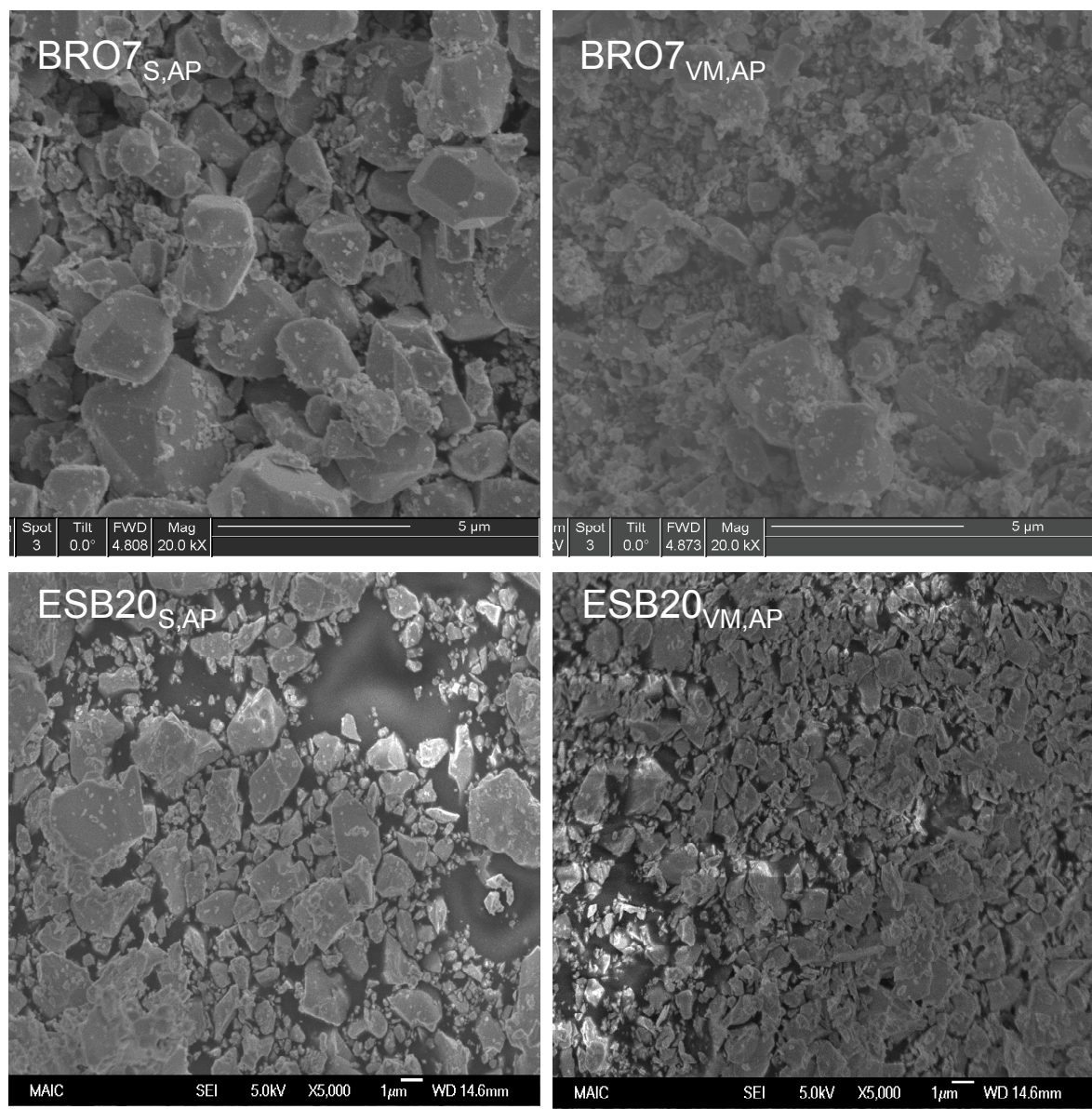

Figure 92. SEM micrograph of as-prepared ESB and BRO powders before (left) and after (right) vibratory-milling.
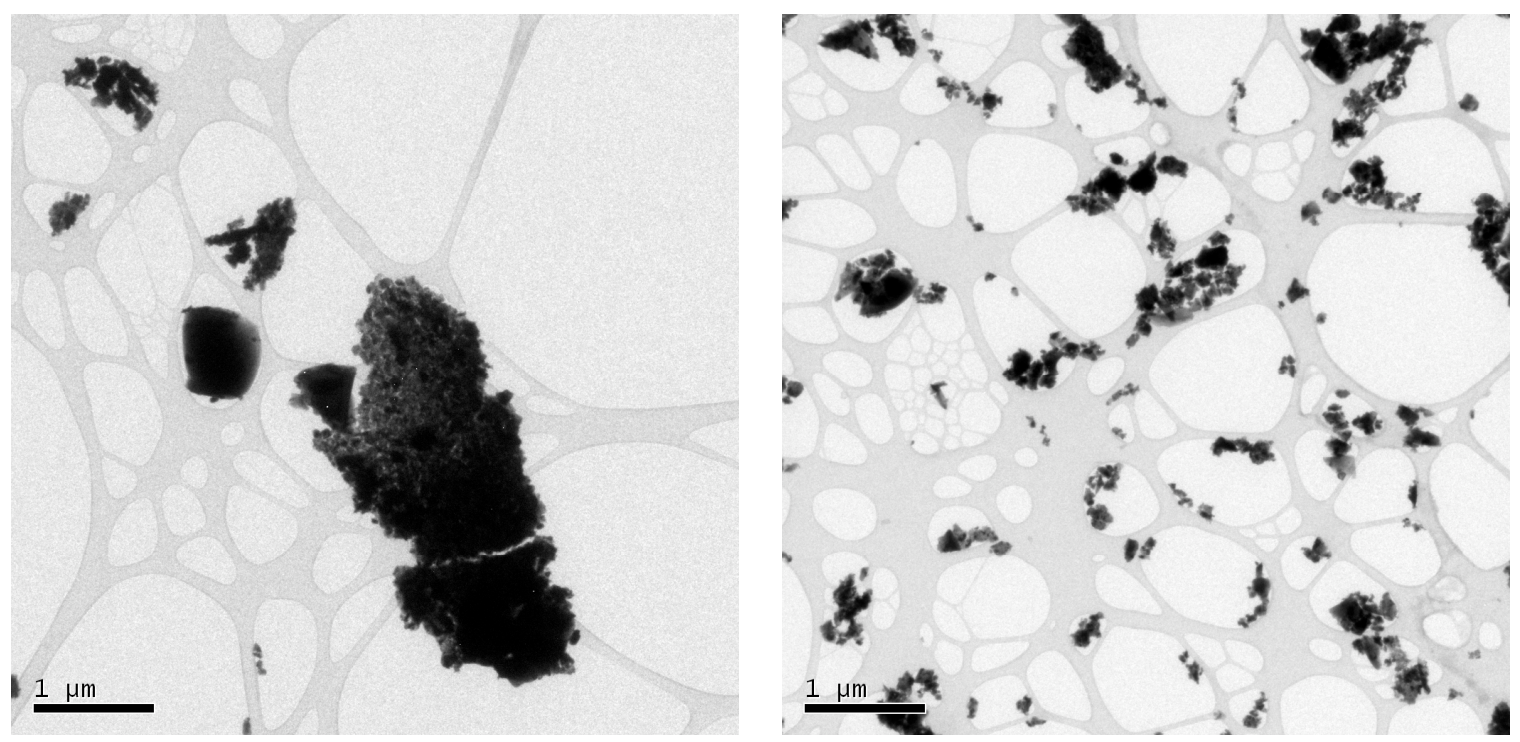

Figure 93. TEM micrograph of as-prepared $\mathrm{BRO}_{\mathrm{VM}}$ powders before (left) and after (right) sonication and sedimentation. 

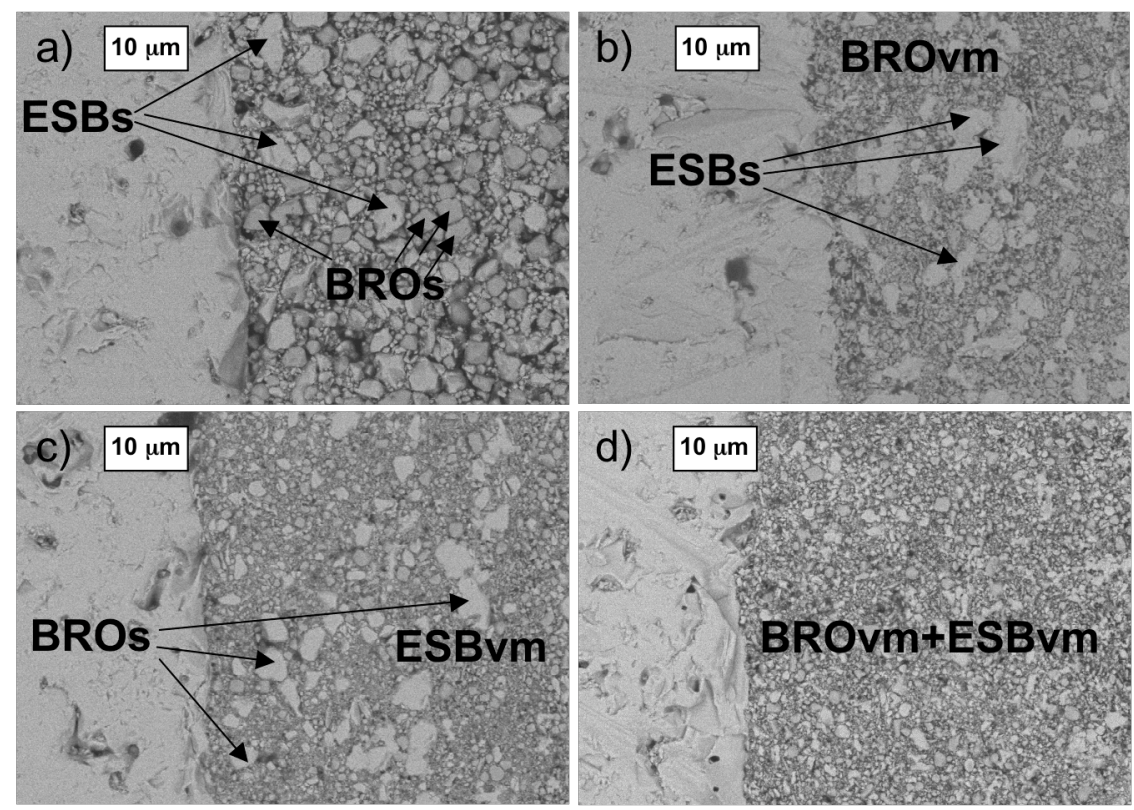

Figure 94. SEM image of four fully-fired $\mathrm{BRO}-\mathrm{ESB}$ cathode systems used in this study- $\mathrm{BRO}_{\mathrm{S}, \mathrm{AP}^{-}}$ $\mathrm{ESB}_{\mathrm{S}, \mathrm{AP}}(\mathrm{a}), \mathrm{BRO}_{\mathrm{VM}, \mathrm{AP}}-\mathrm{ESB}_{\mathrm{S}, \mathrm{AP}}(\mathrm{b}), \mathrm{BRO}_{\mathrm{S}, \mathrm{AP}}-\mathrm{ESB}_{\mathrm{VM}, \mathrm{AP}}(\mathrm{c}), \mathrm{BRO}_{\mathrm{VM}, \mathrm{AP}}-\mathrm{ESB}_{\mathrm{VM}, \mathrm{AP}}$ (d).

composite electrodes. Figures 92 and 93 show representative samples of each particle system used in the present study. Figure 92 compares BRO and ESB powders as prepared from solidstate synthesis, and directly after vibratory milling. Figure 93 shows the further reduction in particle size and agglomeration that can be obtained by sonication and sedimentation.

Particle size analysis for ESB revealed that the average particle size was reduced by about an order of magnitude after seven days of vibratory milling-from several microns to several hundreds of nanometers (Fig. 24). Similar results were obtained for vibratory milling of BRO powders. Note how each set of vibratory-milled powders still contains a small number fraction (but significant volume fraction) of large, unbroken particles. Four different electrode structures were examined $\left(\mathrm{BRO}_{\mathrm{S}, \mathrm{AP}}-\mathrm{ESB}_{\mathrm{S}, \mathrm{AP}}, \mathrm{BRO}_{\mathrm{S}, \mathrm{AP}}-\mathrm{ESB}_{\mathrm{VM}, \mathrm{AP}}, \mathrm{BRO}_{\mathrm{VM}, \mathrm{AP}}-\mathrm{ESB}_{\mathrm{S}, \mathrm{AP}}\right.$, and $\mathrm{BRO}_{\mathrm{VM}, \mathrm{AP}}-\mathrm{ESB}_{\mathrm{VM}, \mathrm{AP}}$ ), each containing a 1:1 volume ratio of the constituent phases. An SEM image of the four fully-fired electrodes is shown in Fig. 94.

Figure 95 shows typical impedance spectra and bode plots obtained at $625^{\circ} \mathrm{C}$ for these electrodes in air under no applied bias. Plots of ASR vs. reciprocal temperature are given in Fig. 96. These results show that the composites exhibiting the lowest resistance are those composed of both large and small particles. All composites containing at least one vibratory-milled phase have significantly lower resistance than the composite composed entirely of large particles, as 

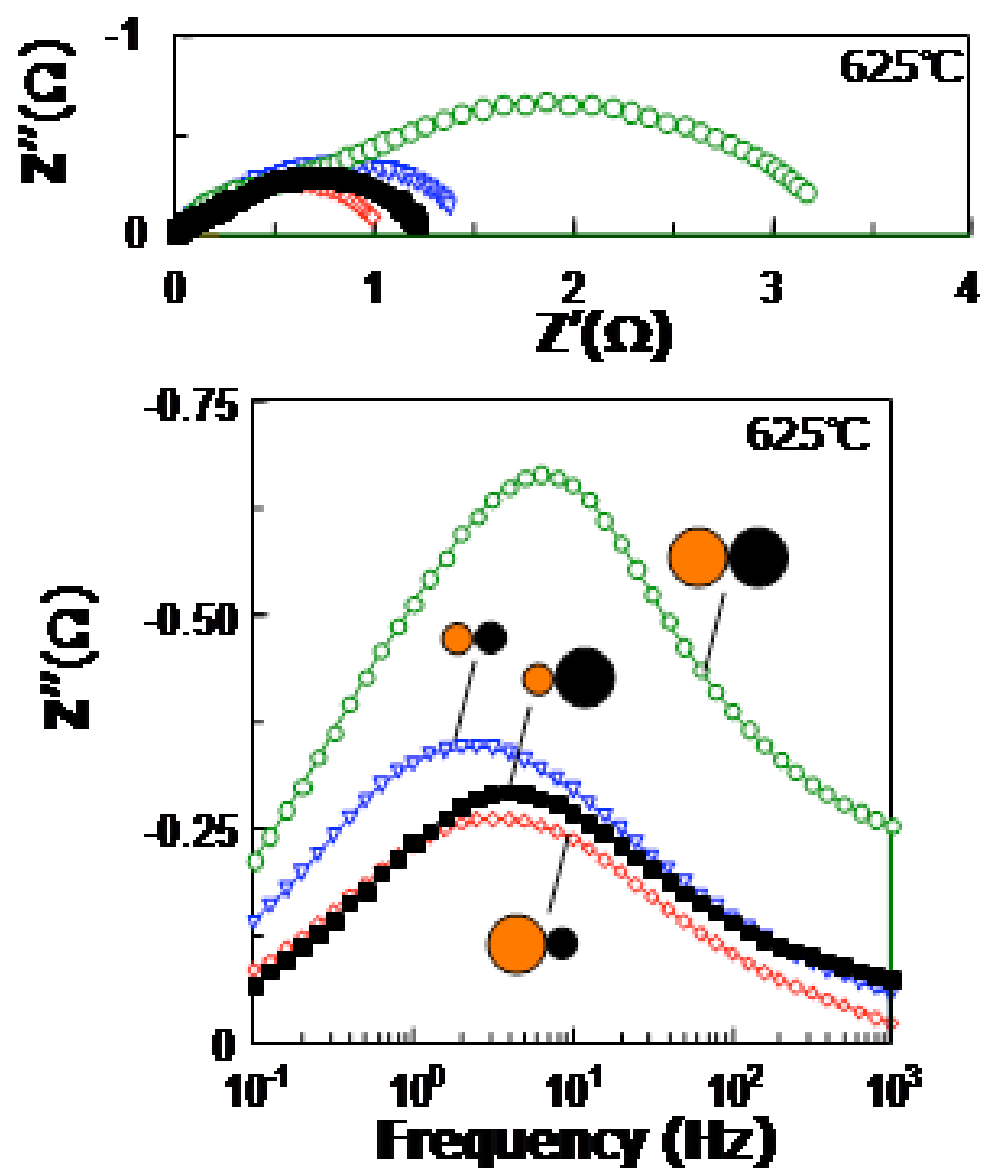

Figure 95. Nyquist (a) and bode (b) plots at $625^{\circ} \mathrm{C}$ for different $50-50 \mathrm{wt} \%$ BRO-ESB electrode microstructures tested in air.

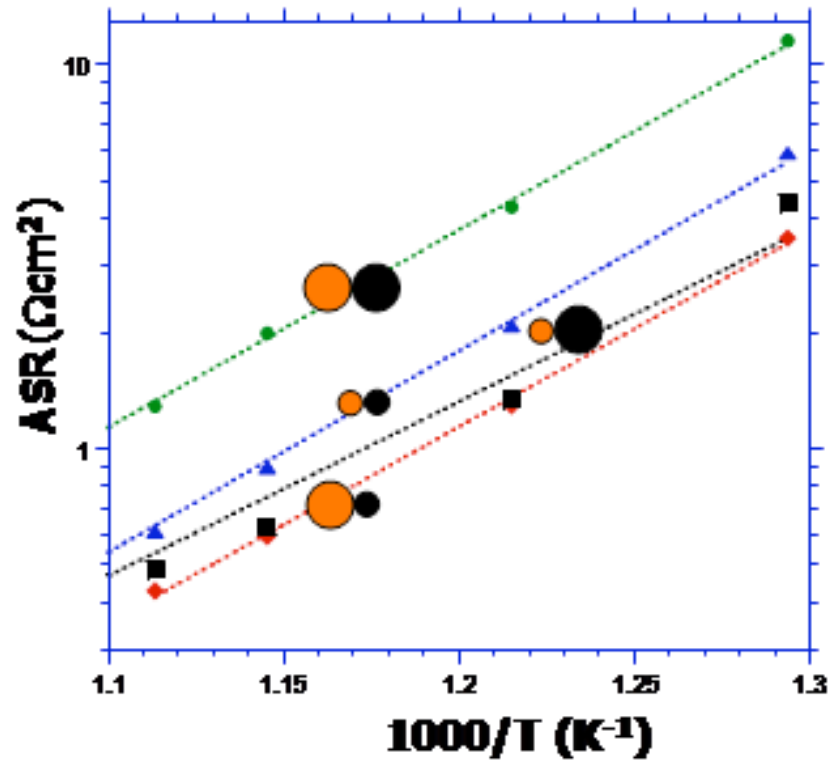

Figure 96. Arrhenius plot of ASR vs reciprocal temperature for the four different microstructures studied. 
expected, due to the increased TPBs. The activation energies for all electrodes are similar $(1.03 \mathrm{eV} \pm 0.03 \mathrm{eV})$, as are their characteristic frequencies (Fig. 95b), suggesting a common ratedetermining mechanism for the different electrodes. It is not known at this time which mechanism is dominant; more work is needed to clarify this issue via testing under different oxygen partial pressures. However, it is evident that the magnitude of the impedance of this mechanism has been markedly affected by these microstructural considerations.

Comparing the two systems where the different phases have more similar grain size $\left(\mathrm{BRO}_{\mathrm{VM}, \mathrm{AP}}-\mathrm{ESB}_{\mathrm{VM}, \mathrm{AP}}\right.$ and $\left.\mathrm{BRO}_{\mathrm{S}, \mathrm{AP}}-\mathrm{ESB}_{\mathrm{S}, \mathrm{AP}}\right)$, the electrode comprised of vibratory-milled particles exhibits the lower ASR, as expected. The systems composed of dissimilarly-sized particles $\left(\mathrm{BRO}_{\mathrm{VM}, \mathrm{AP}}-\mathrm{ESB}_{\mathrm{S}, \mathrm{AP}}\right.$ and $\left.\mathrm{BRO}_{\mathrm{S}, \mathrm{AP}}-\mathrm{ESB}_{\mathrm{VM}, \mathrm{AP}}\right)$ exhibit nearly the same performance, with the $\mathrm{BRO}_{\mathrm{VM}, \mathrm{AP}}-\mathrm{ESB}_{\mathrm{S}, \mathrm{AP}}$ electrode having the lowest $\mathrm{ASR}$ of $0.41 \Omega \mathrm{cm}^{2}$ at $625^{\circ} \mathrm{C}$. Interestingly, the electrodes containing dissimilar grain sizes exhibit lower ASR values than the electrodes containing more similar grain sizes despite being shifted towards non-optimal composition ratios, as discussed above. Recall that, although the optimal composition of $\mathrm{BRO}_{\mathrm{VM}, \mathrm{AP}}-\mathrm{ESB}_{\mathrm{S}, \mathrm{AP}}$, was $56 \mathrm{wt} \% \mathrm{ESB}$, for our microstructural study a 1:1 ratio was used. One possible explanation for this observation could be the formation of soft agglomerates of fine particles during synthesis, as can be seen for the as-prepared $\mathrm{BRO}_{\mathrm{VM}}$ powder in Fig. 93.

As previously mentioned, as-prepared vibratory-milled powders contain a significant volume fraction of unbroken, micron-sized particles. Focused ion beam (FIB) analysis and reconstruction (not shown) also reveals a degree of phase segregation in the fired electrodes. The next stage in the microstructural development involved the use of sedimentation for further reduction in particle size and a narrower particle-size distribution. Also, ultra-sonication was used to break up soft agglomerates and improve phase distribution in the cathode. The results are shown in Figs. 97 and 98. Impedance results show a large reduction in resistance for all systems where the raw vibratory milled phase was replaced with the supernatant phase. The ASR reduction was the most dramatic for the composite comprised entirely of small particles. Clearly this composite benefits the most from the combination of reduced particle size and the more intimate sonicated mixing. Not only were the soft agglomerates of each phase broken up, but also the reduced particle size distribution translates into a larger number fraction of submicron sized particles in each vibratory milled phase. This in turn translates into a larger TPB 

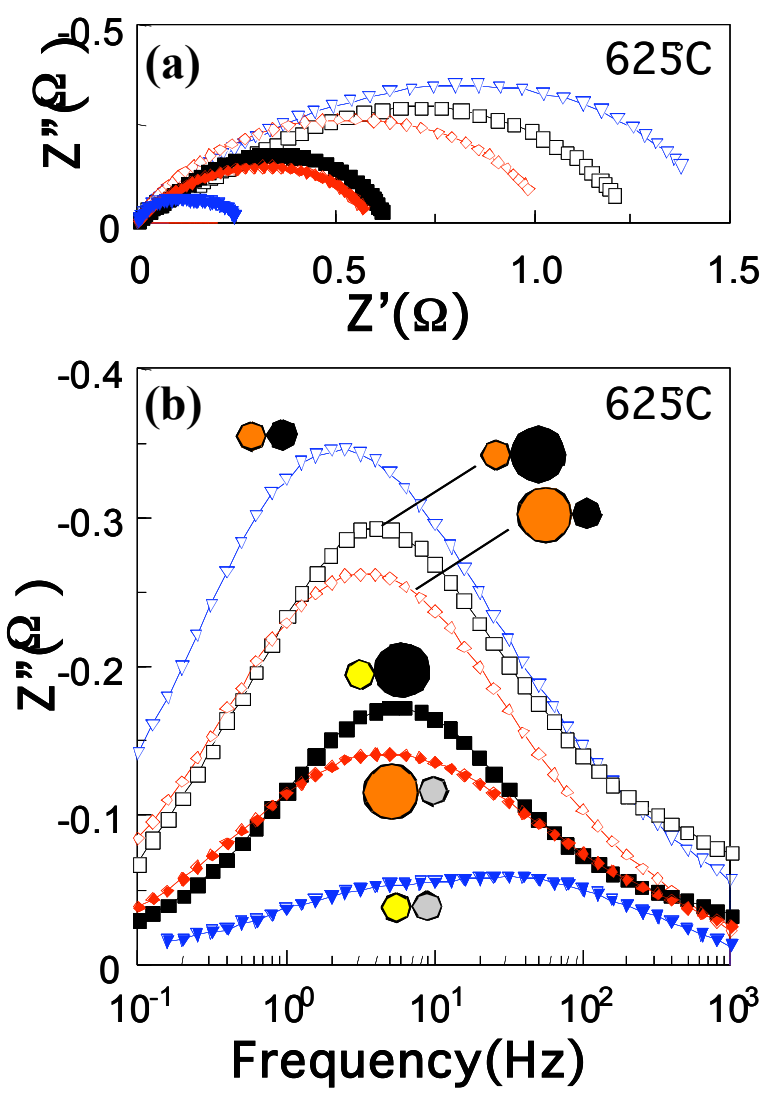

Figure 97. Nyquist (a) and bode (b) plots at $625^{\circ} \mathrm{C}$ for different $50-50 \mathrm{wt} \%$ BRO-ESB electrode microstructures tested in air before (open symbols) and after (closed symbols) sonication and sedimentation of electrode powders.

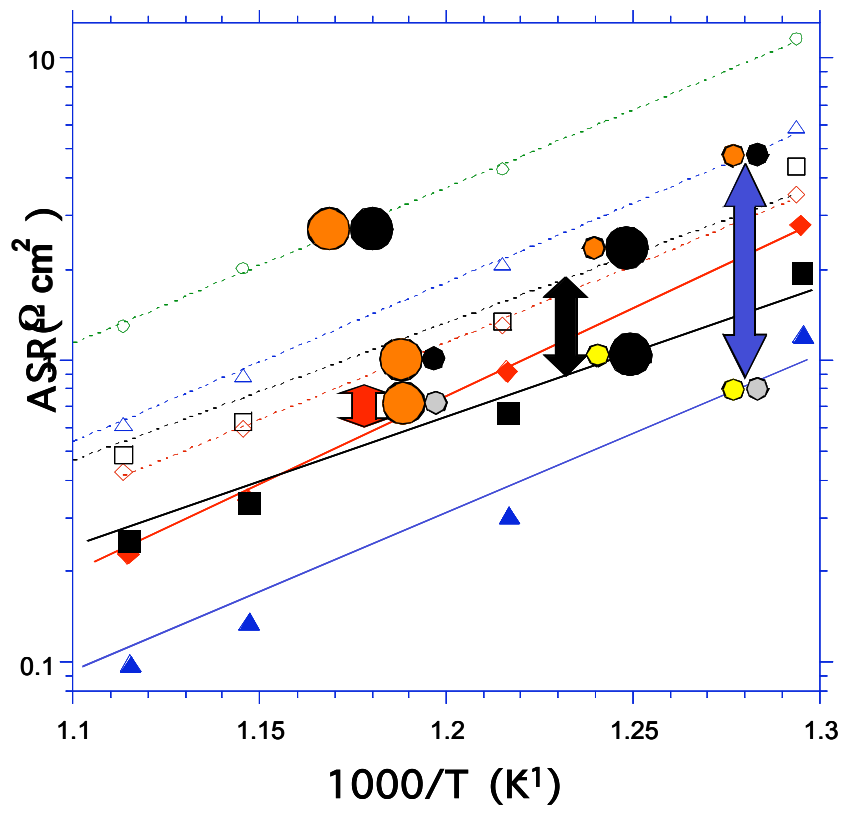

Figure 98. Arrhenius plot of ASR - comparison between electrodes prepared from as-prepared powders (open symbols) and powders which underwent ultrasonication and sedimentation (closed symbols). 


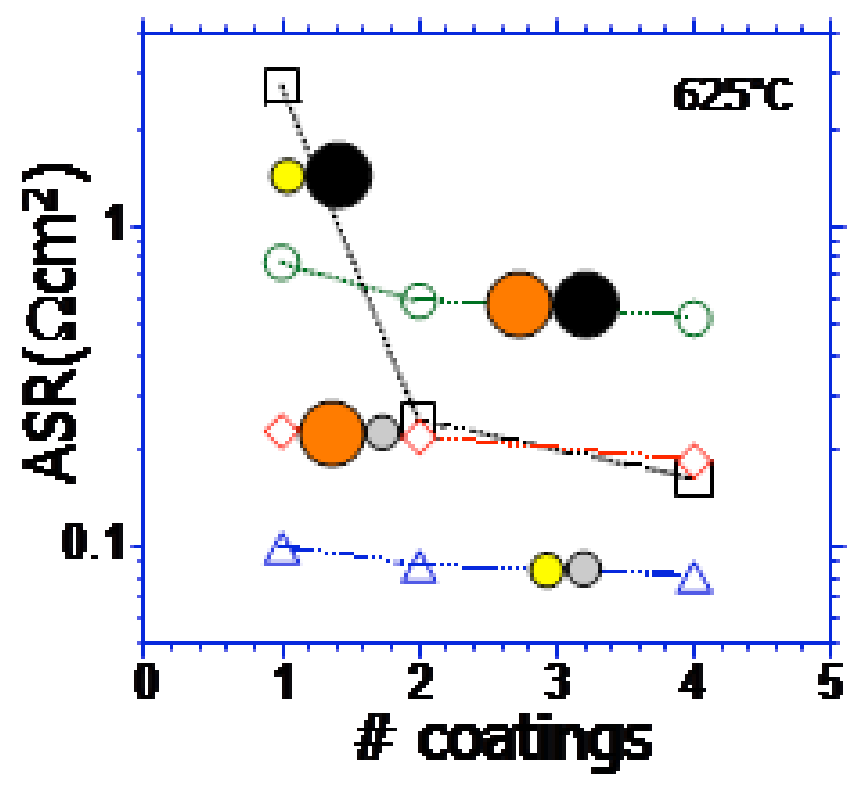

Figure 99. Effect of electrode thickness on ASR at $625{ }^{\circ} \mathrm{C}$ for the four different electrode microstructures prepared after ultrasonication and sedimentation of the as-prepared powders.

length. The minimum ASR observed was $0.10 \Omega \mathrm{cm}^{2}$ at $625^{\circ} \mathrm{C}$ for the $\mathrm{ESB}_{\mathrm{VM}, \mathrm{SUP}}-\mathrm{BRO}_{\mathrm{VM}, \mathrm{SUP}}$ system.

It is clear from Fig. 97b that the impedance spectrum of this composite is composed of two arcs. Comparing the spectrum of this electrode with the other electrodes, it appears that the low frequency process is the most affected by these microstructural changes, and its resistance has been lowered to the point where the low and high frequency processes are in competition with each other.

\section{Further Performance Optimization: Effect of Thickness and Current Collection.} Electrode thickness and current collection can also affect electrode performance through minimizing concentration polarization effects and maximizing the number of active TPB sites. To further drive down ASR values, cells were prepared using electrodes of different thicknesses. In addition, separate studies were conducted using pure BRO current collectors.

The effect of thickness on ASR for the different composite microstructures is illustrated in Fig. 99. In each case, ASR is reduced as thickness is increased, over the range of thicknesses studied. The $\mathrm{ESB}_{\mathrm{VM}, \mathrm{SUP}}-\mathrm{BRO}_{\mathrm{S}, \mathrm{AP}}$ system exhibited a one order of magnitude drop in ASR between the first and second coating (from 2.72 to $0.25 \Omega \mathrm{cm}^{2}$ ). This observation was confirmed 

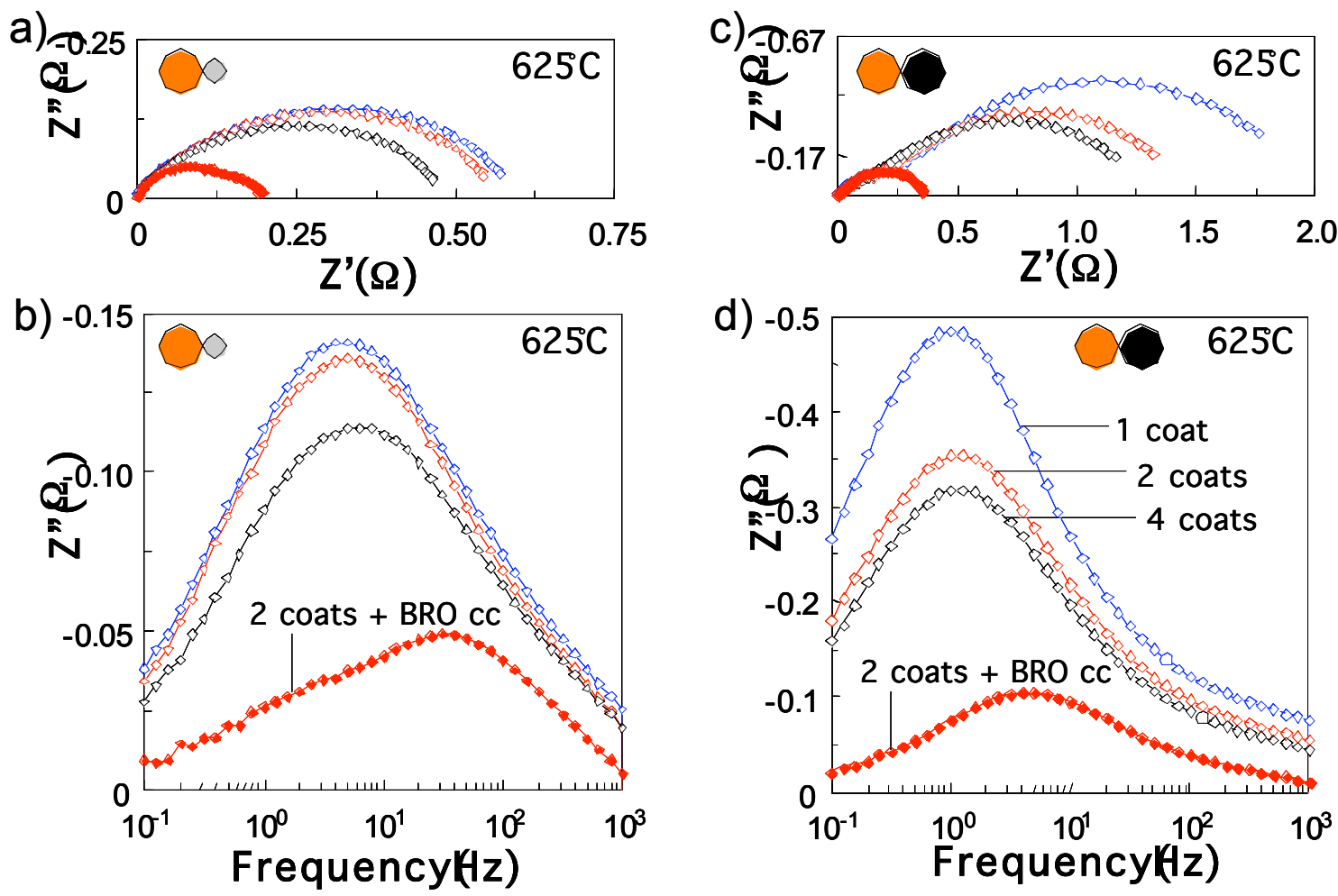

Figure 100. Nyquist $(\mathrm{a}, \mathrm{c})$ and bode $(\mathrm{b}, \mathrm{d})$ plots at $625^{\circ} \mathrm{C}$ for $50-50 \mathrm{wt} \%$ BRO-ESB at different thicknesses without (open symbols) and with (closed symbols) pure BRO current collectors. Note: The $\mathrm{BRO}_{\mathrm{VM}, \mathrm{SUP}}-\mathrm{ESB}_{\mathrm{S}, \mathrm{AP}}$ system is shown at left and $\mathrm{BRO}_{\mathrm{S}, \mathrm{AP}}-\mathrm{ESB}_{\mathrm{S}, \mathrm{AP}}$ is shown at right.

to be reproducible, and is believed to be due to a current collection issue where the electrode thickness is insufficient for BRO phase percolation. That the $\mathrm{ESB}_{\mathrm{S}, \mathrm{AP}}-\mathrm{BRO}_{\mathrm{S}, \mathrm{AP}}$ system did not show as significant an ASR reduction (from 0.77 to $0.58 \Omega \mathrm{cm}^{2}$ ) as the $\mathrm{ESB}_{\mathrm{VM}, \mathrm{SUP}}-\mathrm{BRO}_{\mathrm{S}, \mathrm{AP}}$ system can be attributed to a reduction in BRO phase connectivity caused by the fine $\mathrm{ESB}_{\mathrm{VM}, \mathrm{SUP}}$ particles percolating between adjacent $\mathrm{BRO}_{\mathrm{S}, \mathrm{AP}}$ grains.

As a result of this observation, a new batch of twice-coated samples was prepared, this time using a pure $\mathrm{BRO}_{\mathrm{S}, \mathrm{AP}}$ current collector layer. This layer did not adhere well to the two electrode systems which utilized fine particles of ESB. However, for the other systems, there is a dramatic drop in the resistance of the low-frequency process, as shown in Fig. 100. For the $\mathrm{BRO}_{\mathrm{VM}, \mathrm{SUP}}-\mathrm{ESB}_{\mathrm{S}, \mathrm{AP}}$ system, the high-frequency process now dominates the performance.

As shown in Fig. 101, the ASR of these two systems was cut almost in quarter (from 0.58

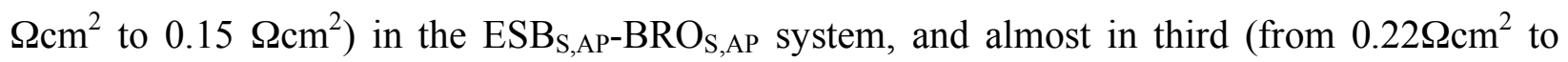
$0.076 \Omega \mathrm{cm}^{2}$ ) in the $\mathrm{ESB}_{\mathrm{S}, \mathrm{AP}}-\mathrm{BRO}_{\mathrm{VM}, \mathrm{SUP}}$ system. The former system composed of large BRO 

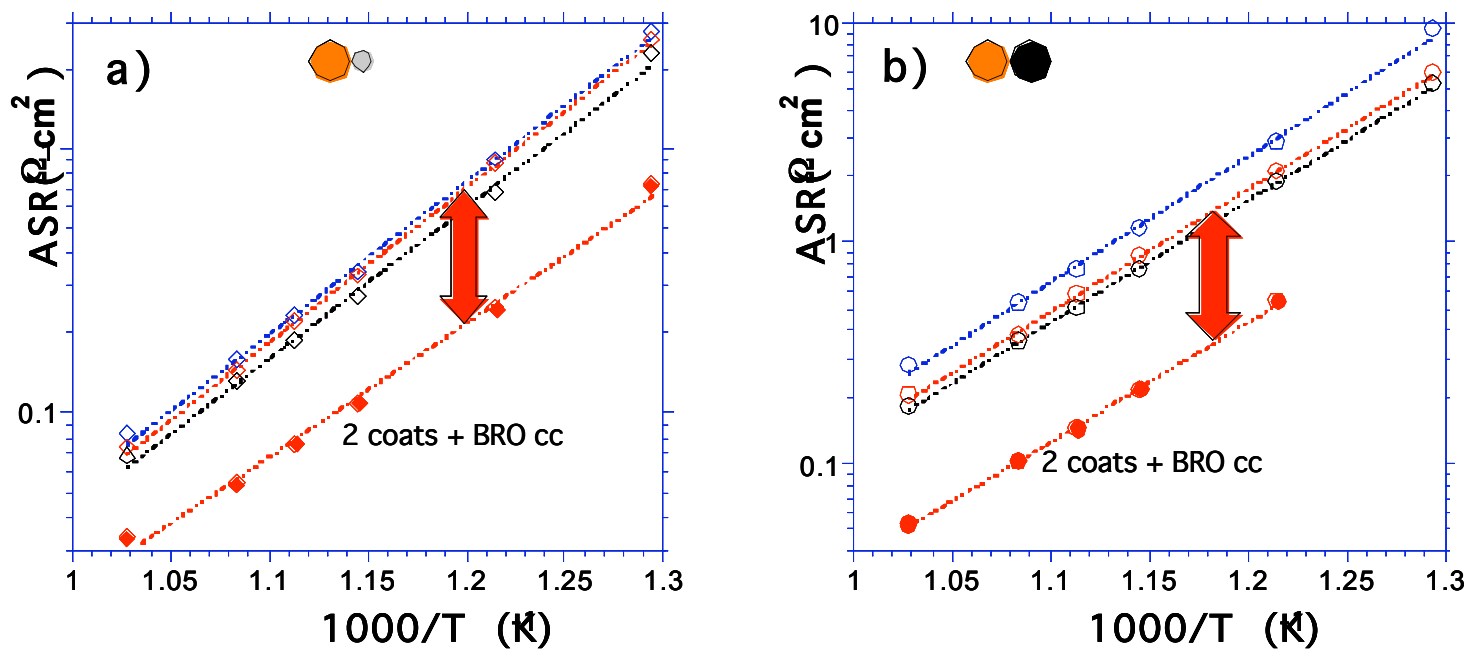

Figure 101. Arrhenius plot of ASR - a comparison between electrodes without (open symbols) and with (closed symbols) current collectors for the $\mathrm{BRO}_{\mathrm{VM}, \mathrm{SUP}}-\mathrm{ESB}_{\mathrm{S}, \mathrm{AP}}(\mathrm{a})$ and $\mathrm{BRO}_{\mathrm{S}, \mathrm{AP}}-\mathrm{ESB}_{\mathrm{S}, \mathrm{AP}}$ (b) systems.

grains exhibited a larger overall ASR reduction than the system composed of fine BRO grains, as expected from enhanced current collection. The latter system exhibited the lowest ASR of all systems studied $\left(0.73 \Omega \mathrm{cm}^{2}\right.$ and $0.03 \Omega \mathrm{cm}^{2}$ at $500{ }^{\circ} \mathrm{C}$ and $700{ }^{\circ} \mathrm{C}$, respectively). This is a marked improvement over the results of obtained in the previous section $\left(3.14 \Omega \mathrm{cm}^{2}\right.$ and 0.08 $\Omega \mathrm{cm}^{2}$ at $500{ }^{\circ} \mathrm{C}$ and $700{ }^{\circ} \mathrm{C}$, respectively) and is believed to be at least the second lowest value of ASR reported to date for IT-SOFCs in the literature ${ }^{89}$.

Further improvements are expected by improving the adhesion of the current collection layer to the system composed entirely of fine particles. In addition, further compositional optimization may be performed on each specific system studied in this work.

To conclude, BRO was shown to be chemically compatible with ESB. Microstructural engineering by a combination of mechanical crushing, ultra-sonication, and sedimentation was shown to be an effective way of lowering electrode ASR, and the results seem to be consistent with TPB length maximization theory. Application of a pure BRO current collector to the electrode surfaces further improved electrode performance. The lowest value of ASR attained ranged from $0.73 \Omega \mathrm{cm}^{2}$ at $500{ }^{\circ} \mathrm{C}$ to $0.03 \Omega \mathrm{cm}^{2}$ at $700{ }^{\circ} \mathrm{C}$ making it one of the lowest SOFC cathode ASR values reported to date. 


\section{Summary}

Bismuth ruthenate-ESB composite cathodes, developed in this study, show performance which is comparable to the very best new IT-SOFC cathode materials ${ }^{79,80,86,87,88,89}$. The high performance of bismuth ruthenate-ESB composites is due to the high ionic conductivity of ESB and high electronic conductivity of bismuth ruthenate. Moreover, both bismuth ruthenate and ESB are catalytic active towards oxygen reduction.

High performance cobalt-containing perovskites have compatibility issues with both stabilized zirconia and stabilized bismuth oxide electrolyte materials ${ }^{85,90}$, and on the other hand Ag-containing cathodes have microstructural stability issues due to electromigration ${ }^{88}$. As shown by Takeda et $a l .{ }^{91}$ and in this study that bismuth ruthenate is compatible with stabilized zirconia, doped ceria, and stabilized bismuth oxide, and therefore, bismuth ruthenate - stabilized bismuth oxide composites could be suitable for IT-SOFCs based on any of the three fluorite electrolyte systems. Further studies involving sinterability, thermal expansion, and microstructual optimization would improve the performance and extended electrochemical testing under fuel cell conditions would assess the potential of these novel bismuth ruthenate stabilized bismuth oxide composite cathodes for IT-SOFCs.

Addition of the ESB phase reduced the ASR of single phase bismuth ruthenate electrode by as much as a factor of twenty. The presence of ESB particles not only increase the concentration of TPBs and ionic conductivity of the composite electrode, but possibly also reduce the surface diffusion path to the TPBs resulting in improved electrode performance. Performance of bismuth ruthenate - stabilized bismuth oxide composite electrodes is promising and further extended studies under fuel cell conditions would determine the potential of these electrodes for IT-SOFCs.

Figure 102 compares the performance of the optimized BRO-ESB system with the optimized Ag-ESB system as well as Ag-YSB reported by Xia et al. ${ }^{16}$ and $\mathrm{Ba}_{0.5} \mathrm{Sr}_{0.5} \mathrm{Co}_{0.8} \mathrm{Fe}_{0.2} \mathrm{O}_{3}$ ${ }_{\delta}(\mathrm{BSCF})$ reported by Shao and Haile ${ }^{89}$ which has become the new benchmark cathode material in the field. At high temperatuers, the optimized BRO-ESB composite has outstanding performance and is comparable with our Ag-ESB. In addition, due to its low activation energy, it is even more competitive at lower temperatures, and has better performance than BSCF at 


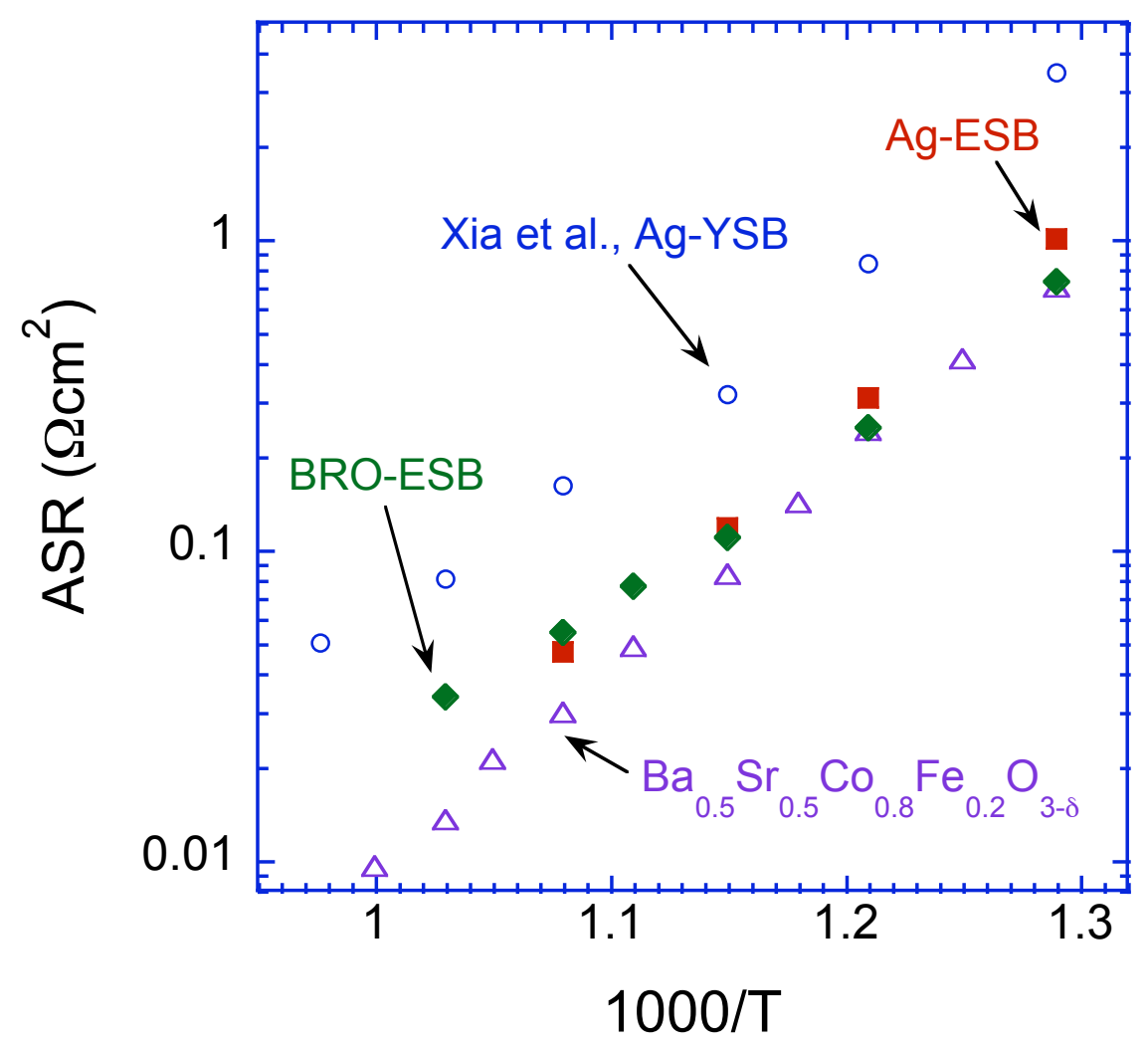

Figure 102. Comparison of ASR vs. reciprocal temperature for Ag-YSB (Xia et. al.), $\mathrm{Ba}_{0.5} \mathrm{Sr}_{0.5} \mathrm{Co}_{0.8} \mathrm{Fe}_{0.8} \mathrm{O}_{3-\delta}$ (Zhang and Haile) and optimized Ag-ESB (this work) and optimized BRO-ESB (this work).

temperatures below $500{ }^{\circ} \mathrm{C}$. Further improvements are likely to result from a compositional study of the optimized electrode. 


\section{CONCLUSION}

This research focused on developing low polarization (area specific resistance, ASR) cathodes for intermediate temperature solid oxide fuel cells (IT-SOFCs). In order to accomplish this we focused on two aspects of cathode development: (1) development of novel materials, based on Ag-bismuth oxide composites, a series of pyrochlore structured ruthenates $\left(\mathrm{Bi}_{2}\right.$ ${ }_{x} \mathrm{M}_{\mathrm{x}} \mathrm{Ru}_{2} \mathrm{O}_{7}$, where $\mathrm{M}=\mathrm{Sr}, \mathrm{Ca}, \mathrm{Ag} ; \mathrm{Pb}_{2} \mathrm{Ru}_{2} \mathrm{O}_{6.5}$; and $\mathrm{Y}_{2-2 \mathrm{x}} \mathrm{Pr}_{2 \mathrm{x}} \mathrm{Ru}_{2} \mathrm{O}_{7}$ ), and composites of the pyrochlore ruthenates with bismuth oxide; and (2) developing the relationships between microstructure and electrochemical performance by optimizing the Ag-bismuth oxide and the ruthenate-bismuth oxide composites in terms of both two-phase composition and particle size/microstructure. We further investigated the role of thickness and current collector on ASR, as well as investigated issues of stability.

Ag-ESB cermet electrodes showed excellent electrochemical performance. Our Ag-ESB composite cathode has an ASR of $0.18 \Omega \mathrm{cm}^{2}$ at $600{ }^{\circ} \mathrm{C}$, making it one of the lowest-resistance electrode systems reported to date and a significant improvement over our benchmark by Xia et. al who obtained an ASR of $0.3 \Omega \mathrm{cm}^{2}$ at $600{ }^{\circ} \mathrm{C}$ for their Ag-YSB composite. However, impedance studies under current bias showed that the electrode microstructure was unstable at high bias currents at $625^{\circ} \mathrm{C}$, primarily due to the electro-migration of Ag along with the oxygen flux. The high oxygen solubility in Ag results in good performance of the electrode, but it also results in the lowering of the melting point of $\mathrm{Ag}$ and its consequent electro-migration.

Addition of $5 \mathrm{vol} \%$ YSZ nano-powders significantly improved unbiased electrode stability by $97 \%$, and reduced the initial, zero time ASR value by $31 \%$. Similar results were obtained when YSZ-free electrodes were prepared from ESB powders composed of particles hundreds of nanometers in size as opposed to electrodes prepared from ESB powders composed of micron-sized particles - the zero time ASR value was reduced by $25 \%$, and ASR vs. time slope during unbiased testing of the silver-ESB system at $650{ }^{\circ} \mathrm{C}$ was reduced by $95 \%$.

ASR vs. time slopes during testing under a $250 \mathrm{mV}$ external applied bias were lowered by $50 \%$ using the smaller ESB particles due to suppression of silver phase electro-migration. The stability of composite Ag-ESB electrodes under an applied bias still needs some 
improvement. Improvements are likely with further reduction in ESB particle size down to several tens of nanometers. Also, as the operating temperature of SOFCs is reduced, the migration of the silver phase will be suppressed even further.

Lead ruthenate (PRO) was successfully synthesized by direct condensation method (DCM). Sintering of PRO electrodes was optimized at $800^{\circ} \mathrm{C}$. Low ASR values, e.g., 0.41 $\Omega \mathrm{cm}^{2}$ at $750{ }^{\circ} \mathrm{C}$, of these PRO electrodes were obtained. Also, ESB and PRO were determined to be compatible and thus suitable constituents of composite electrodes. Above $600^{\circ} \mathrm{C}$ where reaction at the TPB is not rate limiting PRO is a better cathode than PRO-ESB. However, below $600^{\circ} \mathrm{C}$ the extended TPB of the PRO-ESB composite results in a lower ASR cathode. Further optimization of the microstructure and $\mathrm{ESB} / \mathrm{Pb}_{2} \mathrm{Ru}_{2} \mathrm{O}_{6.5}$ ratio could result in lower ASRs.

Yttrium ruthenate (YRO) is compatible with both GDC and ESB since no reaction products were found by XRD analysis after heat-treatment at $800^{\circ} \mathrm{C}$ for $24 \mathrm{~h}$. We evaluated the effect of $\mathrm{Pr}$ doping and found the best performing electrode was $\mathrm{Y}_{1.5} \mathrm{Pr}_{0.5} \mathrm{Ru}_{2} \mathrm{O}_{7}$ with an ASR, at $700{ }^{\circ} \mathrm{C}$, of $0.19 \Omega \mathrm{cm}^{2}$ on an ESB electrolyte and $4.23 \Omega \mathrm{cm}^{2}$ on a GDC electrolyte. The low value of resistivity of the $\mathrm{Y}_{1.5} \mathrm{Pr}_{0.5} \mathrm{Ru}_{2} \mathrm{O}_{7} / \mathrm{ESB} / \mathrm{Y}_{1.5} \mathrm{Pr}_{0.5} \mathrm{Ru}_{2} \mathrm{O}_{7}$ symmetric cell suggests that $\mathrm{Y}_{1.5} \mathrm{Pr}_{0.5} \mathrm{Ru}_{2} \mathrm{O}_{7}$ in a composite with ESB would be a promising cathode material for IT-SOFCs.

This study further showed that the performance of bismuth ruthenate (BRO) cathodes is very promising. However, doping with lower valent cations on the Bi-site, in order to improve the ionic conductivity, was not very effective in improving the performance of bismuth ruthenate cathodes. At $700{ }^{\circ} \mathrm{C}$, the ASRs of undoped, $5 \mathrm{~mol} \% \mathrm{Ca}$, and $5 \mathrm{~mol} \% \mathrm{Sr}$ doped $\mathrm{BRO}$ electrode were $1.45 \Omega \mathrm{cm}^{2}, 1.24 \Omega \mathrm{cm}^{2}$, and $1.41 \Omega \mathrm{cm}^{2}$, respectively. The rate limiting step for the oxygen reduction reaction in $5 \mathrm{~mol} \% \mathrm{Ag}$ doped bismuth ruthenate electrode was found to be the surface diffusion of dissociatively adsorbed oxygen, while for $5 \mathrm{~mol} \% \mathrm{Ca}$ doped system multiple rate limiting steps were observed in the oxygen partial pressure range studied. Doping with $5 \mathrm{~mol} \%$ $\mathrm{Ca}$ and $\mathrm{Ag}$ changed the electrode capacitance behavior, both as function of temperature and oxygen partial pressure.

Finally, BRO-ESB composite cathodes developed in this study show performance that is comparable to the very best new IT-SOFC cathode materials. The high performance of BROESB composites is due to the high ionic conductivity of ESB and high electronic conductivity of BRO. Addition of the ESB phase reduced the ASR of single phase BRO electrode by as much as 
a factor of twenty. The presence of ESB particles not only increases the concentration of TPBs and ionic conductivity of the composite electrode, but possibly also reduces the surface diffusion path to the TPBs resulting in improved electrode performance. Moreover, both BRO and ESB are catalytic active towards oxygen reduction. Furthermore, BRO is compatible with stabilized zirconia, doped ceria, and stabilized bismuth oxide, and therefore, BRO-ESB composites could be suitable for IT-SOFCs based on any of the three fluorite electrolyte systems.

The resulting $\mathrm{Bi}_{2} \mathrm{Ru}_{2} \mathrm{O}_{7}-\mathrm{Bi}_{0.8} \mathrm{Er}_{0.2} \mathrm{O}_{1.5}$ composite cathode has an ASR of $0.73 \Omega \mathrm{cm}^{2}$ at 500 ${ }^{\circ} \mathrm{C}, 0.053 \Omega \mathrm{cm}^{2}$ at $650{ }^{\circ} \mathrm{C}$ and 0.03 at $700{ }^{\circ} \mathrm{C}$. These ASRs are truly impressive and makes them among the lowest IT-SOFC ASRs reported to date. At high temperatures, the optimized BROESB composite has outstanding performance and is comparable with our Ag-ESB. In addition, due to its low activation energy, it is even more competitive at lower temperatures, and has better performance than $\mathrm{BSCF}$ at temperatures below $500{ }^{\circ} \mathrm{C}$. Further improvements are likely to result from a compositional study of the optimized electrode.

The extensive body of work reported herein has resulted in 13 publications in scientific journals, ranging from the Journal of the Electrochemical Society to Solid State Ionics, as seen in Table 3.

Table 3. Scientific Publications submitted so far from this contract.

1. "Silver-Bismuth Oxide Cathodes for IT-SOFCs; Part II - Improving Stability Through Microstructural Control," M. Camaratta and E.D. Wachsman, Solid State Ionics, submitted.

2. "Silver-Bismuth Oxide Cathodes for IT-SOFCs; Part I - Microstructural Instability," M. Camaratta and E.D. Wachsman, Solid State Ionics, submitted.

3. "Novel Bismuth Ruthenate Based Cathodes for IT-SOFCs; Part II: Bismuth Ruthenate - Stabilized Bismuth Oxide Composites," A. Jaiswall, C.T. Hu, and E.D. Wachsman, Journal of the Electrochemical Society, submitted.

4. "Novel Bismuth Ruthenate Based Cathodes for IT-SOFCs; Part I: Doped Bismuth Ruthenates," A. Jaiswall and E.D. Wachsman, Journal of the Electrochemical Society, submitted.

5. “Applicability of $\mathrm{Bi}_{2} \mathrm{Ru}_{2} \mathrm{O}_{7}$ Pyrochlore Electrodes for ESB and BiMEVOX Electrolytes," V. Esposito, B.H. Luong, E.D. Bartolomeo, E.D. Wachsman, and E. Traversa, Journal of the Electrochemical Society, 153, A2232-A2238 (2006).

6. "Synthesis and Characterization of $\mathrm{Y}_{2} \mathrm{Ru}_{2} \mathrm{O}_{7}$ and $\mathrm{Y}_{2-\mathrm{x}} \mathrm{Pr}_{\mathrm{x}} \mathrm{Ru}_{2} \mathrm{O}_{7}$ for the Cathode Application in Intermediate Temperature Solid Oxide Fuel Cells," C. Abate, K. Duncan, V. Esposito, E. Traversa, and E. D. Wachsman, Solid State Ionic Devices IV, ECS Transactions, E.D. Wachsman, F.H. Garzon, E. Traversa, R. Mukundan, and V. Birss, Ed., 1-7, 255-262 (2006). 
7. " $\mathrm{Bi}_{2} \mathrm{Ru}_{2} \mathrm{O}_{7}$ Pyrochlore Electrodes for $\mathrm{Bi}_{2} \mathrm{O}_{3}$ Based Electrolyte for IT-SOFC Applications," V. Esposito, B. H. Luong, E. Di Bartolomeo, E. D. Wachsman, and E. Traversa, Solid State Ionic Devices IV, ECS Transactions, E.D. Wachsman, F.H. Garzon, E. Traversa, R. Mukundan, and V. Birss, Ed., 1-7, 263-278 (2006).

8. "Ag- $\mathrm{Bi}_{1.6} \mathrm{Er}_{0.4} \mathrm{O}_{3}$ as a Potential Cathode Material for IT-SOFCs," M. Camaratta and E. D. Wachsman, Solid State Ionic Devices IV, ECS Transactions, E.D. Wachsman, F.H. Garzon, E. Traversa, R. Mukundan, and V. Birss, Ed., 1-7, 279-292 (2006).

9. "Direct Current Bias Studies on $\left(\mathrm{Bi}_{2} \mathrm{O}_{3}\right)_{0.8}\left(\mathrm{Er}_{2} \mathrm{O}_{3}\right)_{0.2}$ Electrolyte and $\mathrm{Ag}-\left(\mathrm{Bi}_{2} \mathrm{O}_{3}\right)_{0.8}\left(\mathrm{Er}_{2} \mathrm{O}_{3}\right)_{0.2}$ Cermet Electrode," A. Jaiswall and E.D. Wachsman, Solid State Ionics, 177 (7-8), 677-685 (2006).

10. " $\mathrm{Pb}_{2} \mathrm{Ru}_{2} \mathrm{O}_{6.5}$ as a Low-Temperature Cathode for Bismuth Oxide Electrolytes," V. Esposito, E. Traversa, and E.D. Wachsman, Journal of the Electrochemical Society, 152 (12), A2300-2306 (2005).

11. " $\mathrm{RuO}_{2}-$ Based Dense Electrodes for ESB Electrolyte IT-SOFCs," V. Esposito, E. Traversa, and E.D. Wachsman, Solid Oxide Fuel Cells IX, Electrochem. Soc., S.C. Singhal and J. Mizusaki, Ed, 2005-07, 1764-1772 (2005).

12. "Bismuth-Ruthenate-Based Cathodes for IT-SOFCs," A. Jaiswal and E.D. Wachsman, Journal of the Electrochemical Society, 152, A787-790 (2005).

13. "Preparation and Characterization of Lead Ruthenate Based Composite Cathodes for SOFC Applications," V. Esposito, E. Traversa, and E.D. Wachsman, Solid State Ionics-2004, Materials Research Society, P. Knauth, C. Masqulier, E. Traversa, and E.D. Wachsman, Ed., 835, 217-222 (2005). 


\section{REFERENCES}

${ }^{1}$ U. Stimming, et al, Proceedings of the fifth International Symposium on Solid Oxide Fuel Cells 97-40, 69 The Electrochemical Society NJ USA (1997).

2 B. C. H. Steele, Solid State Ionics, 134, 3 (2000).

${ }^{3}$ B. C. H. Steele, J. Mater. Sci., 36, 1053 (2001).

${ }^{4}$ J. M. Ralph, A. C. Schoeler, and M. Krumpelt, J. Mater. Sci., 36, 1161 (2001).

${ }^{5}$ R. Doshi, V. L. Richards, J. D. Carter, X. Wang, and M. Krumpelt, J. Electrochem. Soc., 146, 1273 (1999).

${ }^{6}$ C. Xia, W. Rauch, F. Chen, M. Liu, Solid State Ionics, 149 (1-2), 11 (2002).

7 T. Horita, K. Yamaji, N. Sakai, Y. Xiong, T. Kato, H. Yokokawa, T. Kawada, Journal of Power Sources, 106, 224 (2002).

${ }^{8}$ K. Sasaki, J. Tamura, H. Hosoda, T.N. Lan, K. Yasumoto, M. Dokiya, Solid State Ionics, 148 (3-4), 551 (2002).

${ }^{9}$ S. H. Chan, C. F. Low and O. L. Ding, Journal of Power Sources, 103 (2), 188 (2002).

${ }^{10}$ T. Horita, K. Yamaji, N. Sakai, H. Yokokawa, A. Weber and E. Ivers-Tiffée, Electrochimica Acta, 46 (12), 1837 (2001).

${ }^{11}$ T. Ishihara, T. Kudo, H. Matsuda, Y. Takita, J. Electrochem. Soc., 142 (5), 1519 (1995).

${ }^{12}$ M. Mogensen and S. Skaarup, Solid State Ionics, 86-88, 1151 (1996).

${ }^{13}$ A. J. McEvoy, Solid State Ionics, 132, 159 (2000).

${ }^{14}$ D.Z. de Florio, V. Esposito, E. Di Bartolomeo, R. Muccillo, E. Traversa. J. Electrochem. Soc., In press.

${ }^{15}$ V. Dusastre and J. A. Kilner, Solid State Ionics, 126, 163 (1999).

${ }^{16}$ C. Xia, Y. Zhang and M. Liu, Appl. Phys. Lett., 82, 901 (2003).

${ }^{17}$ T. Arikawa, Y. Murakami, Y. Takasu, J. Appl. Electrochem., 28, 511 (1998), and references therein.

${ }^{18}$ V. Mehta, J. S. Cooper, J. Power Sources, 114, 32 (2003).

${ }^{19}$ R. Kanno, Y. Takeda, T. Yamamoto, Y. Kawamoto, O. Yamamoto, J. Solid State Chem., 102, 106 (1993).

${ }^{20}$ K. S.Lee, J. Solid State Chem., 131, 405 (1997).

${ }^{21}$ J. Prakash, D. Tryk, E.B. Yeager, J. Electrochem. Soc., 146, 4145 (1999).

${ }^{22}$ Y. Shimizu, H. Nishi, H. Suzuki, K. Maeda. Sensors and Actuators, B 65, 141 (2000).

${ }^{23}$ J. Prakash, D. Tryk, W. Aldred, E. Yeager, in: O.J. Murphy, S. Srinivasan, B.E. Conway Eds. , Electrochemistry in Transition, Plenum Press, New York, (1992).

${ }^{24}$ L.D. Burke, O.J. Murphy, J. Electroanal. Chem., 109, 199 (1980). 
${ }^{25}$ A. Ardizzone, G. Fregonara, S. Trasatti, Electrochim. Acta, 35, 263 (1990).

${ }^{26}$ J. Prakash, D. Tryk, E.B. Yeager, J. Electrochem. Soc., 146, 4145 (1999).

${ }^{27}$ H. Tuller, Solid State Ionics, 94, 63 (1997).

${ }^{28}$ T. Takeda, R. Kanno, Y. Kawamoto, Y. Takeda, O. Yamamoto, J.Electrochem. Soc.,147 [5], 1730 (2000).

${ }^{29}$ H.S. Horowitz, J.M. Longo, H.H. Horowitz, and J.T. Lewandoski, Am. Chem. Soc. Symp. Series, 279, 143 (1985).

${ }^{30}$ H. Kobayashi, R. Kanno, Y. Kawamoto, J. Solid State Chem., 114, 15 (1995).

${ }^{31}$ B.C.H. Steele, Solid State Ionics, 75, 157 (1995).

${ }^{32}$ E. Wachsman, J. European Ceram. Soc., 24, 1281 (2004).

${ }^{33}$ P. Shuk, H.D. Wiemhofer, U. Guth, W. Gopel, M. Greenblatt, Solid State Ionics, 89, 179-196 (1996).

${ }^{34}$ K.Z. Fung, A.V. Virkar, D.L. Drobeck, J. Am. Ceram. Soc, 77 (6), 1638 (1994).

${ }^{35}$ K.Z. Fung and A.V. Virkar, J. Am. Ceram. Soc, 74 (8), 1970 (1991).

${ }^{36}$ N. Jiang and E.D. Wachsman, J. Am. Ceram. Soc., 82, 3057 (1999).

${ }^{37}$ A. Jaiswal and E.D. Wachsman, Solid State Ionics, 177, 677 (2006).

${ }^{38}$ M. Camaratta and E.D. Wachsman, Electrochemical Chemical Society Transactions, 1 (7), 279 (2006).

${ }^{39}$ M. J. Verkerk, A. J. Burggraaf, Journal of the Electrochemical Society, 130 (1983) 78.

${ }^{40}$ J. van Herle, A. J. McEvoy, Journal of Physics and Chemistry of Solids, 55 (1994) 339.

${ }^{41}$ J. Assal, B. Hallstedt, L. J. Gauckler, Journal of the American Ceramic Society, 80 (1997) 3054.

42 A. Jaiswal and E.D. Wachsman, Solid State Ionics, 177, 677 (2006).

${ }^{43}$ D. W. Jung, K. Duncan, and E. D. Wachsman, Electrochemical Chemical Society Transactions, 1, 63 (2006).

${ }^{44}$ B. J. Kennedy, T. Vogt, J. Solid State Chem., 126, 261 (1996).

${ }^{45}$ R.M. Biefeld, S.S. White, J. Am. Ceramic Soc., 64 [3], 182 (1981).

${ }^{46}$ E. J. Abram, D. C. Sinclair, A. R. West, J. Electroceram., 10, 165 (2003).

${ }^{47}$ S. B. Adler, Solid State Ionics, 111, 125 (1998).

48 J. R. Macdonald, Impedance Spectroscopy - Emphasizing Solid Material and Systems, Wiley Interscience, New York (1987)

${ }^{49}$ M. T. Colomer, B.C.H. Steele, J.A. Kilner, Solid State Ionics, 147, 41 (2002)

${ }^{50}$ A. Benan and M. Hrovat et al, Materials Research Bulletin, 35, 2415, (2000).

${ }^{51}$ J.-M. Bae and B. C. H. Steele, Journal of Electroceramics, 3, 1, 37, (1999).

${ }^{52}$ Naixiong Jiang, Eric D. Wachsman and Su-Ho Jung, Solid State Ionics, 150, 347, (2002).

${ }^{53}$ B.C.H. Steele, Solid State Ionics, 134, 3, (2000).

${ }^{54}$ M. Hrovat, J. Holc, and D. Kolar, Solid State Ionics, 68, 93 (1994). 
${ }^{55}$ M. Schuler and S. Kemmler-sack, J. Less-Common Met., 102, 105 (1984).

${ }^{56}$ E. Beck and S. Kemmler-sack, J. Less-Common Met., 119, 151 (1986).

${ }^{57}$ M.J. Verkerk and A. J. Burggraaf, J. Electrochem. Soc., 130, 78 (1983).

${ }^{58}$ V. Esposito, E. Traversa and E. D. Wachsman, J. Electrochem. Soc., 152, A2300, (2005).

${ }^{59}$ M. Hrovat, A. Bencan, J. Holc, T. Rojac, and M. Kosec, J. Mater. Res., 18, 1297 (2003).

${ }^{60}$ J.-M. Bae and B. C. H. Steele, J. Electroceram., 3, 37 (1999).

${ }^{61}$ T. Takeda, R. Kanno, Y. Kawamoto, Y. Takeda, and O. Yamamoto, J. Electrochem. Soc., 147, 1730 (2000).

${ }^{62}$ S. Linquette-Mailley, A. Caneiro, E. Djurado, G. Mairesse, and J. Fouletier, Solid State Ionics, 107, 191 (1998).

${ }^{63}$ S. Linquette-Mailley, E. Djurado, G. Mairesse, and J. Fouletier, Sens. Actuators B, 26-27, 364 (1995).

${ }^{64}$ H. Nagamoto and H. Inoue, J. Electrochem. Soc., 136, 2088 (1989).

${ }^{65}$ J. B. Goodenough, Annu. Rev. Mater. Sci., 33, 91 (2003).

${ }^{66}$ M. Schuler and S. Kemmler-Sack, J. Less-Common Met., 102, 105 (1984).

${ }^{67}$ E. Beck and S. Kemmler-Sack, J. Less-Common Met., 119, 151 (1986).

${ }^{68}$ A. Jaiswal and E.D. Wachsman, J. Electrochem. Soc., 152, A787 (2005).

${ }^{69}$ L. S. Wang and S. A. Barnett, Solid State Ionics, 76, 103 (1995).

${ }^{70}$ M. Field, B. J. Kennedy, and B.A. Hunter, J. Solid State Chem., 151, 25 (2000).

${ }^{71}$ R. Kanno, Y. Takeda, T. Yamamoto, Y. Kawamoto, and O. Yamamoto, J. Solid State Chem., 102, 106 (1993).

72 T. Yamamoto, R. Kanno, Y. Takeda, O. Yamamoto, Y. Kawamoto, and M. Takano, J. Solid State Chem., 109, 372 (1994).

${ }^{73}$ F. Ishi and T. Oguchi, J. Phys. Soc. Jpn., 69, 526 (2000).

${ }^{74}$ M. Avdeev, M. K. Haas, J. D. Jorgensen, and R. J. Cava, J. Solid State Chem., 169, 24 (2002).

${ }^{75}$ B. J. Kennedy, J. Solid State Chem., 126, 261 (1996).

${ }^{76}$ A. M. Azad, S. Larose, and S. A. Akbar, J. Mater. Sci., 29, 4135 (1994).

${ }^{77}$ P. Shuk, H. D. Wiemhofer, U. Guth, W. Gopel, and M. Greenblatt, Solid State Ionics, 89, 179 (1996).

${ }^{78}$ N. M. Sammes, G. A. Tompsett, H. Nafe, and F. Aldinger, J. Eur. Ceram. Soc., 19, 1801 (1999).

${ }^{79}$ E. P. Murray and S. A. Barnett, Solid State Ionics, 143, 265 (2001).

${ }^{80}$ V. Dusastre and J. A. Kilner, Solid State Ionics, 126, 163 (1999).

${ }^{81}$ I. I. Prosychev, V. B. Lazarev, and I. S. Shaplygin, Zh. Neorg. Khim., 26, 1877 (1981).

${ }^{82}$ M. Hrovat, S. Bernik, and D. Kolar, J. Mater. Sci. Lett., 7, 637 (1988).

${ }^{83}$ F. Abraham, G. Nowogroc, and D. Thomas, C. R. Hebd. Seances Acad. Sci. C, 278, 421 (1974).

${ }^{84}$ N. Jiang, M.S. Thesis, Stanford University, Stanford, CA (1994). 
${ }^{85}$ A. Jaiswal, PhD Dissertation, University of Florida, Gainesville, FL (2004).

${ }^{86}$ E. P. Murray, M. J. Server, and S. A. Barnett, Solid State Ionics, 148, 27 (2002).

${ }^{87}$ C. R. Xia, Y. Zhang, and M. L. Liu, Appl. Phys. Lett., 82, 901 (2003).

${ }^{88}$ A. Jaiswal and E. D. Wachsman, Solid State Ionics, 177, 677 (2006).

${ }^{89}$ Z. Shao and S. M. Haile, Nature, 431, 170 (2004).

${ }^{90}$ A. Hammou and J. Guindet, in The CRC Handbook of Solid State Electrochemistry, P. J. Gellings and H. J. M. Bouwmeester, Editors, p. 415, CRC Press, Boca Raton, FL (1997).

${ }^{91}$ T. Takeda, R. Kanno, Y. Kawamoto, Y. Takeda, and O. Yamamoto, J. Electrochem. Soc., 147, 1730 (2000). 